Portland State University

PDXScholar

Summer 8-7-2017

\title{
Trade-offs: the Production of Sustainability in Households
}

Kirstin Marie Elizabeth Munro

Portland State University

Follow this and additional works at: https://pdxscholar.library.pdx.edu/open_access_etds

Part of the Home Economics Commons, Sociology Commons, and the Sustainability Commons Let us know how access to this document benefits you.

\section{Recommended Citation}

Munro, Kirstin Marie Elizabeth, "Trade-offs: the Production of Sustainability in Households" (2017). Dissertations and Theses. Paper 3777.

https://doi.org/10.15760/etd.5661

This Dissertation is brought to you for free and open access. It has been accepted for inclusion in Dissertations and Theses by an authorized administrator of PDXScholar. Please contact us if we can make this document more accessible: pdxscholar@pdx.edu. 
Trade-offs: The Production of Sustainability in Households

by

Kirstin Marie Elizabeth Munro

A dissertation submitted in partial fulfillment of the requirements for the degree of

Doctor of Philosophy

in

Urban Studies

Dissertation Committee:

Loren Lutzenhiser, Chair

Mary C. King

Greg Schrock

James Strathman

Portland State University

2017 
C 2017 Kirstin Marie Elizabeth Munro 


\begin{abstract}
Over the past half-century, environmental problems have become increasingly serious and seemingly intractable, and a careless, clueless, or contemptuous consumer is often portrayed as the root cause of this environmental decline. This study takes a different approach to evaluating the demand for resources by households, assessing possible proenvironmental paths forward through a study of highly ecologically-conscious households. By modeling "green" households as producers of sustainability rather than consumers of environmental products, the sustainability work that takes place in households is brought into focus. An investigation of household sustainability production makes possible the evaluation of the trade-offs inherent in these pro-environmental activities.
\end{abstract}

Ethnographic interviews with 23 sustainability-oriented households with young children living in and near Portland, Oregon, provide data on how households balance priorities and get things done in day-to-day life by employing the available resources, limited by constraining factors. An orienting perspective combining neoclassical and radical political economic theories of household production frames the analysis of how households make choices between alternatives. Sociological theories of consumption and theories of social 
practice aid in the analysis of how these choices have evolved over time, and how household members view the social meanings of these choices. Particular attention is paid to areas of day-to-day life neglected in previous research-household waste, comfort, and cleanliness.

The results indicate that there is not one "sustainability" with varying degrees across a "green" spectrum, but rather varying priorities in the sustainability realm-personal health, nature, waste avoidance, technology, and community. This analysis reveals some of the negative consequences of shifting the responsibility for environmental protection to households. Ecologically-conscious households devote substantial time and money to these sustainability efforts, but their efforts frequently stimulate conflicts, and the end results are rarely perfect. Constrained resources and limited information mean household members must make trade-offs between competing priorities, often under duress. The results suggest that policies promoting household-level sustainability efforts may be misguided, as this transfer of institutional responsibility for environmental protection to individuals and groups results in even greater burdens on households whose time and money are already stretched to their limits. 
Dedication

Pour mes chers amis Shoshanna et Uziel.

C'était pour moi un très grand plaisir de vous regarder grandir. 


\section{Acknowledgements}

I owe a large debt to my adviser and committee chair, Loren Lutzenhiser, both for convincing me to finish the PhD l'd abandoned and for charting out the path that made it possible. I feel immensely fortunate for the opportunity to work with and learn from you over the past few years.

Many thanks to my committee members Mary C. King and Jim Strathman, for their important input into this dissertation. Particular thanks are due to Greg Schrock for being the only non-retired member of my committee and for his gracious willingness to participate in a summer defense. I've been lucky to have many excellent academic mentors on my circuitous path to the end of this degree, and am particularly thankful to Noelwah Netusil, Jeff Parker, Barry and Carmel Chiswick, Joe Persky, Dave Merriman, Anna Guevarra, Judith Kegan Gardiner, Mithra Moezzi, and Nona Glazer.

I am grateful to my colleagues George Tolley and Catherine Mertes for their unwavering support over the past seven years and the incredible kindnesses they have shown me. Thanks also to my colleague Don Jones for reminding me that I know how to think like an economist. 
I am thankful to my parents and grandparents for raising me to be critical and hardworking, and for instilling in me an appreciation for intensive self-provisioning and a love of line-dried laundry (even towels). Very special thanks to my dear friend Michelle Lamanet for her excitement about this research, for helping me think of ways to find potential informants, and for supplying the beautiful logo and artwork for my recruitment materials. Wilson and Wendy, thank you for making me laugh every day and demanding I get out of bed at the crack of dawn to feed you each morning-I promise I will be a lot more fun soon as this is over. I am thankful to Mary Oak and David Fries, who fed me encouraging words and ice cream and let me live in a gremlin-like state in their peaceful and beautiful home for the final month of this journey.

This dissertation would not have been possible without the reproductive labor of Chris O'Kane, life companion extraordinaire, who spent countless hours ensuring I had enough food, coffee, clean clothes, and rest to successfully finish this manuscript. Thank you for your tireless care and incredible patience. I think I can make good on the promise to never write this much in a month ever again.

I am grateful to the many friends and colleagues who helped me recruit participants for this research. Most importantly, I am deeply grateful to my informants for welcoming me into their homes and taking the time to speak with me about their lives and values. I am truly humbled and inspired by your efforts. 
Table of Contents

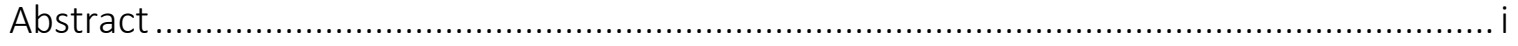

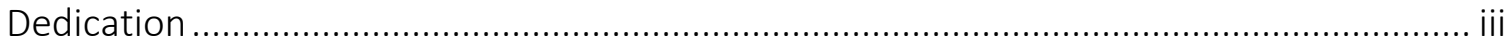

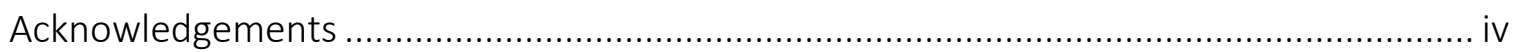

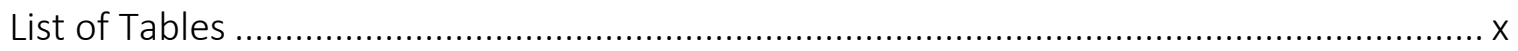

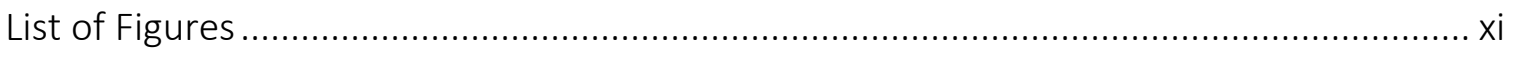

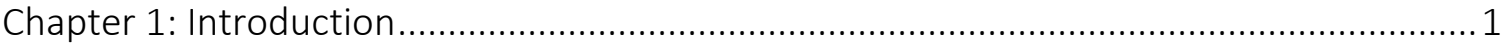

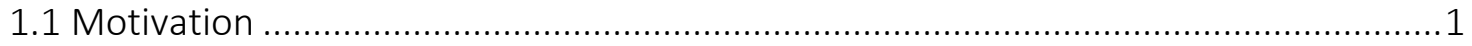

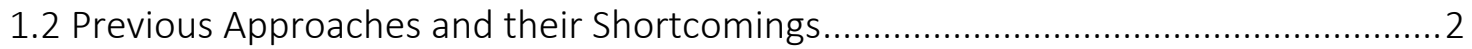

1.3 The Production of Sustainability in Households ......................................................... 4

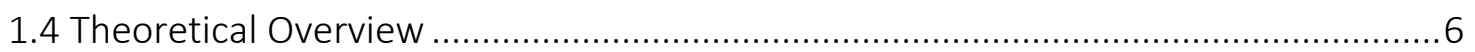

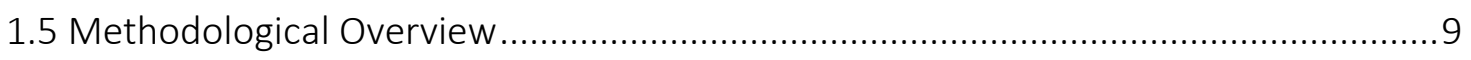

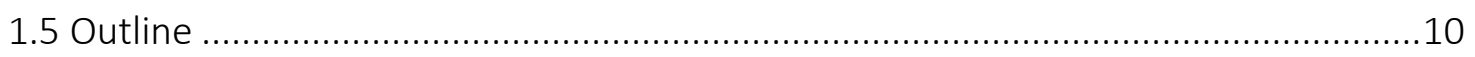

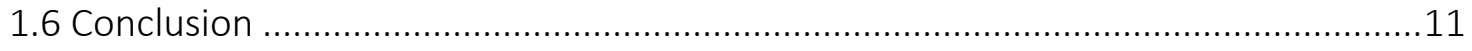

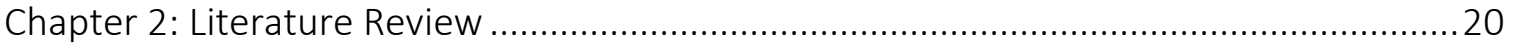

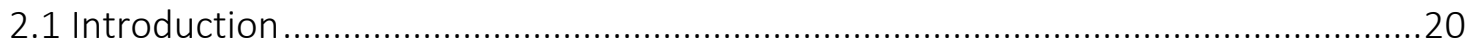

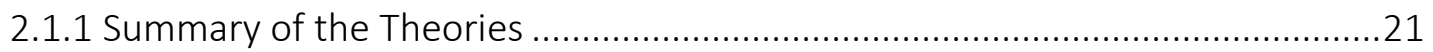

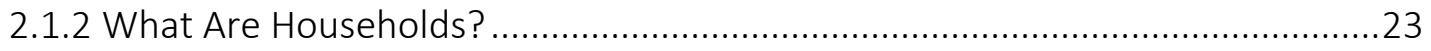

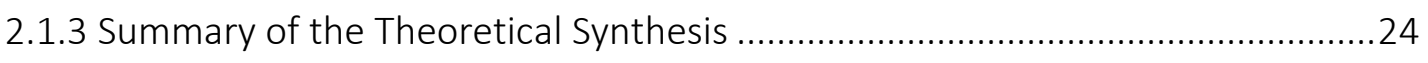

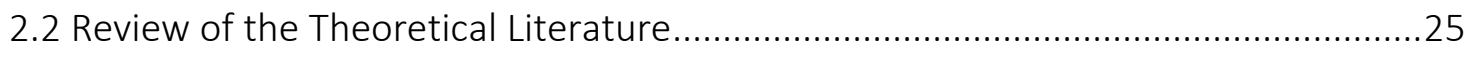

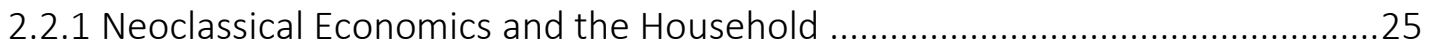

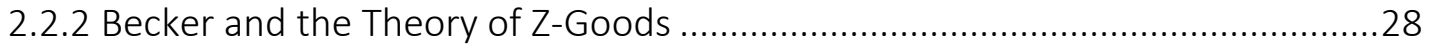

2.2.3 Shortcomings of Neoclassical Theories of the Household ..................................30

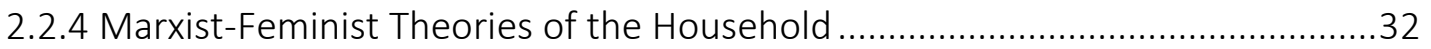

2.2.5 Shortcomings of the Marxist Feminist Theories of the Household....................36

2.2.6 Radical Institutional Thought -Feminist Institutionalists .................................37

2.2.6 Radical Institutional Thought-Conspicuous Consumption .............................39

2.2.7 Shortcomings of the Radical Institutional Economics Theory of the Household

2.2.8 Social and Cultural Theories of Consumption and Applications.........................42 
2.2.9 Shortcomings of Social and Cultural Theories of Consumption .49

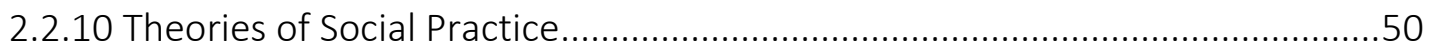

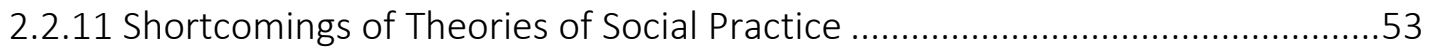

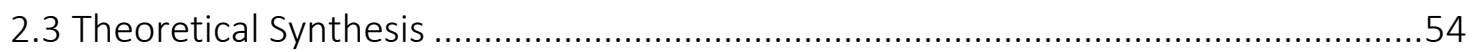

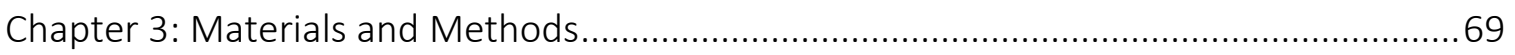

3.1 Research Objectives and Research Methodology .............................................69

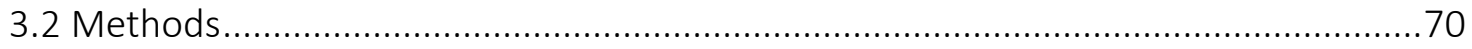

3.2.1 Qualitative Research for Economic Questions ............................................70

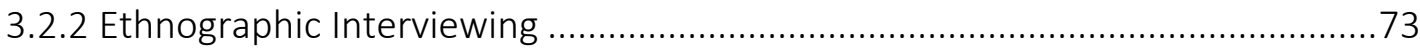

3.2.3 Intimacy, Friendship, and Feminist Research ............................................... 75

3.2.4 Ethnographic Research and Deception .......................................................

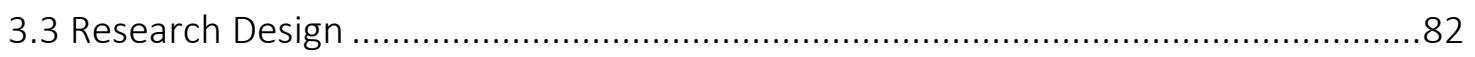

3.3.1 Sample Size and Small Sample Qualitative Research .....................................82

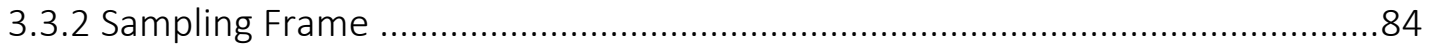

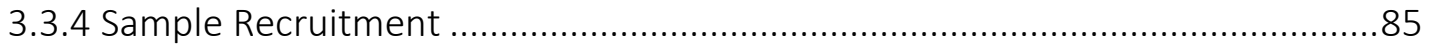

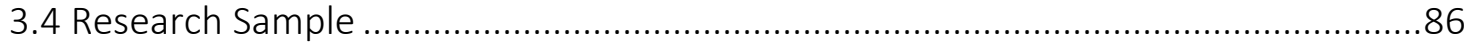

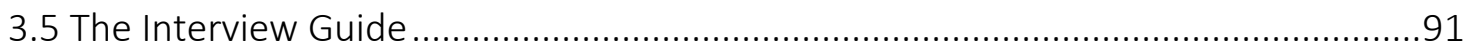

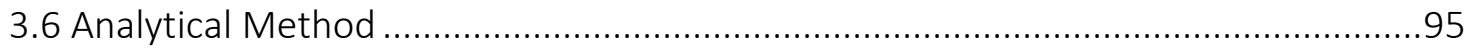

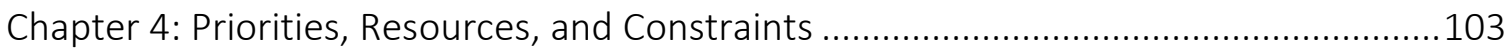

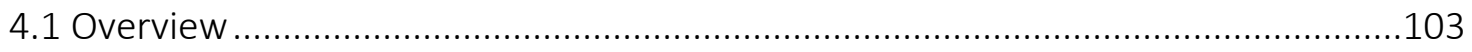

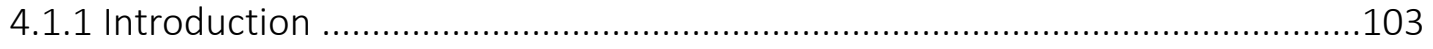

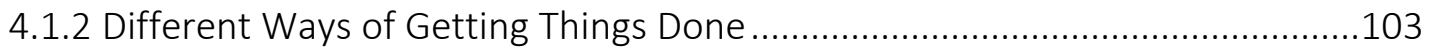

4.1.3 How Households Produce Sustainability ...................................................106

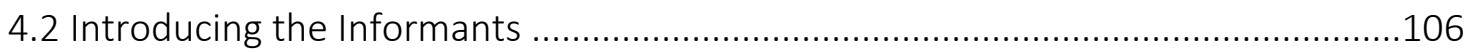

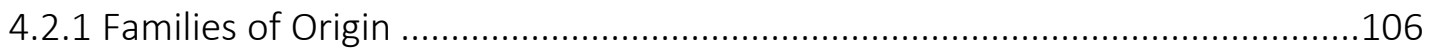

4.2.2 Origins of Sustainability Values and Practices ...............................................110

4.2.3 Current Living Arrangements and Family Structures ..................................113

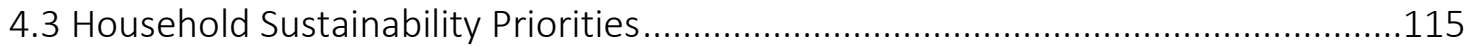

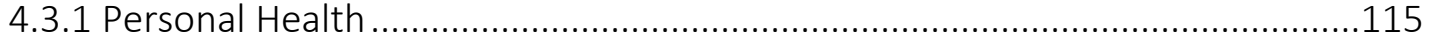

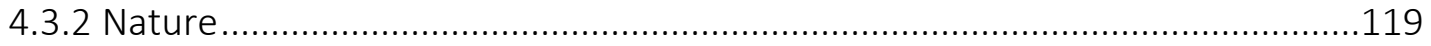

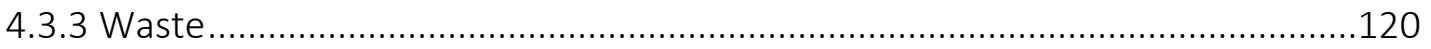




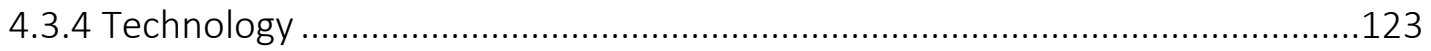

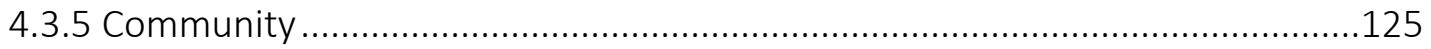

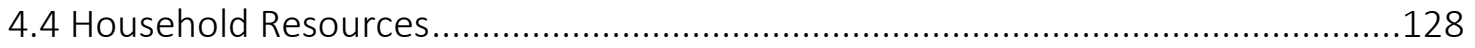

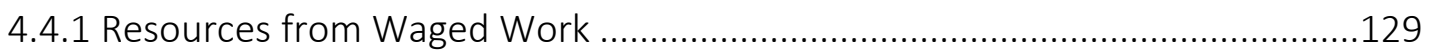

4.4.2 Resources from Extended Family and Friends ..............................................131

4.4.3 Resources from Government and Non-Profits.............................................133

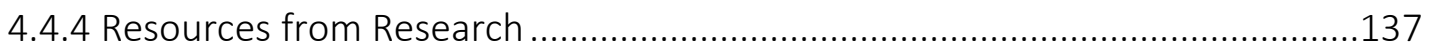

4.4.5 Resources from Gleaning: Borrowed and Free Items, Theft ……...................137

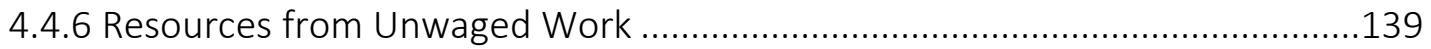

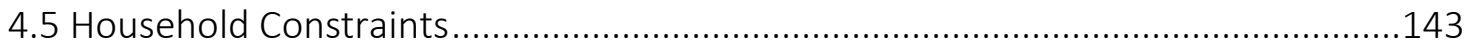

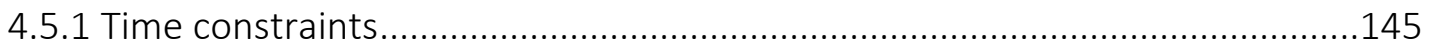

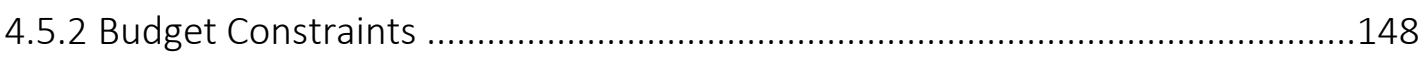

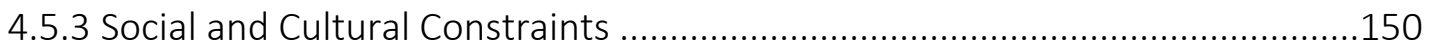

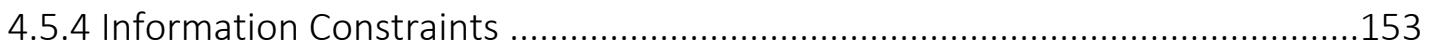

Chapter 5: How Households Get Things Done.............................................................156

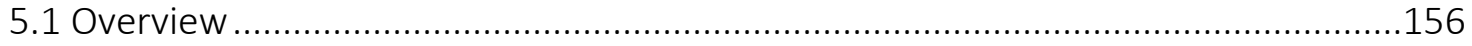

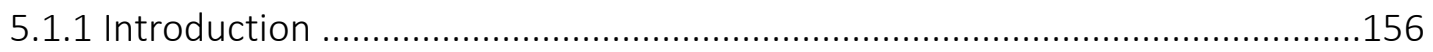

5.1.2 Different Ways of Getting Things Done-Part Two ………………...............156

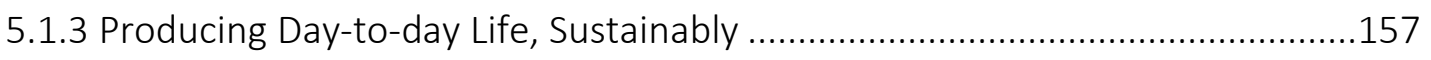

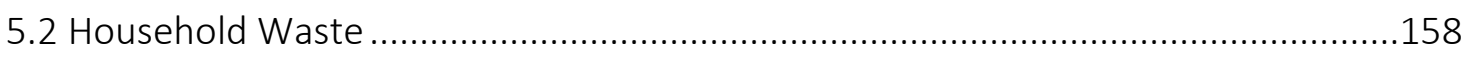

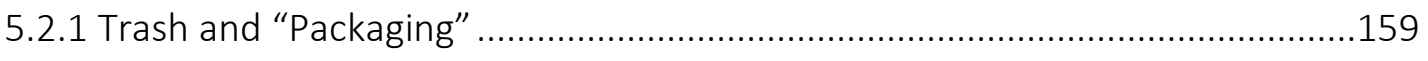

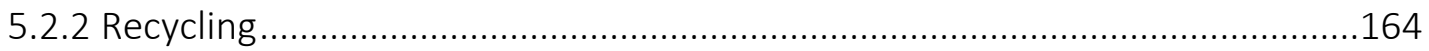

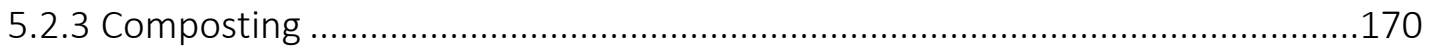

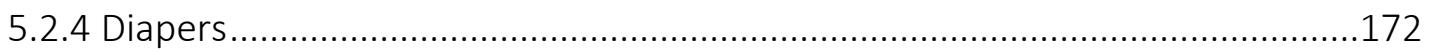

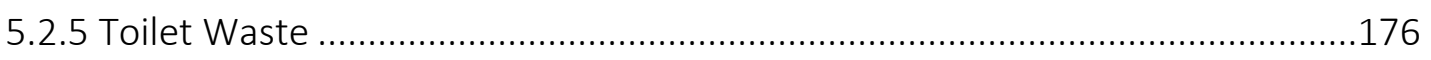

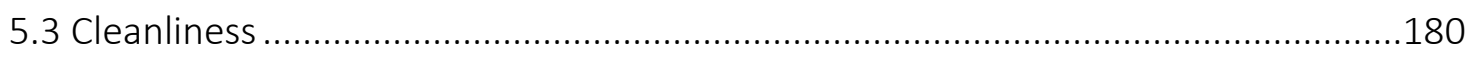

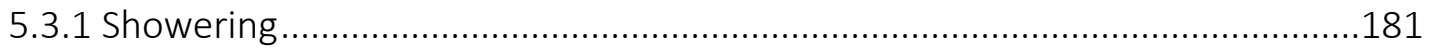

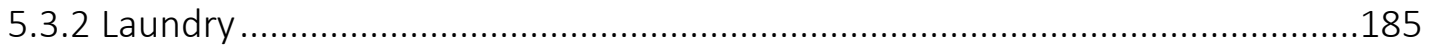

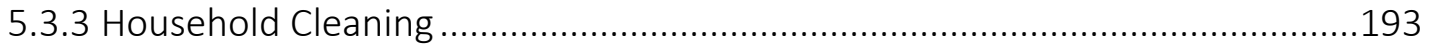

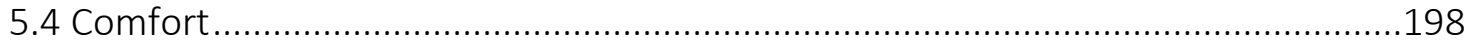

5.4.1 Comfort when it's Cold Outside ……..........................................................199 


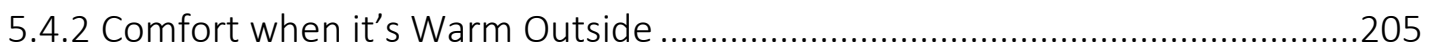

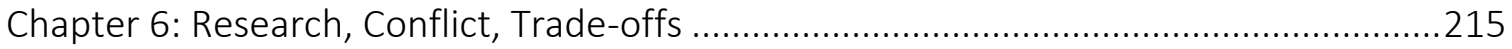

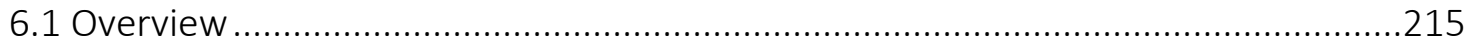

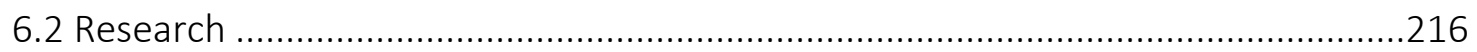

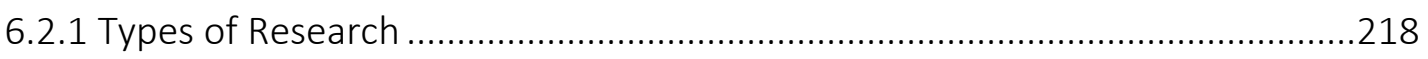

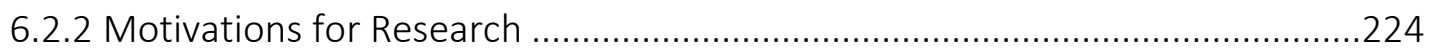

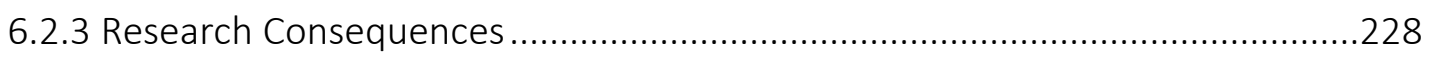

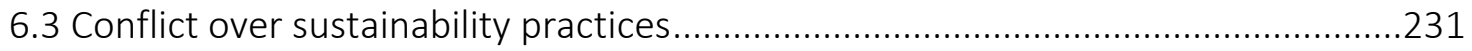

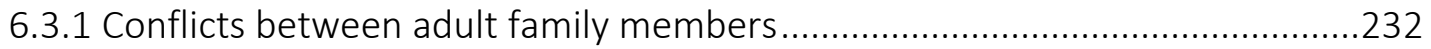

6.3.2 Conflicts between adults and their own parents ...........................................238

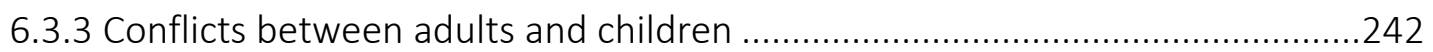

6.3.4 Conflicts between children and the outside world .......................................244

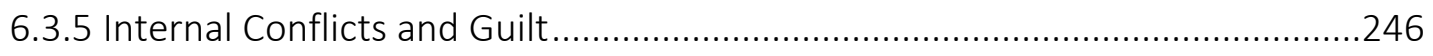

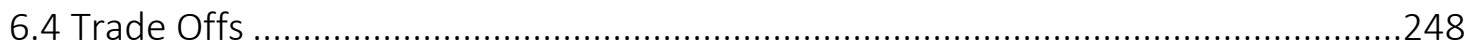

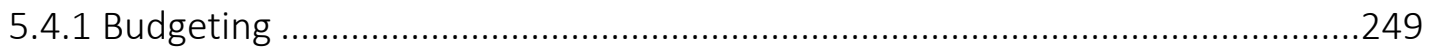

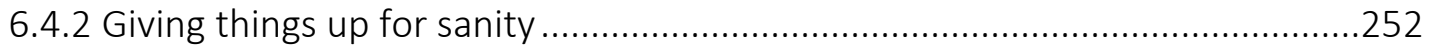

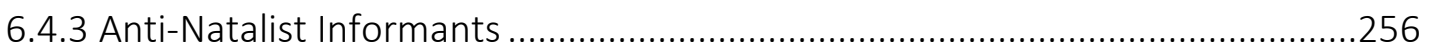

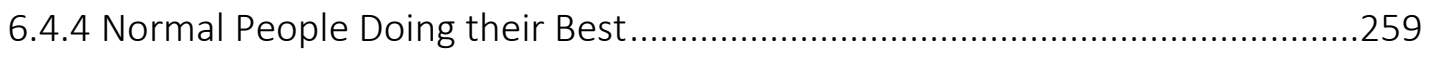

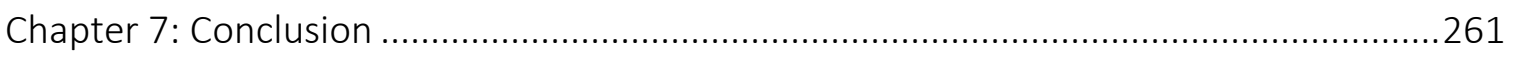

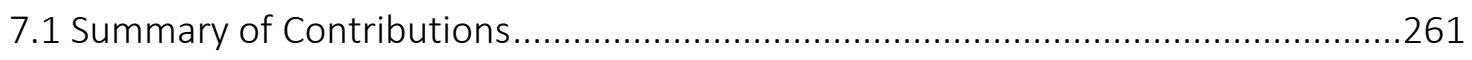

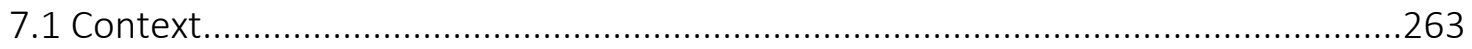

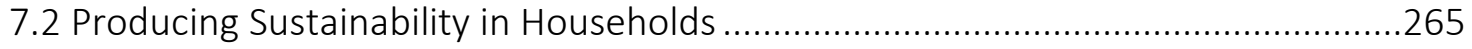

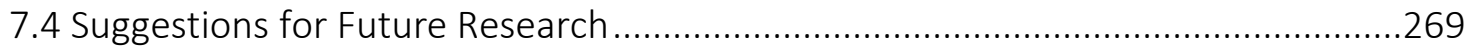

7.5 Conclusions: The Futility of Household-Scale Sustainability Practices ...................271

7.5.1 The Household is the Wrong Site for Sustainability Production .....................271

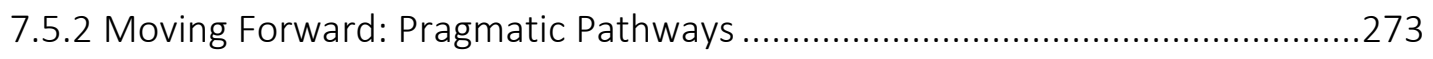

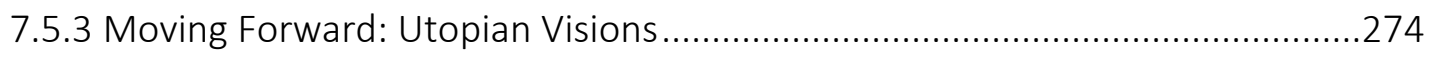

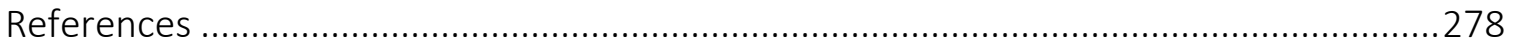

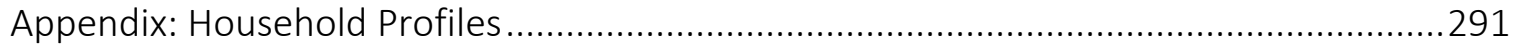


List of Tables

Table 3.1 Sample Size in Ethnographic Studies of Households in Advanced Industrialized

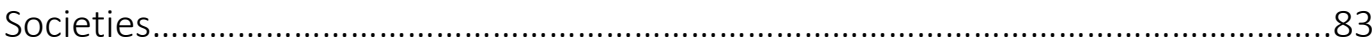

Table 3.2 Sample Size in Ethnographic Household Energy and Technology Studies..........83

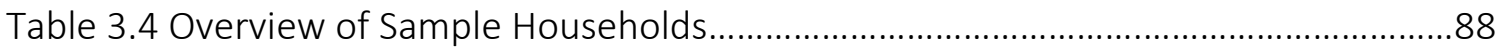

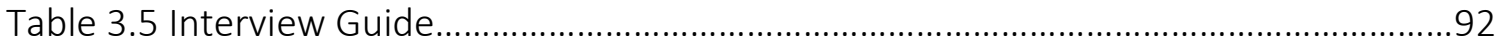

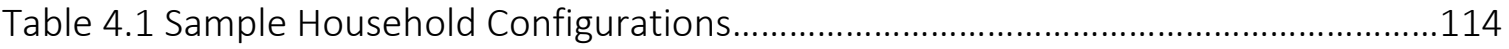


List of Figures

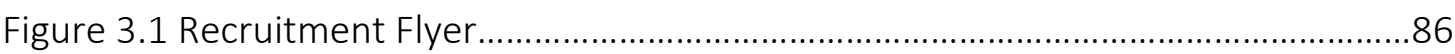


Chapter 1: Introduction

"The many in the one, and the one in the many," (Marshall 1919, 7).

"The modern family... comprises in miniature all those contrasts that later on develop more broadly in society and the state," (Engels 1902, 71).

\subsection{Motivation}

Over the past half-century, environmental problems involving atmospheric emissions, resource depletion, toxic releases, and ecosystem degradation have become increasingly serious and seemingly intractable (Rosa \& Dietz 2003, Brown 2003). The sources of these problems are often attributed to large global social forces such as capitalism (Schnaiberg \& Gould 1994, Foster 2002), industrialization (Malm 2015), or affluence (Ehrlich \& Ehrlich 1978, Dietz \& Rosa 1997). At the national and local levels, attribution has focused on particular industries, such as fossil fuel extraction and refining, electric utilities, internal combustion transportation, and mechanized agriculture. But these systems and their associated environmental harms exist only by virtue of the fact that they are involved in the production of goods and services destined for consumption by persons and social groups, regardless of the mode of production involved in their transformation and distribution. So, a careless, clueless, or contemptuous consumer is also increasingly portrayed as the root cause of environmental decline on a hitherto unimaginable scale (Wilk 2016, Jorgenson 2003). 
In the United States, recent national policy has included initiatives urging citizens to "do their part" and take personal responsibility for the environment and climate change mitigation (The White House 2015, U.S. Environmental Protection Agency 2016, NASA 2017). With the Presidency now held by a man who claimed global warming is a conspiracy "created by and for the Chinese in order to make U.S. manufacturing noncompetitive" (Trump 2012), local governments and environmentally-minded people are finding it more important than ever to take environmental protection into their own hands (Bondar 2017, Bromley-Trujillo 2017, Gannon 2017). Similarly, the Trump Administration's recent greenlighting of the neurotoxic pesticide chlorpyrifos, which the Obama-era Environmental Protection Agency had moved towards banning, has families worried about their health and safety in the face of a federal government that is seemingly unconcerned with their well-being (Levin 2017).

\subsection{Previous Approaches and their Shortcomings}

Studies of the "end-users" of energy, water, food, and other products are not well developed (Stern et al. 1997, OECD 2008). Except for the areas of recycling and energy conservation, public policies and interventions aimed at reining in expectations and demands or changing lifestyles have been fairly rare since they are not compatible with the overarching American celebration of growth and affluence. Energy conservation is an exception because of periodic crises and the clear economic advantage of doing more 
with less energy. But even in the energy efficiency movement, there has been reluctance to touch the "third rail" of lifestyle change (Lutzenhiser \& Gossard 2000), and wellfunded interventions in the most innovative geographies like California have closely adhered to a model that encourages modest energy savings from "cost-effective" technology upgrades (Lutzenhiser et al. 2009).

Some research on "green consumerism" has been undertaken, but most often from a marketing or advertising perspective, with aims related to identifying and selling products to consumers with environmental interests. Usually these types of studies include little reference, beyond individual psychology and descriptive demographics, to social science theories or scholarly empirical literatures (Diamantopoulosa et al. 2003, Rex \& Baumann 2007, Nath et al. 2013, Chekimaa et al. 2016).

Where studies of consumption have taken place, they often draw upon limited data sources and surveys that collect limited information about attitudes and actions across large populations. Drawing upon work by Shove et al. (1998) and Wilhite et al. (2001), Lutzenhiser (2002) considered the prospects of "greening the economy from the bottomup" and identifies a number of difficulties faced by households with the strongest environmental attitudes and the best intentions, including family dynamics, lack of resources, social pressures, and institutional constraints. Little work has been done to 
examine those dynamics and factors, or to empirically apply theories that might shed light on them.

If households and their demands for goods and services are at the core of humanenvironment interactions and ecological decline, it is important that the dynamics of demand be better understood. However, this is easier said than done. Knight $(1944,289)$ notes that, "The treatment of demand is the branch of economic theory in which methodological problems are most important and most difficult. This is because it is here that behavior facts are most inseparably bound up with motivation and that objective data call most imperatively for interpretation by subjective facts and meanings." While there is appropriate social science theory, it is scattered across disciplines and seems to be incomplete in some cases and contradictory in others.

\subsection{The Production of Sustainability in Households}

If changes at the household level are desirable for environmental protection, then the need for better knowledge of is obvious. For example, it would be important to understand the differences in the understandings, practices, and impacts of "high demand," "average," and "low demand" households, as well as differences in practices and beliefs of different socio-economic-demographic groups. Shove notes that, "In real life, escalators do not run backward. Neither do the escalators of demand in economic theory" (Shove 2003, 10) in research that outlines the expectations, infrastructures, and 
social meanings that alter social practices over time in ways that increase the demand for resources. But what does it look like when demand does decline?

Because little of this work has been done, and the focus of a dissertation must be manageably narrow, I have chosen to investigate the lives and habits of a group of selfdescribed sustainable households, focusing on the intentional actions the members of these households take to reduce environmental harm. What these household do, why they do these things, how they think about them, and how they evaluate the results all shed important light on how environmental concern can be translated into proenvironmental action under the best circumstances. So, from these households, perhaps we can learn what changes might be possible, what the limits are to their effectiveness, what the unintended consequences of widely promoting these household-level proenvironmental practices might be, and, ultimately, if household-level efforts to mitigate environmental problems are effective or even desirable.

Lutzenhiser $(2002,4)$ found that "pro-conservation attitudes rarely resulted in action." In response to this challenge, I recruited a sample of action-oriented households who have made fairly major changes to conventional ways of getting things done in day-to-day life to bring their practices into alignment with their sustainability values. The households I spoke with over the course of this research are not green anarcho-primitivists living off the land in a yurt, raising feral children, and making their own clothes out of roadkill 
squirrel pelts. Rather, I deliberately sought out a set of very much on-the-grid households in a metropolitan area living in ways that remain fully engaged with civilization and modernity. Furthermore, I have focused on a portion of the lifecycle when the time and finances of households are under particularly heavy strains, concentrating on adults with young children.

Shove $(2003,9)$ writes that "studies of eco-villagers or investigations into the beliefs of self-confessed environmentalists represent something of a distraction. What counts is the big, and in some cases global, swing of ordinary, routinized and taken-for-granted practice." The households I spoke with over the course of this research have thought carefully about these routinized practices, and have made changes to their expectations, demands, and practices in ways that still allow them to remain connected to contemporary society. These households provide a reasonable window into an alternate reality where demand escalators really do run backwards.

\subsection{Theoretical Overview}

Past research on environmentally-oriented groups, both scholarly and market research, has focused on what people buy and why they buy those things (Straughan \& Roberts 1999, Young et al. 2009, Shrum et al. 2013). This is not a study of consumption and consumers, rather it is a study of the production of day-to-day life-how households get things done. Purchases of market goods and "green consumerism" tell only one part of a 
much larger story. In fact, most of the households I spoke with over the course of this research expressed a great deal of skepticism about "green consumerism" and sustainability marketing (Micheletti 2003; Doane 2010; Boltanski \& Chiapello 2005, 449). The most dramatic changes these eco-conscious households are making involve things that they are doing, not things that they are buying. With few exceptions, past research on human-environment interactions as missed an important point-the consumption that has been implicated in environmental problems is not for its own sake. In an economic manner of speaking, consumption by households is derived demand-demand for goods and services that are used in the production of something else. In the case of households, consumption is an input into the production of daily life: things like physical comfort, cleanliness, waste removal, transportation, provisioning, esteem, and adherence to social norms. And daily life is produced through a series of easily overlooked habits and practices - these practices, their meanings, and their consequences are at the center of this research.

To understand these sustainability-oriented households and their practices, I relied on an orienting theoretical framework grounded in neoclassical economics, feminist radical political economy, and sociology. These theories represent perspectives that focus directly on household production, consumption, and the environment, and that see consumption in households as derived demand. These theories are overlapping and 
sometimes contradictory, but combining them helps me compensate for the gaps left by each one.

Households produce things like cleanliness, nutrition, and comfort for their members, and the way that they go about producing them is influenced by their own unique set of priorities, resources, and constraints. Households are situated in culture, in the economy, in society, and these factors also influence how they get things done and who benefits. Households have varying priorities in the sustainability realm that include personal health, the environment, avoiding waste, technology, and community welfare. They consist of people with needs, desires, and priorities that may not be aligned. Households have resources that include money from waged work used to buy market goods and services, help from extended family and friends, the unpaid work of household members, resources from government and non-profits, productivity due to research/human capital/competence, and materials acquired through gleaning, borrowing, or theft. Each of these resources can serve as substitutes for each other in the production of day-to-day life. Households are constrained by limited time and money, the availability of other resources, cultural norms, and the availability of information. These constraints emerge from the economy and society in which my informants live and cause them to make trade-offs between their priorities in the sustainability realm and other priorities, such as sanity and personal well-being. 
As Shove (2003) has pointed out, the source of demand for natural resources is frequently hidden in mundane and easily overlooked actions that take place in households. This demand for resources is not for its own sake, but rather these resources are used in the production of goods and services for use by household members in the course of day-to-day life. But what we believe day-to-day life should be like is the constantly evolving product of cultural expectations. The households I spoke with over the course of this research have made changes in how they get things done that have changed their expectations for many aspects of daily life-how easy or difficult activities should be, how a person should feel indoors during the winter, what a just-washed towel should feel and smell like, what it means to have a clean body, when a toilet should be flushed.

\subsection{Methodological Overview}

If the household can be thought of as a small factory that produces day-to-day life, then the research I conducted is a factory visit in the tradition of Smith ([1776] 2003) and Marshall (1919). I spoke with informants from 23 households living in the PortlandVancouver-Beaverton metro area in 60- to 90-minute ethnographic interviews about their day-to-day lives. During these conversations, I asked my informants to explain how their sustainability priorities influence their practices - or how they get things donewith respect to household waste, comfort, cleanliness, food, transportation, and childcare. My informants get day-to-day tasks done just like everyone else-by focusing 
on the things that are most important to them, making use of the resources available to them, and subject to the constraints that limit their options. Their sustainability priorities mean that the practices and precise combinations of inputs involved in the production of their day-to-day lives are different from conventional American households. This led me to examine the consequences, intended and unintended, of these sustainability-oriented ways of getting things done.

\subsection{Outline}

In this dissertation, I will introduce you to a group of sustainability-oriented households with young children living in and near Portland, Oregon. I will describe how they balance their priorities and produce a sustainable day-to-day life using the resources they have available to them, limited by the factors that constrain them. I will discuss how these households make choices, how these choices have evolved over time, and how they view the social and cultural meanings of these choices.

In Chapter 2, I provide a review of the relevant literature, primarily from economics and sociology, and I describe the theoretical synthesis that I used both as a framework for my conversations with informants and as an orienting perspective to understand the data I collected. In Chapter 3, I describe the ethnographic interviewing method I used, and explain why this is a valid and useful way to collect information on household production, and its consequences and social meanings. In Chapter 4, I provide a more detailed 
introduction to my informants and their households - who they are, a description of their varied priorities in the sustainability realm, a description of the resources they have available to them to get things done, and a description of the factors that constrain them. In Chapter 5, I describe how households get things done in ways that are informed by their sustainability priorities using the resources available to them and subject to the factors that constrain them. I focus on three areas of day-to-day life that have been neglected in previous research-the disposal of household waste, comfort, and cleanliness. In Chapter 6, I describe some of the consequences for households and individuals of seeking out alternative ways of getting things done-engaging in research, conflicts over sustainability practices, and the sometimes-painful trade-offs that are required to balance priorities. How do they produce day-to-day life using time, knowhow, and purchased/government inputs? In Chapter 7, I conclude by explaining why households are making these interventions into conventional ways of getting things done and what this might mean for policymakers and others who are considering promoting household-level pro-environmental practices.

\subsection{Conclusion}

Netting et al. (1984, xxi) note that, "Perhaps it is this mundane, repetitive, cross-culturally obvious appearance of households that has led observers to think of them as unproblematic and lacking in interest." However, Engels $(1902,71)$ writes that the household represents a microcosm of all of society-within individual households, the 
same conflicts and processes take place as do in the economy and society as a whole.

Fractal-like, the household is a miniature economy within the larger economy, a miniature society within the larger society, existing within but subsumed by these larger structures and bound by their laws. Similarly, Marshall (1919) argued that the processes underlying production in the economy as a whole can be understood by examining a single factory, and that production in a single factory can be understood by first examining the economy as a whole. I will argue that this study of sustainability-oriented households and their activities reveals crucial information about society, the economy, and the state. First, it is these larger structures and institutions that constrain the range of possible actions of individuals and groups. But revealingly, my informants feel obligated to undertake pro-environmental tasks that are often time-consuming and costly because they can't trust institutions to take the large-scale protective actions that they believe are needed for the environment and the health of their families. Even when these household-scale actions are revealed to be futile-or outright counterproductive-my informants continue to press on out of the conviction that their sustainability values and priorities are worthy of their efforts.

In her landmark study of household production, Reid $(1934, \mathrm{v})$ points out that household production is an integral component of the economy, and unless we recognize it as such we will be unable to properly evaluate the costs and benefits associated with moving production into or out of the household. By modeling "green" households as producers 
of sustainability rather than consumers of environmental products, I bring into focus the sustainability work that households and the people that comprise them are engaged in. In doing so, we can begin to evaluate the trade-offs inherent in these pro-environmental activities, and whether or not the household is a desirable site for the production of sustainability.

References:

Boltanski, Luc \& Ève Chiapello. 2005. The New Spirit of Capitalism. London: Verso.

Bondar, Paul. 2017. "A New Era of U.S. Climate Action." Rocky Mountain Institute Outlet June 6, 2017. Accessed 06/07/2017. Available: https://www.rmi.org/news/newera-u-s-climate-action/

Bromley-Trujillo, Rebeca. 2017. “Despite Trump, Many Cities and States are Fighting Climate Change. Including Pittsburgh." The Washington Post, June 6, 2017. Accessed 06/07/2017. Available: https://www.washingtonpost.com/news/monkey-cage/wp/2017/06/06/despitetrump-pittsburghs-working-on-slowing-climate-change-so-are-many-other-citiesand-states/

Brown, Lester. 2003. Rescuing a Planet under Stress and a Civilization in Trouble. New York, NY: W.W. Norton \& Company. 
Chekimaa, Brahim, Syed Azizi Wafa Syed Khalid Wafaa, Oswald Aisat Igaua, Sohaib Chekimab, and Stephen Laison Sondoh Jr. 2016. “Examining green consumerism motivational drivers: does premium price and demographics matter to green purchasing?" Journal of Cleaner Production 112: 3436-3450.

Diamantopoulosa, Adamantios, Bodo Schlegelmilch, Rudolf Sinkovicsd, and Greg Bohlenc. 2003. "Can socio-demographics still play a role in profiling green consumers? A review of the evidence and an empirical investigation." Journal of Business Research 56: 465-480.

Dietz, Thomas and Eugene A. Rosa. 1997. "The effects of population and affluence on $\mathrm{CO}_{2}$ emissions." Proceedings of the National Academy of Sciences of the United States of America 94(1): 175-179.

Doane, Molly. 2010. "Relationship Coffees: Structure and Agency in the Fair Trade System." In Fair Trade and Social Justice: Global Ethnographies, edited by Mark Moberg. New York: NYU Press.

Ehrlich, Paul R. and Anne H. Ehrlich. 1974. The End of Affluence: A Blueprint for your Future. New York, NY: Ballantine Books.

Engels, Friedrich. 1902. The Origin of the Family, Private Property and the State. Translated by Ernest Untermann. Chicago, IL: Charles H. Kerr \& Company. Foster, John Bellamy. 2002. Ecology against Capitalism. New York, NY: Monthly Review Press. 
Gannon, Liz Purchia. 2017. "How to Push Climate Action Forward in the Trump Era." Grist, March 6, 2017. Accessed 06/07/2017. Available: http://grist.org/opinion/how-to-push-climate-action-forward-in-the-trump-era/ Jorgenson, Andrew K. 2003. "Consumption and Environmental Degradation: A CrossNational Analysis of the Ecological Footprint." Social Problems 50(3): 374-394. Knight, Frank H. 1944. "Realism and Relevance in the Theory of Demand." The Journal of Political Economy 54(4): 289-318.

Levin, Sam. 2017. “'Like a Slow Death': Families Fear Pesticide Poisoning after Trump Reverses Ban." The Guardian, April 17, 2017. Accessed 06/07/2017. Available: https://www.theguardian.com/us-news/2017/apr/17/california-pesticidescentral-valley-trump

Lutzenhiser, Loren. 2002. "Greening the Economy from the Bottom-Up? Lessons in Consumption from the Energy Case" in Nicole W. Biggart (ed.), Readings in Economic Sociology. Oxford, UK: Blackwell.

Lutzenhiser, Loren and Maria Gossard. 2000. "Lifestyle, status and energy consumption" Proceedings, American Council for an Energy Efficient Economy. Washington, DC: ACEEE Press 8: 207-222.

Lutzenhiser, Loren, Laura Cesafsky, Heather Chappells, Marcia Gossard, Dulane Moran, Jane Peters, Mersiha Spahic, Paul Stern, Elizabeth Simmons, and Harold Wilhite. 2009. Behavioral Assumptions Underlying California Residential Sector Energy 
Efficiency Programs. Report to the California Public Utilities Commission.

Berkeley, CA: California Institute for Energy and Environment.

Malm, Andreas. 2015. Fossil Capital: The Rise of Steam Power and the Roots of Global Warming. New York: Verso Books.

Marshall, Alfred. 1919. Industry and Trade: A Study of Industrial Technique and Business Organization; and of their Influences on the Conditions of Various Classes and Nations. London, UK: Macmillan.

Micheletti, Michele. 2003. Political Virtue and Shopping: Individuals, Consumerism, and Collective Action. New York, NY: Palgrave Macmillan.

Nath, Vishnu, Rupesh Kumar, Rajat Agrawal, Aditya Gautam, and Vinay Sharma. 2013. "Consumer adoption of green products: Modeling the enablers." Global Business Review 14: 453-470.

National Aeronautics and Space Administration. 2017. “NASA's Climate Kids: What Can We Do to Help?" Accessed 06/07/2017. Available: https://climatekids.nasa.gov/how-to-help/

Netting, Robert McC., Richard R. Wilk, and Eric J. Arnould. 1984. "Introduction." in Robert McC. Netting, Richard R. Wilk, and Eric J. Arnould. (ed.s), Households: Comparative and Historical Studies of the Domestic Group. Berkeley, CA: University of California Press.

OECD. 2008. Household Behaviour and the Environment: Reviewing the Evidence. Paris, France: Organization for Economic Development and Cooperation. 
Reid, Margaret. 1934. The Economics of Household Production. New York, NY: John Wiley \& Sons, Inc.

Rex, Emma and Henrikke Baumann. 2007. "Beyond ecolabels: what green marketing can learn from conventional marketing." Journal of Cleaner Production 15: 567-576.

Rosa, Eugene A. and Thomas Dietz. 2003. "Footprints on the Earth: The environmental consequences of modernity." American Sociological Review 68(2): 279-300.

Schnaiberg, Allan and Kenneth Alan Gould. 1994. Environment and Society: The Enduring Conflict. Caldwell, NJ: The Blackburn Press.

Shove, Elizabeth. 2003. Comfort, Cleanliness, and Convenience: The Social Organization of Normality. Oxford, UK: Berg.

Shove, Elizabeth, Loren Lutzenhiser, Simon Guy, Bruce Hackett, and Harold Wilhite. 1998. "Energy and Social Systems" in Steve Rayner and Elizabeth Malon (eds.), Human Choice and Climate Change. Columbus, $\mathrm{OH}$ : Battelle Press.

Shrum, L.J., John A. McCarty, and Tina M. Lowrey. 1995. "Buyer characteristics of the green consumer and their implications for advertising strategy." Journal of Advertising 24(2): 71-82.

Smith, Adam. 2003. An Inquiry into the Nature and Causes of the Wealth of Nations. New York, NY: Bantam Classic. 
Stern, Paul C., Thomas Dietz, Vernon W. Ruttan, Robert H. Socolow, and James Sweeney, eds. 1997. Environmentally Significant Consumption: Research Directions. Washington, DC: National Academy Press.

Straughan, Robert D. and James A. Roberts. 1999. “Environmental segmentation alternatives: a look at green consumer behavior in the new millennium." Journal of Consumer Marketing 16(6): 558-575.

Trump, Donald (therealdonaldtrump). 2012. "The concept of global warming was created by and for the Chinese in order to make U.S. manufacturing non-competitive." 11:15am, November 6, 2012. Accessed 06/07/2017. Available: https://twitter.com/realdonaldtrump/status/265895292191248385?lang=en

U.S. Environmental Protection Agency. 2016. "What You Can Do about Climate Change." Accessed 06/07/2017. Available: https://19january2017snapshot.epa.gov/climatechange/what-you-can-do-aboutclimate-change_.html

The White House. 2015. "Presidential Proclamation-America Recycles Day, 2015." November 13, 2015. Accessed 06/07/2017. Available: https://obamawhitehouse.archives.gov/the-pressoffice/2015/11/13/presidential-proclamation-america-recycles-day-2015 Wilhite, Harold, Elizabeth Shove, Loren Lutzenhiser, and Willett Kempton. 2001. "The Legacy of Twenty Years of Energy Demand Management: We Know More About 
Individual Behavior But Next to Nothing About Demand" in Ebarhard Jochem, Jayant Sathaye and Daniel Bouille (eds.), Society, Behaviour and Climate Change Mitigation. Dordrecht, Netherlands: Kluwer Academic Publishers.

Wilk, Richard. 2016. "Consuming ourselves to death: The anthropology of consumer culture and climate change." in Susan A. Crate and Mark Nuttall (eds.), Anthropology and Climate Change: From Encounters to Actions. London, UK: Routledge.

Young, William, Kumju Hwang, Seonaidh McDonald, and Caroline J. Oates. 2009. "Sustainable Consumption: Green consumer behavior when purchasing products." Sustainable Development 18(1): 20-31. 
Chapter 2: Literature Review

\subsection{Introduction}

My goal in this study is to learn about a sample of highly eco-conscious or sustainabilityoriented households with young children in the Portland, Oregon, metro area who have made changes in the way they get things done to bring their day-to-day lives into better alignment with their values. The impacts of climate change are already being felt in the United States and elsewhere (U.S. Global Change Research Program 2014), and proenvironmental promotional campaigns contain messages related to personal responsibility and "doing your part" as a key component of climate change mitigation strategies (United Nations 2014). This study of the practices of eco-conscious urban households with young children can help us understand what changes might be possible, the possible unintended consequences and limits to the efficacy of household-level actions, what more conventional households might encounter if they took even a partially "green" turn, and how public discourse and policy deliberations should think about the possibilities for pro-environmental changes at the household level.

A large portion of my objective is simply to describe things about a set of households that haven't previously been examined and described in the social science literature.

However, theoretical lenses provide the orienting perspective that is needed to move beyond description, to adequately make sense of the data, and to identify possible paths 
forward for policy and for households in the resource conservation and sustainability realms. This is a study of economic and social practices, with the actions of the household seen as production rather than consumption, and non-leisure activities and efforts characterized as work, whether paid or unpaid. The frequent framing of households as consumers of goods and services characterizes individuals and households as utilitymaximizing agents (Hicks \& Allen 1934, Schultz 1935), enthusiastic participants in consumer culture who buy things for the sake of buying them (Ewen \& Ewen 1992), or unwitting accomplices to profit-seeking capitalists (Schnaiberg \& Gould 1994). However, I will argue here that household consumption is more accurately thought of as what is known in economics as derived demand (Moslak 1938)-demand for goods and services that are transformed and used in the production of something else. In this case, that something else is day-to-day life: things like physical comfort, cleanliness, waste removal, transportation, provisioning, esteem, adherence to social norms, and the reproduction of labor power.

\subsubsection{Summary of the Theories}

There are many valid ways to go about a study of sustainability-oriented households, though I have focused here on an approach informed by economics and sociology. Potentially useful literatures exist in other social and behavioral sciences, like marketing (Polonsky \& Mintu-Wimsatt 1995), history (Klingle 2003), environmental psychology (Stern 2011), and anthropology (Douglas 2003 [1979]). While these literatures contain 
useful insights, I have chosen to focus on a set of rigorous theories from economics and sociology because they represent perspectives that focus directly on household production, consumption, and the environment. An additional common thread runs through these theories - they all see consumption in households as derived demand, though what this derived demand is in service of varies across the theories.

I make use of five overlapping but frequently contradictory sets of theories in an attempt to compensate for shortcomings in each of them: neoclassical theories of the household, Marxist-feminist theories of the household, feminist radical institutional economics, sociological theories of consumption, and theories of social practice. In her lecture on Marx, Marshall, and Keynes, Robinson writes:

In short, no economic theory gives us ready-made answers. Any theory that we follow blindly will lead us astray. To make good use of an economic theory we must first sort out the relations of the propagandist and the scientific elements in it, then by checking with experience, see how far the scientific element appears convincing, and finally recombine it with our own political views. (1960 [1955],17)

Embedded in several of the theories I rely on here are political principles with which the reader may or may not agree. Following Robinson's suggestion, if the theories "still make sense as a description of reality" (12) when the political underpinnings have been set aside, then these theories are useful for my analysis. These theories will be reviewed in this chapter with a particular emphasis on their applicability to a study of the production of day-to-day life in eco-conscious urban households with young children, and I will provide a synthesis of these theories that I will use in the following chapters as a 
framework for the discussion and analysis of my findings. This synthesis is necessary because no existing theory allows me to simultaneously explain how day-to-day life is produced within households, the social meanings of these production decisions, and how this production is linked to the economy and society as a whole.

\subsubsection{What Are Households?}

While there are damaging effects of the ideologies of family and motherhood in capitalism, this is not to say that the benefits, affective or otherwise, that people perceive to flow out of families or the parental role are illusory-rather, "like every proper ideology, the family too was more than a mere lie," (Frankfurt Institute for Social Research 1973, 138). The informants I spoke with for this research love their children and value their families - for many of my informants, their children and families are the primary motivation for their sustainability practices. However, I have chosen to talk about households rather than families for several reasons. The arrangement of biologically related people into shared dwellings in a "family-household" — the combination of "kinship and co-residence" - is a relatively modern social arrangement (Barrett 1980, 199-213) that is not universal across time or cultures (Wilk \& Netting 1984). In fact, the family-household is not universal in the sample of households I spoke with during the course of this research, as several of my informants live with unrelated persons as roommates, in co-housing, or in intentional community. Similarly, the nuclear family is a modern concept that has been held up politically as an ideal form, but is not universal 
across time, cultures, or classes (Barrett 1980, 199-213). While thirteen of the households I spoke with for this research live together in a nuclear family with oppositegender parents, the remaining ten do not. Households, rather than families, are significant for the things that households do in societies: households are involved in the production and transformation of goods for use or sale, the distribution of goods, transmission of culture, sexual reproduction, and co-residence (Wilk \& Netting 1984). The subject of this research is things that households do through routinized day-to-day tasks: the production and transformation of goods for use, the distribution of these goods, the transmission of culture, and the reproduction of labor power.

\subsubsection{Summary of the Theoretical Synthesis}

In my own synthesis that will be presented at the end of this chapter, I will describe how households produce day-to-day life-things like cleanliness, nutrition, and comfort-for their members through many small, routinized practices. The way that households and their members go about producing daily life is influenced by their priorities, resources, and constraints. A day-to-day life that strives to be consistent with one's sustainability priorities can be thought of as a sort of producer's constrained optimization problememploying the resources available and subject to constraints. However, constraints are not just economic but also social and cultural ones, and "tastes and preferences" are similarly not exogenous but culturally determined and with social meanings. The 
household is not a single utility-maximizing unit, but rather a group of unique human beings with lived experiences and priorities that may not all agree.

\subsection{Review of the Theoretical Literature}

\subsubsection{Neoclassical Economics and the Household}

In the neoclassical model of the firm, inputs into the production process, or "factors of production", are engaged and combined to yield commodities for sale. In the most simplified version, these factors of production are land, labor, and physical capital (that is, machines and other equipment). However, this simplified model can be expanded to include additional inputs necessary for production, like human capital (that is, acquired knowledge and training), raw materials, other intermediate market goods, and government goods and services (for example, roads or the enforcement of property rights). These factors of production are substitutes_for example, additional physical capital can replace workers. But they are also what is known as complements-they must be employed together in order to produce commodities. Even the most sophisticated machine needs human workers to operate it, a building to house it, and transportation infrastructure to bring the end product to market. And without other inputs, labor alone is not capable of producing anything. According to this theory, factors of production will be selected to minimize total costs (or maximize profits) for a given level of production, and employed until the additional productivity of one more unit of each factor exactly equals its cost. A change in the price of any one of these inputs will change the ratios 
employed in production as the firm seeks to minimize costs. If another seller can produce one of the intermediate goods in the production process more cheaply, the producer will purchase that input from the external seller rather than produce it in-house.

In much of neoclassical economic theory, a line is drawn between the private sphere of the home and the public sphere of the market. Households and the people that comprise them are depicted as workers employed outside the home who trade their time for a wage, or private consumers who maximize their utility subject to a budget constraint determined by their wages. However, the contemporary household is a site not only of consumption, but also of production. Household members can be seen as using factors of production within the household-such as household equipment, the time of household members, training in household production, raw materials, and market or government goods and services - to produce the end goods from which they derive pleasure and sustenance. Much like firms, households may substitute between inputs to minimize costs or maximize their enjoyment. Marshall ([1890], 2009 72-73) discusses the production of goods and services in the household, arguing these add to the "income" of the household even as they do not generate wages:

Anything which a person does for which he is paid directly or indirectly in money swells his nominal income; while no services that he performs for himself are commonly reckoned as adding to his nominal income. But, though it is best general best to neglect them when they are trivial, account should for consistency be taken of them, when they are of a kind which people commonly pay for having done for them. Thus a woman who makes her own clothes or a man who digs his own garden or repairs his own house, is earning income; just 
as would the dressmaker, gardener or carpenter who might be hired to do the work.

But five decades earlier, Beecher (2007 [1842], 143) gave the following advice to homemakers:

Another mistake in economy, is often made, by some of the best-educated and most intelligent of mothers. Such will often be found spending day after day at needlework, when, which a comparatively small sum, this labor could be obtained of those who need the money, which such work would procure for them.

Beecher makes a distinctly Ricardian argument about comparative advantage, the gains from trade, and the opportunity cost of time that runs contrary to the advice found in other popular $19^{\text {th }}$ century homemaking manuals ${ }^{1}$ and even to Marshall's discussion of unpaid work in the household: there is an opportunity cost to doing things yourself, and it is more efficient to pay others for certain household tasks if this frees you up to do something more productive with your time. In other words, doing things yourself may not add to your household income, as Marshall argues, but instead subtract from it if there is something more productive you could be doing with that time.

Nearly a century later, Reid (1934) takes up this same idea of the opportunity cost of unpaid household work in her study of household production:

The household is an integral part of our whole economic system. Only if it is viewed in this way can we become aware of the labor costs and productive activities necessary to maintain present standards of living. Unless this is done we cannot rightly appraise the economic role of homekeeping women or act

\footnotetext{
${ }^{1}$ For example, Child (1999 [1844], 3) advises her readers that, "'Time is money.' For this reason, cheap as stockings are, it is good economy to knit them."
} 
intelligently in matters concerning the gainful employment of married women. ( $v)$

Reid makes explicit the link between women's unpaid work in the home and the non-zero opportunity cost of unpaid work in the home. In detailing increases in women's paid employment outside the home and declines in household production, she discusses the conditions required for an increase in household production to make economic sense (371): "Increased household production is an advantage if certain things now being purchased can better be provided by the family." Thus, according to Reid, it is not necessary for women to specialize in unpaid work in the household in order to take advantage of the gains from trade.

\subsubsection{Becker and the Theory of Z-Goods}

Becker (1981) treats the household as a factory that produces utility for its members by allocating work, leisure, and commodities between members in an efficient manner according to relative prices and wages. By commodities (or Z-goods), Becker means nonmarket goods produced within the household by combining consumable and durable market goods, household members' time, and other inputs (Becker 1981, 7-8). Market goods do not provide utility directly-utility is derived instead from leisure and the consumption of Z-goods. Household members trade their time for money in the labor market or devote their time to producing Z-goods in the household according to a constrained utility maximization problem, with specialization and a gender division of labor according to comparative advantage (14-32). Similarly, Z-goods can be more or less 
time-intensive, with substitution and complementarity between purchased goods and the time of household members occurring based on relative prices and wages. A household member's specialization in unwaged work in means that the household has determined that this member's productivity in the household outweighs the market substitutes that could be purchased with her waged labor in that phase of the lifecycle.

The Becker model of the household can be seen as an expansion on his earlier work on the allocation of time (Becker 1965) to include multiple actors in a household that is treated as a single utility-maximizing unit. This model is now commonly used to examine the time allocation decision between paid work outside the home, unpaid work inside the home, and leisure. According to Becker, the most efficient household configuration is one in which a man specializes in waged work outside the home and a woman specializes in unwaged work inside the home, allowing the household to take advantage of the gains from trade (Becker 1981, 21). Applications of the Becker model include health economics (Kolodinksy \& Goldstein 2011, Finkelstein et al. 2005), transportation economics (Bhat \& Koppelman 1999, Jara-Diaz 2000, Gliebe \& Koppelman 2002), and even internet shopping (Bhatnagar et al. 2000).

A useful application for consideration here is Chiswick (1999) and Chiswick \& Chiswick (2000) on the economics of Jewishness. These publications use the Becker model of household production to discuss Jewish identity and the production of a Jewish cultural 
Z-goods in the home. In their model, people can invest in three different types of human capital: human capital related to household production of non-Jewish Z-goods, human capital related to household production of Jewish Z-goods, and human capital related to the production of market goods. Like all Z-goods, Jewish cultural Z-goods require market inputs and time in addition to know-how. The cultural value and the cost to produce Jewish cultural goods may vary by the concentration of Jewish families in the region of the household in question. The value of investments in human capital specific to the production of Jewishness in the home depends on the extent to which these skills are also potential substitutes or compliments for market-specific human capital. For Jewish households, the ratios of the factors of production employed in the making of day-to-day life has social and cultural meaning. The neoclassical model of cultural Z-good production as described by Chiswick (1999) and Chiswick \& Chiswick (2000) demonstrates that this is a potentially useful framework for showing the way sustainable or eco-conscious households produce day-to-day life using varying combinations of paid and unpaid time, market goods and services, government goods and services, and know-how.

\subsubsection{Shortcomings of Neoclassical Theories of the Household}

While this the time allocation decision is not the portion of the Becker model that will be emphasized here, it does warrant some discussion. Underneath the calculus and algebra are a set of political principles. The mathematics may be designed to appear value-free, but the processes of production and exchange it describes have social meaning and 
consequences. Becker's theory of household production and time allocation has been extensively criticized by feminist economists (for example, Sawhill 1977, Ferber \& Birnbaum 1977, Greenwood 1984, Heath \& Ciscel 1988, Bergmann 1995, Ferber 1995, Folbre 1986, Wheelock \& Oughton 1996). For Becker, the household is a single utility maximizing unit rather than individual household members with their own interests and priorities. In this model, the allocation of unpaid in-home production and paid market work between household members is decided according to comparative advantage, and he assumes that women in efficient households will specialize exclusively in unpaid domestic production due to "intrinsic differences between the sexes" (Becker 1981, 21). He goes on to note that same-sex couples will have less efficient households due to their inability to, "profit from the sexual difference in comparative advantage" (23). Women who specialize in work outside the home and men who specialize in unpaid household work are described as "deviants" who "seek a deviant division of labor" in the household, and are contrasted with what Becker calls, "normal persons" (24). This content in Becker's Treatise on the Family represents more than a mere shortcoming-it is an offensive use of neoclassical tools to justify the oppression of women and sexual minorities.

Beyond these critiques of Becker, the neoclassical model is an inadequate framework for understanding all of social and economic life. People are constrained by more than budgets and the number of hours available in a day. Changes in prices and wages often 
do produce changes in consumption or work patterns, but not always. Besides, consumption and patterns of work can change for other reasons. While comparative advantage may be one factor that influences how work is assigned between household members, it is certainly not the only factor. The "tastes and preferences" generally modeled by economists as exogenous and static and do not arise spontaneously and remain constant. They are shaped by culture-by the values, symbols, and norms of the groups someone is a member of-and cultures are shaped by social structures. While neoclassical economists may model individual actors making household production and consumption decisions, in reality these are human beings embedded in social and institutional contexts that influence and limit those exchanges. And those exchanges shape human beings and the ways that they relate to one another. What appear to be freely-made decisions are often made in the presence of substantial constraints.

\subsubsection{Marxist-Feminist Theories of the Household}

It may seem on the surface that neoclassical and Marxist-feminist theories of the household are incompatible. However, when Collins $(1990,10)$ writes that "housewives are mainly involved in processing and maintenance activities - they do not produce the goods necessary for the survival of their families, but change them into a usable form," what she is describing sounds very much like Becker's concept of the Z-good. Indeed, both the Marxian and neoclassical theories have factors of production which are combined to produce output, as both take Ricardo and classical political economy as 
their point of departure. The important difference is that Marx emphasizes the social significance and meaning of these production processes and the exchange of the resulting output.

Marx writes that, "[The worker] is home when he is not working, and when he is working he is not at home," (Marx 1978 [1844], 74). This division between the public and private spheres in economic research has been criticized, for example by Zaretsky (1976). Much of the existing research on the family and households relies on an assumption that there is a "distinction between the family itself, and the larger world" (Rapp et al. 1979). Marxist-feminist theories of the household are helpful for demonstrating how the responsibility for the costs of day-to-day life are shifted and the ways that households and the people that comprise them are recursively connected to the economy as a whole.

Labor is a strange factor of production in that it can't be separated from its supplier (Prasch 2004)-labor is embodied in self-aware human beings who are born, grow up, reproduce, and die. These human beings continue to exist when they are not working, and they need rest, food, leisure, and to be clean and free of disease so they can go on to work productively another day. This may sound no different from livestock or working animals, but there is a key difference-a working dog doesn't make his own dinner and provide his own shelter and clean bed after a long day collecting sheep for his master. 
The costs of maintaining a working dog in good condition are fully absorbed by the shepherd, while the human worker is responsible for these costs himself. Whether these needs are met via paid services or unpaid domestic work, they are tasks frequently performed by women.

The term "reproductive labor" has a history in Marxist-feminist scholarship, and implies a link between these domestic tasks, whether paid or unpaid, and the economy via the process of social reproduction (Dalla Costa \& James 1972; Barrett 1980; Vogel 1983). This work is considered unproductive labor in the classical political economy, because it does not generate a commodity that can be sold or a profit that can be invested. However, the domestic tasks of day-to-day life are characterized as contributing to the economy indirectly because they reproduce social structures and make the continued supply of labor, this funny factor of production, possible.

These theories stress that modern configurations of domestic life are not natural, but are socially reproduced and tied to the capitalist mode of production (Dalla Costa \& James 1972; Barrett 1980; Vogel 1983). Increasingly, the provision of many domestic goods and services has shifted from the state and employers to households. As Laslett \& Brenner $(1989,384)$ point out, this work of social reproduction has been done within families in recent memory, though there is no reason that this must be the case-there are many 
alternative mechanisms, like state or other collective provisioning, that could be used to provide the same services.

While I reject the perspective from classical political economy that restricts economically productive activities to those that generate a tradeable commodity or an investible profit for an employer, it is my view that social reproduction is vitally important for understanding how social structures and power are reproduced over time and across generations. Social reproduction is essential to "the economy" - without people and the societies they inhabit, "the economy" couldn't exist. Dividing the economy into "public" and "private" or "productive" and "unproductive" sectors is a false distinction, particularly in an era where these boundaries between home and work are becoming ever cloudier.

Weinbaum \& Bridges (1976) discuss the domestic work associated with consumption"the other side of the paycheck" - as a neglected area of study. As I will discuss in the following chapters, many of the sustainability-oriented households I spoke with are making a large number of weekly grocery trips, often four or five trips to several different stores to find the just-right items for a good price. However, the time involved in household production often eclipses the time spent shopping. Many households are engaged in time-intensive, in-home production of goods for direct use by the family in the form of scratch-baking and cooking, chicken-raising, homestead-style gardening and 
canning, and making clothing, home remedies, cleaning products, detergents, soaps, and sprays. This phenomenon is explained in Marxist-feminist terms by Collins $(1990,21)$ : "Use values produced within the home are prized for having more time spent on them, rather than less." (Collins 1990, 21). Bradby $(1982,126)$ argues that the household frequently employs its factors of production in ways that are very unlike the costminimizing or profit-maximizing neoclassical factory:

Use-values produced at home very often derive value from having more time spent on them, rather than less, as in capitalist competition. A three-course meal has more 'value' in domestic terms than a quick snack, a carefully ironed shirt more than one pulled straight from the tumble-drier. Sometimes the extra time spent on domestic tasks may be completely 'abstract', in that it does not apparently increase the use-value of the final product at all - its only importance is to show that time has been spent, and domestic value therefore increased. The capitalist firm, on the other hand, increases surplus value by spending less time on each operation than does its rivals. Extra time lavished on a product is unlikely in the long run to be realised.

These theories are useful because they can help us understand some of the consequences and "whys" of household production that the neoclassical model neglects, thus embedding households and individuals in a larger social and economic context.

\subsubsection{Shortcomings of the Marxist Feminist Theories of the Household} Marxist-feminist theories seek to explain historically how production is arranged in the economy, including in households. Rightly or wrongly, these theories are frequently critiqued as reductionist, with an excessive emphasis on class rather than on more nuanced or complicated forms of stratification (Folbre 1982, Folbre 1986). Marxistfeminist Barrett (1990) points out that it is difficult to see who benefits form the social 
arrangements advocated by the ideology of the household-family, and that this lack of clarity means that a more complicated explanation is needed for the endurance of the family and the work of social reproduction that is done by households. Furthermore, the nuclear family with a male breadwinner and a female housewife is by no means ubiquitous across time, cultures, and classes, and thus theories of the household that rely heavily on a gendered division of labor are insufficient. Finally, while Marxist-feminist theories of the household provide useful explanations for largescale changes in household production over time, these theories can't provide micro-level tools for a complete understanding how and why households might change their ways of getting things done, or what the social and cultural meanings of these changes might be. Additional theories are needed.

\subsubsection{Radical Institutional Thought-Feminist Institutionalists}

Radical feminist institutionalists argue that an explanation for the origin and evolution of tastes and preferences is missing from the Marxist-feminist and neoclassical economic models of the household. Unlike other theories in classical political economy and neoclassical economics, Veblen put the status of women and the gendered division of labor at the center of his analysis in The Theory of the Leisure Class ([1899] 1953, 33-34, 52; Jennings 1993, 112; Waddoups 1992). Veblen sees the ownership of women as the origin of all private property — the "seizure of female captives" as "trophies," which evolved into our current "form of ownership-marriage" (34). According to Veblen, 
kidnapped women are the earliest form of conspicuous consumption. In contrast with other approaches to economic thought that devalue reproductive labor or categorize this work as outside the productive economy, Veblen sees basic social provisioning as the only productive work in the economy, while everything else is waste in service of pecuniary emulation (78-79; Greenwood 1984, 667). Thus, the gendered division of labor is between productive employment performed by women, slaves, and servants, "the everyday work of getting a livelihood," and "non-industrial occupations" performed by men, such as "government, fighting, hunting, religious observances, and sports activities," (Foster 1998, 131).

There is a strong tradition of feminist radical institutionalist scholars drawing on this material in Veblen, including Miller (1972), Greenwood (1984), Heath \& Ciscel (1988), Jennings (1993), Wheelock \& Oughton (1996), Peterson (1998), which argues for the continued relevance of Veblen's proto-feminist economic theories. According to Brown $(1998,51)$, a major contribution of Veblen's work is his recognition of, "the extent to which social, non-economic motives like the desires for esteem and status actually drive the economy." The tastes and preferences assumed by neoclassical economists to be exogenous are, according to Veblen, formed as the result of social processes. Veblen argues that the ultimate result of preference-forming social processes and the desire for esteem has been the oppression of women. 
Veblen critiques the role of women as the vicarious symbols of their husbands' pecuniary prowess (Greenwood 1984, 668-669). According to these theories, a woman who has time to clean her home in a manner that requires additional time and effort is sending a signal to the world that she has the time to do so. Conspicuous leisure in this case doesn't mean displays of time spent enjoying oneself, but rather time spent not working for pay. Additional time and effort is a substitute for contemporary cleaning products designed to make these jobs faster and easier. Recall that for Veblen, status is displayed and reinforced through displays related to conspicuous leisure, or time spent not working for money, with wives performing social important displays of vicarious leisure.

\subsubsection{Radical Institutional Thought-Conspicuous Consumption}

Conspicuous consumption is the use of symbolic material consumer goods to signal social status through displays of pecuniary prowess. Veblen $([1899] 1953,42)$ writes that, "In order to gain and to hold the esteem of men it is not sufficient merely to possess wealth or power. The wealth or power must be put in evidence, for esteem is awarded only on evidence." This evidence can take the form of either leisure (i.e., not working for pay) or displays of wasteful consumption. Lutzenhiser $(2002,6)$ attributes this need for display to the lack of an "old and well-accepted class structure" in the United States. However, for Veblen these displays are related to very much to the class structure-people are sorted into reference groups based on income, and "the goal of consumption was to fit into the 
appropriate reference group in a way considered respectable and proper" (Waller \& Robertson 1998, 31).

For Veblen, conspicuous consumption must also be "conspicuous waste." Waste is used as a technical term by Veblen (78-79) indicating expenditures that do not "serve human life or human well-being on the whole" rather than "waste or misdirection of effort or expenditure as viewed from the standpoint of the individual consumer who chooses it." In other words, anything that is purchased or done for the purpose of signaling pecuniary prowess or wealth is waste, while efforts related to basic social provisioning are not waste. Thriftiness and industriousness would only be emulated and held in esteem in the lower classes, as he argues that this is "the only line of emulation that is open to them" ([1899] 1953, 41).

Steiner and Weiss' discussion of counter-snobbery and the nouveau riche (1951) bridges the gap between Veblen's ideas of conspicuous consumption and the high social status associated with thrift and parsimony in Weber, Bourdieu, and others. They write that, "as a result of the long practice of conspicuous consumption, ornate objects have become associated in the common mind with vast wealth. Therefore, if the old elite is to demonstrate a disinterest in money, it must deplore ornateness and adore simplicity" (263). In insisting that only ostentatious displays of waste could demonstrate status, Veblen failed to anticipate the parvenu, and in a cycle in which the old elite are emulated 
by newly wealthy, the old elite must find new ways to signal their status, and so on in a "self-generating cycle in taste" (emphasis original, 268). Status displays and their social and cultural meaning are constantly evolving. Brown (1998) discusses an expansion of status displays beyond the pecuniary prowess discussed by Veblen, noting the contemporary emphasis on self-development as a more general category that confers reputability. He writes that:

If you are not a self-actualizing, becoming, growing individual, then you are left behind, either economically or socially. Alongside the corporate and national race for economic growth there is the internalized and individualized race for personal growth. Both are insatiable quests in which there are winners and losers; both are treadmills of productivism; both are subject to the same status-driven, competitive conditions criticized by Veblen. (Brown 1998, 52).

These changes over time in the factors that confer reputability make sense in the context of Veblen's larger discussion of the constantly evolving nature of the capitalist economy (Veblen 1898).

\subsubsection{Shortcomings of the Radical Institutional Economics Theory of the}

\section{Household}

A shortcoming of the radical institutional economics of Veblen and scholars working in the tradition of Veblen is the condensing of all social behavior to two categories: basic subsistence provisioning or waste. This approach explains all social and economic behavior-beyond eating enough to avoid death from starvation and keeping sheltered enough to avoid death from exposure-as displays of pecuniary prowess, status, and 
prestige. As I will describe in later chapters, I found little evidence that status displays were the major motivating factor for my informants' sustainability activities. While some aspects of social life may be related to status displays, this is not the whole story.

\subsubsection{Social and Cultural Theories of Consumption and Applications}

\section{Consumption and Status Displays}

Shove and Warde (2002) refer to energy consumption as "inconspicuous consumption" in an allusion to Veblen and his theories of conspicuous consumption - the use of symbolic material consumer goods to signal social status through displays of pecuniary prowess. But the domestic appliances that consume energy and goods produced with energy as an input are frequently used to display social status. Somewhat counterintuitively, reductions in energy consumption that are associated with the projection of a "green" or environmentally-conscious lifestyle can also be a display of social status, signaling one's position in a green lifestyle group or perhaps one's non-pecuniary prowess in self-improvement (Brown 1998).

Wilk \& Wilhite (1985) offer a conspicuous consumption explanation for the failure of homeowners in Northern California in the early 1980s to weatherize their homes, even though doing so would have been very low-cost and economically rational. Instead, homeowners favored costly energy-saving projects that would be visible, such as energy efficient windows, solar panels, and heat pumps. Cost-effective weatherization did not 
take place even when homeowners had made considerable investments in insulation, making those insulation investments next-to-useless. So while the homeowners were indeed signaling to neighbors their interest in reducing their energy consumption, the result was a wasteful display rather than legitimate energy conservation.

For Bourdieu $(1984,258)$ social classes distinguish themselves through the tastes that they have in common, demonstrated in part through the consumption of cultural goods and the accumulation of cultural capital. Both Veblen and Bourdieu discuss the role of emulation in status-displaying consumption. In general, high social status is associated with high income and high levels of consumption, while low social status is associated with low income and low levels of consumption (Lutzenhiser \& Gossard 2000, 215). "McMansions" and other configurations of consumption associated with affluence are certainly resource-intensive. On the other hand, Lutzenhiser $(2002,6)$ notes that, “Greater wealth needn't always be associated with higher rates of consumption, and in fact, items are often prized that are longer-lasting and better-performing." Emerging trends of ethical consumption, green consumerism, and minimalism may appear to turn the old notions of consumption and status on their head, but in fact are very much consistent with the previous patterns. Wilhite \& Lutzenhiser $(1999,284)$ argue that, "If trends were to move towards 'green' items with less energy embodied in their use, the dynamic of distinction/emulation might have the opposite effect" (284). 
However, Schnaiberg \& Gould $(1984,94-96,104)$ are highly skeptical of environmental consumerism, as any consumerism still implicated in the "treadmill of production" and the associated unsustainable environmental burdens. Perhaps tellingly, Lutzenhiser $(2002,4)$ finds that, "pro-conservation attitudes rarely resulted in action," and a body of research exists that is critical of so-called ethical and eco-consumerism (for example, Micheletti 2003 and Doane 2010). Consumers were savvy enough to critique the inauthenticity of mainstream green marketing campaigns as early as the 1990s (Boltanski \& Chiapello 2005, 449), and my informants expressed distain for "greenwashing" and eco-consumerism.

\section{Social Status and Reductions in Consumption}

Bernstein (2016) and Chayka (2016) criticize the high social status position that accompanies the current fashion of possessing a carefully curated set of only a few justright items, and Logan (2017) analyzes these trends based on their hidden theological underpinnings and places them in the economic context of contemporary capitalism. Weber noted the ironies of ethnical asceticism and the rejection of luxury consumption in the Protestant Ethic: "[I]nnerworldly Protestant asceticism works with all its force against the uninhibited enjoyment of possessions; it discourages consumption, especially the consumption of luxuries. Conversely, it has the effect of liberating the acquisition of wealth from the inhibitions of traditionalist ethics" ([1905] 2002, 115, emphasis original). Living a spartan lifestyle frees the minimalist to accumulate wealth without suffering the 
ethical or spiritual consequences of enjoying that wealth. Bourdieu emphasizes the "ascetic aristocratism" $(1984,286)$ of high cultural capital intellectuals, teachers, and university professors. The Holt (1997) application of Bourdieu to the American context emphasizes the rejection of "material abundance and luxury" by high cultural capital $[\mathrm{HCC}]$ research subjects: "While they tend to have higher incomes, HCCs live in smaller houses than the economically secure LCCs, are interested in ethnic rather than fine dining, and have furniture that is more worn and less valuable. HCCs have been raised with few material constraints and so experience material deprivation quite differently," (110). These status-enhancing displays of restrained consumption among HCC households can be contrasted with the preference for abundance among working classes discussed by Bourdieu.

Carfagna et al. (2014) describe a new high social status/cultural capital but low income and low consumption group among people who saw themselves as leading a sustainable, pro-environmental, or ethically-conscious lifestyle. This research differs from some earlier critiques of ecological or ethical consumerism in that it emphasizes the group identities of these individuals and the status associated with membership in those groups rather the consumer individualism or failures in the efficacy of ethical consumerism that is emphasized in Schnaiberg \& Gould (1984), Micheletti (2003), and Doane (2010). Carfagna et al $(2014,74)$ describe the high value that the eco-lifestyle practitioners place on manual labor, and the additional time and effort that is associated with using "non- 
toxic" household cleaning products. This additional effort is then "reinforced and validated in their peer groups" - it is the things people are doing rather than the things they are buying that appear to be most esteemed by their peers.

\section{Status and the New Domesticity}

Cowan $(1983,205-207)$ discusses the preoccupation in 1980s households with a "backward search for femininity" in affluent American communities, with women "breastfeeding ... numerous children, raising vegetables in their backyards, crocheting afghans, knitting argyle socks, entertaining at barbecues, ..., giving homemade breads as Christmas presents, and decorating their living rooms with spinning wheels" (205). More recently, Marchar (2013) describes the appeal of what she calls "the new domesticity" as women long for "a more authentic, meaningful life in an economically and environmentally uncertain world" (5). These time-intensive domestic pursuits could be easily substituted with market purchases of goods and services or the government provision of public child care in an alternate economic system. Cowan $(1983,207)$ critically recounts the middle-class man's claims that "two well-organized dinner parties a month would do more for his family's annual income than the salary his wife would be able to earn at a job." These two dinner parties may seem like a small thing compared to the invisible, routinized tasks that take place in households and make it possible for waged workers to work another day, but the dinner parties are the household's chance to conspicuously display their choice to rely on unwaged work rather than substitutes for 
this work. Time-intensive unwaged work may be a more powerful expression of status and the values of the household than the available market and government substitutes, particularly in a world where access to these substitutes is increasingly unreliable.

\section{Ethnographies of Energy Consumption in Households}

Several studies use an ethnographic approach to describe residential energy consumption and the cultural goods produced using energy. Hackett and Lutzenhiser (1991) use some participant observation to explain large differences in energy use and habits across a diverse group of native-born and migrant families living in identical units in a California apartment complex. For example, lack of an in-unit clothes washer could be linked to a desire for social time in the community laundry facility. On the other hand, the presence of an in-unit clothes washer could be linked to a reluctance on the part of the wife to leave the apartment without her husband. Neither of these factors involves prices, incomes, or even convenience. Wilhite et al (1996) establish cultural differences in energy consumption between Japan and Norway. They examine the laundry, dishwashing, lighting, heating, and bathing habits for their cultural meanings. Each of these activities uses energy to produce a cultural service, so the authors argue that policies to reduce energy consumption must not impact the provision of cultural services.

Wilhite \& Wilk (1987) presents a method for self-recording time use survey and energy use behavior by respondents to supplement in-depth ethnographic interviews. They note 
a marked gender division of labor in the results, even in households who saw themselves as egalitarian - "there is evidently a lot more equality in ideology than in fact" (77). Carlsson-Kanyama \& Lindén (2007) also have gender-related conclusions in their report of ethnographic interviews with Swedish households. They find that energy efficiency measures impact men and women differently, especially that interventions involving many small adjustments tend to increase women's unpaid domestic labor. They also find gender differences in comfort temperatures, and note that time of use rates induce women to stay up late at night to run the wash and get up early to hang up the washing to dry. Aune (2007) conducted in-depth interviews in Norway to understand the relationship between residential energy consumption and the cultural services that homes provide. She identifies differences in how respondents view the purpose of the home-in the cultural meanings and material culture of homes - that could be exploited in the service of energy reduction schemes. She also notes two counter-intuitive findings. "Green" lifestyles and their associated material culture are paradoxical in their high demand for energy, for example the energy-intensiveness of making food at home. Similarly, households who saw themselves as thrifty and traditional often lived in older houses and retained older appliances, both of which use more energy than the contemporary equivalents.

Policy Applications of Social and Cultural Theories of Consumption 
While several of the ethnographic researchers discussed here urge decision-makers contemplating consumption-reduction policies to take into account the cultural services that energy provides or the symbolic meanings of dwellings, they offer few ideas for practical applications. Furthermore, an underlying assumption motivating the recommendation by Wilhite et al. (1996) that energy conservation interventions avoid impacting the provision of cultural services is that those cultural services and their meanings are (or ought to be) stable over time. However, ethnographic research into the meanings and determinants of various types of household consumption describes how consumption can differ across households for complex reasons that would be missed by focusing on prices and incomes or through a purely quantitative approach. The level of analysis is the household and individual, who are embedded in and influenced by their cultural contexts, and theories that can offer this type of embeddedness are needed to understand households who are making major interventions into conventional patterns of household consumption and production.

\subsubsection{Shortcomings of Social and Cultural Theories of Consumption}

The focus in this literature is on objects, artifacts, material culture, and their associated symbolic and cultural meanings, while human actions and the way that humans interact with and transform these artifacts are less central. Like the shortcomings of the radical institutionalist approach discussed earlier, reducing economic and social behavior to displays of status and prestige misses out on other possible motivations. The evolving 
meaning of artifacts and the cultural services they provide is illustrated by Veblen's

discussion of the changing cultural significance of candlelight:

For the last dozen years candles have been a more pleasing source of light at dinner than any other. Candlelight is now softer, less distressing to well-bred eyes, than oil, gas, or electric light. The same could not have been said thirty years ago, when candles were, or recently had been, the cheapest available light for domestic use. Veblen ([1899] 1953, 112)

The social meanings of artifacts and material culture are not stable, but rather are context-specific and constantly evolving and mutating. A theory of household production must reflect these dynamics.

\subsubsection{Theories of Social Practice}

Shove \& Pantzar $(2005,44)$ urge researchers to, "move beyond symbolically oriented theories of consumption and to think again about consumers, producers, and the material artifacts with which they deal." In theories of social practice, an area of study more or less in its infancy, consumers, their social practices, technology, and institutions and social structures are all recursively related. In these theories, consumption takes place not for its own sake but in the process of producing social practices. Reckwitz (2002) provides a helpful technical review of practice theories in social thought, tracing their intellectual history and genealogy in social thought. In social practice theories, people are the carriers of practice, "routinized, oversubjective complexes of bodily movements, of forms of interpreting, knowing how and wanting and of the usage of things" (259). For Shove et al. (2012), practice is the combination of competence, 
material, and (social) meaning. This configuration has a parallel in the factors of production in the neoclassical model of the household: human capital, paid and unpaid time, and purchased inputs. Theories of social practice are useful for studying many interconnected habits that constitute everyday life. The day-to-day lives of eco-conscious households involve many small and routinized daily activities that are highly dependent on material goods, know-how, and infrastructures.

Shove \& Walker (2010) argue that policies to encourage energy conservation are not adequate because they ignore the role of people/practitioners and the social meaning of their practices. Social meanings and dynamics are crucial for understanding how energy use has increased over time, but also for figuring out how to decrease energy use. This same approach is useful for thinking about eco-conscious households and their more general resource conservation practices. Shove et al. (2012) discuss these dynamics of practices and meanings, and the "novelty and persistence" of various practices. Shove et al (2015) argue that infrastructures are important for understanding the persistence of some social practices, using car dependence as an example. Infrastructures are:

- Connective and extensive;

- Sustain a range of practices at once;

- Collective-the services they provide are usually for more than one user; and - Resistant to change

Practices come in "bundles" - infrastructures like suburban developments, roads, and strip malls work together recursively to create bundles of practices like commuting, car 
trips for grocery shopping, and space heating and cooling of large domestic spaces.

Alternatively, infrastructures like bike lanes and office showers work together recursively to create bundles of practices like bike commuting, casual office dress, daily showers away from home, and a shift of grocery shopping chores onto a non-cycling spouse. The relative durability of infrastructures mean that the practices that rely on them are difficult to change (Lutzenhiser 2002, 7).

Strengers (2012) applies these ideas to peak electricity demand and utility strategies to "shift" and "shed" energy consumption. She argues for a shift in emphasis from consumers, technology, and individual behaviors to practices and their human carriers (229). Air conditioning use in Australia contributes to growing peak demand, and as a result requires costly upgrades to generation capacity to meet this demand and maintain electrical reliability (i.e., avoid blackouts). Rather than altering home cooling practices through peak pricing schemes, Strengers suggests thinking outside the home and its "material infrastructure" -advising people to leave the home and go to places like libraries and movie theaters or publicly provided cooling centers (231). Policies and research that focus on natural resources, conservation, and efficiency fail to address the meanings and expectations that motivate practitioners, and in failing to do so will be limited in their ability to make large-scale changes in consumption. 
The application of theories of social practice to questions related to consumption and human-environment interactions is still relatively new, but it has proven to be a fruitful area of research providing an alternative to economic or behavioral approaches to mitigate climate change by decreasing the demand for water, energy, and other resources. The DEMAND Centre in Lancaster, UK, is a multi-university consortium dedicated to using theories of social practice to shed light on the social sources of climate change by exploring how practices are evolving, being replaced, and being rediscovered. This research at the DEMAND Centre is gaining the attention of governments and institutions who are interested in new approaches to climate change mitigation, reflected in funding from the International Energy Agency, Research Councils UK, and the European Centre and Laboratories for Energy Efficiency Research.

\subsubsection{Shortcomings of Theories of Social Practice}

Theories of social practice provide a rich and descriptive tool for social research, but the approach is still in its early stages of formation and application to questions of humanenvironment interactions. While these theories are appealing because of their dynamism, historical embeddedness, and their recursive, multi-scalar approach, theories of social practice can become somewhat unmoored and diffuse without some of the more formal analytical elements available from economic theories of the household. 


\subsection{Theoretical Synthesis}

Each of the theories I reviewed above has strengths and weaknesses when it comes to shedding light on how sustainability-oriented households with young children get things done in day-to-day life by balancing their priorities, resources, and constraints. I developed the theoretical synthesis that I use here to make sense of the information I collected over the course of my conversations with informants in these eco-conscious households. Lee \& Cronin $(2016,4)$ and Power (2004) have argued out that the social provisioning process is the "the general research agenda" of non-mainstream economists (Lee \& Cronin 2016, 4), and here I am very much falling in line. There is always a risk of an interdisciplinary approach becoming undisciplined. In this case, my approach is fundamentally an economic one, enriched by social theory to fill in the gaps left by a purely economic view of the world.

The production function from classical and neoclassical economics provides a useful framework that brings into focus the ways that households transform the resources, or factors of production, available to them to produce things used by the household. Producing dinner for a household is a complicated business that could be achieved in several different ways by employing household factors of production in a variety of combinations, with varying degrees of reliance on inputs purchased using money from paid employment, resources from the government and non-profits, the unpaid time of family members, know-how, and assistance from friends and community members. And 
there are ways of getting food on the table, like collective or cooperative kitchens and contractual commercial meal delivery, which used to be common but have largely disappeared (Cowan 1983, 115, 104-105). The same can be said for just about every facet of day-to-day life, from staying comfortable when it's cold outside to dealing with the waste of an infant who isn't yet old enough to control its own bowels.

The neoclassical view suggests that differences in ways of getting things done will be the result of differences in prices. Prices of course can't tell the whole story, and George Stigler, one of the forefathers of Chicago Price Theory, admits as much-"Prices instruct us on what people desire, but prices do not tell us why those things are desired. Our desires are accepted as a datum by economists; desires are some amalgam of biological needs, the cultural values of the society in which we grow up, and our own experience," (Stigler 1966, 14). Thus, other theories are needed to understand where tastes and preferences come from, what factors might cause them to change over time, what role is played by external constraining factors, and how individual households are connected to larger social and economic processes.

From classical and neoclassical economics, I take the concept of the production function and the notion that resources have alternate uses. Feminist radical institutionalist and Marxist-feminist theories introduce important issues and constraining factors related to social structure, power, and class, and Marxist-feminist theories situate the household as 
an essential and interconnected component of the larger economy. Cultural and social theories of consumption emphasize the importance of meanings, symbols, and culture, and the applied research I draw upon adds empirical documentation that draws attention to the importance of recognizing dynamism and uncertainty. Underlying all of this, theories of social practice make human activities the focus of the analysis, bringing a multi-scalar, dynamic, and historically sensitive understanding to the recursive interactions between people, materials, infrastructure, knowledge, and meaning. Theories of social practice serve as a meta-framework here, providing the area of analytical focus - routinized human activities - while at the same time referring back to the economic view with its own factors of production: materials, competence, and meaning.

Households produce things like cleanliness, nutrition, and comfort for their members, and the way that they go about producing them is influenced by their unique set of priorities, resources, and constraints. Households are situated in culture, in the economy, in society, and these factors also influence how they get things done. Households have varying priorities in the sustainability realm that include personal health, the environment, avoiding waste, technology, and community welfare. They consist of people who may have needs, desires, and priorities that may not be aligned. Households have resources that include money from waged work used to buy market goods and services, help from extended family and friends, the unpaid work of household members, 
resources from the government and non-profits, productivity due to research/human capital/competence, and materials acquired through gleaning, borrowing, or theft. Each of these resources can serve as substitutes for each other in the production of day-to-day life. Households are constrained by limited time and money, the availability of other resources, cultural norms, and the availability of information. These constraints cause them to make trade-offs between their priorities in the sustainability realm and other priorities, such as sanity and personal well-being.

I used this theoretical framework in the development of this research in several ways. First, it was used in the development of the interview guide and the areas of focus of my conversations with informants. Second, it provided a way to organize, analyze, and make sense of the material I collected in these conversations. As I will describe in more detail in the following chapters, I engaged my informants in conversations lasting 60-90 minutes about their day-to-day lives, asking them to explain to me how their sustainability priorities influence their practices-or how they get things done-with respect to household waste, comfort, cleanliness, food, transportation, and childcare. I wanted to understand how these practices were different from the way they grew up, and if their practices had changed since becoming parents. My informants get day-to-day tasks done just like everyone else-by focusing on the things that are most important to them, making use of the resources available to them, and subject to the constraints that limit their options. Their sustainability priorities mean that they view the practices and precise 
combinations of inputs involved in the production of their day-to-day lives as different from those employed by more conventional American households. Thus, the orienting perspective provided by these theories was also used to examine the consequences, both intended and unintended, of these sustainability-oriented ways of getting things done.

References:

Aune, Margrethe. 2007. “Energy Comes Home." Energy Policy 35: 5457-5465.

Barrett, Michèle. 1980. Women's Oppression Today: Problems in Marxist Feminist Analysis. London, UK: Verso.

Becker, Gary. 1965. A theory of the allocation of time. The Economic Journal 75(299): 493-517.

Becker, Gary S. 1981. A Treatise on the Family. Cambridge, MA: Harvard University Press. Beecher, Catherine E. 2007. A Treatise on Domestic Economy for the Use of Young Ladies at Home and at School. Project Gutenberg E-Book \#21829. Available: http://www.gutenberg.org/ebooks/21829

Bergmann, Barbara. 1981. "The economic risks of being a housewife." American Economic Review, 71 (2): 81-86

- - . 1995. Becker's theory of the family: Preposterous conclusions. Feminist Economics 1(1): 141-150.

Bernstein, Arielle. 2016. "Marie Kondo and the Privilege of Clutter." The Atlantic March 25, 2016. Accessed 08/19/2016. available: 
http://www.theatlantic.com/entertainment/archive/2016/03/marie-kondo-andthe-privilege-of-clutter/475266/

Bhat, Chandra R. and Frank S. Koppelman. 1999. A retrospective and prospective survey of time-use research. Transportation 26(2): 119-139.

Bhatnagar, Amit, Sanjog Misra \& H. Raghav Rao. 2000. On risk, convenience, and Internet shopping behavior. Communications of the Association for Computing Machinery 43(11): 98-105.

Boltanski, Luc \& Ève Chiapello. 2005. The New Spirit of Capitalism. London: Verso. Bourdieu, Pierre. 1984. Distinction: A Social Critique of the Judgement of Taste. Trans. Richard Nice. Cambridge, MA: Harvard University Press.

Bradby, Barbara. "The Remystification of Value." Capital and Class 6(2): 114-133

Brown, Doug. 1998. Be all you can be: Invidious self-development and its social imperative. in Doug Brown (ed.) Thorstein Veblen in the Twenty-first Century: A Commemoration of the Theory of the Leisure Class (1899-1999). Cheltenham, UK: Edward Elgar.

Carfagna, Lindsey B., Emilie A. DuBois, Connor Fitzmaurice, Monique Y. Ouimette, Juliet B. Schor \& Margaret Willis. 2014. "An emerging eco-habitus: the reconfiguration of high cultural capital practices among ethical consumers." Journal of Consumer Culture 14:2, 158-178.

Carlsson-Kanyama, Annika and Anna-Lisa Lindén. 2007. “Energy efficiency in residencesChallenges for women and men in the North." Energy Policy 35: 2161-2172. 
Chayka, Kyle. 2016. "The Oppressive Gospel of 'Minimalism.'” New York Times July 26, 2016. Accessed 08/19/2016. available: http://www.nytimes.com/2016/07/31/magazine/the-oppressive-gospel-ofminimalism.html?_r=0

Child, Lydia Maria. 1999. The American Frugal Housewife. Mineola, NY: Dover Publications.

Chiswick, Carmel U. 1999. The economics of Jewish continuity. Contemporary Jewry 20(1): 30-56.

Chiswick, Carmel U. \& Barry R. Chiswick. 2000. The cost of living Jewishly and Jewish continuity. Contemporary Jewry 21(1): 78-90.

Collins, Jane L. 1990. Unwaged labor in comparative perspective: recent theories and unanswered questions. in Jane L. Collins and Martha Gimenez (eds.) Work without Wages: Comparative Studies of Domestic Labor and Self-Employment. Albany, NY: State University of New York Press.

Cowan, Ruth Schwarz. More Work for Mother: The Ironies of Household Technologies from the Open Hearth to the Microwave. New York, NY: Basic Books.

Dalla Costa, Mariarosa \& Selma James. 1972. The Power of Women and the Subversion of the Community. Bristol, UK: The Falling Wall Press.

Doane, Molly. 2010. "Relationship Coffees: Structure and Agency in the Fair Trade System." In Fair Trade and Social Justice: Global Ethnographies, edited by Mark Moberg. New York: NYU Press. 
Douglas, Mary. 2003. The World of Goods: Towards an Anthropology of Consumption. London, UK: Routledge.

Ewen, Stuart and Elizebeth Ewen. 1992. Channels of Desire: Mass Images and the Shaping of American Consciousness. Minneapolis, MN: University of Minnesota Press.

Ferber, Marianne A. and Birnbaum, Bonnie G. 1977. The New Home Economics:

Retrospects and Prospects. Journal of Consumer Research 4(1):19-28.

Ferber, Marianne A. 1995. The Study of Economics: A Feminist Critique. The American Economic Review 85(2): 357-361.

Finkelstein, Eric A. Christopher J. Ruhm \& Katherine M. Kosa. 2005. Economic Causes and Consequences of Obesity. Annual Review of Public Health 26: 239-57.

Frankfurt Institute for Social Research. 1972. Aspects of Sociology. Boston, MA: Beacon Press.

Folbre, Nancy. 1982. "Exploitation comes home: A critique of the Marxian theory of labor power." Cambridge Journal of Economics 6(4): 318-329.

Folbre, Nancy. 1986. "Hearts and spades: paradigms of household economics." World Development 14(2): 245-255.

Foster, Gladys Parker. 1998. Veblen and the 'Woman Question' in the Twenty-first Century. in Doug Brown (ed.) Thorstein Veblen in the Twenty-first Century: A Commemoration of the Theory of the Leisure Class (1899-1999). Cheltenham, UK: Edward Elgar. 
Gliebe, John P. \& Frank S. Koppelman. 2002. A model of joint activity participation between household members. Transportation 29(1): 49-72.

Greenwood, Daphne. 1984. The Economic Significance of "Woman's Place" in Society: A New-Institutionalist View. Journal of Economic Issues 18(3): 663-680.

Hackett, Bruce and Loren Lutzenhiser. 1991. Social Structures and Economic Conduct: Interpreting Variations in Household Energy Consumption. Sociological Forum 6(3): 449-470.

Heath, Julia A. \& David H. Ciscel. 1988. Patriarchy, Family Structure and the Exploitation of Women's Labor. Journal of Economic Issues 22(3): 781-794.

Hicks, John R. and R. G. D. Allen. 1934. "A reconsideration of the theory of value: Part I." Economica 1(1): 52-76.

Holt, Douglas. 1997. Distinction in America? Recovering Bourdieu's theory of tastes from its critics. Poetics 25 (2/3): 93-120.

Jara-Díaz, Sergio R. 2000. Allocation and valuation of travel-time savings. In David A. Hensher and Kenneth .J. Button (eds.), Handbook of Transportation Modeling. Amsterdam, the Netherlands: Elsevier.

Jennings, Ann L. 1993. 'Public or Private? Institutional Economics and Feminism' in Marianne A. Ferber \& Julie A. Nelson (eds.) Beyond Economic Man: Feminist Theory and Economics. Chicago, IL: University of Chicago Press.

Klingle, Matthew W. 2003. "Spaces of Consumption in Environmental History." History and Theory 42(4): 94-110. 
Kolodinsky, Jane M. and Amanda B. Goldstein. 2011. Time Use and Food Pattern Influences on Obesity. Obesity 19(12): 2327-2335

Laslett, Barbara and Johanna Brenner. 1989. "Gender and Social Reproduction: Historical Perspectives." Annual Review of Sociology 15: 381-404.

Lee, Frederic and Bruce Cronin (eds.) 2016. "Introduction." Handbook of Research Methods and Applications in Economics. Cheltenham, UK: Edward Elgar Publishing.

Logan, Dana W. 2017. "The Lean Closet: Asceticism in Post-industrial Consumer Culture." Journal of the American Academy of Religion 78(1): 1-39.

Lutzenhiser, Loren. 1992. A cultural model of energy consumption. Energy 17:1, 47-60.

- - - 1993. "Social and behavioral aspects of energy use." Annual Review of Energy and the Environment 18, 247-289.

- - . 2002. "Greening the Economy from the Bottom Up? Lessons in Consumption from the Energy Case." in Nicole Biggard (ed.) Readings in Economic Sociology. Oxford, UK: Blackwell, 345-356.

Lutzenhiser, Loren \& Marcia Hill Gossard. 2000. "Lifestyle, status, and energy consumption." Proceedings of the 2000 ACEEE Summer Study of Energy Efficiency in Buildings 8, 207-222.

Marshall, Alfred. [1890] 2009. Principles of Economics (Abridged Edition) Cosimo Classics: New York, NY. 
Marx, Karl. 1978. "Economic and Philosophic Manuscripts of 1844." in Robert E. Tucker (ed) The Marx-Engels Reader, $2^{\text {nd }}$ Edition. New York, NY: W.W. Norton \& Company.

Matchar, Emily. 2013. Homeward Bound: Why Women are Embracing the New Domesticity. New York, NY: Simon \& Schuster.

Micheletti, Michele. 2003. Political Virtue and Shopping: Individuals, Consumerism, and Collective Action. New York, NY: Palgrave Macmillan.

Miller, Edythe. 1972. Veblen and Women's Lib: A Parallel. Journal of Economic Issues 6(2/3): 75-86.

Mosak, Jacob L. 1938. "Interrelations of production, price, and derived demand." The Journal of Political Economy 46(6): 761-787.

Netting, Robert McC., Richard R. Wilk, and Eric J. Arnould. 1984. "Introduction." in Robert Netting, Richard R. Wilk, \& Eric J. Arnould (eds). 1984. Households: Comparative and Historical Studies of the Domestic Group. Berkeley, CA: University of California Press.

Peterson, Janice. 1998. Veblen and feminist economics: Valuing women's work in the Twenty-first Century. in Doug Brown (ed.) Thorstein Veblen in the Twenty-first Century: A Commemoration of the Theory of the Leisure Class (1899-1999). Cheltenham, UK: Edward Elgar.

Polonsky, Michael J. and Alma T. Mintu-Wimsatt (eds.) 1995. Environmental Marketing: Strategies, Practice, Theory, and Research. New York, NY: The Haworth Press. 
Power, Marilyn. 2004. "Social Provisioning as a Starting Point for Feminist Economics." Feminist Economics 10(3): 3-19.

Prasch, Robert. "How is Labor Distinct from Broccoli? Some Unique Characteristics of Labor and their importance for Economic Analysis and Policy." in The Institutionalist Tradition in Labor Economics, Dell P. Champlin and Janet T. Knoedler. Armonk, NY: M.E. Sharpe.

Reid, Margaret. 1934. The Economics of Household Production. New York, NY: John Wiley \& Sons, Inc.

Robinson, Joan. 1964. "Marshall, Marx, and Keynes: Three Views of Capitalism." in Joan Robinson (ed.), Collected Economic Papers, Volume Two. Oxford, UK: Basil Blackwell.

Rapp, Rayna, Ellen Rosa \& Renate Bridenthal. 1979. "Examining Family History." Feminist Studies 5(1): 174-200.

Reckwitz, Andreas. 2002. "Toward a theory of social practices: a development in culturalist theorizing." European Journal of Social Theory 5:2, 243-263.

Sawhill, Isabel B. 1977. Economic perspectives on the family. Daedalus 106(2): 115-125.

Schnaiberg, Allan and Kenneth Alan Gould. 1994. Environment and Society: The Enduring Conflict. Caldwell, NJ: The Blackburn Press.

Schultz, Henry. 1935. "Interrelations of Demand, Price, and Income." The Journal of Political Economy 43(4): 433-481.

Shove, Elizabeth. 2003. Comfort, Cleanliness and Convenience. Oxford: Berg. 
Shove, Elizabeth \& Alan Warde. 2002. "Inconspicuous Consumption: The Sociology of Consumption, Lifestyles, and the Environment." in Sociological Theory and the Environment: Classical Foundations, Contemporary Insights, edited by Riley E. Dunlap, Frederick H. Buttel, Peter Dickens, \& August Gijswijt, 230-251. Oxford: Rowman \& Littlefield Publishers.

Shove, Elizabeth \& Mika Pantzar. 2005. "Consumers, Producers and Practices Understanding the invention and reinvention of Nordic walking." Journal of consumer culture 5:1, 43-64.

Shove, Elizabeth \& Gordon Walker. 2010. Governing transitions in the sustainability of everyday life. Research Policy 39(4): 471-476.

Shove, Elizabeth, Mika Pantzar \& Matt Watson. 2012. The Dynamics of Social Practice: Everyday Life and How it Changes. London, UK: Sage.

Shove, Elizabeth, Matt Watson \& Nicola Spurling. 2015. Conceptualizing connections: energy demand, infrastructures and social practices. European Journal of Social Theory 18(3): 274-287.

Spaargaren, Gert. 2003. "Sustainable consumption: A theoretical and environmental policy perspective." Society and Natural Resources 16, 687-701.

Stern, Paul C. 2011. "Contributions of psychology to limiting climate change." American Psychologist 66(4): 303-314.

Stigler, George J. 1966. The Theory of Price. New York, NY: MacMillan Publishing Company. 
Strengers, Yolande. 2012. "Peak electricity demand and social practice theories:

Reframing the role of change agents in the energy sector." Energy Policy 44, 226234.

United Nations. 2014. "United Nations and Climate Change: Take Action." Accessed 06/06/2017. Available: http://www.un.org/climatechange/take-action/ U.S. Global Change Research Program. 2014. "2014 National Climate Assessment." Accessed 06/06/2017. Available: http://nca2014.globalchange.gov/repor Veblen, Thorstein. 1898. Why is Economics not an Evolutionary Science? The Quarterly Journal of Economics 12(4): 373-397.

- - . [1899] 1953. The Theory of the Leisure Class: An Economic Study of Institutions. New York: The New American Library.

Vogel, Lise. 1983. Marxism and the Oppression of Women: Toward a Unitary Theory. New Jersey: Rutgers University Press.

Waddoups, Jeffrey. 1992. Thorstein Veblen and the Feminism of Institutional Economists. Revue Internationale de Sociologie 3(3): 182-204.

Waller, William \& Linda R. Robertson. 1998. The politics of consumption and desire. in Doug Brown (ed.) Thorstein Veblen in the Twenty-first Century: A Commemoration of the Theory of the Leisure Class (1899-1999). Cheltenham, UK: Edward Elgar. Weber, Max. [1905] 2002. The Protestant Ethic and the 'Spirit' of Capitalism and Other Writings. Trans. Peter Baehr \& Gordon C. Wells. New York, NY: Penguin Books. 
Weinbaum, Batya and Amy Bridges. 1976. "The Other side of the Paycheck: Monopoly Capital and the Structure of Capitalism." Monthly Review 28(3): 88-103

Wheelock, Jane \& Elizabeth Oughton. 1996. The household as a focus for research. Journal of Economic Issues 30(1): 143-159.

Wilhite, H., H. Nakagami, T. Masuda, Y. Yamaga, and H. Haneda. 1996. "A cross-cultural analysis of household energy use behavior in Japan and Norway." Energy Policy 24:9, 795-803.

Wilhite, Harold L. \& Richard R. Wilk. 1985. "Why don't people weatherize their homes? An ethnographic solution." Energy 10:5, 621-629.

- - . 1987. A method for self-recording household energy use behavior. Energy and Buildings 10: 73-79.

Wilhite, Harold \& Loren Lutzenhiser. 1999. "Social Loading and Sustainable Consumption." Advances in Consumer Research. 26: 281-287.

Zaretsky, Eli. 1986. Capitalism, the Family, and Personal Life. New York, NY: Harper \& Row Publishers. 
Chapter 3: Materials and Methods

\subsection{Research Objectives and Research Methodology}

Though a skilled mathematician, [Alfred Marshall] used mathematics sparingly. He saw that excessive reliance on this instrument might lead us astray in pursuit of intellectual toys, imaginary problems not conforming to the conditions of real life, and, further, might distort our sense of proportion by causing us to neglect factors that could not easily be worked up in the mathematical machine. (Pigou 1956 [1925], 84)

Joan Robinson once said, "I don't know mathematics, therefore I have to think." (Streeten 2002)

As a trained econometrician with over a decade of practice applying quantitative tools to model demand in regulated industries, it would seem only natural to write an econometric dissertation. It would be efficient and practical to make use of a method that I've already mastered, that academic and non-academic audiences tend to find persuasive, and that wouldn't require a relatively introverted person like myself to spend hours in the homes of strangers discussing the minute details of their day-to-day lives. In his classic research methodology textbook, Kaplan writes, "It comes as no particular surprise to discover that a scientist formulates problems in a way which requires for their solution just those techniques in which he himself is especially skilled" (Kaplan [1964] $1998,28)$. There is nothing wrong with this tactic - it is one that I have used in the past and continue to use. 
In this case, my choice of methods is influenced by the pragmatic approach to problem solving and research design (Dewey [1933] 2011, 68-79). Rather than selecting a method and going in search of a suitable question, I began with a question and decided on a suitable way to answer it. The nature of the exploratory research at hand-household variations in sustainability practices and their associated social meanings-does not lend itself well to deductive statistical analysis using a large data set. There is no consensus on what sustainability means to households or how it is produced within them, and there are no existing quantitative data I could pound with my metaphorical econometric hammer, even if I wanted to. Collecting such a data set using survey research would mean becoming trapped by my a priori assumptions -imposing categories and definitions on respondents before conducting the type of exploratory needed to find out what those categories and definitions might be. Such a study would also be prohibitively expensive. Ethnographic interviewing provides a context-specific and inductive approach to generating new knowledge and proposing new uses of theories in the field of sustainability. The insights gathered as part of this project are valuable on their own, but can also useful for designing future quantitative, positivist research (Morgan 2014, 9).

\subsection{Methods}

\subsubsection{Qualitative Research for Economic Questions}

Famously, both Smith ([1776] 2003) and Marshall (1919) based their research on visits to factories, observing industrial production first-hand as a crucial component of economic 
theory-building (Basole \& Ramnarain 2016, 135). Arch-neoclassical economist Marshall

insisted that his observational economic history "is not a purely inductive practice, nor is theory a purely deductive one" (Kerstenetzky 2010), but rather the two are overlapping modes of knowledge production. The purpose of Marshall's factory visits was to obtain

the direct feel of the economic world, something more intimate than can be obtained from merely reading descriptions, something that should enable one ... to set things in their true scale of importance, and not to put in the forefront something that is really secondary merely because it presents a curious problem for [mathematical] analysis. (Pigou 1954 [1925], 85)

The ultimate objective of all of Marshall's research was social betterment and the alleviation of poverty through developing an understanding of the inner workings of the economy (Pigou 1954, 81-84). A few years before his death, Marx ([1880] 1938) designed a 100-question survey to be administered directly to workers with questions related to their wages, working conditions, and the "the general physical, intellectual and moral conditions of life." Rather than using factory accounting ledgers to infer these details, this survey suggested that insights into the work and lives of factory laborers could be obtained from the workers themselves (Haider \& Mohandesi 2013). Much like Marshall, Marx uses economic research to investigate the material circumstances of people's dayto-day lives with the ultimate objective of improving conditions for working people.

Basole and Ramnarain $(2016,149)$ outline five categories of economic research topics for which qualitative research methods may be appropriate:

1. Trust, social networks, institutions, and norms

2. Power relations between actors and institutions 
3. Motivation, decision making processes

4. Identity and perceptions

5. Labor processes and managerial strategies

The research in this project concerns all of these themes, to varying degrees. Basole and Ramnarain $(2016,150-159)$ also provide an inventory of 23 peer-reviewed articles published since 1990 that employ qualitative research techniques to answer economic questions, though these techniques appear to be more common for research in a Less Developed Country context, particularly when the household is the area of focus. Observing the Economy (Gregory \& Altman 1989) is a manual for practitioners of economic ethnography, but it focuses exclusively on the developing country context.

Recent economic studies based on ethnographic interviews with workers in advanced industrialized countries do exist, such as Cobb et al. (2009) and Goldstein and Hillard (2008). Glazer (1993) uses both business accounting information and interviews with paid (nurses) and unpaid (family members) workers performing healthcare tasks in her research on the transfer of tasks from paid to unpaid workers. If the household can be described as a factory that produces utility for its members (Becker 1981, 14-37) or reproduces labor power (Barrett 1980, Dalla Costa \& James 1972), it only makes sense to visit these sites to ask the workers about the techniques and meanings of their production processes. Following Marshall (1919), employing qualitative research methods does not mean taking an atheoretical approach-I make meaning out of the qualitative data using a disciplinary perspective from economics. 


\subsubsection{Ethnographic Interviewing}

Malinowski writes that the goal of the ethnographer is "to grasp the native's point of view, his relation to life, to realise his vision of his world..." (1922, 25). Spradley (1978) argues that the ethnographer achieves this goal by being taught by her research subjects, not by collecting data on them. To learn from my informants, I first had to attempt to assume a "conscious attitude of almost complete ignorance," (Spradley 1978, 4) of the world of pro-environmental practices and sustainability-oriented families. I frequently encountered confused and disturbed looks from the people I was interviewing when I asked them questions like, "Why do you recycle?" I followed up these questions by asking the informants to pretend that I'm from outer space and that I want them to explain normal, seemingly obvious things to me. It wasn't that I was some kind of monster who didn't share their fundamental concern for the environment, a conclusion they might draw about someone who is opposed to recycling or doesn't understand its appeal, but that I wanted to understand their perspective in their own words. I asked my informants to suspend disbelief and to assume I didn't know anything.

While ethnography and field research can frequently mean sustained periods of participant observation lasting months or even years, the ethnographic interview is a method that allows the researcher to make inferences based on what informants say about their beliefs, practices, and artifacts during a shorter study period. Ethnographic 
interviews are a useful way to study sustainability practices and their meanings in households because "notions of materialism, belief, perception, and values are at the core of the sustainability vision," (Murphy \& McDonagh 2016, xiv). The semi-structured ethnographic interview allowed my informants to teach me the meanings of their practices and to guide me to understand what they deem to be important in the environmental realm, without demanding too much of their time and effort.

The goals and epistemological assumptions of ethnographic research are not the same as those of positivist research like econometrics. Objectivity is not an aim, and the results are descriptive and not necessarily generalizable. This research is the product of my subjective but scholarly interpretation of the information that informants shared with me about their day-to-day lives, values, habits, and opinions. Pickborne and Ramnarain (2016) provide a useful discussion of the ontological and epistemological differences between quantitative and qualitative methods for economics research. The first-person narrative style I take here is not informal but rather reflects a tradition in anthropology of first-person, active voice research accounts. In her review of the rise of first-person ethnographies, Tedlock writes that "The world, in a narrative ethnography, is represented as perceived by a situated narrator, who is also present as a character in the story that reveals his own personality. This enables the reader to identify the consciousness which has selected and shaped the experiences within the text," (Tedlock 1991). In this work, I am not the main character, but I am present as the narrator whose 
perspective and subjective interpretations influence the story that is being told. In preparing for this research, I also went a bit "native." I have no children, and do not ever expect to have any. My day-to-day life is not deliberately eco-conscious, though I do share with my informants many practices that they view as environmentally oriented. Bergman argues that "economists would do best if they adopted the strategy of anthropologists, who go to live with the tribe they are studying and become participantobservers" (Bergmann 2007, 2). Over the course of this project, I made my own granola out of bulk bin ingredients, I made my own yogurt and bread, I sewed my own clothes, made two quilts, and I participated in some afterschool pickups and babysat young children from an eco-conscious family. I wanted to do my best to understand the personal worlds of my informants. Ultimately, this research was generated in collaboration with my informants, and the presentation here embodies the "coproduction of ethnographic knowledge, created and represented in the only way it can be, within an interactive Self/Other dialogue" (Tedlock 1991, 82).

\subsubsection{Intimacy, Friendship, and Feminist Research}

Some feminist researchers, such as Stacey $(1988,22)$, suggest that ethnography is particularly well-suited to feminist research because the qualities that make for good ethnography - "empathy, connection, and concern" - are also "women’s special strengths." However, I am both a woman and a highly skilled quantitative researcher, so I 
hardly believe that quantitative, positivist approaches to research are inherently male, masculine, or oppressive, and qualitative research methods are inherently female, feminine, and anti-oppressive. Additionally, I reject the notions that women are by nature more nurturing and intuitive or that women possess a natural inclination towards empathy, care, and human connection [Rich 1986, 42]. That being said, over the course of our conversations, it was impossible to avoid caring about the people who were sharing so much about their day-to-day lives with me.

There is an intimacy involved in sitting in people's homes in conversation, seeing how they live, meeting their children, and holding their babies. While my informants weren't paid for their time, I did bring each household a box of organic herbal tea that I purchased at a local food co-op-this is the kind of hostess gift that I would bring to any friend or acquaintance who invited me into their home. Following the interview, each household for whom I had a mailing address received a written thank-you card in the mail, also a personal habit of mine. After the last interview was completed, I emailed all of my informants offering them the option to stay in touch with me and to receive copies of any publications that are generated out of this research. The people whose thoughts and practices form the basis of this research shared a precious hour of time with me, and for reciprocity's sake it is imperative to share the outcomes of this research with them and to write these materials, to the extent possible, in language that non-academics might also find accessible (Oakley 1981, Harrison et al. 2001). Because it is my view that 
the research was co-produced with my informants, I wanted to avoid abandoning them once their role in the process was done, following the suggestion of Stacey (1988).

The research here is based on are respondent-driven open-ended ethnographic interviews, generally volunteered for on the basis of a belief that the informant's views are important and they are contributing to a cause they believe in-sustainability, whatever that term means to the informant. But part of this willingness to share information with me was based on an assumption by many of my informants that I was "one of them" and producing a piece of research-advocacy that would champion their lifestyles and practices. Stacey (1988) suggests that the intimacy and friendships forged during feminist ethnographic research leaves participants vulnerable to exploitation by the researcher. In this sense, I was indeed exploiting the desire of many of my informants to have their views and practices validated and promoted.

Heather: It was so easy to have you [Kirstin] over because this is something that I'm so passionate about. It's our life.

As a critical social and economic researcher, I did not approach this project from a sustainability advocacy perspective but rather with the goal of critical fact-finding and theory-building in mind.

This is not to say that there are no political motivations underlying this research - this is research on sustainability-oriented households and the day-to-day lives of the people who comprise them, but it is research for households and people, too (Stanley and Wise 
1990, 21). Like Marshall and Marx, my ultimate concern is with the material conditions of people's lives and how those lives and conditions might be improved. To these concerns I add a contemporary one-avoiding environmental devastation. While I was humbled and encouraged by major interventions into day-to-day life that my informants were making in order to bring their practices in line with their values, I remain highly skeptical of the efficacy of individual-level changes in the face of environmental crises. In fact, after listening to my informant's struggles to balance day-to-day tasks with frequently costly and time-consuming sustainability practices, I emerged from this research even more convinced that the household is the incorrect site for these pro-environmental interventions. This may not be the conclusion some of my informants hoped I would draw from our conversations, but I think they would agree that we are hoping for the same things - healthy people and a healthy natural environment.

\subsubsection{Ethnographic Research and Deception}

Researchers trained in positivist methods may also be concerned about the risk of deception in ethnographic interviews. In general, I found all of the informants and their responses to be believable. They tended to be very frank about their day-to-day lives, including their struggles and frustrations with maintaining habits consistent with their environmental values. They were reassured of their anonymity in the study, frequently believed they were contributing to something important, and would gain little from deceiving me. 
Mina: Honestly? *laughs* I don't have any reason to lie to you!

Spouses occasionally disagreed over their partner's portrayal of their habits and

motivations, but generally came to some kind of agreement.

Dayna: We've always been pretty conventional on the laundry detergent. And I'm the one who buys the laundry detergent-I don't know if David has ever bought laundry detergent before. But I'm the one that generally buys that.

David: We've gotten the Seventh Generation and the Bio-Kleen stuff before, but generally we get Tide or All.

Dayna: We actually don't normally get Tide, we only started getting Tide when we started using cloth diapers.

In this case, Dayna asserted herself as the expert on laundry soap, David balked, and Dayna re-asserted herself and "won" the dispute. In several interviews, I was able to visually observe that the home's thermostat was set to a heating temperature higher than the temperature my informants reported. For example, walking into Scott and Sarah's home on a chilly April day, I passed the thermostat on my way to their living room and saw it was set to 72 degrees. All of the members of the household, including the children, were wearing short sleeves. However, they reported their winter thermostat setting to me as 70 degrees during out interview. It could be that Scott and Sarah were purposefully deceiving me, but based on their demeanor I do not believe that any deception was deliberate. Perhaps 70 degrees is the temperature they've programmed their thermostat to, and they increase the temperature manually when they feel too cold. Or perhaps they were telling me a temperature they thought was a correct or ecologically righteous one-the temperature they believe is the maximum ethical heating setting. 
A different possible explanation also emerged in a subsequent interview with two households whose thermostat I didn't observe directly - some ecologically-oriented households alter their typical home heating and cooling temperatures to accommodate guests.

Penny: I usually keep the heat around 64 when I'm home and awake. But my mom was just here visiting, and she was very cold with 64 so we had it at 67.

Quinn: The thermostat is normally set at 67 or 68 for the environment and also money. But if guests are over l'll put it up to 70 so that people are comfortable.

However, if the informants were indeed giving misleading answers about their winter thermostat settings, that too provides important information about social norms and the values of my informants (Rubin \& Rubin 2012, 66-67). It is possible that some of the practices and habits described by the informants may not be the way they live their lives $100 \%$ of the time, but may represent the way they believe they ought to be living their lives or what they believe to be norms for people who share their values. In any case, this is valuable information.

It is also reasonable to wonder whether or not men and women interviewed together will provide honest answers to questions about household tasks and who does them. My conversations with Gloria, Heather, Leonda, Quinn, Wendy, and Yvonne took place without their partners present for reasons related to scheduling, and all of these informants told me, without being prompted to do so, that they believe their 
relationships and households are egalitarian. There are a few tasks that people assigned male at birth are not physically capable of performing, such as giving birth and breastfeeding. A number of my informants were engaged in extended breastfeeding reaching into the toddler years, and this is a time-consuming practice that can't be shared between male and female partners very easily. However, it was difficult to discern any other major imbalances in the overall amount of time spent in work (whether or paid or unpaid), and my informants seem to believe that arrangements in their households are fair.

Among my informants, women were more likely to engage in exclusively unpaid work and to work in more flexible or part-time waged jobs. However, in their view this was an egalitarian arrangement because their unwaged work in the household is a direct substitute for purchases they would be making with the wages they would earn outside the home. It is my informant's perception that the overall hours worked, whether paid or unpaid, are fairly distributed between adults in households with two adults. Furthermore, it is not immediately clear to me that engaging in waged work necessarily involves less oppression or exploitation than unwaged work. Without a time-use survey or extended in-home participant observation, it is difficult to verify the division of labor that was reported to me by my informants. This could be a productive area for future research building on the work here. 


\subsection{Research Design}

\subsubsection{Sample Size and Small Sample Qualitative Research}

Oakley writes that, "There is a widespread tendency in social science and in more popular discussions of opinion/attitude surveys to assume that a large sample provides some automatic guarantee of reliable results, while a small one provides unreliability. This misconception is based on a naïve idea of what constitutes 'validity' and 'representativeness' in research procedure" $(1978,31)$. Over the course of this research, I spoke with informants from 23 different households, a sample size that is much larger than a case study with a sample size of one (Harper 1992), but also far smaller than the sample sizes commonly used in quantitative research. The goals of this research are quite different from those of large-sample quantitative studies - I am making no claims of reproducibility, I am not statistically testing hypotheses, and I am not claiming the sample is representative. This is exploratory qualitative research with a sample size that is consistent with those used in similar research. Table 3.1. contains examples of ethnographic studies of production and consumption in households in advanced industrialized societies. In these seven studies, the average sample size is 28 , increased by the large sample size needed for a cross-cultural comparative study (Ray and Qayum 2009) and decreased by the small sample size used in an extended ethnographic investigation of two extended families (Stacey 1990). Table 3.2 contains examples of ethnographic household energy and/or technology studies. Across these eight studies, the average sample size is 24 , with a minimum of 6 and a maximum of 60 . 


\begin{tabular}{|c|c|c|}
\hline Author (Year) & $\underline{\text { Sample Size }}$ & Description of work \\
\hline $\begin{array}{l}\text { Bott }(2001 \\
[1957])\end{array}$ & 20 couples & Exploratory and descriptive study of households \\
\hline Oakley (1978) & 40 women & $\begin{array}{l}\text { Study of English homemakers across } \\
\text { socioeconomic classes }\end{array}$ \\
\hline Stacey (1990) & 2 families & $\begin{array}{l}\text { In-depth case study of two working-class } \\
\text { extended families }\end{array}$ \\
\hline $\begin{array}{l}\text { Coupland } \\
\text { (2005) }\end{array}$ & 2 households & $\begin{array}{l}\text { Study of the brands of consumer products in } \\
\text { kitchen pantries }\end{array}$ \\
\hline Forsberg (2007) & 8 men & $\begin{array}{l}\text { Study of ideologies of gender equality and the } \\
\text { household work of fatherhood }\end{array}$ \\
\hline $\begin{array}{l}\text { Ray and Qayum } \\
\text { (2009) }\end{array}$ & $\begin{array}{l}52 \\
\text { employers, } \\
44 \text { servants }\end{array}$ & $\begin{array}{l}\text { Comparative study of class relations and } \\
\text { methods of social reproduction in NYC and } \\
\text { Kolkata }\end{array}$ \\
\hline \multicolumn{3}{|c|}{ Table 3.2 Sample Size in Ethnographic Household Energy and Technology Studies } \\
\hline Author (Year) & Sample Size & Description of work \\
\hline $\begin{array}{l}\text { Wilhite \& Wilk } \\
\text { (1985) }\end{array}$ & $\begin{array}{l}60 \\
\text { households }\end{array}$ & $\begin{array}{l}\text { Ethnographic interviews about energy } \\
\text { conservation investments }\end{array}$ \\
\hline $\begin{array}{l}\text { Livingstone } \\
\text { (1992) }\end{array}$ & $\begin{array}{l}16 \\
\text { households }\end{array}$ & $\begin{array}{l}\text { Study of the gendered meanings of household } \\
\text { technologies }\end{array}$ \\
\hline $\begin{array}{l}\text { Wilhite et al } \\
\text { (1996) }\end{array}$ & $\begin{array}{l}34 \\
\text { households }\end{array}$ & $\begin{array}{l}\text { Comparative study of cultural meanings of } \\
\text { energy in Norway and Japan }\end{array}$ \\
\hline Aune (2002) & $\begin{array}{l}17 \\
\text { households }\end{array}$ & $\begin{array}{l}\text { Ethnographic interviews about experiences with } \\
\text { an energy efficiency technology }\end{array}$ \\
\hline $\begin{array}{l}\text { Rode et al. } \\
(2004)\end{array}$ & $\begin{array}{l}9 \\
\text { households }\end{array}$ & $\begin{array}{l}\text { Study of gendered interactions with } \\
\text { programmable household appliances }\end{array}$ \\
\hline $\begin{array}{l}\text { Carlsson- } \\
\text { Kanyama \& } \\
\text { Lindén (2007) }\end{array}$ & $\begin{array}{l}30 \\
\text { households }\end{array}$ & $\begin{array}{l}\text { Study of gendered household responses to } \\
\text { energy policy }\end{array}$ \\
\hline Forlizzi (2007) & $\begin{array}{l}6 \\
\text { households }\end{array}$ & $\begin{array}{l}\text { Study of household interaction with robotic or } \\
\text { non-robotic vacuum cleaners }\end{array}$ \\
\hline $\begin{array}{l}\text { Moroşanu } \\
(2016)\end{array}$ & $\begin{array}{l}20 \\
\text { households }\end{array}$ & $\begin{array}{l}\text { Study of household demand for energy and use } \\
\text { of digital media devices }\end{array}$ \\
\hline
\end{tabular}


While the sample size of this study is small, it is consistent with other published qualitative and ethnographic research on households, and is sufficiently large for my research goals.

\subsubsection{Sampling Frame}

The sampling frame for this study was adults in households in the greater PortlandBeaverton-Vancouver Metro area with children under age 10 who consider their lifestyles eco-conscious or sustainable. My choice to include only families with children under 10 is not an arbitrary one-this allows me to see how households balance sustainability and other priorities at a point in the lifecycle where resources like time and money are particularly constrained. The Portland Metro Area is a convenient place to conduct this research, since it is where I was living at the time of the field work, but it is also an ideal place to recruit highly eco-conscious households. The proportion of adults who report being worried about climate change in Multnomah County ranks in the highest $0.01 \%$ among U.S. Counties (Yale Program on Climate Change Communication 2015) at 66\%. Portland, Oregon, residents routinely rank among the "greenest" in the United States thanks to high rates of non-car transport, renewable energy, and recycling (Bernardo 2016; Rogers 2011; Svoboda et al. 2008). This is a useful setting for investigating the practices and the cultural knowledge (symbols, categories, competence, and language) of households who see themselves as particularly sustainable or eco-friendly. 


\subsubsection{Sample Recruitment}

To recruit my final sample of 23 households, I began by sending an email with a brief description of the study, an image of my recruitment flyer (Figure 3.1) and a link to a screener questionnaire website to over 150 local professional and personal contacts, asking them to forward my request for participants to people they know who might qualify. While none of my own contacts or acquaintances participated in the study, many of my informants were one or two steps removed from people I know. I also posted the announcement on the social networks LinkedIn and Switchboard. Informants outside my own social and professional networks were recruited through the online social platforms Facebook and Meetup.org, where I posted recruitment information in large groups for environmentally-minded parents, corresponded directly with group organizers, and learned about events. I attended several Meetup.org events for ecologically-minded and LGBTQ parents to distribute flyers and tell attendees about my study. The illustration for the flyer was done by my friend Michelle Lamanet, an artist and sustainability-minded parent of two young children. 
Figure 3.1: Recruitment Flyer

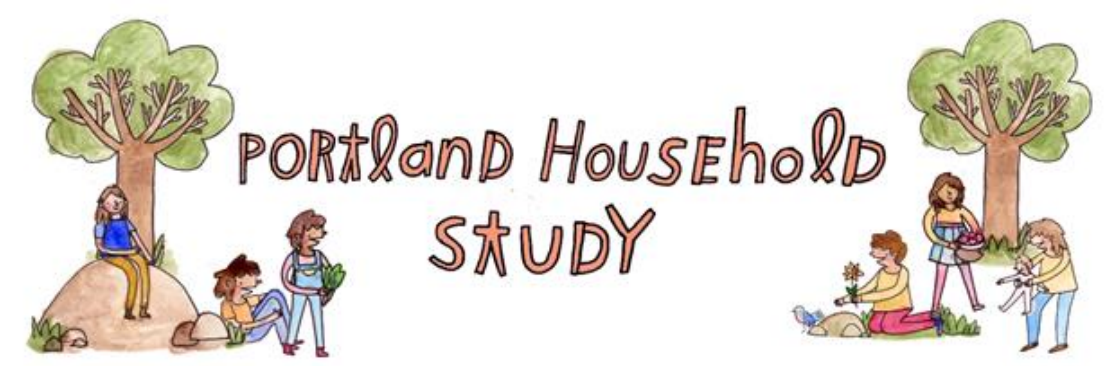

Are you a household with children under age 10 ?

Do you live in the Portland Metro area?

Do you consider your family's lifestyle eco-friendly or sustainable?

If you answered YES to these questions, you may be eligible to participate in a research study. To find out if you are eligible to participate, please fill out a questionnaire at:

\section{https://tinyurl.com/PDXHouseholds}

The purpose of this research study is to understand how eco-friendly families get things done and make decisions about how to use resources in their households. This study is being conducted by Kirstin Munro and Loren Lutzenhiser, researchers at Portland State University.

Please contact Kirstin Munro at munro@pdx.edu for more information.

\subsection{Research Sample}

Based on these recruitment efforts, I received 97 responses to my recruitment questionnaire which resulted in 48 useable responses and 23 interviewed households.

Within two days of their completing the recruitment questionnaire, I contacted households by email inviting them to participate in the study and explaining the scheduling process. I scheduled an interview with every household that was willing to be interviewed following my email contact. No household was excluded except by declining to schedule or being unable to schedule time for an interview prior to the end of my fieldwork period. In this sense, the sample is neither random nor selected on the basis of 
theoretical categories, and it is not intended to be representative of any population.

Glaser \& Strauss $(1967,60-62)$ suggest that a non-random qualitative research sample is adequate when it has reached theoretical saturation - in other words, when new interviews yield little or no new information. While demonstrating that the sample has achieved saturation is not straightforward, I stopped interviewing new informants when I was receiving little new information out of each additional interview.

Table 3.4 contains a summary of the 23 households in the sample. The final sample includes a great deal of diversity in socio-economic status, household structure, race, and priorities in the sustainability realm. While I had initially expected to find mostly white nuclear families with relatively high incomes, this self-selected sample of households told a different story. Narrative descriptions of each household are available in the appendix, and the following chapters will introduce you to who my informants are, what priorities, resources, and constraints influence how they get things done in day-to-day life, examples of how they employ these resources to produce day-to-day life subject to constraints and in-line with their sustainability priorities, and finally what some of the consequences are for households of the unconventional ways they get things done. 


\begin{tabular}{|c|c|c|c|c|c|}
\hline Sample ID & Household Adult(s) & $\begin{array}{l}\text { Household } \\
\text { Children }\end{array}$ & Home & Commute & Priorities \\
\hline Household A & $\begin{array}{l}\text { Andrew (white, early 40s, scientist); } \\
\text { Amy (east Asian, early 40s, medical } \\
\text { professional); Amy's father (part- } \\
\text { time) }\end{array}$ & 8,5 & $\begin{array}{l}\text { own; } 3,000 \text { sqft; } 1910 \text { s; inner } \\
\text { eastside Portland }\end{array}$ & $\begin{array}{l}\text { Bike }(M) \text {, Bike } \\
(\mathrm{F})\end{array}$ & $\begin{array}{l}\text { Personal } \\
\text { Health, } \\
\text { Environment }\end{array}$ \\
\hline Household B & $\begin{array}{l}\text { Brian (white, early } 40 \text { s, city planning } \\
\text { consultant) }\end{array}$ & 8 (part-time) & $\begin{array}{l}\text { own; } 1,500 \text { sqft; } 1990 \text { s; inner } \\
\text { eastside Portland }\end{array}$ & Bike (M) & $\begin{array}{l}\text { Waste, } \\
\text { Technology }\end{array}$ \\
\hline Household C & $\begin{array}{l}\text { Chris (white, late 30s, renewable } \\
\text { energy field), Carrie (white, late 30s, } \\
\text { development field) }\end{array}$ & 8,4 & $\begin{array}{l}\text { own; 3,000 sqft; } 1950 \text { s; } \\
\text { eastside Portland }\end{array}$ & Bike (M), Car (F) & $\begin{array}{l}\text { Environment, } \\
\text { Community }\end{array}$ \\
\hline Household D & $\begin{array}{l}\text { David (white, mid-30s, research } \\
\text { manager), Dayna (white, early 30s, } \\
\text { renewable energy field) }\end{array}$ & 1 & $\begin{array}{l}\text { own; } 1,500 \text { sqft; } 1910 \text { s; inner } \\
\text { eastside Portland }\end{array}$ & $\begin{array}{l}\text { Bike }(M), \text { Bike } \\
(F)\end{array}$ & $\begin{array}{l}\text { Technology, } \\
\text { Environment }\end{array}$ \\
\hline Household E & $\begin{array}{l}\text { Eric (white, late } 30 \text { s, consultant), } \\
\text { Emily (white, early } 40 \text { s, consultant) }\end{array}$ & 8,5 & $\begin{array}{l}\text { own; 3,000 sqft; 1930s; inner } \\
\text { eastside Portland }\end{array}$ & $\begin{array}{l}\text { Bike (M), WFH } \\
(F)\end{array}$ & $\begin{array}{l}\text { Personal } \\
\text { Health, } \\
\text { Environment }\end{array}$ \\
\hline Household F & $\begin{array}{l}\text { Fiona (white, late 30s, preschool } \\
\text { teacher) }\end{array}$ & 15,2 & $\begin{array}{l}\text { rent; } 1,000 \text { sqft; } 1960 \text { s; inner } \\
\text { eastside Portland }\end{array}$ & Bus $(F)$ & $\begin{array}{l}\text { Environment, } \\
\text { Community }\end{array}$ \\
\hline Household G & $\begin{array}{l}\text { Gloria (white, late 30s, SAHM), G's } \\
\text { Husband (unknown, unknown, } \\
\text { computer programmer) }\end{array}$ & $6,6,5,3$ & $\begin{array}{l}\text { own; } 2,400 \text { sqft ; suburb of } \\
\text { Portland }\end{array}$ & $\begin{array}{l}\text { WFH (M), WFH } \\
(F)\end{array}$ & $\begin{array}{l}\text { Waste, } \\
\text { Personal } \\
\text { Health }\end{array}$ \\
\hline Household H & $\begin{array}{l}\text { Heather (white; late 30s, nurse and } \\
\text { doula); H's Husband (white, late 30s, } \\
\text { contractor) }\end{array}$ & $6,4,2$ & $\begin{array}{l}\text { own; } 2,000 \text { sqft; } 1920 \text { s; outer } \\
\text { westside Portland }\end{array}$ & $\operatorname{Car}(\mathrm{M}), \operatorname{Car}(\mathrm{F})$ & $\begin{array}{l}\text { Personal } \\
\text { Health }\end{array}$ \\
\hline Household I & $\begin{array}{l}\text { Ian (white, mid 30s, self-employed } \\
\text { artist), Ivy (white, early 30s, non- } \\
\text { profit manager) }\end{array}$ & 6 & $\begin{array}{l}\text { own; } 1,500 \text { sqft; } 1920 \text { s; inner } \\
\text { eastside Portland }\end{array}$ & $\begin{array}{l}\text { WFH (M), } \\
\text { Car/Bike (F) }\end{array}$ & $\begin{array}{l}\text { Waste, } \\
\text { Environment }\end{array}$ \\
\hline Household J & $\begin{array}{l}\text { Jim (white, early } 40 \text { s, attorney), Jess } \\
\text { (white, late 30s, city government) }\end{array}$ & 2 & $\begin{array}{l}\text { own; <1,000 sqft; 1930s; } \\
\text { eastside Portland }\end{array}$ & $\begin{array}{l}\text { Bike (M), Bike } \\
(\mathrm{F})\end{array}$ & $\begin{array}{l}\text { Environment, } \\
\text { Waste }\end{array}$ \\
\hline
\end{tabular}




\begin{tabular}{|c|c|c|c|c|c|}
\hline Sample ID & Household Adult(s) & $\frac{\text { Household }}{\text { Children }}$ & Home & Commute & Priorities \\
\hline Household K & $\begin{array}{l}\text { Kyle (white, mid-40s, non-profit } \\
\text { manager), Kelly (white, late } 30 \text { s, } \\
\text { midwife), Kelly's mother, } 2 \text { adult } \\
\text { roommates }\end{array}$ & $\begin{array}{l}\text {, plus } \\
\text { roommate (3) }\end{array}$ & $\begin{array}{l}\text { own; } 4,000 \text { sqft; } 1880 \text { s; inner } \\
\text { eastside Portland }\end{array}$ & Bike $(M)$, Car $(F)$ & $\begin{array}{l}\text { Community, } \\
\text { Environment }\end{array}$ \\
\hline Household L & $\begin{array}{l}\text { Leonda (black, early 20s, } \\
\text { AmeriCorps volunteer), L's Husband } \\
\text { (unknown, customer service, mid- } \\
\text { 20s), Roommate (unknown, early } \\
\text { 20s, unemployed) }\end{array}$ & 3 & $\begin{array}{l}\text { rent; } 1,000 \text { sqft; } 1960 \text { s; suburb } \\
\text { of Portland }\end{array}$ & $\begin{array}{l}\text { Bike (N), Car } \\
(\mathrm{M})\end{array}$ & $\begin{array}{l}\text { Environment, } \\
\text { Community }\end{array}$ \\
\hline Household M & $\begin{array}{l}\text { Mike (white, early 40s, design } \\
\text { professional), Mina (white, early } \\
\text { 40s, SAHM) }\end{array}$ & 5,3 & $\begin{array}{l}\text { own; } 1,500 \text { sqft; } 1980 \text { s; suburb } \\
\text { of Portland }\end{array}$ & $\operatorname{Car}(\mathrm{M}), \operatorname{Car}(\mathrm{F})$ & $\begin{array}{l}\text { Personal } \\
\text { Health, } \\
\text { Environment }\end{array}$ \\
\hline Household N & $\begin{array}{l}\text { Nathan (white, early } 60 \text { s, marketing } \\
\text { executive), Nicole (white, early } 40 \text { s, } \\
\text { engineer) }\end{array}$ & 5, 4 (Nicole's) & $\begin{array}{l}\text { own; } 4,000 \text { sqft; } 2000 \text { s; suburb } \\
\text { of Portland }\end{array}$ & $\begin{array}{l}\text { WFH (M), Car } \\
(\mathrm{F})\end{array}$ & $\begin{array}{l}\text { Technology, } \\
\text { Waste }\end{array}$ \\
\hline Household O & $\begin{array}{l}\text { Owen (white, mid-40s, design } \\
\text { professional), Orla (white, late 30s, } \\
\text { non-profit manager) }\end{array}$ & 4,2 & $\begin{array}{l}\text { own; } 1,500 \text { sqft; } 1930 \text { s; } \\
\text { eastside Portland }\end{array}$ & $\operatorname{Car}(\mathrm{M}), \operatorname{Bus}(\mathrm{F})$ & $\begin{array}{l}\text { Waste, } \\
\text { Personal } \\
\text { Health }\end{array}$ \\
\hline Household P & $\begin{array}{l}\text { Penny (white, late-30s, } \\
\text { environmental educator) }\end{array}$ & 9,6 & $\begin{array}{l}\text { own; <1,000 sqft; 1980s; } \\
\text { eastside Portland }\end{array}$ & $\operatorname{Car}(\mathrm{F})$ & $\begin{array}{l}\text { Environment, } \\
\text { Community }\end{array}$ \\
\hline Household Q & $\begin{array}{l}\text { Quinn (white, mid-40s, office } \\
\text { worker), Q's Husband (white, mid } \\
\text { 40s, engineer) }\end{array}$ & 8 (adopted) & $\begin{array}{l}\text { own; } 1,500 \text { sqft; } 1900 \text { s; } \\
\text { eastside Portland }\end{array}$ & $\begin{array}{l}\text { Bus/Bike (M), } \\
\text { Bus (F) }\end{array}$ & $\begin{array}{l}\text { Environment, } \\
\text { Community }\end{array}$ \\
\hline Household R & $\begin{array}{l}\text { Rob (white, mid-30s, marketing } \\
\text { professional), Rebecca (white, mid- } \\
\text { 30s, educator) }\end{array}$ & 4,1 & $\begin{array}{l}\text { own; } 1,500 \text { sqft; } 1980 \text { s; } \\
\text { eastside Portland }\end{array}$ & $\begin{array}{l}\text { Car/Bike (M), } \\
\text { Car(F) }\end{array}$ & $\begin{array}{l}\text { Community, } \\
\text { Environment }\end{array}$ \\
\hline
\end{tabular}




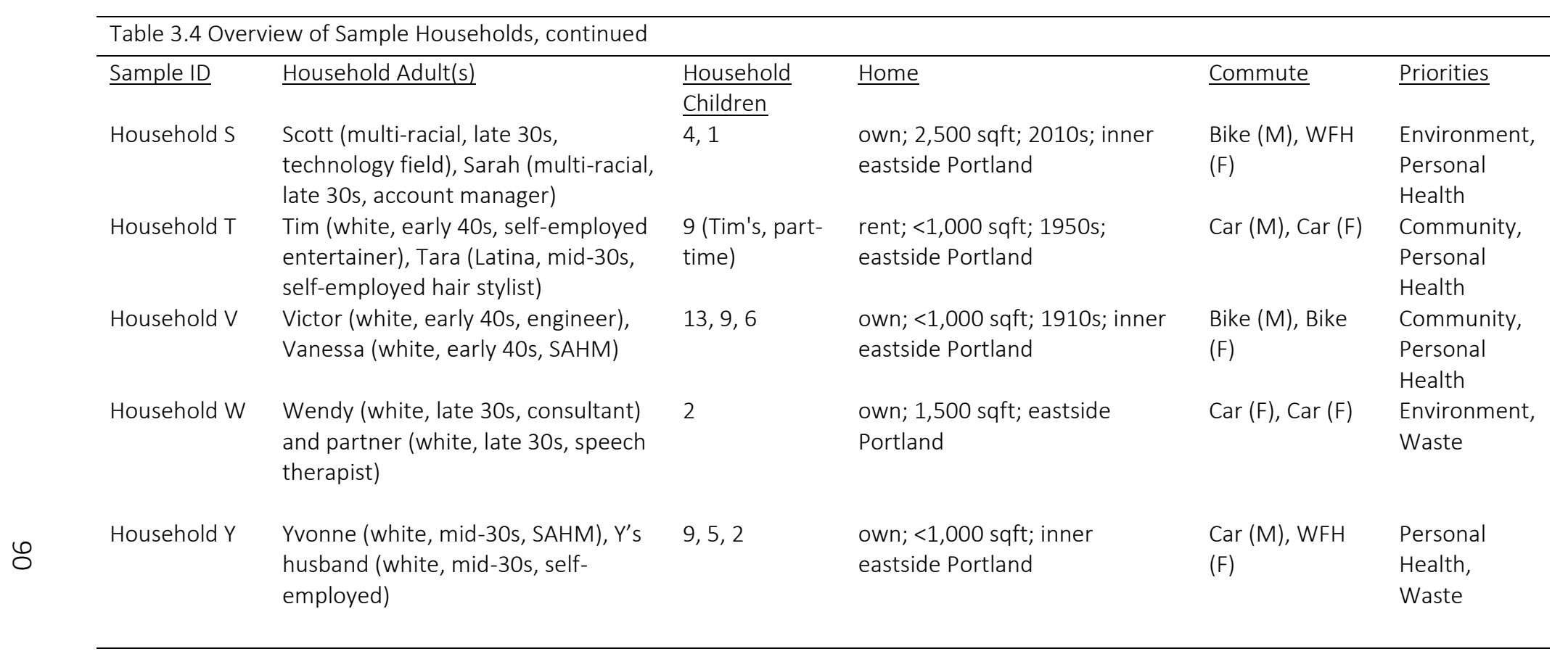

\section{Abbreviations}

WFH: Works from home

SAHM: Stay at home mom 


\subsection{The Interview Guide}

I prepared an interview guide that was informed by the literatures reviewed in Chapter 2, with a particular focus on the primary practices most likely to be associated with intentional pro-environmental interventions into conventional ways of getting things done. The guide and methodology were reviewed and approved by the Portland State University Institutional Review Board, though the protocol was not pre-tested. My interviews generally followed the guide, but I allowed deviations from the set topics based on my informants' interests and elaboration, with the conversation steered back to remaining guide questions. The interview guide questions are shown in Table 3.5 below. 
Table 3.5 Interview Guide Questions

Introductory Questions

What was your family like growing up, what was important to your parents, and how was it different from how you live now and what is important to you now?

Are there any words people use to describe their lifestyles that you identify with, or any that you do not identify with? Examples might be sustainable, eco-conscious, and "crunchy".

Who lives here, and what are their ages, genders, and occupations?

How many square feet is your home, around how old is it, and how long have you been living here?

Waste

What are the ways you deal with household waste (trash, recycling, compost, diapers)?

Is this something you did growing up? How did you learn this practice?

Do you practice selective flushing?

Is this something you did growing up? How did you learn this practice?

How do you know when it is time to flush?

Comfort

What temperature do you keep your home when it's cold outside? What kind of heating equipment do you have? 
Is there anything else you do to feel comfortable when it's cold outside?

Is this something you did growing up? How did you learn this practice?

What temperature do you keep your home when it's hot outside?

What kind of cooling equipment do you have?

Is there anything else you do to feel comfortable when it's hot outside?

Is this something you did growing up? How did you learn this practice?

Cleanliness

Showering

Are you daily showerers?

Is this something you did growing up? How did you learn this practice?

How do you know when it's time to shower?

Laundry

What type of laundry soap do you use, and how did you pick it?

Do you ever hang-dry your clothes?

Are there certain things you don't hang-dry?

Is this different from how you grew up?

Cleaning the home

What times of products or tools do you use to clean your home?

What do you use to clean your toilet?

Transportation

How do you get to work? 
How do you bring your child to school and other activities?

What factors influence your decision to drive or not drive? Or to bike/bus or not?

Food

How often do you go grocery shopping?

Who does most of the cooking?

How important is buying things organic to your family? How do you decide what to buy organic or not?

Are there any foods you don't let your children have?

Are there any other ways you get food?

Other Provisioning

How do you get childcare done?

Are there any other ways you get things your household needs?

Is there anything you would do differently if you had more time?

Is there anything you would do differently if you had more money? 


\section{$\underline{3.6 \text { Analytical Method }}$}

During the months of April and May of 2017, I conducted 22 interviews lasting around 60 minutes each with 37 informants representing 23 households. I interviewed Heather and Gloria, representing two different households, during a single 90 minute focus group style interview at Heather's home while Gloria and her children were visiting for a playdate. My conversation with Yvonne took place over the phone while her youngest child was napping, since between recent travel and her various obligations it was difficult to find a good time to meet in-person to talk. I met with Nathan and Nicole at a busy suburban brew pub in an outdoor mall, I met Leonda at a coffee shop in a strip mall in the suburbs, and I met Wendy at a coffee shop in Southeast Portland. The remaining households invited me to their homes for our interviews. I changed the names of all my informants, with a different letter assigned to each household in roughly the order in which I interviewed them. I only assigned names to informants I interviewed - in households where I spoke with only one member of a couple for scheduling reasons, I did not assign a name to the household members who were not interviewed.

The interviews were open-ended and lasted between 60 and 90 minutes, though I tried to keep our conversations as close to 60 minutes as possible. The theories discussed in Chapter 2 provide an orienting perspective that guides the questions in the interviews. While I let my informants lead me to the topics they found the most important and interesting, I asked them a set of questions about how they get things done in day-to-day 
life in a set of household realms (waste, comfort, cleanliness, food, transportation, and general provisioning). I asked my informants follow-up questions to help me understand how they developed their current practices, what resources are employed in the production of these practices, what these practices mean to my informants, what their motivations for these practices are, and what they might do differently if they had more time or money. I rarely asked the questions in the exact order of the interview guide, preferring instead for the conversation to flow as naturally as possible.

I recorded my interviews in an MP3 digital format using a Sony ICD-UX533 Digital Voice Recorder. I did not take notes during the interview, because doing so would disrupt the casual, friendly conversational style of the interviews. Instead, I composed approximately 1,500 words of descriptive field notes and my general impressions immediately following each interview. In a header in my field notes, I recorded key concepts from the interview, the household composition, and the occupations and approximate ages of the household members. Then, I transcribed the interviews and coded these interviews thematically in Atlas.ti, a qualitative research tool. This tool allowed me to code quotations from the interviews into categories, identify themes, and make meaning out of the information I collected over the course of nearly 30 hours of interviews.

\section{References:}


Aune, Margrethe. 2002. "Users versus utilities - the domestication of an energy controlling technology." in Andrew Jamison and Harald Rohracher (eds.), Technology Studies and Sustainable Development. Munich: Profil Verlag, 383-406.

Basole, Amit and Smita Ramnarain. 2016. "Qualitative and ethnographic methods in economics." in Fred Lee and Bruce Cronin (eds.), Handbook of Research Methods and Applications in Heterodox Economics. Cheltenham, UK: Edward Elgar.

Bergmann, Barbara. 2007. "Needed: A new empiricism." The Economists' Voice 4(1): 1-4 Bernardo, Richie. 2016. "2016's Greenest Cities in America." WalletHub October 12, 2016. Available: https://wallethub.com/edu/most-least-green-cities/16246/ accessed 03/26/2017.

Bott, Elizabeth. 2001. Family and Social Network: Roles, Norms, and External Relationships in Ordinary Urban Families, $2^{\text {nd }}$ Edition. Abingdon, UK: Routledge. Carlsson-Kanyama, Annika and Anna-Lisa Lindén. 2007. “Energy efficiency in residencesChallenges for women and men in the North." Energy Policy 35: 2161-2172.

Cobb, Carrie L., Mary C. King, and Leopoldo Rodriguez. 2009. "Betwixt and between: The spectrum of formality revealed in the labor market experiences of Mexican migrant workers in the United States." Review of Radical Political Economics 41(3): 365-371.

Coupland, Jennifer Chang. 2005. "Invisible brands: an ethnography of households and the brands in their kitchen pantries." Journal of Consumer Research 32(1): 106-118. 
Dewey, John. 2011. How We Think. Project Gutenberg EBook \#37423. Available:

https://www.gutenberg.org/files/37423/37423-h/37423-h.htm

Forlizzi, Jodi. 2007. "How robotic products become social products: an ethnographic study of cleaning in the house." Human-Computer Interaction Institute. Paper 40.

Forsberg, Lucas. 2007. “Negotiating involved fatherhood: Household work, childcare, and spending time with children." Nordic Journal for Masculinity Studies 2(2): 109126.

Glaser, Barney P. and Anselm L. Strauss. 1967. The Discovery of Grounded Theory: Strategies for Qualitative Research. New Brunswick, NJ: Aldine Transaction. Goldstein, Jonathan P. and Michael G. Hillard. 2008. "Taking the high road only to arrive at the low road: The creation of a reserve army of petty capitalists in the North Maine Woods." Review of Radical Political Economics 40(4): 479-509.

Gregory, Chris A. and John C. Altman. 1989. Observing the Economy. New York, NY: Routledge.

Haider, Asad and Salar Mohandesi. 2013. "Workers' Inquiry: A Genealogy." Viewpoint Magazine, September 27, 2013. Available: https://www.viewpointmag.com/2013/09/27/workers-inquiry-a-genealogy/ Harper, Douglas. 1992. "Small N's and community case studies." In Charles C. Ragin and Howard S. Becker, What is a Case? Exploring the Foundations of Social Inquiry. Cambridge, UK: Cambridge University press, 139-158. 
Harrison, Jane, Lesley MacGibbon, and Missy Morton. 2001. "Regimes of trustworthiness in qualitative research: the rigors of reciprocity." Qualitative Inquiry 7(3): 323-345. Kaplan, Abraham. 1998. The Conduct of Inquiry: Methodology for Behavioral Science. New Brunswick, NJ: Transaction Publishers.

Kerstenetzky, Jaques. 2010. "Alfred Marshall on big business." Cambridge Journal of Economics 34: 569-586.

Livingstone, Sonia. 1992. "The meaning of domestic technologies: a personal construct analysis of familial gender relations." in Eric Hirsch and Roger Silverstone (eds.), Consuming Technologies: Media and Information in Domestic Spaces. London, UK: Routledge.

Malinowski, Bronislaw. 1922. Argonauts of the Western Pacific: An Account of Native Enterprise and Adventure in the Archipelagoes of Melanesian New Guinea. London, UK: Routledge \& Sons, Ltd.

Marshall, Alfred. 1919. Industry and Trade: A Study of Industrial Technique and Business Organization; and of their Influences on the Conditions of Various Classes and Nations. London, UK: Macmillan.

Marx, Karl. 1938. "A worker's inquiry." New International 4(12): 379-381. Available: https://www.marxists.org/history/etol/newspape/ni/vol04/no12/marx.htm Morgan, David. 1981. "Men, masculinity, and the process of sociological enquiry" in Helen Roberts (ed.), Doing Feminist Research. London, UK: Routledge \& Kegan Paul Ltd. 30-61. 
Morgan, David L. 2014. Integrating Qualitative and Quantitative Methods: A Pragmatic Approach. Los Angeles, CA: Sage Publications, Inc.

Morgan, Gareth and Linda Smircich. 1980. "The case for qualitative research." The Academy of Management Review 5(4): 491-500.

Moroşanu, Roxana. 2016. An Ethnography of Household Energy Demand in the UK: Everyday Temporailities of Digital Media Usage. New York, NY: Palgrave Macmillan.

Murphy, Fiona and Pierre McDonagh. 2016. "Introduction." In Fiona Murphy and Pierre McDonagh (eds.), Envisioning Sustainabilities: Towards an Anthropology of Sustainability. Newcastle upon Tyne, UK: Cambridge Scholars Publishing. Netting, Robert, Richard R. Wilk, and Eric J. Arnould. 1984. Households: Comparative and Historical Studies of the Domestic Group. Berkeley, CA: University of California Press.

Oakley, Ann. 1978. The Sociology of Housework. Bath, UK: The Pittman Press.

Oakley, Ann. 1981. "Interviewing women: a contradiction in terms." in Helen Roberts (ed.), Doing Feminist Research. London, UK: Routledge \& Kegan Paul Ltd., 30-61. Pickbourn, Lynda and Smita Ramnarain. 2016. "Separate or symbiotic? Quantitative and qualitative methods in (heterodox) economics research." in Fred Lee and Bruce Cronin (eds.), Handbook of research methods and applications in heterodox economics. Cheltenham, UK: Edward Elgar. 
Pigou, Arthur Cecil. 1956. "In Memoriam: Alfred Marshall" in Memorials of Alfred Marshall, A.C. Pigou (ed.). New York, NY: Kelley \& Millman, Inc.

Ray, Raka and Seemin Qayum. 2009. Cultures of Servitude: Modernity, Domesticity, and Class in India. Stanford, CA: Stanford University Press.

Rich, Adrienne. 1986. Of woman born: Motherhood as experience and institution. New York, NY: W. W. Norton \& Company.

Rode, Jennifer A., Eleanor F. Toye, and Alan F. Blackwell. 2004. "The fuzzy felt ethnography-understanding the programming pattern of domestic appliances." Personal and Ubiquitous Computing 8(3): 161-176.

Rogers, Stephanie. "Hard economic times be damned: 10 U.S. cities make their own green." Ecosalon, October 26, 2011. Available: http://ecosalon.com/americasgreenest-cities-319/ Accessed 03/26/2017.

Rubin, Herbert J. and Irene S. Rubin. 2012. Qualitative Interviewing: The Art of Hearing Data, $2^{\text {nd }}$ Edition. Thousand Oaks, CA: SAGE Publications.

Smith, Adam. 2003. An Inquiry into the Nature and Causes of the Wealth of Nations. New York, NY: Bantam Classic.

Spradley, James P. 1979. The Ethnographic Interview. Long Grove, IL: Waveland Press, Inc. Stacey, Judith. 1988. "Can there be a feminist ethnography?" Women's Studies International Forum 11(1): 21-27.

Stacey, Judith. 1990. Brave New Families: Stories of Domestic Upheaval in Late Twentieth Century America. New York, NY: Basic Books. 
Stanley, Liz and Sue Wise. 1990. "Method, methodology and epistemology in feminist research processes." in Liz Stanley (ed.), Feminist Praxis: Research, Theory and Epistemology in Feminist Sociology. London, UK: Routledge.

Streeten, Paul. 2002. "What's wrong with contemporary economics?" Interdisciplinary Science Reviews 27(1): 13-24.

Svoboda, Elizabeth, Eric Mika and Saba Berhie. 2008. "America's Top 50 Green Cities." Popular Science February 8, 2008. Available: http://www.popsci.com/environment/article/2008-02/americas-50-greenestcities?page=1 Accessed 03/26/2017.

Wilhite, H., H. Nakagami, T. Masuda, Y. Yamaga, and H. Haneda. 1996. “A cross-cultural analysis of household energy use behavior in Japan and Norway." Energy Policy 24(9): 795-803.

Wilhite, Harold L. \& Richard R. Wilk. 1985. "Why don't people weatherize their homes? An ethnographic solution." Energy 10(5), 621-629.

Yale Program on Climate Change Communication. 2015. Yale Climate Opinion Maps Data -U.S. 2015. Available: http://climatecommunication.yale.edu/visualizationsdata/ycom-us-2015/. Accessed 11/18/2016. 
Chapter 4: Priorities, Resources, and Constraints

\subsection{Overview}

\subsubsection{Introduction}

In this chapter, I will introduce you to my informants and their families. First, I will describe how they grew up and what they view as the origins of their sustainability values. Next, I will describe the priorities of my informants in the sustainability realmpersonal health, nature, waste avoidance, technology, and community. It is these priorities that motivate the changes my informants have made in their lives compared to what they see as more conventional ways of getting things done. The resources available to my informants - from waged work, extended family and friends, governments and non-profits, from research, gleaning, borrowing, and theft, and from unwaged work-can be thought of as the "factors of production" for their household. These resources are the inputs into their household production function, and represent the tools they use to get things done. Finally, their constraints - time, budgets, social and cultural norms, and a lack of information - are the factors that limit their options and restrict my informants' choices.

\subsubsection{Different Ways of Getting Things Done}

The 23 households I met with over the course of the spring had were more different than I initially expected. I had assumed that sustainability in Portland, Oregon, would be a 
largely liberal white upper middle class phenomenon, and that the practices would primarily serve as conspicuous forms of class distinction and display. However, the informants and households I spoke with represented more diversity than I projected-in household configurations, socio-economic status, political leanings, education, race and ethnicity, and gender identity and the gender of the householders.

Despite these differences, the adults in these households share a common, sincerely held desire to do the right thing for their children, families, communities, and planet. They try to make decisions for their families and balance their sustainability priorities with constrained resources, which often involves fairly major interventions into conventional ways of getting things done in order to bring their day-to-day practices into alignment with their values. I learned that there is not a single "sustainability" with households engaging in sustainability practices to varying degrees of intensity along a green spectrum. Rather, sustainability represents a broad set of values and beliefs for these Portland households, with sustainability practices influenced by the unique combinations of priorities, resources, and constraints in each household.

Mike and Mina have two large cars that they use for long daily drives from their suburban home to their various obligations, but Mina's primary concern in the sustainability realm is the health of herself and her family members. For this reason, she makes her own natural deodorant, gives her children alternative remedies like elderberry syrup, and 
prepares elaborate home-cooked vegetarian meals with organic ingredients she buys during her frequent trips to far-flung grocery stores. As a stay-at-home mother, she sees her unpaid time as her major contribution to the household. David and Dayna, on the other hand, are both professionals who work in downtown Portland. They own only one car and commute to their daily obligations almost exclusively by bicycle, including to drop their infant child off at daycare. They have government-subsidized solar panels and energy efficiency devices in their home, but eat a lot of frozen convenience foods and takeout meals since becoming parents. They pride themselves on their self-sufficiency. Technology and electronic gadgets are a primary focus of their sustainability practices, which they see as a solution to environmental problems. Leonda bikes to her position as an AmeriCorps volunteer, practices selective flushing, and was so committed to cloth diapering that she hand-washed diapers in the bathtub when she was living in an apartment without access to laundry facilities. However, she finds it difficult to learn how to make healthy meals for her family since she grew up eating mostly fast food, a habit she is trying to break, and her WIC benefits have restrictions that prevent her from using the funds to buy natural food items. Growing up in a heavily contaminated region of Appalachia, Leonda's primary sustainability concerns are environmental justice and the community impacts of corporate pollution. 


\subsubsection{How Households Produce Sustainability}

In each of these cases, my informants balance their resources and constraints to produce sustainability practices in their households that prioritize the things they care about the most. The overlapping sustainability priorities of the households in this study include community well-being, the health of individual family members, nature, technology, and waste avoidance. Resources in the households include wages from paid work, the unpaid work of household members and extended family and friends, help from paid caregivers, government assistance (transfer payments and benefits, low income programs, and subsidies for energy-saving home improvements), and previous investments in knowledge and know-how. Households are constrained by their limited time and money as well as cultural concerns and their ability to learn practices and obtain accurate information, though the largest constraints are imposed by the economy and society in which they live.

\subsection{Introducing the Informants}

\subsubsection{Families of Origin}

How my informants grew up often had a significant influence on their current priorities and practices. For some informants, particularly ones who were raised by countercultural or highly thrift-oriented parents, this is because the habits and values of their families of origin were carried forward into their current lives. For others, their practices and values as adults were formed in contraposition to those of their families of origin, a 
theme that was prevalent for informants who described their childhoods as typically suburban and their parents as excessively invested in consumer culture. Informants who retained resource-saving practices they had learned from their parents often attributed those habits to their upbringing. For example, Chris likes to wash out and re-use plastic bags, something his parents did faithfully. However, more conventional ways of getting things done, such as owning two cars or eating microwaved food, were rarely explained as habits and values learned from their own parents. Tara, a particularly self-aware and reflective informant, was an exception, as she attributes her positive associations with and desire for consumer goods to her conventional upbringing and the materialistic values of her parents.

Chris, Carrie, Fiona, Jim, and Scott were raised by parents with strong links to the 1960 and 1970s hippy counter-culture and environmental activism. Chris recalls hang-drying clothes and occasionally bringing them inside frozen during the winter, and his wife Carrie was raised in a spiritual intentional community that impressed upon her a belief in the importance of bearing in mind her impact on other people. Fiona and Jim were raised by parents influenced by Back-to-the-Land ideals, though they both remarked on the shifting emphasis as their parents aged, with an increased value placed on comfort and convenience. Scott's parents were involved in early pro-environmental litigation and activism, though he commented on an incongruity between the environmental values of his parents and many of their personal habits and choices. 
Other informants were raised by more conventional parents. Gloria, Jess, Owen, Penny, and Tara see themselves as rebelling against the excessive consumerism and emphasis on material goods from their suburban middle class families of origin. Owen describes his childhood as "Midwestern Leave it to Beaver", and talks about air conditioning as something households in his community would install to show their neighbors that they'd "made it". Gloria says that her mother's materialistic values were based in shame and a need to prove her worth as a single parent through buying things. Tara still struggles occasionally with the linkage, instilled by her family of origin, between love and consumer goods. Penny recalls a Midwestern suburban home so large that her family members had to yell across the house to communicate with each other. As an adult, she finds it odd that the home was climate controlled to the same temperature year-round.

Leonda and Heather were both raised by low income single mothers and left their family homes prior to graduating high school. Heather, in particular, sees herself as a strong and independent person because she had to be so responsible for herself and her siblings growing up. She contrasts herself as a parent with her mother by saying they have different priorities for how they spend their time. Leonda recalls their grandmother, who partially raised them, teaching them how to apply for food stamps and other government benefits as a teenager in Appalachia. Ivy was raised in a low income and highly religious family in a manufactured home in Central Oregon. While her husband complemented 
Ivy's mother for her resourcefulness and thrift, the parallels between her mother's life skills and her own were less obvious to Ivy, who sees her adult lifestyle as a rebellion against her mother's consumerism and desire for comfort.

While Kyle, Nathan, Orla, Tim, and Yvonne also grew up in low income households, they described thrift as a guiding principle for their parents that was independent of their financial status. Kyle's father died when he was young, leaving his mother to raise him and his siblings alone. He expressed gratitude for his mother's resourcefulness and he appreciated her decision to live without a car in a medium sized Midwestern city. Yvonne also told me that she appreciates the skills and resilience she and her husband learned growing up in low income families as well as the food storage equipment they receive as gifts from her husband's LDS parents. Tim's parents are members of a strict religious sect who believe in an impending Biblical End Times. According to their faith, they were the meek who would inherit the earth, so they were extremely thrifty and mindful of the natural environment-they did not want to spend the rest of eternity cleaning up after people who were not saved. Nathan's father was a minister and his parents were progressives who were involved in Vietnam War protests and the early Environmental movement. He was taught by his father to fix everything and waste nothing, and these values are carried forward to his present lifestyle and habits. Jim wonders in hindsight if his father's thrift and pro-environmental behaviors were purely based on ethical choices, or were also motivated by raising two children on his own with few financial resources. 
Orla's father continues to live an extremely thrifty lifestyle, recently collecting old pallets off the side of the road over a period of years until he had saved up enough wood to build himself a new work shed.

\subsubsection{Origins of Sustainability Values and Practices}

While the households in the study come from diverse cultural and socio-economic backgrounds, the importance of personal contacts in influencing my informant's current values and practices in the sustainability realm was almost universal. Fiona credits her siblings with many of her sustainability practices - she became a vegetarian when her brother showed her that eating meat wasn't necessary, and she started flushing selectively after living with her sister and realizing she didn't have to flush the toilet after urinating. Leonda did not have any sustainability-oriented contacts until she was in her teens, but began turning off lights in unoccupied rooms after seeing an energy conservation PSA on television and started flushing selectively after watching the 2004 movie Meet the Fockers, which has a scene about "letting it mellow." Many of her other practices and values were taught to her by environmental activists in her community who were a few years older than she was, who she met through her Unitarian Universalist faith community. Similarly, Tara was influenced by older people in her profession she met after moving away from home who made deliberate ethical consumption choices and ate more nutritious foods than she had been exposed to growing up. Dayna says a close friend with similar values convinced her that she could use cloth diapers, and reduced 
the burden of research by teaching her and giving her information about why and how to use the diapers. Mina was a fairly conventional parent prior to moving to Portland and sending her children to a cooperative preschool. Now that she has adopted some of the sustainability practices of the other parents from her preschool, her old friends jokingly tell her that she's become a hippy.

Education, particularly post-secondary education, also played an important role in influencing the environmental and social values of several informants. Chris, Emily, Fiona, Heather, Owen, and Penny all had meaningful experiences with college coursework that influenced their current worldviews. Emily believes that her environmental science education is a privilege that enables her to be aware of sustainability issues and the possible health impacts of her family members, and she recognizes that not all families have the same ability to access and process health information. Fiona and Penny share a conviction that their interdisciplinary environmental science educations helped them understand how their actions impact ecosystems and people living in less developed countries. Owen had a conventional Midwestern upbringing, and a nature photography course that brought him to Oregon introduced him to environmental issues and the importance and beauty of the natural environment. Chris took a course about environmental crises when he was 19 that he called "a body-blow of a class where I was so depressed afterwards." Even though he was raised by unconventional 
environmentalist parents, he credits this course with shaping his worldview and the way he lives his life today.

The sustainability-oriented households in my sample had considerable variation in terms of their political affiliations and beliefs motivating their sustainability values and practices, with beliefs that sometimes even diverged within individual couples. Some amount of homogeneity in the political beliefs and sustainability motivations is to be expected in a sample deliberately drawn from a single, highly liberal metro area. Informants volunteered based on their self-identification as members of an ecoconscious or sustainable household, but belief in climate change and environmental concern are increasingly a matter of tribal knowledge, with wide divergence in the opinions of Democrats and Republicans (Dunlap \& McCright 2008). However, my informants included anti-capitalist socialists, democratic socialists, moderate Republicans confused by the recent election of Donald Trump, vaguely libertarian moderates, moderate Democrats, left-of-center progressive Democrats, Green Party voters, and even one informant who described his overall value system using terms and concepts linked to white supremacy and the so-called alt-right. From the far right or far left or somewhere in between, the sustainability-oriented households I spoke with describe their lifestyles as deliberately constructed in opposition to particular elements of mainstream American culture that they oppose: individualism, consumerism, wastefulness and a lack of gratitude, technology and social media, instant gratification, 
selfishness, and the loss of traditional values. A national sample of households engaging in these practices might include even greater variation in motivations and political beliefs driving sustainability practices.

While there is no ethnographic social practices research on American households that I could use for a comparison to my households, their perspective was clear-they view their sustainability practices as an alternative to conventional ways of getting things done.

\subsubsection{Current Living Arrangements and Family Structures}

Of the 23 households in the sample, 13 households were people living in a nuclear family with two opposite-sex parents and their related children. However, the remaining 10 households represented other configurations of people living together, including a same sex couple, a couple in which one of the members is gender non-conforming, intentional communal living arrangements with non-related people, single parents, blended families, roommates, and extended families. The full list of household configurations is available in Table 4.1. 


\begin{tabular}{lc}
\hline Table 4.1 Sample Household Configurations & \\
\hline Description & Number \\
\hline Nuclear Family with two opposite-sex & 13 \\
parents & 1 \\
Nuclear Family with two same-sex parents & 2 \\
Single parent, children present part-time & 1 \\
Single parent, children present full-time & 1 \\
Blended family, children present full-time & 1 \\
Blended family, children present part-time & 1 \\
Nuclear family with two parents, one male & \\
and one gender non-conforming, and one & \\
adult roommate & 1 \\
Nuclear family with two opposite-sex & \\
parents and one grandparent & 1 \\
Nuclear family with two opposite-sex & \\
parents, one grandparent, and a non- & \\
related nuclear family in intentional & \\
community & \\
Nuclear family with two opposite-sex & \\
parents in cohousing community & \\
\hline
\end{tabular}

Many of foundational theories discussing work and households in the context of an advanced industrialized society presuppose a particular household arrangement-two parents, a man who engages in paid work outside the home and a woman who does not, living in the same space as their biological children. This type of living arrangement, the joining of kinship and cohabitation, may be promoted by the state and other institutions as the ideal, but it is a modern one that was at no time universal in industrialized countries (Barrett 1980, 200-204; Wilk \& Netting 1984; Collins 2000 [1990], 45-68). The sample, like the real world, includes a diverse array of household configurations. 


\section{$\underline{4.3 \text { Household Sustainability Priorities }}$}

The households in this study were self-selected on the basis of their own perception that their values and practices have a sustainability or pro-environmental orientation. However, the sustainability priorities and practices in these households were not variations along a single "green" spectrum. Rather, households had sustainability priorities related to personal health, nature, waste, technology, and community. Households' priorities generally consisted of two or three of these sustainability realms, with one facet of sustainability generally standing out as the primary concern. Another difference between households was whether the motivation for informant's sustainability interests was primarily oriented towards household members or people, animals, and ecosystems external to household members. Households with priorities related to personal health, waste, and technology tended to have a more internal orientation in their motivations, while households who were most concerned with nature and community tended to have a more external motivation. This section discusses these household sustainability priorities in more detail.

\subsubsection{Personal Health}

Households whose sustainability priority is personal health are worried about contamination, specifically with chemicals, and the impacts of chemicals on the health of their children and themselves. 
Emily: I don't want my kids to be exposed to chemicals. I certainly value the environment second to my family of all my priorities in life, but the health of the kids is the primary driver of these decisions for me.

Chemicals is a very vague term that my informants use to talk about properties of foods, additives, and medicines that are not "natural." They have high levels of distrust of large corporations, conventional medicine and the medical field, and the government and associated regulatory bodies.

Yvonne: I don't want to sound like a conspiracy theorist, but I don't really trust the government. It's been proven time and time again that money prevails. It is constantly being shown that we are the last ones to know about things being done that are adverse for our health. To get anywhere in politics, politicians have to put companies before people because that's where their money is coming from.

The focus of personal health-related sustainability practices is avoiding potential negative health impacts on people inside the household related to particular purchases, like food items, medications, personal care products, and cleaning products. These informants spend time researching alternative ways of getting things done to avoid chemicals, such as making their own laundry detergent and alternative medical treatments. These interests are not necessarily linked to the environment, but the informants consider them to be part of their sustainability values. Informants with personal health as a priority might not consider the environment in their day-to-day choices:

Heather: We don't think about saving energy much at all! Heather has made major interventions into her day-to-day practices-extended breastfeeding, buying all organic food, homeschooling her three children, keeping a large food garden and chickens, and making her own cleaning products out of natural 
ingredients and essential oils. However, larger environmental considerations are off her radar.

While Heather and Amy have medical training and work in the medical field, other health-oriented informants see themselves as amateur researchers and doctors.

Heather: I'm a nurse, so I live in medicine. That's what I do for my profession, but I probably buck against the system as much as I can, against Western Medicine. In the sense that when we seek out more natural alternatives that are treating the source of the problem. Not masking, and not using pharmaceuticals. So, we are not like families who trust that system.

Yvonne calls herself an "amateur herbalist." She uses books to research herbalism, and forages for treatments for her son's severe asthma and her own chronic health condition because she is "not comfortable" with the idea of treating these ailments with corticosteroids. Earlier in his life, Victor had wanted to be a doctor. While he ultimately decided on a different career, he retained this interest in medicine and enjoys reading about health and going doing nutrition and natural health experiments on his family members.

Given the controversial nature of the subject, none of my informants admitted to having unvaccinated children, nor did I ask about vaccinations. Vanessa mentioned that she thinks children probably have all of their vaccinations now, but she used an alternative vaccination schedule. Discussions with Mina and Rebecca, two parents who did vaccinate their children, gave the impression that anti-vaccine sentiment was prevalent among 
sustainability-oriented households in Portland. Oregon has the highest non-medical vaccination exception rate in the country, and The Portland Village School, a sustainability-focused Waldorf-inspired public charter school, has a non-medical vaccination opt-out rate of 53 percent, the highest for a public school in the state (FodenVencil 2015).

Mina spoke to me in a whisper when she told me that she knows a quarter of the children in her preschool are unvaccinated. She thinks the other parents would have a negative opinion of her if they knew her children received all of their vaccinations on the conventional schedule. Rebecca was less apologetic and unconcerned with how parents of unvaccinated children perceive her.

Rebecca: My kids are $100 \%$ vaccinated. I feel that it is a disservice... no, that's not strong enough of a word. I feel that if you do not vaccinate your child, you should not be allowed to attend public school or take them into public where there are children who are too young or people who are medically fragile and can't get those vaccines. I think people who are not vaccinating their children believe in pseudoscience and believe in personal choice over the public good. And those things seem directly in conflict with being environmentally conscious. Being environmentally conscious is about the public good and creating an environment that is healthy for ALL OF US, as well as believing in the science that tells us that there is a demonstrable shift in our environment based on our human habits. One is pretty anti-science and one is pro-science.

While Rebecca frames this issue as pro-science and anti-science, the health-oriented families I spoke with do not see their views and practices as "anti-science." They devote a considerable amount of effort into researching their choices, and have concluded that mainstream science and medicine are wrong about certain topics. However, Rebecca 
does point out an important distinction between her sustainability priorities and the priorities of some health-oriented informants: Rebecca's primary concern and motivation for her sustainability practices is public welfare, while health-oriented families are most concerned with the well-being of the members of their immediate household.

\subsubsection{Nature}

Households whose sustainability focus is nature express a concern for the environment and ecosystems for their own sake. This concern for the environment is not oriented towards household members and often not towards human beings at all.

Andrew: What we're doing in our house isn't just good for us, it's because we care about the environment in general.

Fiona: I value the planet as a living organism. Even if humans weren't a part of that, I would still want to care for all of the other creatures and ecosystems at large.

Informants for whom nature is a high sustainability priority are concerned with the carbon impacts of their purchases and activities, the impacts of air pollution and effluent, and the welfare of animals.

Jim: For me the preeminent environmental motivator is the carbon impact, and then secondary to that would be the public health impacts.

Some of these households also tied their interest in sustainability to experiences enjoying nature recreationally, and childhood experiences in nature were cited as inspiring their current sustainability interests.

Quinn: Nature was important to my parents, and taking us outside. 
Andrew: I became interested in sustainability growing up, I was just exposed to the mountains and to things outside of the city. There's green in the city, too, but I got out into nature just growing up, so I got an appreciation for nature and preserving it.

Eric: My step-dad took me camping a lot, we spent a lot of time in the Sierras, and canoeing around. And that imparted an appreciation for nature that is the underpinning of [my sustainability practices] now.

These experiences in childhood inspired my informants to make efforts to take their children into natural areas.

Emily: An appreciation for nature is a big thing for me. We try to get them out into the woods, we take them hiking a lot. Getting them out of the city and trying to instill an appreciation for the natural environment. That's a big priority for us.

Quinn: I think it's important for my kid to get out in nature and appreciate nature, because I hope that when he's older that will mean he will want to do things to help the environment.

They believe that if their children learn to enjoy nature for its recreational value, they will be motivated to have pro-environmental views and practices as adults.

\subsubsection{Waste}

Households whose sustainability focus is waste are concerned about wasting resources because thrift and avoiding wasting is an important value in and of itself. This sustainability priority reflects the religious and cultural impulse towards asceticism noted by Weber ([1905] 2002, 115) and Bourdieu $(1984,286)$. Kyrk $(1923,74)$ describes these impulses in the American context: "Self-sacrifice and deprivation are goods in 
themselves" -thrift and deprivation are social goods that serve as a display of one's

values and good moral character.

Nathan: It's all part of the same philosophy-don't waste shit. Wasting money, wasting anything else. Don't waste a minute, don't waste a dollar, don't waste a thing.

This avoidance of waste particularly applies to energy and the packaging of consumer

goods.

Dayna: And that concern about waste, packaging, David has always been more focused on that and that's been more of a mission for him and I've been chastised by him for not doing stuff because I'm just like "Uuuuggh."

Eric: But I hate how everything goes into a container and that's the default in our culture and our stores. Container within container within container. It's so unnecessary.

Quinn: We teach our son about recycling, and to turn off the lights if you're not in the room. We don't have many conversations, but we more teach by example.

The priority of waste avoidance also applies to households who have an interest in "voluntary simplicity," try to buy as little as possible, or avoid buying new consumer goods, reflecting a current trend in American culture of possessing a carefully curated set of only a few just-right items (Bernstein 2016, Chayka 2016, Logan 2017).

Gloria: We have what we need and we need what we have. We try really hard not to frivolously acquire. We try to bring things into the house that have several purposes that are very useful. And I mean that in terms of food, clothing, anything from food to an appliance.

Fiona: We really avoid getting a lot of things and just see what we can do with what we have. And that's my approach to everything: how can I use what I already have. 
Heather: Less is more. Minimalism in a sense. Though I sometimes feel that it's not possible. We don't really splurge on a whole lot. Whether it means that we're going to the library for our books. "Less is more" also applies to medicine, and we always research what we're doing to make sure it is healthy. And we are working on being more sustainable as far as doing things here, the gardening and the chickens.

Like Heather, Brian admits that voluntary simplicity is often more of a goal than an accurate description of the way he actually lives.

Brian: The one other thing that is more of an aspiration is "simple," just "simple lifestyle."

Some households refer to this value as "thrift" and discuss previous generations'

experience during times of poverty, particularly the Great Depression.

Nathan: My parents were Depression kids, so this ethic of “if it doesn't work, fix it" comes from them.

Orla: My dad is what a lot of people would consider cheap. He does not like to waste anything. He has a thirty-year-old fridge, but he doesn't want to get a new one because that would be wasteful. He grew up with parents who were a little bit older, definitely influenced by the Great Depression era.

Kyle: The driver for my mother was being a child of survivors of the Great Depression, and depression-era economics, which she carried on. She had those skills from her childhood which she brought into our household. These are values from close to 100 years ago being moved forward. They were transmitted to my mother and then to me. Economizing, and not taking more than you need, and figuring out how to re-use things. There is a real continuity there that the environmental movement relies on.

These informants see their own values and practices as their inheritance from past experiences of economic crisis in their families of origin. 


\subsubsection{Technology}

Households whose sustainability focus is technology often value technology for its own sake. When asked about the motivations for his interest in sustainability, David answered that enjoying "gadgets" is a major impetus for their pro-environmental practices.

David: For me it's also just gadgets and geeky energy stuff. Like geeky energy stuff, I just enjoy. I'm always looking around like, "What could I do next?"

Some of these informants see their technology purchases as direct expressions of their sustainability values, while others see their interest in technology as a conflict for their sustainability values.

Brian: And I think as much as my ideal self would be living very simply, I do have a bit of a technology.... Not quite a fetish, but definitely a predilection... It's something that I can kind of justify by saying it is part of my world, it is part of my job. But the reality is that it's just one of my interests, and it's one of the areas where I kind of think that that kind of simplicity, that buying fewer things, kind of breaks down in my life.

David and Dayna pride themselves on thrift in many areas of their lives, except when it comes to technology.

Dayna: We are not the kind of people who will do the better option at any price.

David: Except for some things.

Kirstin: What's an example of that?

David: Pretty much any energy efficiency gadget.

For Brian, David, Dayna, Nathan, and Nicole, technology and energy efficiency improvements are solutions to environmental problems. Brian has one of the warmer 
winter temperature settings of my informants, and recently installed a smart thermostat he can control from his computer or phone. This device allows him to prevent the heat turning on automatically when he decides last-minute to spend the evening at his new girlfriend's house. David and Dayna believe see technology-a dual-flush toilet they recently purchased-as a solution that allow them to save water without practicing selective flushing, and they recently changed all of the light switches in their home to motion-sensor switches, because they believed carrying an infant was preventing them from always switching off lights.

David: I probably do have a higher tolerance [for selective flushing]. I would go a few more flushes probably, but I think the dual flush toilet solved that problem.

They also admit that they just find the technology fun and interesting. David and Dayna are evangelical about their robot vacuum cleaner and solar panels. While Nathan calculated the return on investment of his costly geothermal system and decided that it was the most cost-effective way to heat and cool his home, he also refers to the system as a "toy."

Kirstin: And what was the main motivation behind installing the solar panels?

Dayna: Because solar is fantastic!

Nathan: We have geothermal heating and cooling. It is a really high efficiency rating system. Both radiant floor and forced air. It is totally cool. You've got to see this thing. We are geeks at heart, so the technology is just really exciting. It's a cool toy.

Nicole: I am more willing to spend money on cool stuff just because it is cool or helpful. 
Some of the households I spoke with see technology as a social and environmental problem, something that contributes to wasted resources, escalating consumption, and prevents human intimacy in communities. Despite an awareness of these criticisms, informants with a technology focus believe that technology has a positive role to play in their lives and the world.

\subsubsection{Community}

Households whose sustainability focus is community are concerned with the well-being of people outside their own families - either on a local or global scale-and see their community-oriented lifestyle as an expression of their sustainability values. Sometimes this interest in community is expressed as contrasting with others who are more oriented towards their nuclear families, while for other informants this value of community is a social justice focus. Gloria summarizes her community-oriented sustainability focus by emphasizing that her children are not her sole motivation for environmental choices.

Gloria: Community is what I'm trying to save. Community is my motivation for environmental choices... it's for the whole world! I don't want to just save my children's future. I want to be woven in.

Fiona is concerned with environmental justice, and frames her interest in the environment in terms of a concern for the impact of her choices on other people, both locally and globally.

Fiona: I want other people to not be exposed to toxins, and especially I think in American culture there tends to be a lot of waste in resource use, and that makes me concerned about the impacts on other parts of the world. I feel like 
there's some environmental injustice that happens when we ship all of our garbage off to other places.

Leonda and Rebecca are motivated by concerns related to social justice, and see social

justice and environmental justice as linked.

Rebecca: My views on social justice are very much related to my beliefs about the environment. One of the things that has caused all of these problems with the environment is a sense of entitlement and a lack of community-mindedness.

Leonda: My social justice and environmental interests overlap. What I noticed, when I was younger, was that a lot of environmental damage happens in places that have more poverty, like the place I grew up. In 2014, there was a chemical spill in our drinking water, and it wasn't reported for a while after the fact. I was pregnant at that time, and I drank that water. It smelled and tasted weird. And what I found out later was that the chemical that was leaked into our drinking water was a chemical used to clean coal. Where I grew up, there are chemical plants all over the place, but they are in the poor areas. Not up in the mountains near the people who have money. People with more money, the CEOs of the plants, they don't really care about "uneducated" poor folks who haven't been given a lot of opportunity. The people in charge see us as a nuisance.

While Rebecca's concerns about social justice are related to her work as an educator and her reading, Leonda's concerns about social and environmental justice are the result of their first-hand experience as the victim of a chemical spill in a highly industrial poor region of the U.S.

Penny contracts her own priorities with those of other sustainability-oriented people she knows.

Penny: A lot of people who buy organic food, it's because they're trying to avoid pesticides for themselves or their children. They're not trying to think about the impact that's having on water pollution or air pollution or anyone else's health that's working on or living near those conventional fields. Personal care products, maybe they're buying them not because those products are less 
impactful for the environment, but more because they believe it's better for them. Or my vegetarian friends are because they care about the individual animals or they think it's healthier for themselves, but it's never about the greenhouse gasses or the pollution or the environment.

While Penny is mostly concerned with the large-scale global impacts of her choices, she sees other sustainability-minded households as being more worried about the impacts on their own household members than the larger community or concerned with individual abstract farm animals rather than entire ecosystems. This same contrast is evident in the way that Jim and Sarah talk about their motivations for buying organic items.

Jim: I feel like a lot of people buy organic cotton because they feel like the pesticides are a problem for their own health, but we are more interested in the environmental impacts of the growing of the cotton. Like water consumption and pesticides. I am more interested in the public effects on the people working on the fields and the environmental effects on non-humans.

Sarah: We try to do everything organic. We've always been big organic buyers, and that's something that I grew up with, too. I don't want to hurt things or do things that are bad for the environment. We found out about some pesticides that were sterilizing the men who were picking fruit. I wasn't as concerned about myself as I was about the workers and the effect on them, and what it means if something like that is going into the ground. It just seems like a really bad thing. That's messed up.

Penny, Jim, and Sarah see themselves as different from the people they know who are interested in sustainability because personal health is not their primary motivation for these practices and concerns.

For Kyle and Kelly, the arrangement of nuclear families into homes drives a pattern of consumption that they see as absurd and unsustainable. 
Kyle: The intentional community and commune culture is appealing to mebenign tribalism where people get to have community and join forces economically, personally, and culturally. Everyone doesn't need to have their own washing machine that goes unused $95 \%$ of the time, or your own car, or your own house! People living in their own houses is just absurd. The consumer culture driven by the need to sell stuff for ever higher profits creates these absurdities. And you need to be intentional if you want to do something different.

The community-focus of their sustainability practices extends to their decision to turn their own home into an intentional community that houses a group of people who would conventionally live in three separate dwellings. They see living in community as a solution to both environmental and social problems.

\section{$\underline{4.4 \text { Household Resources }}$}

Households draw upon a variety of resources to get things done, but these resources can be simplified to three overlapping categories: money, time, and know-how. Money is used to buy items the household uses or transforms, pay for assistance, and pay for education and training. Money is obtained through government assistance, trading adult's time for wages or self-employment income, and directly (cash) or indirectly (gifts) from extended family members. Time is used to transform purchased inputs into usable commodities, to locate free or cheaper items, to obtain money through waged work, and to obtain know-how. Time can come from household adults or extended family and friends. Know-how (competence in theories of social practice or human capital in the neoclassical model) is the skills that allow household members to produce usable commodities in the home, to trade their time for a higher-than-subsistence wage, and to 
find and understand information about sustainability practices. Obtaining know-how requires time, and in some cases money. This section will discuss these household resources in the forms of waged work, resources from extended family and friends, government assistance, know-how and research, free and gleaned items, and unwaged work.

\subsubsection{Resources from Waged Work}

Every household I spoke with had at least one adult who engaged in waged work or selfemployment for money, and both adults worked for money in nearly all of the households with two adults. Heather decided on a career as a nurse because she knew the schedule would be compatible with her desire be available for her children during the day, and Emily's hours worked as a consultant have been flexible and allow her to adjust her schedule to accommodate childcare obligations during her children's different life stages. Scott's work flexibility allows him to be home when Sarah travels for work, and Jim spent time at home while Jess worked when their child was a baby, but overall women were more likely to have flexible jobs for childcare purposes or to not work outside the home. Penny worked part time while her children were young and she was married. Since her recent divorce, she would like to work more, but her employer so far hasn't been willing to increase her hours. On the other hand, Orla has been working between 50-60 hours fairly consistently, a schedule that she finds challenging. 
While Emily, Gloria's husband, and Sarah telecommute, most of my informants do travel to jobs with worksites outside the home, which takes additional time. Quinn's bus commute is close to an hour and a half each way, though she will also take her bike home when the weather is nice out. Jess used to commute by car to a job around 90 minutes away, but is happier now that she can ride her bike to work in downtown Portland, just a few miles away. Informants told me that they appreciate having jobs that allow them to bike commute or take public transportation, with on-site showers making the bike commute more feasible during summer months. The lack of employer-provided parking downtown also contributes to the decision to get to work by bus or bike, as does the fact that rush hour traffic often means that taking a car to work will take longer. For other informants, a lack of time contributes to their need to drive to work.

Many of the informants in this study have jobs at least tangentially related to their sustainability interests. There are several possible explanations for this. First, people who have a strong interest in sustainability may feel that it is important for their choice of paid employment to also be an expression of these values. Second, Portland is a city with a large number of these kinds of "green" jobs. Third, consistent with Chiswick (1999) and Chiswick \& Chiswick (2000), there may be feedback loops between sustainability practices inside the home and sustainability employment outside the home. It may be the case that employment-specific sustainability human capital that one acquires in college, for example in an environmental sciences degree, or on the job, for example as 
an energy efficiency consultant, also makes it easier to engage in sustainability practices in the home, for example by decreasing the amount of work required to find out about recycling sorting or energy efficiency rebates. The reverse may also be true. The domestic-specific human capital acquired on-the-job as a sustainability-oriented parent may also have some usefulness for certain paid jobs, influencing Fiona's career as a preschool teacher and Heather's work as a doula. Kelly began working as a midwife prior to becoming a parent, and struggles with this career choice. She has been pondering switching another career that is more consistent with her overall values of service, community, and social justice, because she is concerned her current work doesn't meet an "unmet need" in Portland. There were very few people I spoke with who had completely conventional corporate careers - having a job that is consistent with their values is important to my informants.

\subsubsection{Resources from Extended Family and Friends}

Two of the households I spoke with had grandparents who were living in the household at least part of the time to provide extra help getting things done. Amy's father has been living in their home part of the time to help Amy and Andrew cope with their busy jobs.

Andrew: Amy's father has been living with us a bit, sort of on and off to help with kids as we're juggling our schedules.

Kelly's mother moved in to her home to help her and Kyle with childcare, and Kelly's mother now also runs a preschool business out of the home. Prior to having their second child, Mike and Mina relocated to Portland from another state to be closer to Mina's 
parents and extended family. Eric and Emily relocated to be closer to Eric's parents hoping to get additional support and assistance with their children, but returned to Portland when they weren't getting the type of help they had wanted. Grandparents also help by buying things for the household, even if they aren't present living in the household, as Amy and Andrew, Fiona, Eric and Emily reported. This kind of help can sometimes be a problem for sustainability-oriented families when grandparents have different priorities and don't understand what is wanted for needed and why.

Other friends, neighbors, and community members also provide help. Sometimes this help is paid, such as the neighbor that Eric and Emily pay to watch their son on days he is not in daycare. Sometimes this help is based on reciprocity, like carpooling, the childcare agreements in a cohousing community, or shared food and meals in an intentional community. Victor and Vanessa take advantage of carpooling to get their children to out of town soccer games. They also rely on their neighbors in their cohousing community to keep an eye on their children when they leave them alone. Kyle and Kelly share childcare tasks and meals with the other family living in their home in intentional community. Gloria does not have close connections with her biological family, but enjoys the reciprocity of sharing resources in her community.

Gloria: Receiving help and offering help are vital for us.

Other informants de-emphasized the importance of help in their lives, priding themselves on self-reliance and independence as expressions of their sustainability values. 
Dayna: I'd say self-sufficiency or self-reliance is something that is a theme for a lot of the decisions that we make.

Dayna: Gardening ties back to an aspect of self-sufficiency for me. And I just like it? It brings me a lot of satisfaction. I get a similar sense of satisfaction from growing my own electricity as growing my own food. I can! It is something that is achievable and is something that I can do. And it makes me feel good.

However, there were ironies involved. For example, David and Dayna purchased a dilapidated home, which they renovated extensively with the help of Dayna's father, a retired general contractor, who supplied the tools and four months of his free labor. They would not have been able to afford to buy an inhabitable home, and buying a house that was "condemned" and fixing it up made home ownership possible.

\subsubsection{Resources from Government and Non-Profits}

Households also employ resources from government programs and non-profit organizations, though the redistributive nature of these programs was not highlighted by informants who benefited from these programs. Leonda told me about receiving Temporary Assistance for Needy Families (TANF), food benefits, and Special Supplemental Nutrition for Women, Infants, and Children (WIC).

Leonda: It's a generational kind of thing. My grandmother had benefits, and then my mom had it, and then when I got pregnant my grandmother told me I needed to go get benefits.

She also visits food banks to get extra food for her family. It is likely that, based on their incomes, more of my informants receive food benefits, Medicaid, and other government transfer payments, but they did not discuss these programs with me. Fiona told me about 
participating in a low income program that gave her a free set of cloth diapers on a rental basis. When she received her tax refund, presumably including state and federal Earned Income Tax Credits, she returned the rental diapers and purchased her own set of cloth diapers.

Other redistributive programs accessed by my informants are not targeted towards lowincome households, and may in fact transfer wealth from low-income households to moderate and high-income households. Eric and Emily and Owen and Orla had made energy efficiency improvements to their homes that were subsidized, paid for out of the public purpose charge for all Oregon utility ratepayers with additional tax deductions in some cases. In addition to other subsidized energy efficiency improvements, Chris and Carrie, David and Dayna, and Kyle and Kelly have solar panels on their homes. While Chris and Carrie seemed ambivalent about their solar panels and Kyle was vocally skeptical of them, Dayna was an enthusiastic advocate for residential solar power. The current net metering tariff in Oregon is designed such that Dayna's family pays only a monthly connection fee. Dayna's household generates more electricity than it uses in a given year, and the utility is required to credit the household for their excess generation at the retail rate. This means at night and during the peak electricity demand hours when their solar panels are not generating electricity, Dayna's household cashes in their electricity credits. In addition to the subsidy to their monthly bills, the households with solar panels also received a combination of subsidies for the installation of the panels, including subsidies 
paid for by the public purpose charge and state and federal tax credits. David and Dayna report that their savings in electricity costs over the past eight years have more than made up for their up-front costs of buying and installing their solar system. Ironically, these solar panels represent independence, self-sufficiency, and a lack of reliance on the electric utility for David and Dayna.

Dayna: I like that I feel that we are self-sufficient. The self-sufficiency aspect. The same way that it makes me feel good to be able to grow a portion of our own food. To be able to be generating our own electricity, that makes me feel really good. It's just damn satisfying, too. Our system produces $100 \%$ of our electricity on an annual basis. And it is so satisfying every March to get our net excess generation letter from PGE where they're like "you had excess generation credit because your system produced more electricity than you used in a year."

David: And as long as our solar electric system is on the roof, that will always be the case unless something happens to net metering. That's pretty great because we pre-purchased our electricity for the foreseeable future and we never have to worry about that expense ever again. And the upfront investment I think is essentially paid off now.

Kirstin: So, you think it's paid for itself through the lower electricity costs?

Dayna: Yeah, the combination of the incentives and tax credits that we got. Those rolled in within the first four years of the system.

Of course, our conversation took place after dark, and their home was lightedpresumably with electricity from the grid.

Brian, Victor and Vanessa, and Yvonne send their children to sustainability-oriented public schools. Victor and Vanessa like the fact that their children's school reflects the values and priorities of their family with school policies like requiring children not be allowed any "screen time" during the week at home. Heather and Gloria, on the other 
hand, homeschool their children because they believe that public schools don't adequately reflect the values and priorities of their families. Brian acknowledges that these special schools are somewhat controversial, as not everyone has the money needed to afford to buy or rent property near the school his child attends, but he is happy that his child is receiving a high-quality free education. The remainder of the households I spoke with were sending their school-aged children to their neighborhood public school. Other than daycares and preschools, none of the households I spoke with were sending their children to private schools.

Public transportation and cycling infrastructure like bike lanes and off-street bike paths provided by the city are another way my informants' sustainability practices benefit from government-provided resources. While not ubiquitous, biking and taking public transportation was the most common way the informants I spoke with got to their jobs.

Fiona: The bus is so easy and quick here. In Corvallis, it doesn't run past $6 \mathrm{pm}$ or on Sunday which is absurd! So, bigger towns and bigger cities, the transit system really makes a huge impact.

Andrew: being in a place like Portland where infrastructure exists and culture exists where these things are encouraged and made easier... not everything is easy, but, you know where it is easier to do things... That for me is key.

The availability of these government resources reduces the costs of car-free commutes and makes it easier to get around in a way that is consistent with my informant's priorities. 


\subsubsection{Resources from Research}

My informants told me that they feel fortunate to be able to do research into sustainability practices, to understand this research, and to have the types of educations that allow them to access these types of information. Research allows my respondents to become more efficient at their sustainability practices, to learn new ways of doing things that are consistent with their priorities, and find out information about the potential impacts of their practices. A more detailed discussion of household research, the factors that motivate this research, and the social meanings of this research, as well as its limitations, appears in Chapter 6.

\subsubsection{Resources from Gleaning: Borrowed and Free Items, Theft}

While many of my informants try to reduce their overall waste by giving away unwanted items for free to friends or through online groups, other informants actively engage in provisioning for their families through "gleaning" - a reference to the 2000 French documentary film Les Glaneurs et la Glaneuse meaning obtaining items for free that other people no longer want. Vanessa says she "can't resist a good free box", meaning items left on the sidewalk for people to pick through and take what they want. Similarly, lan says he probably takes things home that he finds in sidewalk free boxes more than would be ideal, and his wife agrees.

Ian: I don't really like buying new things. I do a good amount of free boxing. Probably more than I should, I'll pick something up.

Ivy: Oh great, more shit! Look at our house! It is insane in here! 
When her household relocated to Oregon, Leonda was able to get most of their furniture for free from coworkers and online free groups. Orla points out that obtaining things her household needs for free takes additional time that a working family with children can't always devote to this type of "scavenging".

Orla: Since becoming a parent, I do much less scavenging for free stuff. You have to search and you have to have the flexibility to go and get stuff right when you see it. I would like to do more of that.

She believes her friends without children are much more successful at gleaning than she is able to be, and she looks forward to getting back to doing more gleaning when she has more time. Gloria told me that her husband is much more willing to spend time getting they need second hand or for free-Gloria is much more likely to prefer the less timeconsuming route, while her husband has a high tolerance for spending time hunting for the things they need for cheap or free.

Gleaning and free boxes were not the only ways that my informants got things without paying for them-Leonda told me about stealing health food items from grocery stores.

Leonda: I don't put my produce in plastic bags except for apples. And I'm not going to tell you why because its illegal! *laughing* I put a different number in at the self-checkout because the Gala apples are always on sale, so I put the more expensive organic apples in the bag, and tie it up and call it Galas. I do it with dried mangoes, too. I call that bananas.

Her friends who have worked in grocery stores taught her how to use the wrong bulk bin codes at the self-checkout. She does this because she feels that can't afford to buy the items she wants on her budget, even with food stamps. 


\subsubsection{Resources from Unwaged Work}

Only three of the adults in this study do not work for money outside the home-Gloria, Mina, and Vanessa. These informants and their households see their unpaid work as a direct substitute for paid work and the goods and services that they would need to pay for if these women were working outside the home.

Mina: I'm a stay at home mom and my time is my value to the household.

Victor: There are some major savings associated with having Vanessa stay home: child care, less convenience meals out, fewer vehicle expenses, less income taxes. And there is almost just as large a number of small savings which one has to be plugged into the "alt-mom" community to know about. Being able to put time and effort into tracking sales, pacing purchases, and planning where and when you shop to get the best discounts can make for huge savings. I don't keep close track anymore, but our grocery spend for a family of 5 is about $\$ 1000-$ $1200 /$ month. 15 years ago, when it was just be and Vanessa, we probably spent $\$ 800-900$ a month. The difference then is that we both worked full-time. If Vanessa went back to working full-time, I bet our grocery bill would go up 50\%. There's also a lot less self-medicating with junk food, "nights out," and fancy vacations when one's not stressed from being over-scheduled all the time.

But this is not to say they aren't working outside the home, they just aren't being paid for this work. Both Mina and Vanessa engage in considerable unpaid work outside the home in their children's schools, and Vanessa does the laundry at her church on a volunteer basis. Gloria prides herself on giving back to her community, and her connections to community are her primary motivation for her sustainability practices. She also homeschools her four children, a decision she made in order to remove her children from what she believes is a disrespectful culture that is excessively focused on consumerism. 
Yvonne works around 15 hours a week for her husband's landscaping business, but she sees herself as a stay-at-home mother and views her work on their urban homestead as contributing to the household in a way that substitutes for paid employment.

Yvonne: I used to work full-time. I had two jobs - I was a bartender and worked in a restaurant. We were a double-income family like most families probably are. When I was seven months pregnant with my third child, we decided as a family that the trade-off for me not working would be me doing all of the homesteading-type things. If both parents are working full-time, it is just too hard to do the amount of work that is required for homesteading, to be that sustainable. We decided that if we want this to be our lifestyle, then I need to be here full-time. This is my job-to make up for my lack of income through all of the other ways I help us save money.

While Heather works more than full time between her waged job and self-employment ventures, her overnight weekend work as a nurse enables her to act as a stay-at-home mother and homeschool her three children during the week. Having been raised by an unreliable single mother, being present for her own children and involved in their lives is an important priority for Heather.

Of course, unpaid work in households is not limited to women who are stay-at-home mothers or whose schedules allow them to act as stay-at-home mothers. Informants whose households have two adults who work full-time on conventional schedules also get things done using their time and effort, and an interest in sustainability often means additional tasks or more time-consuming ones. Tasks like health care, child care, food preparation, home repairs, transportation, shopping cleaning-most of the tasks in dayto-day life-are chores that my informants could pay someone else to do or that the 
government could provide on a collective basis, but that they frequently choose to do themselves instead.

Many informants valorized the idea of doing things themselves, particularly in the realms of intensive food preparation and home improvements. Home-cooked meals from scratch were particularly important to many informants. During our conversation, Kelly shared some delicious homemade seaweed crackers with me-because of her flexible work schedule, she winds up doing more than half of the food preparation in their immediate family, though the other adults living in their homes also share the burden. Chris says that most of the food his family eats is cooked from scratch except crackers and English muffins, though he bakes all of the family's bread and makes elaborate meals. A combination of personal interest, ability, and work schedules drives Leonda, Jim, Owen, Nathan, Rebecca, and Tim to be the primary evening meal cooks in their households, and the remaining households with two working adults told me that this chore is shared about evenly.

Home improvement tasks were largely a male enterprise. Heather and Gloria's husbands built their chicken coops, and Heather describes a division of labor in their home in which her husband, who is a professional carpenter, is responsible for things on the "outside" of the home, while Heather, a nurse, is responsible for tasks on the "inside" of the home.

Heather: He does most of the work with the chickens. He built the chicken coop, he does most of the cleaning of it. He puts them out and lets them in every day. 
Outside is him. But inside the house, it's flip-flopped. When it comes to caring for the kids, making the medical decisions, making the nutritional decisions.

Andrew and Amy recently moved into their old home, and Andrew has been spending time on repairs and renovations. Kyle and David and Dayna point to the "sweat equity" that they invested in their homes, the extensive renovations of which would not have been possible without the unpaid work done by themselves and others.

Informants who were not able to engage in some of these more intensive practices, relying instead on purchased inputs, frequently expressed feelings of guilt or inadequacy. While Fiona does cook nightly meals for herself and her children, she wishes she were doing more intensive scratch cooking from dry ingredients and whole foods rather than relying on what she sees as convenience items like canned beans. David and Dayna and Quinn's families eat a lot of frozen convenience foods, which save time.

Quinn: If I had more time, I would eat less packaged food and less convenience food.

Fiona: With working and coming home so late on the bus, it is less frequent that I make meals that are just bulk grains and beans and things like that. So that's still kind of a goal, but it doesn't happen as much.

Informants frequently told me that they would do more intensive cooking if they had more time to engage in this work.

Heather, Gloria, Ivy, and Mina all spoke longingly of the idea of homesteading, or selfsufficient subsistence home farming and provisioning involving large expenditures of 
unwaged time and few purchased inputs. They see this living arrangement of intensive home production as a perfect embodiment of sustainable living.

IVy: When I think about homesteading, I feel like my whole body would thank me and my spirit would calm. I feel like I would be a healthier, happier person because I wouldn't be like rushing around, going to work, doing this, you know? There is just something so calming and healthy about the homesteading life. You have a lot of work to do, but it is all great for your body and you're doing it for the people around you.

Homesteading is thought of favorably by many - but not all - of my informants. Rebecca and Kyle weren't interested in homesteading as a sustainability practice, Rebecca because she didn't feel that she would enjoy the homesteading lifestyle and Kyle because he is skeptical that it is a more environmental choice.

Rebecca: My brother and sister-in-law have two kids, and they grow all of their own food, they reuse a lot of things, they make their own yogurt, they do a lot of sewing, and his business is around using salvaged wood. They do it very cheaply because they have a stay-at-home parent and more of a homestead thing. They are substituting time for money.

Similarly, Jim would prefer to live in a homesteading-style living situation in a rural area, but he believes this is a less environmental option than living in an urban area. However, for many of the sustainability-oriented households I spoke with, it seems that the ideal would be to rely to the greatest extent possible on unwaged work in the home and as little as possible on purchased inputs and government resources.

\subsection{Household Constraints}

The resources available to households to get things done in day-to-day life are not present in infinite quantities. In particular, households describe making decisions on a 
foundation of limited time and limited money, with time constraints by far the most common concern of my informants. Households are also constrained by social and cultural norms, particularly around cleanliness. Finally, information about sustainability and sustainability practices can be difficult to find, and in some cases accurate information is not available at all.

These constraints may be related to larger economic and social structures, they may be related to cultural and social conventions, or they may be related to path-dependent factors in the lives of individuals - though these sources are recursively related. There is nothing that forces my informants to work long hours at their paid jobs, limiting the time they have available for other activities. However, they may feel very much compelled to work these hours for a variety of reasons - a desire to provide a certain level of consumption to their families that is achieved in this society through paid work, a feeling of investment in the mission of their employer, or because these hours have become the convention for full-time workers. On the other side of this coin, budgets may be limited because no full-time work is available. There is nothing that requires children be raised by their parents in households, but this is the convention in the culture and society in which we live, and this type of time-intensive childcare provided by family members limits the time available to adults for other activities. There is nothing that forces anyone to take a particular job (whether paid or unpaid), but the path towards this occupation likely began 
decades prior, limited by initial conditions and with potential options narrowing with each passing year.

Robbins ([1932] 2007, 15) writes that "the economist studies the disposal of scarce means." However, a full understanding of social conditions requires also understanding the underlying sources of scarcity and constraints. Prior to Robbins' popularization of the scarcity definition of economics, the common description of economics was as "a study of the causes of material welfare" (4). Robbins is of course correct in pointing out that "There are only twenty-four hours in the day. We have to choose between the different uses to which they may be put" (14). But constraints, both external and ones that may appear to be self-imposed, place real limits on my informant's choices. The range of options is restricted before the choosing can begin.

\subsubsection{Time constraints}

A concern about lack of time was expressed in almost every conversation with informants for this study. Families find it difficult to cope with the burdens of their paid jobs, the unpaid work of day-to-day life as a parent, and the frequently time-consuming sustainability practices they've undertaken. Even stay-at-home mothers felt pressed for time as they juggled the many obligations of an intensive and professionalized mothering métier. An editorial from over sixty years ago rings true today: "When millions of workers are expressing the same gripe about their job..., it is no longer a gripe, it becomes a social 
problem. That gripe or grievance no longer affects just this or that individual, it affects all of society" ("Gripes and Grievances" 1955, 4). My informants told me that they often feel exhausted and depleted. They make trade-offs in order to cope with life's demands, but they are not happy about having to make these compromises. There is simply not enough time in the day to get everything done.

Several informants told me in general terms that they didn't have enough time, linking this reality to the demands of work and parenting young children.

Emily: I think Eric would agree with the assessment that the thing we are most short on is free time.

Andrew: I feel like for me it's a balancing act. You know, I have all of these things that I'm dealing with on a daily basis, with kids, and job, and whatever, right? I have really limited bandwidth at this point in my life I feel like time is becoming more and more valuable, because I feel like I don't have enough of it, right?

Emily and Andrew's households both attempted to alleviate the time-intensive parenting burdens by relying on help from grandparents, with mixed success.

After long days of work, my informants were exhausted and find that they lack the time and energy to get day-to-day tasks done, like buying groceries and basic meal preparation.

Sarah: We order the groceries online for delivery from a local store pretty regularly. We are just so tired, and then if one of us goes out to get the groceries, then the other is stuck here with the kids. 
Quinn: We eat a lot of processed foods, a lot of microwaved foods. A lot of Amy's [brand frozen meals]. We're working and then getting home, and we're just tired.

Sarah and Quinn wind up substituting market goods and services-delivery service and frozen convenience foods - for more time-intensive ways of getting shopping and meal preparation done.

Other informants told me that they often lack time for time-intensive sustainability practices, so they wind up relying on what they view as less sustainable or less healthy ways of getting things done.

Leonda: I am lazy, that's my only real reason for not making my own laundry detergent and dish soap. I could totally make that stuff, but it is very time consuming and seems like a daunting task when I already have so much else to do.

Orla: If we had more time, we wouldn't have to buy so much packaged snack food for the kids. We go through a lot of apple sauce pouches. We recycle them, but it would be nice to not buy them in the first place. I don't have time to refill reusable pouches, and I don't want to do the dishes associated.

Amy: If I had more time, I would want to make the kids' snacks and stuff more versus just buying the packaged stuff. But that's something that I don't have time for, so it doesn't happen.

Chris: No, but the other piece of it [biking commuting less frequently] was just the time biking back home was starting to feel like more of a crunch. And my job just got more stressful over a little while during that time. And I was needing to stay later, so just the sheer time was an impediment.

Time-intensive sustainability practices get put on the back burner when other stresses of day-to-day life take a priority, but my informants rarely feel good about these compromises. 


\subsubsection{Budget Constraints}

None of my informants emphasized feeling financially constrained, including those of my informants who reported the lowest incomes. Perhaps financial resources are in many cases the flip side of time constraints, though this is not always the case. The low income households I spoke with also reported feeling significantly pressed for time. Even Penny, a single mother who works part time and has two school-aged children who live with her half of the time, felt far more constrained by her schedule than by her budget. To some extent, an interest in the sustainability realm means that these households are generally aware of and engaging in sustainability practices that also save money, for example: turning down the heat and not using much space cooling, cloth diapering, reducing their over-all consumption, vegetable gardening and putting food by, owning fewer vehicles, and obtaining needed items for free or second-hand.

My informants did share with me some ways that they maintain their sustainability practices on their budgets. Emily, Mina, and Vanessa make over four grocery store trips per week to a variety of stores to buy the items their households need at the specific stores where these items are the cheapest. Households rarely told me that they buy all food items organic, instead prioritizing the "Dirty Dozen" list of products that have the highest amount of pesticide and other chemical residues. Jim and Wendy told me about 
being unhappy with occasionally buying children's clothes at Target rather than second hand or boutique organic items that would be unaffordable for a fast-growing toddler.

When I asked my informants if they believed living in a sustainable way was more expensive than a conventional lifestyle, the answer I heard most frequently was some variation of, "Not if you're doing it right."

Gloria: It seems expensive, because maybe the bottle of sustainable shampoo is so much more expensive than a conventional bottle. But you're taking a shorter shower, and you're using towels that you've had for ten years because you don't buy new ones every three years when you also repaint all the walls. Item by item, these things can be far more expensive. But the lifestyle is incredibly economical.

Penny: If you want to grow your own food, that will be the most sustainable and also the cheapest. Or you can buy that food, and it is going to be expensive.

While certain aspects of a sustainability-oriented way of getting things done may be more expensive, like out-of-season organic produce or other specialty items, my informants generally believe that a truly sustainable household wouldn't be buying things like that in the first place. An exception to this was the renters in my sample, Fiona and Tim and Tara, who talked about their incomes preventing them from buying their own homes. They believe home-ownership would allow them to make more drastic sustainability lifestyle choices, such as intensive vegetable gardening, raising home livestock, and installing solar panels. 


\subsubsection{Social and Cultural Constraints}

My informants have made changes to conventional ways of getting things done, but they often remain constrained in their ability to make changes because of a desire to life in a way that is compatible with the wider culture and social understandings of the boundaries of acceptable behavior. Penny is an environmental educator, and as a result of her training and career she was one of my most ecologically-aware informants. At the same time, she was very honest and pragmatic about her life and the trade-offs involved in her practices. When I spoke with her, she was wearing the most fashionable athletic zip-up jacket that I'd ever seen, with a jaunty asymmetrical collar.

Penny: If you really wanted to be as sustainable as possible, you would never buy any new clothes or get everything out of free boxes. You could stay dressed for free, but you might not look very stylish. ... In the perfect world, you could not consume anything and be OK with it. But in reality, we live in a society where there are other pressures and we don't have as much time as it would take to live in a way that would be nice to live.

Heather told me about wanting to make sure her children were able to integrate into the mainstream culture, unlike some "wild and free" families she knows who live more extreme rural homesteading lifestyles.

Heather: We have friends who are like constantly naked outside. Which is fine... And I can appreciate why they do that, but I feel like we need some balance to be able to function in our society.

There are limits to how far my informants are willing to go outside the bounds of culturally acceptable behavior for their sustainability practices. 
To some extent, living in a place with a lot of like-minded people means being surrounded by a different cultural mindset than if my informants lived in a more conventional place, or a place with more people who are hostile to environmental concerns. Victor, Vanessa, David, Dayna, Eric, and Brian all expressed a feeling that their reliance on bicycles for transportation is largely enabled by Portland's "bike culture" and acceptance of cycling as a valid way for adults to get to work. The lack of social acceptance of cycling in other regions may limit the abilities of adults in those places to bike commute, both indirectly through raised eyebrows or a lack of awareness of cycling as an option or more directly through a lack of the infrastructures that help enable cycling like workplace showers and bike lanes. However, not everything about a sustainability-oriented local culture is necessarily a good thing. Mina spoke to me in hushed tones when she told me that all of her children are fully vaccinated, and that they received those vaccinations on the conventional schedule. She believes that the other parents at her preschool, where a large proportion of the children are unvaccinated, would judge her harshly for vaccinating her children.

Cultural expectations for comfort and cleanliness also place constraints on the ways that my informants get things done, as will be discussed in more detail in Chapter 5. Many mundane, taken-for-granted, day-to-day things in our lives are the product of culture: what a clean bathroom looks like and how it gets that way, how often a person should shower, what the inside of a home should feel like in hot weather and cold weather, 
what clothing should smell like, where to store eggs. One particular subject stood out as having particular cultural significance for my informants: what a clean bathroom towel should feel like.

Jim: We use the dryer as little as possible. Almost never. Towels and sheets we line dry, and guests complain about them for sure.

Because tumble driers are relatively ubiquitous in American single family homes, most of my informants grew up with towels that were washed in a conventional washing machine and dried in a tumble drier. Chris and Wendy were the exceptions. Wendy grew up in South America with line-dried towels, and loves the feeling of towels fresh off the line. For Wendy, soft towels that were dried in a tumble-drier feel dirty and don't smell right. Chris had unconventional ecologically-oriented parents who line-dried all of their laundry, and when he went to college he learned to love the feeling of soft, tumble-dried laundry.

Chris: Yeah, the dryer I've always loved. It was a total guilty pleasure when I went to college and I didn't have to hang up my clothes anymore! I remember that.

While Heather grew up with tumble-dried towels, she lived for a few years in England as an adult and hated the crunchy line-dried laundry. Other than Wendy and Jim and Jess, towels are an item that must be dried in the tumble drier for my informants who line-dry their clothes.

Penny: When it's warm, I hang out my laundry in the back yard. I don't like when towels are hung out to dry because they aren't soft. So sometimes I will hang them out to dry, and then finish them off in the dryer to fluff them up. 
David: We just sort of started doing it because we were cognizant of the amount of energy a dryer uses. So, when the weather is nice we opt to hang it up.

Dayna: It is better. Everything except for towels. Towels do better in the dryer.

David: That's true. They get so scratchy when they're sun-dried.

Cultural expectations for cleanliness and comfort shape the way my informants get things done, and they have grown accustomed to towels that feel and smell a certain way. While they have made a major intervention into a conventional way of getting things done in the United States by line-drying their laundry, the culture they live in has taught them that towels should be soft and fluffy. Cultural and social norms place limits on how far my informants are willing to go for their sustainability practices.

\subsubsection{Information Constraints}

My informants divert time away from other priorities and day-to-day tasks to research their practices and consumption decisions, but there are limits to the available information. Emily told me that she believes it is harder for people who don't have exposure to sustainability ideas or the type of education she received to understand the research she seeks out for her family. Many informants were discouraged by contradictory information and difficulties finding good information about sustainability practices. Jim and Victor expressed the most frustration with the lack of comprehensive, accurate research on sustainability and personal health. They want to know the best ways to get things done to protect the environment and their families, but find that conclusive evidence and solid, unambiguous advice rarely exists. Victor attempts to solve 
this problem by conducting his own experiments on his family, for example by testing the efficacy of different supplement regimes, but that is not the same as definitive health research. Jim searches for good information to help him make the best environmental choices, but finds it is rarely available.

Jim: I find it frustrating that I can't find information that I trust. A lot of the decisions or non-decisions that we make are because we just don't know what the right thing to do is.

He wishes he could find information about the precise relative carbon impacts of all of his choices, for example whether or not it is a good environmental choice to replace his old car with a more fuel efficient one. Jim becomes upset at the futility of his attempts to make the best environmental choices, a feeling that becomes acute when he believes, in hindsight, that he made the wrong choice because of bad or inaccurate information.

\section{References}

California Department of Water Resources. 1993. California's 1987-92 Drought: A Summary of Six Years of Drought. Accessed 05/29/2017. Available: http://www.water.ca.gov/waterconditions/docs/2_drought-1987-92.pdf Collins, Patricia Hill. 2000. Black Feminist Thought: Knowledge, Consciousness, and the Politics of Empowerment. New York, NY: Routledge. 
Dunlap, Riley E. and Araon M. McCright. 2008. “A widening gap: Republican and Democratic views on climate change." Environment: Science and Policy for Sustainable Development 50(5): 26-35

Foden-Vencil, Kristian. 2015. "Oregon has Highest Vaccine Exemption Rate in US." Oregon Public Broadcasting News. February 4, 2015. Accessed 05/30/2017. Available: http://www.opb.org/news/article/oregon-has-highest-vaccineexemption-rate-in-us/\#FindSchool

Kelly, Daniel. 2011. Yuck! The Nature and Moral Significance of Disgust. Cambridge, MA: The MIT Press.

Robbins, Lionel. 2007. An Essay on the Nature and Significance of Economic Science. Auburn, Alabama: The Mises Institute.

"Gripes and Grievances," Correspondence, 2(2): 4. Cited in Haider, Asad and Salar Mohandesi. 2013. "Workers' Inquiry: A Genealogy." Viewpoint Magazine, September 27, 2013. Available:

https://www.viewpointmag.com/2013/09/27/workers-inquiry-a-genealogy/ 
Chapter 5: How Households Get Things Done

\subsection{Overview}

\section{1 .1 Introduction}

In the last chapter, I described a set of households and the priorities, resources, and constraints that influence how they get things done in day-to-day life. In this chapter, I will describe how these factors combine to produce a set of fundamental human activities in households. In trying to learn about how households get things done, I focused my conversations with informants on their practices with respect to six categories of daily life: waste, comfort, cleanliness, food, transportation, childcare, and general provisioning. I will focus the discussion here on waste, comfort, and cleanliness, since these are aspects of day-to-day life that have not received extensive attention elsewhere. Because of my interest in how practices change or are resistant to change, I asked follow-up questions to help me understand how my informants learned these practices, how they differ from the way they themselves grew up, how things have changed since becoming a parent, and what they would do differently if they had more time or money.

\subsubsection{Different Ways of Getting Things Done-Part Two}

Nathan and Nicole have high wage incomes and work long hours, so they can afford to have a personal assistant who takes care of home maintenance, babysits, and does their 
recycling and can return for them. They also have a housekeeper who cleans their home and helps with laundry. Since technology and avoiding waste are their sustainability priorities, they have spent a lot of money on a geothermal heat pump system and insulating their home. Eric and Emily are both white collar professionals, and they stretched their household budget to afford a home in a neighborhood that will allow their children to walk to school from elementary school through high school. Eric bikes to work, and Emily telecommutes. Because personal health is a household priority, Emily goes to various grocery stores by car at least four times a week so that she can purchase their family health food staples at the best possible prices. Penny is a single mother of two who works part-time as an environmental educator but wishes she could work fulltime. Recently, her furnace broke and she figured out how to repair it herself by watching instructional videos online. She makes special reusable toilet paper for her family out of old flannel sheets. Because she is most concerned about the impacts of her consumption choices on other people and the natural environment, she decided to commit to buying nothing other than food and fuel for the first six months of this year.

\subsubsection{Producing Day-to-day Life, Sustainably}

The precise ways that these sustainability-oriented households take care of their day-today tasks varies based on their individual combination of priorities, resources, and constraints. The households I spoke with differ in their sustainability priorities, and these differences in emphasis impact what areas of day-to-day life my informants have made changes to, and how they go about those changes. They also vary in terms of the amount 
of money they earn through paid employment, their access to help from friends and family, their knowledge from research or schooling, the resources they receive from the government and non-profits, and how much time they have available for household tasks. Finally, these households diverge in the extent to which they are constrained by time, budgets, social and cultural concerns, and a lack of information. In this chapter, I will describe how these differences in inputs contribute to diverse outcomes in the ways that my informants remove waste from their households, achieve cleanliness, and stay comfortable indoors. As part of this account, I will consider the changing social and cultural meanings of waste, cleanliness, and comfort for these households.

\subsection{Household Waste}

Household waste includes trash and "packaging," compost, recycling, diapers, and toilet waste. The eco-conscious households I spoke with were almost universally concerned with reducing their consumption, and for many, the waste generated by their lifestyles and practices serves as an uncomfortable reminder of their shortcomings in the sustainability realm. For some households, practices that prevented waste from going to a landfill, such as composting and recycling, are sufficient to alleviate the guilt associated with waste-generating consumption. Other households attempt to purchase items with as little packaging as possible because recycling and composting are not enough for them

to feel absolved. Waste is visible, tangible evidence of things you consumed. Once every week or two, your neighbors can see all of your trash awaiting removal right in front of 
your home. It smells, it is unsightly, it attracts vermin, and it triggers disgust through our instinctive drive to avoid risks of contamination, parasites, and disease (Kelly 2011, 1-58). In this sample of households, the topic of packaging - things like plastic films and cardboard boxes-elicited powerful and unexpected reactions from my informants, while practices that involve allowing organic matter to decompose in the backyard or leaving urine in a toilet bowl unflushed elicited few negative reactions. Weinbaum \& Bridges (1976) point out that the work involved in consumption is the "other side of the paycheck." For these eco-conscious households, practices involving the disposal of household waste are the other side of the other side of the paycheck-the final phase of the consumption they wish they could avoid.

\subsubsection{Trash and "Packaging"}

Informants think about trash in ways that are linked to the anti-littering public service announcement campaigns and images of swelling landfills of their childhoods (Shabecoff 1987, Cialdini 2001).

lan: I remember in junior high them telling us not to trash the environment. And they had someone come to school in a costume dressed as a trash heap to teach us about the environment.

Owen: Growing up in the Midwest in the 1970s, people didn't talk about recycling or the environment. Our consideration of the environment was the TV commercial with a Native American guy crying because a white guy threw a beer can out the window. "Don't Litter" was it. There just wasn't a movement going on where I lived.

Tim: When I was a kid, the crying Indian ad was really big. And I remember there was a joke at the end of a Steve Martin record, where he says, "You know, it's 
really important if you can keep a litter bag in your car. It doesn't take up too much space. And when it's full you can throw the whole littler bag out the window." That's how he ended his whole set! That is so of that moment. That was the whole point of the crying Indian ad. Have a litter bag in your car instead of throwing it out the window.

Eric: For whatever reason, whenever I think of sustainability, or when I first realized that I had some kind of impact, was cutting the six-pack rings. Seeing a picture of one around a bird's neck, and realizing that I should cut all of those up. That was something that someone suggested to me, and so I was adamant that we should do that. And I would cut them into the smallest pieces in the world.

Trash is an evocative symbol of human impacts on the natural environment. The image of an Italian-American dressed up as a Native American shedding a tear over litter and pollution (Aleiss 1999) stuck in the minds of my informants, even if they cite the Keep America Beautiful public service announcement campaign with an eye roll. During the 1970s and 1980s, concerns about landfills and the negative impacts of litter formed the basis of much of popular environmental concern, and these images and campaigns are my informants' earliest memories of pro-environmental practices.

In 2011, the city of Portland switched from weekly to every-other-week trash pickup with weekly recycling pickup, justifying this change by allowing residents to begin putting food scraps into the yard waste bins (Sarasohn 2011). While this took some getting used to for some households, the response among my informants was positive.

Amy: I think a good aspect of Portland is that there are a lot of monetary incentives for being more environmentally conscious, which I think will help motivate people who may not be leaning towards it just for the sake of doing it. But just making it easier with the trash situation, making it more expensive to have more trash pickup or bigger cans. In [Texas] you have this HUGE trash can 
that gets picked up every week, you get a tiny recycling box that picks up every other week, and there's no composting. We are finally living someplace that was more in-line with what we wanted, which was the big recycling can and the small trash can.

Andrew: The thing that was so beautiful about it was how symmetric it is. You know, it was literally the exact opposite. In terms of which size different cans are and the frequency of pick up.

Brian: I'm kind of a passive supporter or the way that the city has pushed down trash in relation to recycling. So, making it less frequent pickup, making it smaller containers, trying to push more into the recycling stream... And I've got past the point where every other week trash collection was an issue, and if I forget on a particular week [to take out the trash] it's not a problem. So, my overall level of trash has just continued to decline

They like that the city is encouraging people to recycle and compost through these kinds of "incentives" and policies that make sending things to the landfill more expensive or difficult. This policy change reflected my informants' belief that the city makes decisions about how to get things done-at least some of the time-that are consistent with the values and priorities of my informants.

When I asked informants about trash in general, only Gloria expressed strong emotions.

Gloria: Throwing stuff away really affects me. I don't like throwing stuff away. It makes me feel ungracious and greedy and truly guilty. Spoiled! Because I know where it's going. It's never actually going away.

For most of my informants, some quantity of soiled, contaminated, or no longer useful items are a fact of life. However, informants in nearly every household I spoke with brought up the topic of "packaging" without being asked, and I was surprised by the intensity of their negative reaction to packaging. What they mean by packaging is the things - whether recyclable or not - that surround the products they buy to protect them 
for transportation and distribution. This includes materials like cardboard boxes that

online purchases come in, plastic films, plastic bags, and rigid plastic clamshell containers.

Avoiding packaging in items they buy is something that many of the households I spoke

with put active effort into.

Brian: I do pretty actively make choices on purchases based on low levels of packaging, low levels of creating a lot of that waste.

Chris: I'm always buying bulk and trying to avoid buying stuff that's in clamshells or things like that. And then for other items, like if you're getting sandwich bread we will save the bags and re-use them for other stuff. We use a lot of yogurt containers and things like that for food storage later.

Scott: We've been doing Blue Apron for a few months, but I think we are going to stop that because of all the packaging. The food service is a real benefit because it helps us avoid wasting food. I think we're going to switch to Sun Basket, which is a similar service, but with purely recyclable and compostable packaging. The freezer packs are just water and cotton.

Eric: I think we got Blue Apron [recipe and meal delivery service] for a month or two. It was just way too much packaging. They tout that it is pre-portioned to avoid waste, and everything's recyclable, and it's not. Like, no. After like a month or two of that, I was disgusted with it. It is so wasteful. Our situation is not unique. A lot of people are in this situation in terms of how the limited time, and us trying to survive, and sustainability intersect. That's one of the ways it did. We make a decision in terms of sustainability when we decided to cancel Blue Apron.

Eric is a person whose wife describes him as "super laid-back and chill." He has a pleasant, friendly, and go-with-the-flow demeanor, but I could hear genuine anger and frustration in his voice every time he brought up packaging. He was able to eliminate this one source of packaging from his household, but it is hard to avoid packaging when buying both food and other consumer goods, particularly as a parent. 
Amy: It's hard to spend the extra time and money on making sure you consume less plastic. Everything is in a plastic thing, and then it's in a box, and then it's...

Carrie: Toys always have so much packaging and weird plastic parts, and it is harder to come buy stuff like that without a lot of packaging.

Tim: They are feeding kids this constant drip of snacks. Morning snack, afternoon snack, "Where's my snack?" I'm bummed that it's a bunch of gummies most of the time, and its wrapper is its own negative impact on the ecosystem. Oil, plastic lining, and a bunch of ink. It's just silly.

Several informants told me that one of the biggest changes in their habits since becoming a parent is purchasing large quantities of packaged snacks for their children. They feel bad about the packaging associated with feeding their children this way, but for many households, the alternative -making all snack food items for their children from scratch or portioning out foods from a larger container into smaller reusable containers - takes too much time.

Out of all of Fiona's actions that she can think of that could be harmful for the environment, she believes that the packaging surrounding the food she buys has the biggest adverse effect.

Fiona: I feel that our biggest negative environmental impact is food packaging, for sure.

Similarly, Rob told me point-blank that he does not like packaging, and Eric says that plastic packaging is the thing that bothers him the most.

Rob: I do not like packaging waste and things of that nature.

Eric: Plastic is probably the thing that gets under my skin more than anything else. Whenever I go to the grocery store, I never put any of the produce in 
plastic. I just put it in the cart and put it on the belt. I can tell some people are really put off by that.

Packaging is reviled. It is a necessary evil, a cost associated with provisioning that protects purchases from damage and spoilage as they travel to their final destination. Chris and Fiona try to re-use elements of packaging for storage, but in general packaging serves no useful purpose once items arrive. Packaging feels unnecessary and excessive, and it accumulates quickly in a busy household. Packaging is a reminder to my informants of the futility of many of their sustainability practices, a symbol of their lack of control, their participation in consumer culture, and their collusion with the economic institutions they oppose. The strong negative responses to packaging are perhaps a displacement of a reality far too upsetting to acknowledge-that the most sustainable option would be not existing at all.

\subsubsection{Recycling}

When I asked Yvonne, an urban homesteader who buys close to nothing new and runs a permaculture business with her husband, about the most important thing proenvironmental thing she does, her answer was immediate: recycling. For many of my informants, recycling provokes an emotional reaction opposite to the one elicited by

packaging. People love recycling. The inverse of negative images of litter and landfills and strangulated birds from their childhoods, recycling was associated with powerful memories and positive feelings of making a difference in the world. 
Orla: The environment and environmental causes were big from a young age in school. The whole Reduce, Reuse, Recycle. It is now painful to me to not recycle something.

Both Penny and Quinn had recycling volunteer projects during high school in the early 1990s. Quinn went to a local recycling center to help out on weekends, and Penny and some friends organized paper and aluminum can recycling at their school, which had no recycling program prior to their efforts. Some respondents' families of origin participated in curbside recycling programs growing up, while others have memories of their ecologically-oriented parents driving their recyclable waste to the closest processing center. Nicole remembers spending summers collecting discarded beer cans off the beach and earning pocket money by returning them. Some informants did not grow up recycling, and curbside recycling has only recently become available in the places where they grew up.

Recycling is a universal practice in the households I spoke with. In fact, not recycling was considered socially taboo.

Rebecca: Here, everyone recycles. Not recycling is on the same level as spanking here. If someone told me here that they don't recycle, I'd be like, "What?!? That is antiquated and NOT ok!"

Tara: Everyone recycles in Portland. If someone told me that they don't recycle, it would be shocking. For me, I think what would be hard about that would be knowing the shame associated with not knowing any better. Maybe they haven't had anyone who taught them, and then they are feeling judged. 
Owen compared the practice of recycling in Portland to church-going in his Midwestern hometown. It is just something you do to let everyone in your community know that you're a decent human being.

Owen: I don't want to throw a ton of stuff in a landfill or be wasteful, but there is also a social norm aspect to recycling.

When my informants talked about recycling, they were generally referring to two things - curbside recycling and bottle return. Curbside recycling involves sorting recyclable items into a separate bin for weekly home pickup by a waste disposal service, while bottle return involves taking certain items, like aluminum cans and glass bottles, to a machine at a grocery store for a return of the deposit paid at the time of purchase. Items with a bottle return deposit can be recycled at the curbside, but doing so forfeits the deposit. Only two of my informants talked to me about participating in bottle return. While Mina is in charge of curbside recycling and nearly all of her household's sustainability practices, bottle return is Mike's chore. He views it as a separate activity from recycling, and it is his job to collect aluminum cans and beer bottles and return them to the store for the deposits. Nathan and Nicole have a personal assistant who helps them with various chores for twenty hours a week, and returning cans and bottles is his one of his jobs, though he does not get to keep the money from the deposits.

Everyone I spoke with participates in curbside recycling, though they have different levels of investment in recycling rules. Sorting recycling properly takes time and know-how. 
Many respondents admit that they find it difficult to keep track of which items are recyclable, and that they find the rules occasionally counter-intuitive.

Quinn: It seems like some of the things I'd like to put in the recycling, I've found out that they can't take in the curbside recycling. Plastic strawberry containers are an example of that. You have to take that to a special recycling place.

Kirstin: How do you learn about what can be recycled and not?

Carrie: *laughs*

Chris: It's such a pain in the neck. I feel like it changes a lot. We get the thing [mailer] from Metro annually, and ...

Carrie: There are still certain plastic pieces that I'm never quite sure...

Chris: We used to just keep that thing around, but I feel like we've just....

Carrie: Oh, the guide?

Chris: Yeah, the guide. But I feel like we've just gotten into a routine about what stuff is recyclable or not. But I know that they've increased some things.

Carrie: Yeah, there's certain plastics that I throw out that probably...

Chris: You know, the plastic lids... that can now go on top of the whatever plastic containers...

Carrie: *laughing* I could use more education on the specific plastic items.

Some of the more committed recyclers seek out information and educate themselves on proper recycling, which requires both investing time and knowing where to look to find this information in the first place. Dayna is able to get this information from her workplace, where she learns sustainability skills on the job that that are also helpful when she is at home.

Brian: I learn about what is recyclable from Metro! I actually really pay attention to those things! I hear also the local and national media about how recycling 
works, and I've heard things like the fact that the quality of recycled paper is going down because of mixed stream recycling. So, it really is important for you to keep your food-related crap out of the recycling! So just kind of general news research, and then the local notifications and educational campaigns and that kind of thing. I actively seek out information, but I also actually read the information that's sent to me! *laughing*

Kirstin: How do you find out about recycling sorting?

Dayna: I tell David how it is, and he tries to disagree with the rules! *laughing* about what's recyclable and how to sort? I rely on people that I know who are like Master Recyclers and have taught me what is recyclable and we have some folks in our office who have done a great job of educating, and there is always the guide from the city.

Dayna and David's recycling conflicts will be discussed in more detail in the next chapter. In many households, there is one member of a couple who is more invested in recycling and the rules of recycling than the other. Quinn says that she is more "anal" about recycling, and will take the extra effort to rip plastic pieces off cardboard packaging so the cardboard can be recycled. Nicole sorts through the recycling to correct what she believes to be recycling errors that Nathan has made, and Leonda picks recyclable items out of the trash that their roommate and husband have discarded.

Recyclable items that can't be recycled via the curbside system can still be recycled through non-curbside recycling. Some informants, like Ivy and Eric, take items to New Seasons, a local natural foods store that provides recycling processing of items that aren't accepted through curbside recycling. Penny takes items, including not just packaging but also broken plastic toys, to a local recycling center that takes a larger number of items 
than can be recycled at the curbside. Several other households wish they could practice non-curbside recycling, but they don't feel that they have the time for this extra chore.

Chris: You can take certain things over to Far West Fibers, but then the added effort is usually an impediment.

Rebecca: There is not really time during the weekend between grocery shopping and kids' activities to make a special trip to the recycling center, but down the line I can see that those are things that we would want to do. Right now, we are prioritizing sanity.

Amy: We don't typically take the plastic bags in. Like I know you can do it to grocery stores, but that extra step doesn't seem to happen very easily.

Many of my informants are passionate about recycling. They like the idea of their waste having another life after it is no longer useful to them, and it alleviates their guilt related to consumption.

Emily: I always feel a little guilty when I get something from Amazon or something that is egregiously packaged. We just do our best to recycle the components.

While Yvonne believes that recycling is the most important thing her household does for the environment, Kelly believes that recycling is the most insignificant pro-environmental practices a person can engage in.

Kelly: I think recycling is a rather small drop in the bucket of how we are affecting the environment. I saw a bumper sticker recently that said, "Recycling: It really is the least you can do." And I think, yes, that's true it really is the least we can do. And Portland makes it ridiculously easy.

For several informants, recycling waste is not sufficient for them to feel absolved.

Eric: I think we are pretty good on the post-processing end. But we could definitely take some steps on the pre-end. For example, I took all the film stuff to New Seasons the other night. And as I was going through the process of recycling it, I am thinking to myself, "This is too much." Even though we're 
recycling it in this way. So that's something that's been on my mind as an opportunity as a household to improve.

Orla: We go through a lot of apple sauce pouches. We recycle them, but it would be nice to not buy them in the first place.

Penny: I will take plastic things to the special recycling place, including toys, just all plastic that isn't curbside recycled I take over there. But I did some research and found out that they just ship it to China. So, then it is going on a boat across the world, and maybe not great things are happening with it.

Fiona: If I'm buying something I try to think about if the packaging is something that I can reuse as opposed to just recycle because I know that even recycling takes energy.

These informants realize that there are environmental costs associated with producing and recycling these materials, and the best option would be neither recycling nor sending materials to the landfill. They would prefer to not generate this waste in the first place, but are constrained in their ability to avoid all waste-generating consumption.

\subsubsection{Composting}

When my informants talked about compost, what they meant was food scraps and foodsoiled paper that is diverted from landfills and allowed to decompose into soil. Only a few of my informants grew up composting, and those who did had parents who were particularly ecologically-minded.

Tim: We composted growing up, but it meant that my first experience being attacked by animals was because I was walking around in my backyard and I stepped on a hornet's nest in this garbage pile. 
This was sometimes as a way to divert waste from landfills, and sometimes, as in Tim's case, as a way to produce fertilizer to enrich the soil so his parents could grow vegetables.

At the same time as trash pickup was changed to every-other-week, Portland began allowing residents to put food waste and food-soiled paper into their yard waste bin for weekly pickup (Sarasohn 2011). Informants living in single family homes in Portland take advantage of curbside composting, though some of them also use backyard composting systems. Ian and David spoke specifically about putting bones other things that are not good for backyard compost into the city curbside compost.

Ian: We do a little bit of the city compost for bones and bread, and then we have a backyard compost for the good stuff, all of our vegetables.

Renters and owners of attached homes, like Brian, Fiona, and Tim and Tara, did not have access to composting. Tim diverts this waste from the landfill by saving it to use for broth, which he also sees as an important learning opportunity for his son, who lives with them on weekends.

Tim: We keep all of our vegetable waste and bones to make broth out of. I want my kid to see us using the whole plant and animal to show him some alternatives what he gets at his mom's house-ripping off the plastic wrap and digging in.

Brian says that because he doesn't have access to curbside composting, he uses the garbage disposal in his townhome instead of throwing food in the trash.

Brian: Rather than it [food waste] going into the garbage, most of the food waste that can goes down my garbage disposal and weighs down the water 
treatment plants. *laughing* That's the trade-off. But it's kind of staying more in that biosphere, rather than going to the dump.

Mike and Mina live in the suburbs between 30-45 minutes outside Portland, and the city where they live doesn't offer curbside composting. They recently ordered a subsidized backyard composting system from Metro, the regional government. Mina is new to many sustainability practices, so the backyard vegetable garden she is planting will be her first, and she is looking forward to using the compost as fertilizer.

Dayna and David and Heather feed food scraps and waste to their backyard chickens rather than throwing this waste into the trash or curbside compost.

David: We've had a backyard composting thing since we moved into this house 10 years ago, and then when the city composting came along, that was quite helpful because there were certain things that we couldn't put in our backyard compost like meat and bones, and we could get that and put it in the city compost. And then the chickens are our zero waste system.

Dayna: And you don't have to feel guilty that we didn't get to the bottom of that sour cream container and it went off.

For Dayna and David, their three-pronged approach to composting alleviates some of the guilt associated with wasting food that has spoiled or they can't finish.

\subsubsection{Diapers}

An unavoidable part of being a parent of young children is dealing with the waste of an infant who isn't yet toilet trained. Victor and Vanessa were able to mostly avoid diapers altogether by practicing assisted infant toilet training or "elimination communication" 
(Gross-Loh 2009) - because Vanessa practiced a form of attachment parenting, she was able to toilet train her children at a few months old. When they did use diapers, they used a disposable eco-friendly brand. This is an incredibly time-intensive practice, as it involves closely monitoring the infant at all times for the subtle signs that it might need to eliminate, and then holding the baby over a sink or toilet so it can relieve itself. For the rest of the households, the choice was between eco-friendly disposable diapers, cloth diapers washed at home, and cloth diapers washed via a delivery diaper washing service. To break the practice of diapering down even further, cloth diapers washed at home could be machine washed and machine dried or machine washed and hang-dried. Some households also installed additional equipment in their homes like spray hoses to help with pre-washing the diapers, and researched the best soaps for washing the diapers. This topic tended to come up mostly with parents whose children were still in diapers, while parents of older children focused on other topics.

For households with very young children the decision about whether or not to use cloth diapers was an important one. Households with a health priority and attachment parenting philosophies are more concerned with the health impacts of disposable diapers on their babies or the idea that disposable diapers might not be comfortable. Households who are more concerned with the environment and avoiding waste tried to weigh the environmental impact of their diapering choice. 
David and Dayna relied on a friend with similar values who had researched diapering. This friend was helpful in steering them towards the choice of cloth diapering and reduced some of the burden involved in learning about how to do cloth diapering. They also believe that cloth diapering is saving them money in the long-run.

David: Our biggest thing that we've committed to to reduce trash is the cloth diapers. It's an ongoing commitment.

Kirstin: Do you have a [diaper washing] service?

Dayna: No, we do it ourselves, and it is definitely that you are sacrificing time and convenience.

David: Every couple days it's a pretty significant time investment to wash them and fold them.

The choice of cloth diapers, whether motivated by environmental or health concerns, requires a large investment of time. Cloth diapering also restricts which preschools and daycares a child can attend-this was an important factor for cloth diapering families in selecting childcare providers. There is also an investment in materials required for cloth diapering. Using cloth diapers requires more than a set of at least 24 cloth diapers to get a newborn through two days between laundry loads, but also a diaper pail to hold soiled diapers, a wet bag to carry soiled diapers away from home, pins, inserts, and diaper covers (Wels 2011, 213). Fiona was able to obtain cloth diapers through a low-income diaper rental program, but made her own cloth diapers out of old clothes prior to that. Kelly installed a spray hose in her bathroom to help pre-wash diapers by rinsing off feces prior to laundering, which now doubles as an improvised bidet. 
Jim and Jess don't use their tumble drier for environmental reasons, so they hang-dry cloth diapers year-round. David and Dayna hang-dry diapers in the summer, and believe that drying diapers in the sun them much cleaner than drying them in the tumble drier. For Rob and Rebecca, having their cloth diapers cleaned through a commercial diaper service costs money but makes cloth diapering feasible for their household by helping them avoid some of the most time-intensive aspects of the practice.

Compared with cloth diapers, disposable diapers take much less time and don't require upfront investments in learning or materials. Heather wound up transitioning each of her children to eco-friendly disposable diapers to save time, though they all started out in cloth diapers. Fiona uses disposable diapers around $10 \%$ of the time as an investment in her sanity, and Rob and Rebecca also use disposable diapers part of the time, particularly overnight. Fiona and Heather both told me that they feel bad about using disposable diapers on their children, and Rob and Rebecca disagreed on the proportion of disposable diapers that they use-Rebecca believes they use a higher proportion of cloth diapers than Rob does.

Jim and Jess spent a lot of time researching the impacts of cloth versus disposable diapers, and Jim now believes that he made the wrong decision, despite all of the research.

Jim: Cloth diapering was an environmental choice, and I think in retrospect that it was the wrong choice. Now I think disposable diapers are the better choice. 
But that's a good example of not being able to find good information and thinking we were making the right environmental choice. It was definitely a very conscious, researched choice. And I think I got it wrong. But we put a lot of thought into it.

The informants I spoke with who use cloth diapers are spending substantial amounts of time to do so because they are convinced that this is the best choice for their children and the environment. Though as Jim points out, the facts are not clear and my informants are just doing the best they can to make the right decisions in spite of limited information, time, and money.

\subsubsection{Toilet Waste}

"Selective flushing" is the practice of flushing the toilet following a bowel movement, but not flushing after urinating. While no one I spoke with had heard the term before, they all knew what I was talking about immediately and were familiar with the practice-people commonly call this practice, "If it's yellow, let it mellow. If it's brown, flush it down."

Quinn: I don't flush every time. If it's pee, we'll probably let it go three or four before we flush. If there's enough toilet paper in there and it's yellow and it starts to smell when it's hot outside, then it's time to flush.

Only a few of my informants grew up with selective flushing, and the ones who did frequently mentioned learning this practice during the 1987-1992 drought in California (California Department of Water Resources 1993). This experience of drought and the associated water conservation practices spread to some of my informants who grew up in other regions via their contact with friends from California. 
Scott: I remember being reprimanded by a buddy who was over watching me do dishes because I was just running the water, and he said, "You obviously didn't grow up in California when there was a drought."

Orla practiced selective flushing growing up in Oregon because her parents were driven to save money on their water bills, and Carrie grew up with selective flushing in an intentional community on the east coast.

Carrie: Yeah, I learned about that growing up. And friends of mine that would like never flush and I'd be like, "Blarrrrrrg! Come on! We don't need to take it that far!"

For everyone else, selective flushing was something that they adopted as adults, often after being exposed to the practice through college roommates or other friends.

Fiona: That [selective flushing] was something that probably even in the past 5 years that I was exposed to, and I was like, "Oh, yeah! That makes sense." My sister lived with us for a while, and that's what they do. And that introduced me to that.

Kelly: We don't flush when we pee. I think I encountered that when I moved out here, and I thought, "OK that makes sense."

Tara: It's time to flush when you do a number two. We're not going to leave presents in there!

Leonda recalls first hearing about selective flushing from the 2004 comedy Meet the Fockers, which inspired her to adopt the practice to save water.

The practice was very common among my respondents, but not universal. Jim recalls encountering some resistance to his flushing practices after college.

Jim: I learned about [selective flushing] in college. I think it was a trendy thing to do. But when I moved to the East Coast, I attempted to selectively flush, and my 
roommates just thought it was disgusting. It was definitely not part of the culture over there.

Nicole knows some households who practice selective flushing, but she thinks not flushing the toilet for the environment is going too far.

Nicole: Selective flushing. Ew. I mean I get it, but...

Dayna accepts but does not like selective flushing, and has a gender-based explanation.

Dayna: I am cool with "letting it mellow", but to a certain extent my threshold is just different from David's. For women, you are closer to the mellowing source so you are more aware of the smell than a guy generally is, because he has greater distance. So being in the miasma of the situation... yeah.

Tim also doesn't like selective flushing, and also has a gender-based explanation: he believes that men's urine smells worse than women's urine.

Tim: I flush every time because I feel like guy pee has some kind of marking our territory thing left over from our animal ancestors, so I think there is an odor that gets really crazy really fast.

Owen has trouble with selective flushing because he has memories of getting in trouble growing up for not flushing.

Owen: Orla is probably better at selective flushing than I am, because I grew up getting yelled at when I would forget to flush.

Eric and Emily and lan and Ivy say that their children frequently forget to flush solid waste, and that they need to remind them to flush rather than train them not to flush every time.

My informants have other water and resource-saving toilet practices beyond selective flushing. Because of their differences in tolerance for selective flushing, Dayna and David 178 
say they "solved that problem" by buying a dual-flush toilet that uses a small amount of water for liquid waste and larger amount of water for solid waste. Penny takes old sheets to make washable toilet wipes for her daughter, a practice Mina refers to as "family cloth":

Mina: We don't do "family cloth" homemade toilet paper. That's a level we can't do.

Kyle and Kelly practice selective flushing, but they also put bottles inside the toilet tank to displace water, resulting in less water used in each flush. Kyle says they need to put some smaller bottles in the tanks, because he is finding himself having to flush twice sometimes to wash all of the solid waste out of the toilet bowl.

Selective flushing is a sustainability interesting practice because it doesn't involve buying anything and it doesn't involve additional effort-in fact it involves not doing something that is a common activity. Practicing selective flushing means re-learning a hygiene habit taught to children as soon as they begin toilet training. The practice is not on display outside the home. Several households practicing selective flushing had never even discussed the habit among themselves - it had become an automatic and taken-forgranted practice for these informants by the time they arrived at the stage of forming a household with their partners. Ivy recently used a composting toilet on a friend's property and commented that the conventional way of dealing with human waste is actually quite strange. 
Ivy: It weirds me out that we shit in clean water. We just went to a friend's farm, and they have a composting toilet. This is so much better than shitting in fresh water! Dumping water like that, it just doesn't make any sense.

Once people start looking into alternative ways of getting things done, the absurdities of taken-for-granted conventions and conventional practices become evident.

\section{$\underline{5.3 \text { Cleanliness }}$}

The social and cultural meaning of cleanliness has evolved over time, generally in ways that demand more resources (Shove 2003). Ironically, as new time-saving domestic technologies emerge, cleaning practices and the demand for cleanliness have changed in ways that demand more unpaid time rather than less (Cowan 1983). Changes in infrastructures and technologies, like central heating and in-home clothes washing machines, make these evolutions in cultural expectations possible, and even recursively reinforce the normalcy of these expectations. Showering, laundry, and household cleaning involve practices and mundane habits that are easily taken-for-granted, my but my informants have made changes to conventional ways of getting things done to make their practices more sustainable. Shove $(2003,10)$ says that demand escalators don't run backwards, but the ways that my informants have changed their showering, laundry, and household cleaning habits provide concrete examples of very real demand-decreasing changes in practices and accompanying changes in the meaning of cleanliness. 


\subsubsection{Showering}

The history of personal hygiene in America by Bushman and Bushman (1988) reveals that the meaning and practices associated with personal cleanliness have changed substantially since the $18^{\text {th }}$ century, when even affluent Americans might never bathe, cleaning themselves instead with an occasional sponge bath-a wet cloth and no soap. The accompanying infrastructure-a washbasin - was still a fairly rare item to find in American homes, and bathtubs were completely absent. By 1900, bathing practices had changed such that most Americans bathed fairly regularly, though still far less than we do today, as bodily cleanliness began to take on new social and moral meanings. In fact, the first soap for washing the body was only introduced around this time. Bushman and Bushman $(1988,1238)$ write that, "Now the wish to be clean feels more like a natural instinct than a cultural overlay." In questioning so many other taken-for-granted assumptions about how to get things done in day-to-day life, many of my informants have also changed the way they keep their bodies clean. Like selective flushing, practices that decrease the frequency of bathing are an intriguing sustainability practice. While short showers and low-flow showerheads allow a daily shower to become more efficient, showering less often is a way that my informants save resources, time, and money. The main cost is a social and cultural one, as bathing and cleanliness are saturated with deep cultural meanings. 
The majority of my informants shower less frequently than they did growing up, and often this change was a deliberate one related to sustainability.

Quinn: I grew up with a daily shower, and now I take a quick shower every three or four days. It's probably about five years that I've been doing that.

Leonda: My husband and I shower probably once every week, and our roommate showers maybe once every two weeks. I remember one of the first times I was spending time around the environmental activists in my community, and I saw a woman across the room and she put her arms above her head, and there was hair there! I thought, "Wait, what? You can be a woman and not shave? That's so crazy!" So, I never shaved again after that.

Kyle: I shower every two or three days depending on the temperature and the smell-test. I used to be a daily showerer.

Kelly: Probably every three or four days. I'll do the pit wash. PTA in the sink [pits, tits, and ass]. We installed a spray hose for cloth diapers, and now it's sort of a bidet for me. I've considered getting a bidet attachment for the upstairs toilet. I feel like that's one reason to shower regularly. If you can actually clean your ass, you don't need to shower that much.

Exposure to non-dominant cultural norms changed Leonda's perception of taken-forgranted personal grooming practices - once they realized there were alternatives, they changed their habits immediately. Kyle and Kelly use a spray hose they installed for cleaning cloth diapers as a bidet to allow them to go longer between showers, and will do what they call a "TPA" [tits, pits, and ass] sponge bath using a face cloth and the sink. Andrew and Amy are daily bike commuters, but take showers every two to three days.

Andrew: Yeah, with me I just go by how thick my stubble is. That's my measure for when I need to take a shower. Like oh yeah this is pretty thick. I need to go take a shower. Because that's when I shave.

Andrew decides when to shower based on a factor that has nothing to do with smell or a feeling of cleanliness - when his facial hair gets long enough that he wants to shave it. 
A striking example of a demand escalator running backwards is the story of Tara's conversion from someone who would habitually take several showers a day to someone who takes only one shower a day for environmental reasons.

Tara: When I was younger, I used to have no problem just showering three times a day. Wake up, shower. Go to the gym, shower. Going out that night, shower to get ready. It was no big deal to shower all the time! Now, I try my best to take fewer showers. I do take really short showers, but now I don't want to take a shower when I wake up just to take a shower again a few hours later after I exercise. Now, showering more than once a day seems excessive to me. But I used to take two or three showers every day. I grew up in this very excessive environment where you just do what you want when you want to do it. Now, being in Portland, I try to think about those things a little bit more. I don't feel comfortable without a daily shower, but I am trying to be mindful now so I'm not an excessive water user.

She still feels uncomfortable unless she has at least one shower, and as a hair stylist she works in close proximity to her clients, whom she doesn't want to offend. However, she has dramatically reduced her demand for hot water, and her views on when to shower and what being clean feels like have changed after moving to a place with different norms than where she grew up.

Some social norms around cleanliness are enforced by spouses. Ian has decreased the amount he showers compared to the daily shower he took as a teenager, but his wife would prefer him to bathe more frequently.

Ian: I was a daily showerer when I was a teenager, but I'm not anymore. Now maybe once every two days. Sometimes I push it...

Ivy: And then I get mad! I'm like "TAKE A SHOWER!" You smell. 
While she was laughing and joking around during the interview, it was clear that she does occasionally demand that lan shower because she doesn't like the smell. Ivy showers daily, but she also mostly bikes to her office job a few miles away. For some of my informants, the sustainability practice of bike commuting causes an increase in demand for resources in another area by causing them to shower more frequently. Eric, Kyle, Brian, David and Dayna all told me about showering at their workplaces following their bike commutes.

Other informants shower everyday so that they can smell and feel clean.

Tim: I will talk to people who tell me they only need a shower once every two weeks, but I do a bit of an internal eye-roll. Oh man, you DO need a shower, what do you mean? Good on you for not showering, but that is bad for me!

Heather: My husband is a more than once a day showerer. He showers once in the morning and once when he gets home. He has to be clean.

While there were still daily showerers-and some more than once daily showers-among my informants, the overall bathing patterns here demonstrate that it is indeed possible to change the meaning of personal cleanliness and the methods that produce personal cleanliness in ways that decrease the consumption of resources like water and water heating. 


\subsubsection{Laundry}

Like bathing, laundry has a cultural and technological history in America, and the mundane and habitual nature of laundry makes these changes easy to overlook. Shove $(2003,2004)$ has pointed repeatedly to transitions in laundry practices as a valuable topic for research into "normality" and the implications that social and cultural norms have for the environment through the demands they place on resources like water and energy $(2004,77)$. The history of this evolution in American laundry practices over time is instructive. Hoy $(1995,153)$ describes the prevalent laundry norms among the American poor in the 1930s, when undergarments might be changed once a season, and other clothes washed weekly or even monthly. Working people had very few clothes at this time, and washing them was laborious, unpleasant, and time-consuming. Laundry is a recursive practice-the ease of washing and drying clothing makes having more clothes more appealing, and having more clothes you'd like to keep clean makes having a way to wash them more appealing. Parr $(1997,183)$ points out that the early users of automatic home washing machines took notice of the amount of resources these machines consumed, accustomed as they were to hauling and pumping water and monitoring their septic systems. Parr reports that in 1955, one Canadian housewife wrote:

I have been appalled at the amount of water that seems necessary to do a normal family wash in the new spin-dry type of machine. I believe one brand boasted that it rinsed clothes seven times, and all of them threw the water out after one use. There is hardly a city or town in Canada that does not have some water shortage in summer months. Large sums are being spent on reforestation, conservation and dams. It would appear that this trend towards excessive use of water should be checked now. 
Not every culture immediately accepts new laundry technologies and their associated practices - despite geographic and linguistic proximity, Canadians took decades longer to adopt automatic home clothes washing machines than their American counterparts (Parr 1997, 159).

There is more than one way to get clothes washing done, of course, and the history of laundry tells a story of a chore being transferred from the home to the commercial sector and then back into the home again (Watson 2015). Cowan $(1983,105-108)$ discusses commercial laundries, which used to be commonplace and used for at least part of the washing by most households as the demand for clean clothes increased in the late $19^{\text {th }}$ and early $20^{\text {th }}$ centuries, and this unpleasant and grueling domestic task was outsourced. Along with their reluctance to adopt automatic clothes washing machines, Canadian households from all classes also made use of commercial clothes washing services well into the mid-20 ${ }^{\text {th }}$ century (Parr 1997, 173). Lynd and Lynd (1929) found that by the mid1920s in Muncie, Indiana, the appearance of clothes washing machines and electric irons in homes began to shift these laundry tasks from commercial laundries back into individual homes. This increase in home clothes washing machines represents a sociotechnological pattern that

tends to perpetuate a questionable institutional set-up-whereby many individual homes repeat common tasks day after day in isolated units - by forcing back into the individual home a process that was following belatedly the trend in industry toward centralized operation. (Lynd \& Lynd 1929, 175) 
Cowan $(1983,110)$ points out that outsourced domestic washing is generally reserved just for the dry cleaning of men's suits and button-up shirts. An exception to this tendency in my sample of households was Rob and Rebecca, who make use of a cloth diaper washing service.

Shove $(2003,117)$ points out that, unlike showering, there are deep gender divisions in laundry practices. American women spend over three times as much time doing laundry than men (U.S. Bureau of Labor Statistics 2016). There was some minor evidence in my discussions with informants that women in the opposite-gender dual-earner households did more of the laundry than their husbands, though laundry did frequently appear to be an equally-shared task. David apparently did not know what type of laundry detergent his household uses, and Dayna claimed that he had never purchased laundry detergent for their household. Heather told me that she does the laundry for their household, but she saw this chore as part of an egalitarian division of household tasks that involved specialization. She saw the assignment of the laundry chore to herself as an even trade, since her husband was in charge of doing the dishes and keeping the kitchen clean, a chore that Heather hates.

One way my informants integrated their sustainability priorities with their laundry practices was wearing clothing more than one time between washings.

Fiona: I do laundry less often. I'Il wear clothes again instead of just tossing them in the hamper. 
Eric and Emily have been teaching their children not to wear some clothes more than once at the same time as they are beginning to ask them to throw their dirty clothes down the laundry chute as a daily chore.

Eric: We try to communicate to the kids that they don't need to put their pajamas that they wore like from after they took a shower until when they woke up in the morning in the laundry. The idea that you can wear things a couple of times.

Emily: But that they should put their underwear in the laundry! *laughing* While Eric and Emily's children struggle at times to understand the nuances of these distinctions, they are mature for their ages and keen to be helpful around the house. Amy's children are roughly the same age as Emily's, but she describes a different experience teaching her children their sustainability practices related to laundry.

Amy: Well, I do try to motivate the kids to not put their stuff in the laundry like every time they wear it, and that's kind of an ongoing battle, because they just want to kind of just chuck it into a basket and call it a day.

Amy interprets her children's tendency to put clothes into the laundry hamper after a single wear as laziness rather than a misdirected desire to be helpful and tidy. During our Saturday morning interview, Andrew and Amy's children were serious and quietly working on extracurricular foreign language exercises and math worksheets.

The choice of laundry soap between ecological and conventional alternatives was a topic that came up frequently in my conversations with informants. Emily uses a scent-free conventional soap because the natural soap she prefers was causing her high efficiency 
washing machine to grow mold. Even though she is using a free-and-clear version of Tide detergent, she told me that she was upset about having to switch to a conventional laundry soap. Orla and Owen have been using a free-and-clear ecological detergent since they moved into their current home. This is in part because of the sensitive skin of household members, and in part because the house isn't on the municipal sewer system and drains to a cess pool in the back yard. Using this soap has changed the associations Owen has with the scent of Tide detergent. Now, when he smells someone who washes their clothes with conventional detergents, he finds the scent very unpleasant. David and Dayna use Tide because they believe it is the most effective on cloth diapers following online research, while other households use Charlie's Soap on their cloth diapers after researching the best soaps for washing diapers. Heather and Yvonne make their own laundry soap by adding Borax to bars of soap that they grate with a cheese grater. Yvonne isn't sure whether or not this is better for the environment, but she believes the large expenditure of time involved in grating bars of soap into flakes saves her household money. Penny used to make her own laundry soap in this way, but she decided she didn't believe it was more sustainable than commercially-available natural laundry soaps. Leonda wishes she could make her own laundry soap, and has friends who do this, but she feels like she doesn't have enough time.

Clothes dryers are ubiquitous in the United States - 79 percent of all American households own and use a tumble dryer at home, compared with 57 percent in the U.K. 
(U.K. Office for National Statistics 2011) and 4 percent in Italy (Project Laundry List 2013).

And 97 percent of Americans households in detached single family homes own and use a tumble dryer (U.S. Energy Information Administration 2013). But the mere existence of the tumble dyer in a home doesn't tell the whole story. While over half of U.K. households own a tumble dryer, 93 percent line-dry their laundry, while only 6-12 percent of U.S. households air dry their clothes (Project Laundry List 2013, Fischer \& Kaufmann 2013). Shove $(2013,152-153)$ writes about the social meanings of line-dried laundry for the majority of U.K. households that strongly prefer it-hanging up the wash is enjoyable, the laundry smells better, and it is fresher and cleaner. An English interview subject reports feeling guilty for using the tumble dryer (152). These same associations and meanings with line-dried laundry are not prevalent the American context, though some of my informants, almost always contrary to the way they were raised, have started to line-dry their laundry for environmental reasons.

Jim and Jess line-dry all of their laundry, including sheets and towels, year-round. They have two large drying racks that they use for clothes, and they dry their bedlinens by hanging them over doorframes. They made the deliberate choice to live in an 800 square foot home, and the drying racks take up a lot of space inside.

Jim: Line drying is a conscious environmental decision because the dryer is a huge user of energy. It's probably one of the bigger things that we do. It's a big time commitment. We use two big drying racks in our room, and sheets and towels go over the doors around the house. It's a compromise because this is such a small house it takes up quite a bit of space in our room. 
Line drying clothing year-round takes more time than drying clothes using a tumble dryer, but the environmental impact of this choice makes the trade-off worthwhile for Jim and Jess. Because the Portland area is so frequently rainy, Penny, David, and Dayna line-dry their clothes only during the relatively dry summers. When I asked the technologically-oriented Dayna, a scientist by training, how she learned about line-drying laundry and what competence and materials were involved, she looked at me quizzically.

Kirstin: Did you research line-drying before you did it?

Dayna: Is there research to research?

Kirstin: Well, there's equipment involved, right?

Dayna: Ours is a retractable string from Fred Meyer. It was like five dollars.

This was an interviewing blunder I made early in the interviewing process - for Dayna, unlike for a social researcher, equipment means complex technologies, not a five dollar string. Neither Dayna nor David grew up line-drying their laundry, and in fact they believed their parents would be hostile to the idea of line-drying. Dayna recalled her grandmother line-drying clothes when she'd visit her in Florida growing up, and called her a "big believer" in drying clothes this way. Still, this was a lost practice that Dayna had to re-learn, re-adopt, and restore for her own household. Rilke (1968 [1908], 334) writes in a letter to his wife about

the first state of bliss: when a much earlier thing is given back to one so that one may grasp it and take it to oneself with a love meantime become more just. Here begins the revision of categories, where something past comes again, as though out of the future; something formerly accomplished as something to be completed. 
Many of my informants' sustainability practices are practices that have sat dormant for a generation or two, only to reemerge with new significance and cultural meaning.

Andrew, Chris, Carrie, and Rob told me that they line-dry only certain things sometimesthis is just for delicate items or items informants really want to last.

Andrew: The reason I dry some of my clothes outside of the dryer is mainly because I don't want them to shrink. It's not really as much sustainability motivated as much just about the clothes.

In the suburb where Nathan and Nicole live, there are regulations against line-drying clothes. They line-dry items associated with Nicole's five dogs, mostly beds and towels, but they must do so in an area that is not visible from the road. Nathan grew up linedrying everything year-round, but now he prefers to put his clothes, towels, and bedlinens in the tumble dryer. He is worried that line-drying these items will cause them to attract pollen that will trigger his allergies.

While sustainability practices that involve washing clothes less often mean that households can spent less time doing laundry, line-drying clothing winds up taking more time and effort than drying clothes quickly in a tumble dryer. The time required to linedry laundry is a major barrier for some households, even Heather's, with two adults who were accustomed to having line-dried clothes in England.

Heather: In California, l'd have some drying racks outside, but it was always sunny. But here, we've only been in Portland for a couple years. But to be honest, hang-drying clothes takes a lot of work and a lot more time. And now that there's five of us, there is a lot more laundry. 
But beyond time spent or saved to conserve resources, there are other consequences to making sustainability-oriented changes to laundry practices. Changing laundry soap, washing clothes less, and line-drying clothes all involve changes to expectations and the cultural meaning of cleanliness for my informants as they strive to make choices that are healthier for their families and the environment.

\subsubsection{Household Cleaning}

Three households told me that they had housekeeping help-Rob and Rebecca, Scott and Sarah, and Nathan and Nicole-substituting a purchased input for their own unwaged time. Not coincidentally, these were among the highest income households in my sample. Other households may have had this help, but they did not volunteer this information. From the way my informants talked about cleaning, I did not get the impression that many had paid cleaning services. Kyle and Kelly live in community, so all household chores are rotated through the five adults living in the home. Leonda and their husband live with a roommate, but the roommate doesn't contribute much by way of helping with household chores. While Victor and Vanessa live in a co-housing community, an aspect that Victor likes about this living arrangement is the fact that the chores on the outside of the home like yardwork are shared by his community, but the chores on the inside of the home are done by his wife. While there are different ways of arranging the work of household cleaning, most of my informants arranged this work in a conventional way-by doing it themselves. 
As with laundry, there are gender divisions in the assignment of tasks related to household cleaning in America that were apparent in some of my conversations with informants.

Dayna: We have a mix of what I would consider earth-friendly stuff and then some not-so-earth-friendly stuff.

Kirstin: Where does the not-earth friendly stuff go?

Dayna: When I think it is required.

David: What would that even be, like bleach?

David's seeming ignorance of both the type of laundry detergent, discussed earlier, and the household cleaning products and methods betrays his likely lack of involvement in this area of household work. However, this did not appear to be the norm for the households I spoke with who had two working opposite-gender adults.

The primary connection between sustainability practices and household cleaning my informants made involved the selection of products and methods for cleaning. A common theme among my informants was a belief that conventional cleaning products are able to clean more effectively and faster than more ecologically-friendly alternatives, which either don't work or require more effort. Dayna doesn't believe that Bon Ami can be "natural" alternative to bleach-based scouring products because it is so effective, and initially listed it among the conventional products the household uses for cleaning. 
Mina: I fully believe that vinegar, baking soda, and hydrogen peroxide can take care of anything. In the dishwasher is my only concession for using a conventional product. Seventh Generation was too much of a compromise and it was not getting things clean. It wasn't working.

Amy: I still use something for the toilet that's not just necessarily just vinegar and baking soda. I guess for me the toilet is just like a grosser place and I want to make sure I'm getting the bacteria and e. coli aspect of it, but also probably effectiveness and ability to do it quickly as well.

When more natural products fail or the job triggers fears of contamination, harsher conventional products are needed. These conventional products are believed to save time and effort.

Several households claimed to use exclusively natural cleaning products, and then when asked specifically about bathrooms admitted to using conventional products on toilets and in the bathroom.

Chris: For cleaning the house I have a grapefruit cleansing thing-a-ma-bobber.

Carrie: And like if we wash... the few times a year we actually mop our floors, mostly we might just use vinegar or water.

Chris: Maybe a little dish soap or something.

Carrie: Nothing too...

Chris: Mostly we just vacuum.

Kirstin: What about in the bathroom?

Carrie: We have a few kind of mildew stain type things we use in the bathroom.

Chris: Yeah, we'll bleach the shower.

Kirstin: So you use more conventional products in the bathroom? 
Carrie: Yeaaaah.

This pattern of additional interview probing after an informant claimed to use exclusively natural products took place in several interviews.

Heather: Cleaning products would be something that I choose and that we make. I make my own laundry detergent, and we try to do that mindfully by using the Environmental Working Group website. I make my own shower sprays, I make my own counter cleaners. We make our own bug sprays. Out of essential oils, white vinegar, baking soda.

Kirstin: What about the toilet?

Heather: For the inside of the toilet, I use a conventional bleach-based gel but the outside of the toilet I use my own products that I make. For the dishwasher, I use a Seventh Generation pod. We buy dish soap that he picks up at Trader Joe's. For the floors we use almond oil. We don't use anything else.

For most of my informants who prefer to use natural cleaning products, toilets and bathrooms are an area that requires conventional products with disinfecting properties. Ian and Ivy were an exception. They tend not to use cleaning products at all, whether in the toilet or anywhere else in the house. She says that elbow grease is enough to get the job done.

Ivy: We honestly rarely use soap on the toilet. If we do, it is like Seventh Generation. But I just scrub it once a week, and I feel like that gets it pretty clean. Eight years ago, I bought a bottle of bleach and we've had that same bottle. And I will use that on mold. And I feel like I've used it maybe three times.

While the toilet and bathrooms aren't the trigger for disinfecting products, the appearance of mold does drive lan and Ivy to use bleach. 
Jim doesn't mind using conventional cleaning products for everything because he believes they make the job go quicker and he is mostly concerned with the "footprint" of his choices on the natural environment and public health.

Jim: I do not make environmental decisions for household cleaning products. I definitely prefer cleaning with bleach and cleaning with nasty chemicals. My feeling is that it is such a small footprint, so it is OK. It is just more effective and a way to get the house cleaner.

He believes the footprint of household cleaning products is small, he cares less about finding eco-conscious alternatives for cleaning products than he does about other things. Besides, he believes conventional products work better and make the job easier so using them are worthwhile based on Jim's value system.

In household cleaning as in other facets of day-to-day life, my informants make trade-offs between priorities to get things done using the resources available to them and subject to the factors that constrain them. Households with strong sustainability priorities in the personal health arena take the extra time to use, and sometimes even produce, natural cleaning products in their homes. However, many households find that their cultural expectations for cleanliness take precedence over their health-related sustainability concerns, and influence their decision to use conventional disinfecting products in the bathroom. Other households, particularly ones who are most concerned with the carbon impacts of their choices or not wasting resources, decide to save time by using conventional cleaning products. Other houses use even more time and effort to clean 
with no products at all, or use their wages to purchase cleaning services so the time can be used elsewhere. The possible combinations of priorities, resources, and constraints used to produce cleanliness in sustainable households are seemingly boundless.

\subsection{Comfort}

Much like cleanliness, the production and social meanings of indoor comfort have changed over time and are not consistent across cultures. By comfort what I mean is the practices, materials, meanings, and infrastructures involved in feeling like you are at a comfortable temperature when you are inside, a notion borrowed from Shove (2003).

During cold months, being comfortable might involve some combination of adjusting a thermostat connected to central heating, using portable space heaters, putting on additional clothing, drinking warm drinks or alcohol, sitting under blankets, putting on a fire, or congregating in a single room. During warm months, being comfortable might involve some combination of adjusting a thermostat connected to central air conditioning, using window or portable air conditioning units, using electric fans or swamp coolers, opening and closing windows and blinds, wearing fewer clothes, cutting your hair short or wearing your hair up, taking a cold shower, drinking cold drinks, going to the river or public splash pads or pool, running through the sprinklers, taking a siesta, or going to the movies or an air conditioned shopping center. 
The temperatures that feel comfortable indoors and the actions people take and the equipment they use to remain comfortable are a matter of cultural expectations and social norms, but the equipment and infrastructures in homes recursively reinforces expectations about how people should feel indoors and what steps they ought to take to feel that way.

\subsubsection{Comfort when it's Cold Outside}

\section{Temperatures}

Common indoor temperatures during cold weather were between 68 and 70 on the high end and between 64 and 66 on the low end for awake-and-home temperatures, though some of the extremes were 74 on the high end and lan and Ivy's unheated home, which Ivy thinks gets into the 50s and below, on the low end. Some households turn their heat all the way off at night and when they are not home because their home is so wellinsulated, and some households use no set back at all. Other households set the temperature back a few degrees, and Orla and David and Dayna researched the optimal setbacks for their heating systems.

There was a ten degree range-from 64 to 74 -between the temperatures at which my informants told me they feel most comfortable in the winter. Sometimes these optimal comfort temperatures were different between members of a couple.

Heather: Because my husband is from England, he prefers it to be cold. If it's hot out, he is complaining. Even 70 degrees he starts to complain. We are OK with 
70 inside during the winter, but at that temperature, the front door is open, windows stay open, the basement door is open. I feel a draft! When it is cold outside, it does not affect him to even think about closing doors and windows.

These differences generally meant that the member of the couple who would prefer it to be warmer inside needed to take adaptive steps to remain comfortable, though not always. Heather's husband leaves doors and windows open during the window to keep it a bit cooler than the thermostat setting that Heather prefers. Fiona tells me she likes it very warm during the winter, and she and her child were wearing short-sleeved shirts and shorts inside on a crisp spring day.

Fiona: I feel like my tendency towards comfort is stronger than other people than I know. Like everyone in my family keeps their house colder than I do. You can see that the baby and I are both in t-shirts right now, and I still feel flushed and hot. I think that I like my house warmer, and I don't feel as comfortable bundled up in my house.

My informants ascribed these differences in comfort temperatures to some combination of biology, habits related to how and where they grew up, and personal preference.

\section{Equipment}

Most, but not all, of my informants had electric or natural gas central heating in their homes - a furnace or a heat pump. Nathan installed a costly geothermal system, in part because he calculated that it was cost-effective, and in part because he likes the technology.

Nathan: We have geothermal heating and cooling. It is a really high efficiency rating system. Both radiant floor and forced air. It is totally cool. 
Renters Leonda, Tim and Tara, and Fiona have baseboard heat, so they never really know what temperature it is inside, though Leonda and Fiona tell me that they keep it quite warm, and Tim and Tara try to heat their apartment as little as possible. Ian and Ivy's home has no central heating, and baseboard heating in only one room-their daughter's.

Ivy: We don't have a heating system in the house. In the winter overnight, it's probably in the 50s. It's really cold. I put on blankets and don't move from that spot on the sofa and read there. Our bedroom is in the attic, so it is very subject to the elements. I've always been pretty whiny about it. I make a big fuss about it, but I don't really do anything about it either.

The result is that Ivy is very uncomfortable in the evenings during the winter, and huddles under a duvet in the living room from when she gets home from work until it is time to go to sleep. She describes herself as "whiny" for wishing the home had functioning heat. Scott uses a space heater under his desk in his office when he's working from home, and Jim and Jess use a space heater to keep the overnight temperature in their child's room warmer than the temperature that they'd prefer for themselves. Kyle likes to use a space heater in a small space to make the temperature "luxurious" sometimes.

Investments in insulation, weather-stripping, and double-paned windows were fairly common, and these investments were seen as helping keep the temperature comfortable inside during both hot and cold weather. One of the first things that Andrew and Amy did when they moved into their home was replace the original windows with more efficient ones. Kyle also replaced windows early on in his home renovations, and Mike and Mina say that the next project in their new home will be window replacement. 
Orla, on the other hand, decided that replacing windows wouldn't be cost-effective and instead focused on adding extra insulation to the walls and attic. All of the households who made energy efficiency improvements took advantage of available tax incentives and other rebates, though generally my informants had already decided to make the improvements regardless of the incentives.

\section{Actions}

One way that my informants stay comfortable when it is cold out is to use their heating systems and space heaters. Most of the households I spoke with have programmed thermostats that run on a set schedule, and sometimes my informants adjust the settings when the regular program is making them feel too hot or too cold. Tim and Tara say they run their heat just to take the bite out of the air, and set their baseboard heaters "to the first click." They try to occupy the same room when they are home, to avoid heating more than one space at a time.

Fires and gas fireplace inserts were also a popular way to heat homes, used fairly regularly by Andrew and Amy and Jim and Jess.

Jim: We try to heat with the fireplace as much as possible.

Jess: And I'm conflicted because it generates a lot of particulate matter.

Jim: We don't really know if it's the right choice or not, but I feel that from a climate perspective it is a better choice. But from a particulate matter perspective, it is not a better choice. But from a climate perspective, it is a better choice than our gas furnace. 
Both of the households who use fires to heat their homes are conflicted about whether or not this is a good environmental choice. Quinn and Chris and Carrie and Scott and Sarah have natural gas fireplace inserts. Quinn enjoys sitting in front of the fireplace, though she says she knows it's "bad." Chris doesn't like it when his children run the fire on cold mornings, because he believes it's wasteful and bad for the environment. Scott and Sarah mostly just use theirs when they have company over rather than just for their family.

Some of my informants who live in homes with central heating would prefer to heat as little as possible or not at all, for some combination of environmental and financial reasons.

Gloria: I would prefer to not use the heat at all. I would prefer to put on my wool socks, and some sweatshirts.

Wendy didn't run the heat in her home at all until a colleague told her it was not good for her home and might cause mildew to grow on the house because of Oregon's damp climate. Quinn's husband also argues with her about the thermostat settings, because Quinn would prefer it to be cooler in the home to save money and for environmental reasons. Her husband is an engineer, so they compromised because of his concerns about the integrity of the home at Quinn's preferred temperature. 
My informants have ways of staying comfortable inside when it's cold out other than adjusting the thermostat or using auxiliary heaters. They talked about wearing sweaters and sweatshirts, wearing coats and scarves inside, and using a heated blanket.

Nicole: Usually I'm always cold, so I put on a lot of layers.

Jess: I try to wear a lot of sweaters, and we use blankets. I like to wear my coat around the house.

Carrie: We definitely put on clothing. Scarves, if needed. I think just this morning I was walking around with my scarf on because I was cold. You know, I've got my slippers, things like that.

Quinn: We also have a heated blanket which helps us keep the thermostat lower at night.

Orla: If he doesn't feel warm enough, he is more likely to hit the button and turn the heat up. I try not to do that. I would rather put on a sweater or drink warm drinks.

Owen: That is your cheapness coming out.

The degree to which my informants relied on these types of actions depended on their priorities, their expectations for how warm they should feel inside, and the extent to which members of a couple disagreed about what temperature they should keep it inside. Households who were very concerned with waste and their impacts on nature tended to rely more on interventions like putting on more clothes or sitting under a blanket, while households who were most worried about personal health and community concerns were generally less worried about saving energy. 


\subsubsection{Comfort when it's Warm Outside}

\section{Temperatures}

The indoor temperatures my informants prefer during hot weather varied considerably, from Scott and Sarah and Mike and Mina, who all recently relocated to Portland from California and run their air conditioner at 70 degrees all summer, to Gloria who recently relocated from the Midwest and says the indoor temperature that triggers her to turn on an air conditioner is "94 degrees inside at night." Nearly all of my informants who have space cooling equipment expressed a belief that the equipment should be used as little as possible and only when the indoor temperature is unbearable, even if their preference would be a lower indoor temperature.

Chris: In the summer, I think we tend to set it more for 78-80, and sometimes lower. But usually it's not that bad in Portland, or it hadn't been. I think I prefer it to be more like 75, but I would never set the air conditioner to that because that would make me want to punch myself in the face.

Emily: My goal is to set it at 78. Which feels pretty nice on a 100 degree day. But I work from home, but if I'm just sweating, I have to tap it down. But I try to never go below 72. That's my floor.

Kirstin: Why do you have that as a floor?

Emily: It's random. It just feels like you shouldn't need it to be any cooler than that when it's like 100 out. 72 is pretty nice. And you just dress appropriately and drink ice water.

Brian: On the cooling side, I don't turn on air conditioning until I absolutely have to.

Kirstin: Do you have central air or window units?

Brian: I do have central air, and it's a heat pump with air conditioner. I think that it got to the high 90s before I finally turned on the air conditioning last year. 
There appears to be a moral dimension for many informants associated with using air conditioning equipment during hot weather, and they had trouble explaining where these seemingly arbitrary boundaries come from.

Penny's home has central air conditioning, but she sets it to 78 , mostly for the pets. Nicole also thinks about her pets when she turns on the air conditioning.

Nicole: I actually hate AC, and I am more willing to let it get up to around 78. And we have five long-haired dogs, and so I'll turn it on if it looks like they are getting uncomfortable.

Both Penny and Nicole would prefer to use passive cooling techniques. Eric, too, prefers to sacrifice a couple of degrees and deal with his home being hotter so that he can use his passive cooling routine rather than run the central air conditioning in his home. Informants without cooling equipment are somewhat at the mercy of the weather when it comes to their indoor air temperature, but they also have ways of keeping it cool inside or ways to avoid being inside altogether.

\section{Equipment}

Most, but not all, of my informants had either central air or at least one window air conditioning unit, while others used floor and ceiling fans. Andrew bought sun sails, planted a tree, and planted hops to help block the direct sun that heats his house, and

Mike and Mina put up blinds. Scott and Sarah said they were thinking about getting some 
kind of window coverings because the direct sunlight meant that keeping their home cool, even with their central air conditioning, was a challenge.

Kyle and Kelly installed ceiling fans, and also have one window air conditioning unit for their young child. Several of my informants purchased air conditioning units for their children or during pregnancy.

Kyle: We have one window AC unit for our kid's room. She's up on the third floor and it gets really hot. She goes to bed when the sun is still blasting into her room.

Ivy: Getting the window AC unit was motivated by having a baby and making sure her room wasn't 100 degrees.

In a moment of desperation, Wendy bought a window air conditioning unit because she was so uncomfortable the summer she was pregnant, but she returned it to the store without opening it. Jim nearly bought a window unit when his child was an infant, but the temperature cooled off before he went through with the purchase.

Air conditioning is also described as being important for the evenings and for helping my informants get comfortable enough to sleep at night.

Heather: We don't have central cooling, we only have central heating. Once it gets hot out, we put window units only in our bedrooms. Neither of us can sleep when it's hot. We both like it cold when we're sleeping.

Brian: I usually end up with a week or more where air conditioning's on if I' $m$ in the house in the evening because it's too uncomfortable otherwise. 
Several households mention "breaking down" and buying window air conditioning during a very hot summer in Portland two years earlier. A single, very hot year can have a lasting impact on energy consumption and the ways that people stay comfortable inside when it's hot out.

Tim: We used to be able to get by just by opening the windows and closing the blinds and having that routine, but it seems like summers have been more severe the past few years. We just gave in and bought a portable AC two years ago. We needed a few nights of good sleep where we could get the air cool enough so we weren't dying.

Now that they have the air conditioning equipment, they use it during the summer even though Tim had lived in Portland for over 15 years with no air conditioning. A single, very hot summer has permanently altered Tim and Tara's demand for energy.

Despite owning and using the air conditioning unit, Tim prefers not to use air conditioning because he doesn't like the way refrigerated air feels. Several informants mentioned they would prefer to be slightly hotter inside and rely on electric fans and open windows to move air around.

Tim: I would prefer having two fans instead and being able to feel air moving. I don't like AC air at all.

Emily: At night when he comes home, he's more often the one who's like, "Let's turn off the AC and open up the windows!" And I'm like, "Uuuuugh. It's still 88 degrees out!" We get like two weeks of summer that's like that. But.

Eric: And I'd say my motivation for doing that is like half financial, half that I just like feeling air movement, so that's just my preference even if we give up a couple degrees to get that.

Quinn: I grew up in the south, and we didn't have central air. I was used to just having fans so I'm comfortable with that. I put large window fans in the windows 
at night and get the breeze coming in. I don't put down blinds because the cats like to be in the sun, so I think about that.

Jim and Jess and Andrew and Amy replaced windows in their homes that were permanently stuck shut to allow for more passive cooling.

Jess: We insulated this house, and we replaced the windows so they can open. And that makes a huge difference. And we have a ceiling fan in our room.

This is a substantial investment, but it allows these households to avoid relying on more energy-intensive ways of cooling the air.

\section{Actions}

While Mike and Mina and Scott and Sarah were unapologetic about their air conditioning use, most of my informants told me they try to use their air conditioning as sparingly as possible. They rely on other ways to stay comfortable when it's hot out, which they believe is an increasingly common occurrence in Portland.

Passive cooling rituals involving fans, blinds, and opening and closing windows were the most common way, other than air conditioning, to keep indoor spaces comfortable during hot weather.

Rob: I have my own pseudoscience way of arranging the fans that makes me believe it is creating an optimal airflow. I won't open the front windows for security reasons. We point the fans to point the fans in, and I've always wondered if it's better to blow the air in or out. And then I have another fan that I position at the bottom of the staircase to circulate the air upstairs. 
Eric: When you live in the Central Valley [of California], you learn to have these routines. In the morning you open everything up. And then you're watching the temperature, and then you close everything, turn it [the air conditioning] on, and then as soon as you can... Just because one, because of how extreme the heat is during the summer, and two because electrical bills are so much more expensive.

Fiona: I keep my shades down when it's hot out, for sure. That's something that I learned from my mom's house where my step-dad would get up early on hot days and crack all the windows, and put all the blinds up for two hours to cool it off. And then as soon as it started getting hot put all the blinds down and close all the windows.

Kirstin: So he had like a whole routine?

Fiona: *laughing* he has a system.

Kirstin: So do you follow his whole system, or have you just taken a piece of his system?

Fiona: I pretty much do exactly that. I'll crack the windows, and turn the blinds down all day and leave them open all night so it cools off during the night.

Kyle: My friend is from the south and spent a lot of years there as a working class person, and he had a lot of skills around keeping cool without air conditioning. We were fortunate to have that practical introduction to another way to do things.

Carrie: Oh! And there is a whole routine that he did learn from his parents about windows and blinds and like keeping... you know we open up as soon as...

Chris: *laughing*

Kirstin: And who does those the window routine?

Carrie: Well, you know we both participate *laughing* I'll participate in it.

Kirstin: But you [looking at Chris] are the driver of this? Of passive heating and cooling?

Chris: Yeah for sure. 
Carrie: But yeah, you know just open it up at whatever point at night that it gets cool enough, and keep them open until either we leave the house or the point that it gets warm enough, and then we close the windows, close the shades.

Chris: Shut everything down.

Carrie: It definitely helps.

Chris: It makes a huge difference.

My informants generally told me that they learned their passive cooling techniques from someone who had developed a "system" or "routine", often a parent or a roommate.

Owen: A number of years here, we had a window AC unit but we didn't really want to run them so we'd put fans in the windows. We learned that from her dad.

When Owen and Orla had window air conditioning units, they tried to use them very sparingly and rely instead on the passive cooling techniques they learned from Orla's father. Now that they replaced their oil furnace with a heat pump, they rely on the air conditioning function of the heat pump more frequently.

Other actions my informants take involve moving to a cooler part of the home, leaving the home, playing in water, eating popsicles, drinking cool drinks, putting cold wet or frozen towels on, or sitting on blocks of ice.

Kyle: When it's hot out we use fans and go to the river. Try to leave. Splash pads in the parks downtown. We have heat-trapping blinds and open all of the windows at night.

Fiona: In Oregon, I feel like there are two days a year when air conditioning might be useful, but instead we go to the river or eat popsicles. Cold showers if we're not able to go somewhere. 
Carrie: Our basement is really comfortable in the summer.

Chris: Yeah we would go down there because it stays really cool down in the basement.

These techniques bring to mind the suggestion of Strengers (2012) to think outside the home and its "material infrastructure" to truly change the demand for electricity. My informants have changed the meaning of comfort when it's hot outside from a matter of achieving a particular indoor air temperature to interventions that frequently involve cooling their bodies directly with cold or frozen items, moving to a different part of the home, or leaving the home altogether.

References.

Aleiss, Angela. 1999. "Iron Eyes Cody: Wannabe Indian." Cinéaste 25(1): 31.

Cialdini, Robert B. 2001. "Littering: When Every Litter Bit Hurts." in Public Communication Campaigns, Ronald E. Rice and Charles K. Atkin (eds.). Thousand Oaks, CA: Sage Publications.

Fischer, Barry and Nate Kaufman. 2013. "America's most unpopular way to save energy is one of Europe's favorites." Demand Side Management (Opower blog). Accessed 06/22/2013. Available: https://blogs.oracle.com/utilities/americas-mostunpopular-way-of-saving-energy-is-one-of-europes-favorites

Gross-Loh, Christine. 2009. The Diaper-Free Baby: The Natural Toilet Training Alternative. New York, NY: Harper-Collins. 
Lynd, Robert S. and Helen Merrell Lynd. 1929. Middletown: A Study in American Culture. San Diego, CA: Harcourt Brace Jovanovich, Publishers.

Parr, Joy. 1997. "What Makes Washday Less Blue? Gender, Nation, and Technology Choice in Postwar Canada." Technology and Culture 38(1): 153-186.

Project Laundry List. 2013. "Laundry Fact Sheet." Accessed 06/22/2017. Available: http://www.laundrylist.org/wp-content/uploads/2013/08/facts.pdf

Rilke, Rainer Maria. 1969. Letters of Rainer Maria Rilke, 1892-1910. Translated by Jane Bannard Greene and M.D. Herter Norton. New York, NY: W.W. Norton.

Sarasohn, David. 2011. "Biweekly trash pickup: Get to Know your Garbage." The Oregonian, December 10, 2011. Accessed 05/30/2017. Available: http://www.oregonlive.com/news/oregonian/david_sarasohn/index.ssf/2011/12/ biweekly_trash_pickup_get_to_k.html

Shabecoff, Philip. 1987. "With No Room at the Dump, U.S. Faces a Garbage Crisis." New York Times, June 29. 1987. Accessed 05/30/2017. Available: http://www.nytimes.com/1987/06/29/us/with-no-room-at-the-dump-us-faces-agarbage-crisis.html

Shove, Elizabeth. 2003. Comfort, Cleanliness, and Convenience: The Social Organization of Normality. Oxford, UK: Berg.

- - . 2004. "Sustainability, system innovation and the laundry." in Boelie Elzen, Frank W. Geels, and Kenneth Green (eds.), System Innovation and the Transition to 
Sustainability: Theory, Evidence and Policy. Cheltenham, UK: Edward Elgar Publishing.

U.K. Office for National Statistics. 2011. "Living Costs and Food Survey." Accessed 06/22/2017. Available: http://www.ons.gov.uk/ons/rel/family-spending/familyspending/family-spending-2011-edition/consumer-durables-nugget.xls

U.S. Bureau of Labor Statistics. 2016. "American Time Use Survey: Chart 15." Accessed 06/22/2017. Available: https://www.bls.gov/tus/charts/chart15.txt U.S. Energy Information Administration. 2013. "2009 Residential Energy Consumption Survey: Table HC3.1 Appliances in U.S. Homes, by Housing Unit Type, 2009." Accessed 06/22/2017. Available: https://www.eia.gov/consumption/residential/data/2009/hc/hc3.1.xls

Watson, Sophie. 2015. Mundane objects in the city: Laundry practices and the making and remaking of public/private sociality and space in London and New York. Urban Studies 52(5): 876-890.

Wels, Kelly. 2011. Changing Diapers: The Hip Mom's Guide to Modern Cloth Diapering. South Paris, MA: Green Team Enterprises. 
Chapter 6: Research, Conflict, Trade-offs

\section{$\underline{6.1 \text { Overview }}$}

In the last two chapters, I attempted to provide an introduction to a set of sustainabilityoriented households in Portland, Oregon, by describing who they are, what their priorities are, and how they get things done on a day-to-day basis. This chapter is a thematic exploration of how these households make choices and the social meanings and consequences of their sustainability-inspired interventions into day-to-day practices. A final question-why are these households taking these unconventional steps to live sustainably-will be answered somewhat speculatively in the conclusion. Understanding the consequences of pro-environmental households' efforts to alter conventional ways of getting things done can help shed light on the efficacy and desirability of household-level sustainability practices.

The households I spoke with perceive many of their sustainability practices and priorities to be outside the American mainstream, even if they are very much within the mainstream for Portland, Oregon. It was always possible for my informants to think of other households who were making more extreme sustainability interventions into dayto-day practices, and they also had no trouble thinking of households who were doing much less. Because their practices and priorities tended to be outside the mainstream, many informants were investing considerable amounts of time and effort into research on these alternative ways of getting things done. In particular, informants researched 
their personal health choices, how to do sustainability tasks, and the impacts of their choices on the environment. Living an alternative lifestyle also opened up my informants to potential conflicts with people with more conventional lifestyles or who don't share my informants' priorities. In our conversations, I heard about conflicts over sustainability practices that emerged between household adults, between adults and their parents, between adults and their children, between children and the outside world, and the internal conflict of guilt over their own choices. Finally, my informants described giveand-take in their lives as they choose between competing priorities, including priorities outside the sustainability realm. Informants budget their time and money to get things done and achieve their sustainability objectives at the same time. Trade-offs take place between sustainability priorities and other important considerations-for example, my informants' sanity and well-being. For a few households I spoke with, the decision to become a parent represents the ultimate compromise of sustainability priorities.

\section{$\underline{6.2 \text { Research }}$}

Kirstin: Can you describe a family that you know where you're like, "I am not like that, and I don't want to be like that?"

Heather: That's easy! Someone who doesn't do their own research. Followers.

None of my informants grew up exactly the same way that they live now, so many of them had to spend considerable amounts of time and effort to learn about sustainability and new sustainable ways of getting things done. The result of these efforts might be 
called "Human Capital" in the neoclassical model or "competence" in theories of social practice-their research represents time (and in some cases, also money) that could have been used for some other purpose but that was dedicated to gaining this know-how. Research changes the way sustainability-oriented households get things done because it gives them information about their choices or makes them better (or more efficient) at certain practices. Research and knowledge about some sustainable household practices might also make people more efficient in waged employment-a substitute for other types of human capital. Or knowledge gained on the job in paid employment might people more efficient at household sustainability practices. In some cases, the people I spoke with had to learn for themselves to care about sustainability issues, since this was not a priority in the households or communities they grew up in, and then had to learn new practices to bring their lifestyles into harmony with their values. People raised in families with ties to environmentalism or other counter-cultural movements may have absorbed some of their current priorities and practices from their parents, but adaptation occurs - to an urban setting, to account for contemporary climate change or health considerations, or to a household with two working parents. Household research topics were varied, but most often included research into health information, skills and how to do things, and information about the environmental impact of different choices. My informants were motivated to conduct this research because of a general lack of trust in institutions and the government, as well as a desire for self-sufficiency. They do not feel that they can rely on the state or other institutions to operate with their priorities or 
best interests in mind, and they believe in self-reliance and personal responsibility for their health and environmental impacts.

\subsubsection{Types of Research}

Households try to get information about health practices and the health and safety of consumer goods, about how to get things done in sustainable ways, and about the environmental impact of their choices. They feel they can't trust consumer goods or medical treatments to be safe, they feel a sense of personal responsibility for climate change mitigation, and they believe governments aren't regulating companies sufficiently to ensure environmental preservation. This means that the task of learning about sustainability and sustainability practices falls to people like my respondents.

\section{Health Research}

Research was particularly important for families with a strong personal health priority. Most often, they rely on internet sources for information on the safety of medical interventions, food, and personal care products. Emily describes herself as an anxious person, and since becoming a parent, a lot of her anxiety is directed towards making choices for her children:

Emily: I think there are a lot of things that are stressful about parenting. You worry that they're going to get hit by a car. You worry about pretty much everything. Are they developing right? Does my kid have autism? There's a million and five things to worry about. 
Emily's personality and background in environmental science also make her a fastidious researcher of her family's heath choices. She reads websites run by organizations like The Environmental Working Group to learn about chemicals and contaminants in consumer goods.

Emily: Every decision that I make, especially around the parenting arena, is really tortuously considered. Looking up information, and looking up pros and cons of circumcision, vaccination, food, is it worth it to pay extra for this organic food? And I look up the Dirty Dozen, and I think, OK well, we definitely have to buy strawberries and apples and broccoli organic, but avocados we don't have to buy those organic. Like very, very careful but I approach it [sustainability] more from a health standpoint.

This practice of researching health and nutrition choices predates her children, and started when she realized she had some food intolerances, but she brings a scientific approach to her research habits.

Emily: I have been kind of like a hobby nutritional researcher. I was always doing it, even before becoming a parent. Just trying to weed through conflicting messaging and trying to land in a place where I feel good. For example, reading both sides of is it good to eat dairy or not.

Heather's education and career as a nurse also influence her approach to researching the health choices she makes for her family. She is very critical of conventional medicine, conventionally grown food, and conventional cleaning products. She also uses The Environmental Working Group website as a source for information, but she also uses more alternative sources for information, such as her initial opposition to water fluoridation and fluoride toothpaste.

Heather: I make my own laundry detergent, and we try to do that mindfully by using the Environmental Working Group website as a reference. Our environment in modern day society has so many toxins. If I can provide my 
children something that is less toxic... my children are my motivation for all of this.

While Emily is sensitive to barriers related to socioeconomic class and education that may prevent people from doing the same type of research and making the same choices she makes for her family, Heather is critical of people who don't seek out non-mainstream heath alternatives:

Heather: So many people just go through parenthood without really making it something they need to look into and research. My younger sister just had a baby, and she just does mainstream without looking into it a little deeper.

For Heather, part of being a good parent is "looking into it a little deeper" and seeing out and researching what she sees as healthier alternatives to conventional ways of getting things done. She is very strong in her belief that she is making the best choices for her children, and it seems to disappoint her that more people don't share her priorities and practices. Victor was unable to find the exact health information that he was looking for, so he's started conducting experiments on his family with various supplements.

One of the problems with research into chemicals and toxins and contamination is that there is no way to eliminate all possibility of contamination. Indeed, some informants are unconvinced of the benefits of exhaustive health research into what their children are eating and doing.

Brian: I'm more skeptical of health claims than other parents, I think. There's this kind of unavoidable pressure on parenting that is always on doing parenting a little bit better, which I try to avoid. And to the Nth degree. It just gets ridiculous. People get more and more obsessive about, "I'm exposing my child to some risk of injury," or whatever else. And I think that in Portland, or in similar 
cities across the country, I think that there is an, "Are you giving food that might give your kid some exposure to some ingredient that they might possibly form an allergy to?" Or that *laughing* or is maybe possibly dangerous to them? And I'm pretty sensitive to that stuff. And I do think there are ingredients that are dangerous. And I do think there are things in our food system that are a real freaking mess, but... Parenting has become kind of a high-stakes thing.

Brian loves his child dearly and cares about his well-being. He also acknowledges a lack of appropriate health and safety regulation of food and other industries in the United States. Given these realities, there is no end to the amount of research a person could do.

\section{Learning Skills}

Because few of my informants grew up in highly ecologically-conscious households, they need to learn ways of getting things done that are different from the ways they were raised and their parents got things done. Their late teens and early 20 s were an important life phase in life when my informants were frequently exposed to new ideas and learned new habits, such as selective flushing and preparing and eating fresh foods. Other informants told me that moving to Portland and being exposed to people getting things done more sustainably was a big influence, prompting them to adopt practices like bike commuting and natural parenting. Still, it is important to my informants to make these practices and skills their own.

Heather: We know a family who are doing a sort of Into the Wild thing. Her husband lived in complete nature for 20 years where he lived off the land. And that is amazing, but that is not us. And he has lots of skills to teach us, which I think are important for us to get back to our roots, but integrating them into our lifestyle. 
After her family's resent move to Portland, Heather has encountered other highly

sustainability-oriented families, some with practices that are more extreme than the ones she chooses to adopt. Finding balance is important for her household, who are not explicitly opposed to living in civilization.

The internet also plays a large role in learning new skills and practices. To learn how to fix her broken furnace, Penny relied on online tutorials and instructional videos which saved her money and gave her a sense of pride in accomplishing the repair herself. Fiona was able to learn how to make her own cloth diapers out of unwanted clothes before she had access to a low-income cloth diaper rental program, and later funds from her Earned Income Tax Credit. Mina relies on blogs about natural parenting and eco-conscious alternatives to conventional ways of getting things done.

Mina: When I am looking for people who are promoting a more environmentally-conscious way of life, what I find is a lot of people who don't trust vaccines, or think other medical things are also bad. For example, Wellness Mama [website]. She's got a ton of information for nettle tea, and essential oils, and making your own this or that. She has recipes for everything, and she has like six kids, and she homeschools. Its bananas. But I remember how she handles her children's colds. She gives them Vitamin C on the hour every hour, and I'm thinking, "Oh my gosh. Who has the time?"

While she finds some of the information about skills useful, there are other elements about the blogs that she doesn't like, such as promoting anti-vaccine views and types of intensive mothering that are "bananas." She no longer uses the social network Facebook because she found the communities for alternative parenting similarly too intense. 
Research about the Environmental Impact of Choices

For my informants whose sustainability practices are motivated by an interest in environmental preservation, conducting research into the relative environmental impacts of choices is an important aspect of household decision-making. Dayna and David rely on friends and co-workers who they trust. Since these personal contacts have similar values and have already done this research, David and Dayna feel comfortable following their advice. Penny and Ivy like to talk to the employees of a recycling center to learn more about how to properly sort and recycle their household waste that isn't accepted for curbside recycling. Penny has also done additional research online about recycling to learn where the materials are sent and how they are processed. Wendy and her partner read books to find out the relative carbon/environmental impact of choices, something that is particularly important to Wendy's partner. Rebecca did research online to find out about the relative impacts of cloth and disposable diapers.

Rebecca: We use cloth diapers and we use a local diaper service. And I did research and I don't think it is more sustainable than disposable because of the amount of hot water that you need to use to launder them.

Her household uses both disposable and cloth diapers, but she is not convinced that the cloth diapers are obviously more sustainable than disposable diapers because the process of washing them is also resource-intensive. 
Jim came to similar conclusions about cloth diapering, though he and Jess did use cloth diapers for their child after doing extensive research into the relative environmental impacts of cloth and disposable diapers. He still feels bad about having made the wrong environmental choice, and frustrated about not having access to definitive information about the relative impacts of his choices. In addition to the diapers, he told me about researching the carbon impacts of food, travel, bed linens, his clothing, and whether to buy a new car or keep his household's old one.

Jim: I struggle with where to find information. Not just with food but with all environmental choices. I've read quite a few books, and some are better than others. A book that was helpful was How Bad are Bananas?. It tries to establish a carbon impact of food and other lifestyle choices. A lot of it is estimates, which gives you a good starting point. It's super important and also nearly impossible to get accurate information about the relative carbon impacts of different choices.

He relies on books and websites, but finds the lack of clear information unsatisfying and vexing.

Jim: I enjoy talking about our environmental choices with Jess, I enjoy researching it, but I find it frustrating that I can't find information that I trust. A lot of the decisions or non-decisions that we make are because we just don't know what the right thing to do is.

He wants to make the right choices for the environment, but the information he would need to make all of the right choices is rarely clear, when it is even available.

\subsubsection{Motivations for Research}

Regardless of the informant's particular combination of priorities in the sustainability realm, this research is largely inspired by a singular cause-the protection of the 
environment and the health of household members has become the responsibility of my informants. Each household does this research and modifies their practices because they don't trust other institutions to take action against these potential harms on a larger scale. Because my informants feel that they can't trust institutions to make decisions that reflect their sustainability values, many of the households I spoke with value selfsufficiency as a way of getting things done.

Particularly for informants with a strong health priority, the interest in sustainability grew out of a lack of trust both in western medicine but also that the products available to consumers will be safe and that the government will adequately regulate corporations.

Heather: Families who solely trust the system are not us.

Emily: The FDA or the USDA approves chemicals because they haven't been proven to be unsafe. But nobody's proven that they're safe. Where's the 30year study on Roundup? And who is doing the study? And are they being paid by Monsanto?

Because they can't trust the government and the companies that produce and sell products to prioritize the health of my informants and their children, they must do this research for themselves. My informants who see the protection of the environment as their personal responsibility must do research to learn about environmental impactminimizing practices because they don't believe appropriate actions to mitigate climate change and other environmental and social problems are being taken at other levels. Informants like Jim and Nathan also don't trust other people who see themselves as sustainability-oriented to make the right choices. 
Jim: I am skeptical of calling ourselves "environmentalists" even though we strive to make the right environmental choices. We are always skeptical or realistic that we're doing enough. Whereas other people might recycle or buy a Prius and feel like they've solved the problem. We never feel like we are doing enough, and I never feel like I can solve any problem with choices I make in my lifestyle.

Nathan: I don't think there is any meaningful difference between organic and not. I don't think there is sufficient control over the concept of organic that I can understand it. I think a lot of that is a matter of marketing. I am actually proGMO because I understand it's consequences in terms of energy efficiency in production. The farmer doesn't benefit much from the organic label, and it's really hard on him economically. Yes, your prices go up a little bit, and your costs go up exponentially.

My informants feel out-of-step with mainstream America, and many of them also feel like they have little in common with others who care about sustainability issues because of what they've learned from their research.

While my informants may feel like their lives are very different from more conventional Americans, many of them share a very American value that motivates much of their research and many of their practices: a desire for self-sufficiency.

Dayna: self-sufficiency or self-reliance is something that is a theme for a lot of the decisions that we make.

Learning ways to be self-sufficient and finding information on sustainability practices related to self-sufficiency is an important type of research.

Gloria: I get information from the internet, I get information from the library, and I get information from getting to know people who are already doing what I want to do. And then doing it myself and the trial and error, whether it's composting, or chickens, or the vegetable garden. 
Ivy: I literally googled "things to think about when moving out of the city to the farm." And reading the blogs of people who have done that.

My informants who are passionate about self-sufficiency were not very clear on why self-

sufficiency is a good thing other than that it "feels good" or has some affective benefits.

IVy: If I wasn't working and I could just be a stay-at-home farm mom, I would be the happiest woman alive. I'd make EVERYTHING. My kid would be wearing all these crooked clothes and so would I! That's ideal! Being able to completely sustain yourself. Growing all your food... that's the Holy Grail. It's healthy and wholesome.

Dayna: I like that I feel that we are self-sufficient. The self-sufficiency aspect. The same way that it makes me feel good to be able to grow a portion of our own food. To be able to be generating our own electricity, that makes me feel really good. It's just damn satisfying, too.

Not all of my informants emphasized this idea of self-sufficiency and the affective benefits. Kyle, a socialist living in intentional community, believes that homesteading and self-sufficiency is not an environmentally-friendly way to live.

Kyle: Homesteaders aspire to being on the land and out of a city. And in terms of my environmentalism, I have a practical mind and I believe the most efficient way to live is in an urban area. It involves less consumption. Rural living is just very carbon-intensive and the schlepping of stuff unless you are a survivalist. But that requires a very large tract of land per person.

Penny also felt good and empowered when she was able to fix her furnace with only the help of online tutorials. However, Penny believes in the importance of community and understanding the impact of her actions on others, and doesn't see living in isolation as a solution to environmental problems.

Gloria: The part of "off the grid" that doesn't sit well with me is the association that off the grid excludes community. "Off the grid" and community are mutually exclusive. You cannot live off the grid and have a community. 
Gloria sees self-sufficiency practices like vegetable gardening and owning chickens as a solution to the high costs of local and organic produce, but sees living in isolation as antithetical to her sustainability priorities.

\subsubsection{Research Consequences}

Households often had a particular family member with a designated researcher role. In some cases, with Heather, this is due to differences in education, while for Emily, Jim, and Mina this is more due to differences in personality and interests.

Heather: He is always on board. He knows I have all the right intentions and that I do all the right research. He knows that I have the background and the education. It's never an argument. He trusts me. And that's also true when it comes to parenting things like not "crying it out" and co-sleeping and stuff like that. He's the workhorse and I'm the mastermind.

Eric: I get the benefit from all the heavy thinking and research that Emily does. I would say that I'm a little bit more pragmatic. I won't do the exhaustive research. I am either following Emily's lead or I'm looking at the options that are available to me and just kind of making a quick instinctive decision - I think is the one that is the better option from an environmental perspective.

The "researcher" in the couple does the research, and the other member of the couple generally goes along with their ideas, or, in the case of Mike, ignores them.

A disproportionate number of informants in my sample have paid work in what might be called the "sustainability industrial complex." This is at least in-part due to the generally anti-corporate values of my informants. 
Kyle: I've never worked in the for-profit sector. I worked in the government sector, and I was a consultant to non-profits and worked for non-profits. So I've always stayed away from organizations whose values I can't get on board with.

But another possible explanation is that an information or competence feedback loop between paid work in the sustainability sector and unpaid sustainability production in the home means that there is some kind of substitutability for the know-hows (or human capital) involved in both paid and unpaid sustainability work, as I discussed earlier in section 4.2.1.

Carrie: Through his job, he learns about the stuff and we take advantage of certain opportunities, so it's definitely influential just knowing what exists and how to do things.

David's education and training is in the health field, but he now works at an environmental non-profit after his involvement in making major energy efficiency improvements to his home during the gut remodel. Dayna learned about recycling from Master Recyclers at her office, and the organization where she works has lunchtime seminars with speakers on sustainability topics.

Dayna: Learning about things occasionally deeply influences my thinking. Maybe that's going to happen with me with cosmetics and body stuff when I learn more about that. I'm not a cosmetics and like body products person but I'm afraid learning more is going to ruin them for me.

She brings what she learns home and implements changes to the way she gets things done, most recently by deciding to eat less red meat because of the carbon impacts of beef production. 
Several informants told me that they believe more people would make these same choices and engage in similar sustainability practices if they were only exposed to the right information.

Gloria: If it was just loaded into your brain like Neo in the Matrix, the benefits, the costs of attachment parenting and the draw-backs. The benefits, the costs of cry-it-out and the draw-backs. If people understood all of that, I think most people would make a different choice and choose the alternative way of doing things.

Fiona: I have a concern with being what I would call classist. What I am really trying to avoid is saying that people who choose those [sustainability] things are better. I just think that if you have the choice and the information and the resources that you would probably make those [sustainability] choices.

Eric: We feel fortunate that we're able to make some of the decisions that we are because of both education reasons and financial reasons. And recognize that we are more sustainable because we have those means available to us. And we are aware of that, and that allows us to be more sustainable than we otherwise would be.

Fiona and Eric see this access to information as a privilege, and feel grateful for their ability to understand research, to know where to find information, and for the ability to follow through and make changes to the way they get things done.

At the end of the day, the reason my informants are having to do this research at all is because they believe it is their personal responsibility to keep the environment and their families safe from potentially harmful industries and the impacts of pollution and chemicals. As Emily said, the research about what is and isn't safe for her children isn't being done, and in the rare cases when the research is being conducted, she doesn't trust the results. My informants look at mainstream America, and they don't like what 
they see. For this reason, many of them want to separate themselves from conventional American society to create their own communities or to live in isolation from the aspects of contemporary life that they find distasteful or in conflict with their priorities. Somewhat ironically, this ethic of independence and self-sufficiency is at the core of American identity (Fineman 2000).

\section{$\underline{6.3 \text { Conflict over sustainability practices }}$}

My informants see their practices and priorities as unconventional, and many have made deliberate choices to distance themselves from mainstream American values and ways of getting things done. A consequence is that these households sometimes come into conflict with others who do not share these priorities and practices. Within individual households, there tended to be differences between the adults in their sustainability priorities - either one adult will be more committed to alternative ways of getting things done, or adults will have different priorities in the sustainability realm. Differences in the priorities of my adult informants and their own parents also provoked conflicts, some minor and some more relationship-altering. While never framed as an outright conflict, my informants were working to teach their children to behave in ways that matched the household's sustainability priorities. These lessons often emerged when children were doing something my informants deemed wasteful. My informants acknowledged that their unconventional practices and priorities may result in conflicts between their 
children and conventional elements of the world outside their household. Finally, my informants discussed internal struggles and guilt associated with making choices that are not aligned with their sustainability priorities.

\subsubsection{Conflicts between adult family members}

Many of the couples I spoke with began their relationships on the basis of their shared values and priorities or developed these sustainability views and habits over the course of their relationship together. Conflicts arise between adults when they have different sustainability priorities, when they share priorities but have different beliefs and information, when their priorities are held with different levels of intensity, or when one partner is the sole member of the household driving the sustainability priorities and efforts.

One way that conflicts between adults can arise is when a couple who shares sustainability priorities nonetheless has different beliefs and knowledge about sustainability practices. Recycling was one of the areas where this conflict occurred fairly regularly in the households I spoke with. Portland has recycling rules that change over time and that my informants find are not always intuitive. While recycling was a universal practice in the households I spoke with, household members had different levels of compliance with recycling rules. There was often a member of the couple who was the recycling expert, and worked to enforce recycling rules in the household. A conversation 
between Dayna and David about their different opinions on recycling brings this type of

conflict into focus:

Dayna: David goes based on the spirit of what he thinks should be recyclable. This is a big, long-term marital thing were David thinks that things he thinks he should be able to recycle at the curbside, if he puts it in the curbside recycling bin, even though it's not recyclable it's "sending a message" that they should be taking this thing. And I'm just like, you're making people's lives more difficult.

Kirstin: So, David, you're laughing.

Dayna: Because it's true!

David: I mean, it's like... marginally true. I may have used to have done that.

Kirstin: So what is something that you think should be recyclable that you have put in the recycling?

David: Like clamshells, plastic clamshells. Those aren't supposed to go in the recycling, but I sneak those in there.

Dayna: Mostly it's plastics, for David. A lot of plastics or to-go containers or wax...

David: Dayna always tells me that the paper boxes that go in the freezer...

Dayna: ARE NOT RECYCLABLE!

David: But they look like they should be recyclable and they have the recycling symbol on them...

Dayna: So David puts them in there anyway! And I'm like NO! You're not following the rules! The Master Recycler people have been very clear.

David: Even the ones with the little symbol on them? I mean, it looks like they're recyclable.

Dayna: NO. So.... *laughing* 
Quinn describes a similar recycling dynamic in her household. She will also take items that she believes are recyclable out of the trash bin at work at put them into the recycling bin, though she admits that she isn't always sure of the rules and occasionally learns she is wrong. Quinn and her husband are both vegans, primarily for animal welfare reasons, though the environment is also a major consideration in their day-to-day choices like food and transportation. Despite shared priorities, Quinn's husband places a greater premium on comfort and convenience when it comes to getting things done.

Quinn: My husband does consider the environment for sure, but I think I get more anal about certain things like running the heat. If there is an item that as a little bit of plastic but is mostly paper, I'll rip off the plastic and put the paper in the recycling. My husband isn't as good about the recycling. I get pretty anal about the recycling. And sometimes he will take a Car2Go [short-term car rental] home. And it is probably because he's running late, but I would never put our money towards that. To me it doesn't make sense when there's a bus right there.

Different sustainability knowledge doesn't always lead to spousal conflict, as in the case with Rob and Rebecca.

Rob: Let's be clear-Rebecca is driving most all of these decisions. And I am completely OK with that. She has a passion and an education for it, and I don't. Since our values are basically in accordance, I'm like, "Cool. Let's roll with it."

Rob appreciates Rebecca's knowledge and dedication to their sustainability practices, and their joint commitment to pragmatically balancing their pro-environmental and community-oriented priorities with their own sanity helps them avoid disagreements over anything becoming "too extreme." Wendy told me that her partner's commitment to sustainability is inspiring and is something she loves about her. 
Other couples share their sustainability priorities, but one member of the couple is more insistent on their practices than the other. Jess enjoys running long distances, but her refusal to replace worn-out footwear causes her physical harm. This concerns her husband, who intervenes.

Jim: Jess buys nothing. Almost nothing. We have to force her to buy work clothes. You buy nothing! I bought workout shoes for you because yours has no soles on them, so you couldn't function.

Several of my informants insist on keeping the temperature of their homes so low that their spouses are uncomfortable. Ivy and lan's home does not have central heating, and has only one working baseboard heater, which is in their child's room. In the winter Ivy needs to lie under blankets in the living room as soon as she gets home from work. She describes herself as a "whiner" for not being able to adequately cope with indoor temperatures between 50 and 60 degrees. Victor is the one in his household who knows how to program the thermostat, and he set it to 62 degrees during the day when only Vanessa is usually home. This is much colder than Vanessa would like, so each day she has to manually increase the temperature to 66 degrees to feel comfortable. Victor will not change the thermostat program, figuring that Vanessa might have obligations outside the home so it is better to have a low default setting that she can increase rather than the reverse, which could potentially be wasteful. Orla is far more waste-conscious than Owen, and would prefer to keep their home colder during the winter to save resources. 
Orla: If he doesn't feel warm enough, he is more likely to hit the button and turn the heat up. I try not to do that. I would put on a sweater or drink warm drinks.

Owen: That is your cheapness coming out.

Gloria would prefer to not run the heat at all, but compromises with her husband by

picking a temperature between their two preferences:

Gloria: My husband makes a lot of the heating and cooling decisions because I don't want to spend the money. I would prefer to not use the heat at all. I would prefer to put on my wool socks and some sweatshirts. We keep it low... like 65. I would want it at 60, and my husband would want it at 70, so we settle on 65. And then I try to supplement with the wood stove. In the spring and the fall, it's just off. Once it's 65 outside, it's off.

Some sets of spouses have different priorities in the sustainability realm. Nicole wishes Nathan wouldn't spend his time fixing cheap things that could be replaced, and Nathan is less interested in recycling than Nicole is.

Nathan: There are varying degrees of OCD in this household. There are issues that I am OCD on and she's not, and vice versa. And the recycling is something she is OCD on and I'm not. We both do it, but she will take things out of the garbage to fix it. I won't clean out a grody can.

Nicole: We have debates all the time about fixing things that we could replace. I add the financial piece. It is just not worth the effort. Your time is a fixed commodity.

Gloria sees the differences in sustainability priorities between her spouse and herself as a benefit, since it allows the household to follow through on a larger number of sustainability practices.

Gloria: We divide the work very evenly, it's very 50-50. The strength of our interest varies, so it kind of comes out as a wash. He's very interested in not 
buying new stuff. He's very driven to find used stuff. He is very motivated to do that work. And sometimes I'm like, "Ikea is like, right there! They have solar panels on their roof, it's fine!" It's easier for me to fail in certain realms that he's very strong in, and vice-versa.

Like many of my informants, Gloria views the division of labor in her household as egalitarian, though this may or may not be the case.

Conflicts also arose in households where only one of the spouses had interests or priorities in the sustainability realm. Mina's strong interest in sustainability practices only arose in the last couple years following her relocation to the Portland area. Mike appeared to tolerate many of her new practices as long as they didn't impact him too much. He spent most of our interview sitting silently with his arms crossed across his chest, but he does care about the environment or the health of his family members. In fact, he supports Mina's efforts and even suggested donating to the Sierra Club following the election of Donald Trump.

Mina: When I start getting into GMOs and parabens and phthalates land, he tunes me out.

Mike: Part of why I loved moving to Oregon is that I love nature. I don't think fracking is awesome. I care about the environment, but I don't do the day-today.

Not doing "the day-to-day" for Mike means that he ignores a lot of Mina's sustainability practices and eats convenience foods he makes for himself separately from the rest of the family.

Mina: You won't eat most of the food that I make.

Mike: It's not what I prefer to eat. I'm horrible about food. I love GMOs. 
Mike has adapted to Mina's new interest by taking a non-confrontational but slightly defensive approach, at least as far as his interactions with me went. But again, these differences did not always lead to conflicts. Heather describes trying to be sensitive to her non-sustainability-oriented spouse and his needs:

Heather: I constantly feel like I'm changing things to be more sustainable, and I wonder how much more my husband can take and how much more of his lifestyle can be changed. He's on board, but I feel like it is at least once a week that I'm coming to him with a new idea. We can eat this, and now we can't eat this. And now we can't eat gluten. And he's just like, "I don't know what to eat. I don't know what I can feed the kids when we're out. It's really hard." And so he buys a gluten-free macaroni and cheese in a box. And I'm like, "That's why we did Whole 30! So we don't have to buy that stuff!" But he needs the simplicity for being able to feed the kids.

Despite these concerns for her husband's ability to cope with their dietary changes, Heather is forging ahead with their whole foods-based diet.

\subsubsection{Conflicts between adults and their own parents}

My informants' parents frequently had different priorities than my informants, and this sometimes caused conflicts or disagreements. Grandparents attempting to help out by purchasing toys and other items for their grandchildren is a problem for Penny and Fiona, single mothers who appreciate their parents' willingness to help but wish they would do so in a way that was consistent with sustainability priorities. Penny's parents buy poorly made plastic toys:

Penny: They'll get presents from their grandparents, and they'll be these plastic horrible things that they tend to not even really use. So it's a balance-- how 
pushy should I be to ask them to stop sending us that stuff, versus how much should I just let it drop?

But Penny tries to be diplomatic, and struggles with knowing when to intervene. Fiona's parents also don't buy the right things, and she has to educate them about what to buy so that their help is consistent with her priorities.

Fiona: Yeah, there have been a couple disagreements with my parents over kids' toys. I'm trying to avoid plastic-y stuff, and just more stuff. Like you saw, he will entertain himself for half an hour with kitchen implements. So very few toys is my goal. So family gets him more stuff than I'd like him to have. And I rotate stuff out just so that I don't have it all out at once. There have been some uncomfortable moments of wishing they would be thinking about things more the same as me. Or wishing they had more time to do research. Because my mom works full time, too, she'll order something online. But I feel like she's gotten more consistent with asking, "What exactly do you want?" and they'll contribute more in those ways.

Some conflicts arise not out of the attachment of the grandparents to consumer culture but rather to thrift. Emily describes Eric's mother as cheap and a bargain-hunter, while for her household sustainability practices are worth the extra money and effort.

Emily: I make Eric's mom use only physical barrier sunscreens on the kids, and she just rolls her eyes at me. "But the spray is so easy!" And I'm like, "You can't use the spray on the kids." I don't really argue with her about very much of anything, but that was the one thing where I was like, "I have to ask you to not use the spray sunscreen. I know it's easy. I know it is." But it's just not proven to be safe.

Eric: Our parents are putting in some effort to meet us half-way. They know that we care about those things, and they will let us drive that. And we try to meet them halfway. Like we try to bring the sunscreen as opposed to us expecting them to change what they do, and expecting them to have certain things available to use on the children. 
However, as Eric explains, he and Emily go out of their way to accommodate their

parents and make it as easy as possible for them to follow their sustainability practices.

Andrew and Amy similarly struggle with the thrift-mindedness of Amy's father, who has

been living with them part of the time to help out with the children and other tasks.

Andrew: Amy's father is more traditional. He's been living with us a bit, sort of on and off to help with kids as we're juggling our schedules, and he is much more traditional in his food-buying practices. Much more traditional in the sense that he gets everything from Winco and Safeway and these kinds of places. And so there is a little bit of a tension there sometimes, right? In that, especially when it comes to like raw produce, things that you aren't cooking, like lettuce. There's certain things that I really would prefer were organic versus like mass farmed with whatever chemicals are being used to grow it.

Amy: Sometimes we just mention it, or we try to say, "There are certain things, if you need it, then put it on a list or tell us, and we'll go get it." But, it's an especially difficult time with our schedules, so he tries to take that burden away by going to the store and buying stuff, and it's hard and he won't really take money from us, but his biggest concern is cost.

Andrew: Yeah, he's all about cost.

Amy: So it's a difficult interplay right now.

Andrew and Amy deeply appreciate Amy's father's help during a challenging period when time is particularly scarce, and they try to be respectful of his priorities and values.

However, avoiding conventional produce is very important to their household, so they are still working out ways to accommodate this difference in priorities.

Dayna and David's parents don't understand their priorities, and give them a hard time about their old car, their bicycle commuting, and their smaller home. The couple like to 
have "less stuff", and their parents are particularly upset that the couple occasionally

gives away family heirlooms on Craigslist:

David: Yeah my mom definitely feels like an emotional attachment to everything that was passed down from her parents. Like their artwork and their stuff and holds on to it very dearly. And when something comes our way, we're kind of like, "Eeeeeh. Craigslist!" And she's horrified by that notion.

Dayna: Less is more. We are trying to rid ourselves of the concern that just because there is something you own that someone spent a lot of money on at some point, and now you have it... but it's like a stone around your neck. Just let it go! Get rid of it! That's definitely a difference of opinion we have between us and our parents.

Andrew's father makes fun of him for the contradictions involved in some of his choices.

Andrew: We have this wood-burning stove that we use a little bit. My dad who is super conservative keeps like poking at us, "You know that's like the most polluting way to heat your eco-friendly house! You guys are polluting the earth!"

But some of the interactions are more antagonistic and involve name-calling.

Penny: My dad will call me a tree hugger and a crazy eco-person.

Both Gloria and Heather have periods where they cut off communication with their

mothers because conflicts over priorities and parenting get so heated.

Gloria: My mother is hardcore Republican crazy. I'm in a phase of deciding whether or not I will maintain a friendship with my mother because it's gotten quite toxic. With my mother there is so much conflict. The differences in our values are so pointed.

Heather interprets her mother's lack of sustainability priorities as indicating she doesn't care about Heather or the children.

Heather: You can speak to someone like my mom, who is a Republican, who could have voted to have the non-GMO bill passed. But she chose to vote against it because she felt like she is older now and she wasn't affected. And that made me so angry. Because what about her children, her grandchildren, 
her grandchildren's children, and the environment that they're going to be living in. That's a huge conflict.

She will go a couple of years at a time without talking to her mother, but ultimately caves and decides to maintain a relationship because she feels it is important for her children to know their grandmother.

\subsubsection{Conflicts between adults and children}

Sustainability conflicts between adults and children generally revolve around teaching children the sustainability priorities and practices of the household. Several respondents discussed teaching their children to avoid wasting resources around the house. Carrie, Ivy, and Owen and Orla told me about talking to their children about conserving water.

Carrie: I remember pretty early on telling them, "Turn off the faucet, save some water for the fish." But we had explained in the past that we need to conserve water.

Ivy: Outside when she's playing with the hose. "What are you doing? You left the hose on!" So I tell her, this is why you need to do this. That's where those lessons come from, normally when she's doing something that she's not supposed to be doing!

However, Owen and Orla found that these lessons can be complicated to teach young children who don't yet have a concept of what "waste" means:

Owen: Our oldest kid is a terrible water waster. Both of us are constantly on him like, "Shut if off! Don't waste water!"

Orla: I realized the other day that I was telling him all the time not to waste water, and it occurred to me that he might not know what I meant when I was saying that. So I asked him if he knew what I meant when I told him not to waste something, and he said, "Nope!" So I had to explain! We are trying to train them and encourage them not to waste, but I think the grasp is still pretty loose. 
Ian also struggles to find age-appropriate ways to communicate with his daughter about their sustainability practices and priorities, and the reasons behind them.

Ian: If she doesn't eat all of her food, I talk about what that means for the environment because it took a lot of energy to make that food, and then they're the off-gassing. She's six and it's probably not going to stick, but I want to have those conversations with her because it's important to us.

Similarly, children struggle to turn off lights in empty rooms, something that is also related to their difficulty in understanding the concept of "waste".

Heather: See? I just turned the lights off, and my daughter was like, "Why did you just turn that light off?" In the kitchen that nobody's in!

Amy: I've been trying to talk about leaving the lights on and things like that, and they just have no concept of wasting electricity.

Chris humorously linked this propensity for children to waste resources to global warming, implying that his children's use of a natural gas fireplace insert was hastening their own deaths due to global warming.

Chris: I think about it a lot with the gas fireplace. They turn on that fireplace, and I'm just like, "You're just killing yourself slowly!!!" *laughing* I didn't say that to them, but I thought that.

And Quinn has conversations linking their practices to larger global humanitarian issues when her son complains about biking home from school in the rain:

Quinn: If my son is complaining on the bike ride home because it's raining, I believe he needs to learn to deal with that. And I tell him that there are kids who walk much further than this every day just to get water. 
Being a child in these families means learning the priorities and practices of the household's culture.

\subsubsection{Conflicts between children and the outside world}

My informants expressed that they are aware that the lifestyle and choices they are making for their children are outside the mainstream, and may impact the way that their children interact with their peers. They recall the pressures they experienced themselves as children and teenagers, and don't want their children to experience negative consequences because of the unconventional priorities and practices of their households. Penny dislikes the plastic children acquire from places like arcades and birthday parties, but she also understands these items are part of a typical childhood experience.

Penny: I wish I could be more rigid and not allow any plastic into the house. But at the same time, I recognize that it would be hard to be the kid of someone who was rigid like that.

She decides not to be "rigid", because she is aware that putting these kinds of limitations on her children could be stifling and cause them social problems with their peers.

Chris is strongly against consumerism as part of his environmental priorities. He is trying to teach his children to share these values, while at the same time trying to be understanding of the pressures his kids might be under with their peers at school.

Chris: Yeah, there were kids at school who were really into Pokémon, and now he's got a couple other friends that are into these soccer cards. So he was actually really open about it, and I said, when you buy those is it just because 
you want something shiny? Which I totally understand, because shiny is important. Or are you trying to impress your friends? What are your motivations? And he was like, "Well, it's a little bit of both." And I was talking to him about that more in terms of well, to me it is much more impressive when you can show your friends something that you made or something that you can do versus something that just anyone can buy. That to me isn't particularly impressive. And that's maybe not the perfect example, but I remember a different conversation where he was talking about wanting to buy some other things, and I'm not remembering what it was off the top of my head, but I remember saying to him, "When I find myself in that situation... when I just want this thing so I can have it, but it doesn't have any real bearing on my life or it's not going to last or I'm not going to be able to use it do to something with... Well, then I just feel like I should just punch myself in the face because I just want something." *laughing* So you know, maybe not the best language with an eight-year-old...

He approached the conversation with his son with humor but also sensitivity and empathy, telling his son he understands the appeal of "shiny" consumer culture and explaining why it isn't in line with his values. Orla feels that her children are still too young for these types of conversations about consumerism and consumer culture, but she says she is looking forward to sharing her values with them.

Orla: I think a lot about what I want them to learn about consumerism and the impacts of the choices that they make. They're too young to understand money, but I'm looking forward to having those discussions with them. I remember having those discussions with my parents when they taught me that I don't need to buy everything that I see that I like. Maybe it's just a temporary desire and having this thing wouldn't really make my life that much better.

Gloria homeschools her children, who don't have much exposure to devices or technology.

Gloria: To a fault, my kids don't have any experience with devices, video games, apps... I think they're going to be at a disadvantage. 
For now, she is happy with the way things are, but she worries that this lack of exposure to technology might be harmful in the long-run. Amy is strict about what her children can eat, but she is flexible when it comes to school and birthday parties. In her view, being balanced to avoid social problems for the children.

Amy: The kids eat school lunch on Thursdays for pizza day. I assume it's not good, but I think we also try to practice a balance. Like try not to be too crazy about things as long as it's not the norm. If there is a birthday party, they are going to have cake and whatever that cake is, but we're never going to buy stuff that has food coloring and frosting.

My informants see elements of the conventional, outside world as harmful to their children, but at the same time they want their children to grow up into healthy, welladjusted adults. Picking how much conventional outside influence to allow is a balancing act.

\subsubsection{Internal Conflicts and Guilt}

My informants care deeply about sustainability and believe that their day-to-day choices have important impacts. This means that when they make a choice that isn't aligned with their priorities, they sometimes feel guilt and remorse. Carrie likes to travel, and finds that difficult to reconcile with her knowledge that the carbon impacts of travel are much larger than many of the day-to-day carbon impacts she works to avoid.

Carrie: I feel guilty about flying in airplanes. My carbon footprint is terrible! All the little things we do don't nearly add up to carbon impact of flying places. But I really like to travel! So I am not really sure what to do about that one. 
Because Eric and Emily both work full time, the household relies on Amazon.com

frequently for the convenience and time-savings of having items delivered to their home.

Emily: I always feel a little guilty when I get something from Amazon or something that is egregiously packaged.

She knows this decision is not good for the environment, and feels bad about this compromise in her values for convenience's sake.

Carrie: I have to be way better about all of the packaging, and I've taken to ordering things online, and then I feel bad about packaging.

Kirstin: What drives the decision to order things online?

Carrie: Ease and time constraints.

Guilt over Amazon.com purchases and the associated packaging was a fairly common subject that informants brought up. They feel that packaging is bad for the environment, but they also feel such pressing time constraints that the ease of ordering needed items online is worth the emotional discomfort of dealing with the packaging once the items arrive.

Heather also found it necessary to stop cloth diapering after she had her third child.

Heather: It [cloth diapers] was a priority, but when it became too much work, I had to let something go. And I still have a little bit of guilt about not doing it as long as I could have.

Penny compares herself to other people she knows who consider themselves sustainable, but don't appear to have the same kind of guilt that she does about driving places to save time. 
Penny: I drive a lot, but I feel a lot of guilt about that. A lot of my friends will drive everywhere, and it would never occur to them to take the bus.

She knows that she is doing better than most of her peers, but her awareness of environmental issues means she also knows she could be doing more.

\section{$\underline{6.4 \text { Trade Offs }}$}

Possibly the most central idea in neoclassical economics can be summed up in a single line from Kevin Costner's 1995 flop of a post-apocalyptic film about life after the melting of the polar ice caps: "Nothing's free in Waterworld." Or from a popular introductory economics textbook, "To get one thing that we like, we usually have to give up another thing that we like. Making decisions requires trading off one goal against another," (Mankiw 2012, 4). Trade-offs may be what neoclassical economics is all about, but this concept of scarcity, popularized by Robbins ([1932] 2007, 15), must be understood in context. External forces - such as the economy, society, and cultures in which we liveinfluence and constrain decisions that economists model as made freely by autonomous individuals. These constraints frequently mean that my informants find they can't do everything they'd like when it comes to their sustainability values.

Emily: The realities of life are what they are, and everybody just needs to do the best they can. And just because I really am an anxious person, I really needed to be like "I can't have this on my shoulders." This can't be all up to me. I'm just going to do the best that I can, and... So in many regards, I think I've sort of stepped back from having it [environmental causes] be a driving force.

Prior to becoming a parent, Emily had more time and energy to make the environment and sustainability a top priority. Now, with all of the other responsibilities and concerns 
she is juggling, she feels like she is no longer able to take on the additional burden of worrying about the environment as much as she used to. Something had to give.

Trade-offs between priorities are most apparent in my informants' day-to-day lives when it comes to budgeting their scarce time and financial resources. Some sustainability tasks they are unable to do because of not enough time or money, while some informants told me that they substitute money for time or time for money when it comes to sustainability practices. Mental and emotional energy is also in limited supply and my informants need to rest between all of their paid and unpaid work. So even when they feel like they have enough time or money, they have decided to stop or decrease their adherence to certain practices to preserve their own sanity. A particularly poignant example of trade-offs in the lives of some of my nature-focused informants is the decision to have children despite a firmly-held conviction that having children is the worst thing they could do for the environment. Balancing regular life with sustainability priorities means that my informants are frequently faced with difficult decisions, and the compromises involved make them feel guilty and upset about their inability to live in a way that is fully compatible with their ideals.

\subsubsection{Budgeting}

My informants balance their time and money to get things done in day-to-day life, but they do not have either in limitless supply. Sometimes, financial budgets took the priority 
over sustainability goals. Jim and Wendy told me about needing to buy clothing for their children at mass retailers like Target, where they know the clothes were not produced sustainably or according to their values surrounding the treatment of workers.

Jim: It is depressing when we have to go to Target and get environmentally bad crappy new clothes for our kid. I guess the other option would be to get organic cotton at boutiques, but that's not really economically reasonable.

The alternative to a high-cost organic children's clothing boutique would be trying to find items in a second-hard store or free, but I was told by many parents that children's clothing is difficult to find for many age groups because the clothes get worn out and destroyed so quickly.

For other households, a lack of time caused them to abandon certain sustainability practices.

Fiona: There have been, in my life situations, where I know that I could do this [sustainability practice] but it would be TEN TIMES HARDER. So there is a little bit of selectiveness in that some things are easier than others.

Andrew: I feel like for me it's a balancing act. I have all of these things that I'm dealing with on a daily basis, with kids, and job, and whatever. I have really limited bandwidth at this point in my life, and I feel like time is becoming more and more valuable. I feel like I don't have enough of it. And so it becomes this balancing act of: what are the things that I can do, lifestyle wise, environmentally, that are going to have the biggest impact but are not going to take insane amounts of time and energy to make happen.

Fiona tends to select the practices that are the easiest and take the least amount of time, while Andrew told me that he does a mental cost-benefit analysis to select the practices that have the highest environmental impact for the least effort. 
Other households, like Yvonne's and Victor and Vanessa's, have decided to substitute time for money in getting their sustainability practices done. Yvonne quit her two jobs in the service sector so that she could focus on intensive urban homesteading tasks like making her own laundry soap, growing much of their own produce, and making meals for her family from scratch. Yvonne's unpaid sustainability work allows her family to live on one income. Victor sees his household's decision to substitute Vanessa's unpaid time for market purchases in larger terms.

Victor: This is the big Faustian bargain of the modern economy. People see themselves struggling to get by and cannot imagine what a 30-50\% drop in income would do to their finances. But that's the lie. Income may drop 30-50\%, but expenses drop an entirely commensurate amount with virtually no economic sacrifice to the family's standard of living. 30-50 hours a week, depending on full or part time and the amount of commuting required, is freed up to "work" for the family. Frankly, I think families with both parents working are nuts, and accounts for the falling, sub-replacement birthrates among western countries.

Victor sees his wife's unwaged work for the family as more than replacing her lost income, and believes that it is better for families in general if women avoid working outside the home. The extra money that waged work could add to the household budget is not worth the cost. While few of the households I spoke with were making the same kinds of choices as Yvonne and Victor and Vanessa, most of my informants were aware that these choices were a possibility.

Rebecca: I think that the way we try to make sustainability choices is more expensive, but I don't think that's true in general. My brother and sister-in-law have two kids, and they grow all of their own food, they reuse a lot of things, they make their own yogurt, they do a lot of sewing, and his business is around 
using salvaged wood. They do it very cheaply because they have a stay-at-home parent and more of a homestead thing. They are substituting time for money.

Rebecca likes her job and working outside the home, and she doesn't particularly enjoy gardening, intensive food preparation, and crafts, so she is happy with the decision that she and Rob have made to both work for wages.

Several of the higher-income households I spoke with told me that they were aware of cheaper ways to get things done sustainably, but that because of their work schedules they wind up substituting money for unwaged time in their sustainability practices.

Owen: I feel like our more traditional career-focused jobs make it more difficult to not spend more money to be eco-conscious. Orla and I both work more than 40 hours a week, we are continually at the office, or taking care of the kids, or putting in extra hours from home. So if we want to make eco-conscious things happen, we pay to make them happen by buying certain things.

Rob: Relatively speaking, we are doing phenomenally well economically. And that gives us the privilege to make a lot of these choices with limited hassle. That makes it easier for us to make these choices.

Rob and Owen see the wages that household members earn from their paid jobs as allowing them to make sustainability-oriented choices with limited difficulty.

\subsubsection{Giving things up for sanity}

Some of my informants feel that they have enough time and money but find that they need to prioritize their mental health over certain sustainability goals. Because mental and emotional energy also need to be budgeted, many households tell me that they have been "giving things up for sanity." Jim is extremely conscious of the carbon impact of his 
choices, but he has found that strictly limiting his food purchases to minimize his

environmental impact was no longer practical once he had a child.

Jim: He's a picky two-year-old. His health trumps environmental choices. If he doesn't eat, he's grumpy. So really his health and our sanity is driving some purchases of packaged food and out-of-season produce.

So that they can remain sane, making sure that their child eats and sleeps is now a top priority for Jim and Jess. This causes them to buy food they wouldn't buy otherwise, and to run an electric heater in their child's bedroom, which they believe is bad for the environment.

The idea of prioritizing sanity was often framed as a way that my informants give themselves permission to make a less labor-intensive but also less sustainable choice.

Penny: There are times when I am cleaning out the refrigerator and I'll find a gross yogurt container or something, and I don't want to go through the pain to clean it out to recycle it. There are moments for my own sanity when I have to say, "OK in this moment, I need to just not care."

Fiona: We use cloth diapers probably $90 \%$ of the time. Occasionally l'll get really tired of laundry or behind on the laundry, and so l'll use disposable sometimes in those situations. I have the disposables around for my own laziness... but maybe it's really just self-care. Keeping my sanity about the laundry.

Heather: We used cloth diapers for the most part with my first, and then for less time with my second, and the third she may have gotten maybe the first six weeks. It was a priority, but when it became too much work, I had to let something go.

They recognize that it is not possible to live a perfectly sustainable life, and sometimes it is necessary to allow themselves to revert to more conventional ways of getting things 
done, even if they find it personally upsetting to abandon certain sustainability practices in favor of their mental health.

Gloria takes a pragmatic approach to sanity out of necessity-she was unable to balance her sustainability priorities with her desire for a clean home while simultaneously caring for three children under 13 months of age.

Gloria: Baby \#3 was born 13 months after the twins. And she was a real catalyst for letting go. It helped me learn to stop being so crazy about cleaning. But that's when things came into my life like a Swiffer. But I hate throwing things away, so I made a little sock thing for the Swiffer. I tried to find things that were convenient that I could adapt to my values.

To stay sane, she found ways to compromise a little bit in each area-cleanliness and sustainability - so that she could manage the demands of her work as a mother of young children.

While both Eric and Emily care deeply about the environment and the health of their children, Emily's personality means that she can have trouble letting go of things that are important to her. Eric is more laid-back, and has encouraged Emily make herself and her own well-being a priority, too.

Eric: I think it's largely a bandwidth issue. We both work and we have two kids under 10. Day to day survival starts to take more of a priority. Some of those [environmental] micro decisions start to fall off a little bit.

Emily: We're seven and a half years into this parenting game now, and I think there was a point where our son was two, and he was a really challenging toddler, that I think it was like "something has to give." I was really stressed out. 
Eric doesn't really get stressed out, but he was not happy with me being unhappy. There comes a point where you have to be like, "I can't do it all."

A similar pattern emerged in my conversation with Rob and Rebecca. Rebecca has a strong community-minded approach to her sustainability priorities, but she also values her own sanity-a concept that came up several times during our conversation. It was clear that she and Rob have on ongoing dialogue about balance between time-intensive sustainability practices and their ability to take care of personal needs and the needs of their young children.

Rebecca: I feel like in general, and it's because capitalism does this, people prioritize themselves over everyone together. Which I do, which we do, when we decide not to do certain [sustainability] things so we can maintain our sanity. But it makes it hard to have respect for people who prioritize themselves all the time.

Rob: We are trying to reduce our impact on the environment, but we are very cool with making compromises for what's within our sanity and financial resources.

Rebecca: There is not really time during the weekend between grocery shopping and kids' activities to make a special trip to the recycling center, but down the line I can see that those are things that we would want to do. Right now, we are prioritizing sanity.

My informants find it necessary to give themselves permission to occasionally deemphasize their sustainability practices, giving up some of these practices so that they can remain sane. Rebecca doesn't like to give up these sustainability practices, and she feels that doing so is in conflict with her values, but she has a limited supply of energy and feels like she has no other choice. 


\subsubsection{Anti-Natalist Informants}

My informants called their children things like "water-wasters," "energy hogs," or "little consumer machines" and told me that most sustainability practices don't come naturally to children. Others look forward to their children getting older, when they believe they will have more time to get back to some of the time-intensive sustainability practices that they had abandoned when they became parents. For some of my informants, the decision to have children at all represents the ultimate compromise of their sustainability priorities. They believe that having children is one of the worst things a person can do for the environment.

Quinn: There is a car-free family here who has five biological children. And maybe they'll all end up car-free when they grow up, or maybe three of them will end up with cars one day. And maybe she'll end up with 25 grandkids. There's no guarantee that the children will have the same values. In fact, maybe they'll grow up to be really opposed to those environmental values. So now that I think about it, I don't think they are more sustainable than me because I don't have biological children.

Chris believes the decision he and Carrie made to become parents to two children was a major concession of his environmental values. Like several others in the study, it is Chris' view that being a parent is antithetical to sustainability.

Chris: I think raising kids in a first-world country is probably the least sustainable thing that we can do! But you know, you make your choices in relationships.

Kyle and Kelly decided to have only one child for environmental reasons, reflecting the reasoning in Maybe One: A Case for Small Families, McKibben's 1999 polemic on the environmental destruction associated with of overpopulation in the United States. 
Kyle: We live in one of the richest countries in the world, most highly consumptive. And we decided to have a child! And that is one of the worst, most consumptive things to do is to create another person who in turn is going to consume more.

Kelly: We got together knowing we wanted to have a family. But we have decided to only have one child, partly because of our environmental values, and also *laughing* because it's a lot of fucking work!

Kyle and Kelly entered their relationship knowing that they wanted to be parents, and they saw having just one child as an appropriate compromise of their environmental values. That being said, they do not shy away from their conviction that this decision was bad for the environment. Jim and Jess also emphasize that they have retained their view that having children is bad for the environment even after becoming parents.

Jim: We still feel that having a kid is a bad environmental choice. It's not that we've changed our mind about the environmental impact of a kid. We just changed our mind and decided we were willing to compromise or forgo our ethics. We decided it was more important to have a kid than to sustain that environmental ethic.

They entered their relationship agreeing that they did not want to have biological children on environmental grounds. Later in their relationship, Jim and Jess decided they wanted to be parents and tried to adopt, but became frustrated by their inability to find adoption resources and support for couples who were adopting for environmental reasons. Eventually, they decided that their desire to be parents was more important than their environmental values, and that they needed to make a compromise.

Jim: Some people think they are environmentally-minded, but in my mind the worst environmental choice you can make is to have a family, to have kids. That speaks to me to enormous hypocrisy to say you're an environmentalist and to have kids. But it is such a sensitive subject because it is a very personal decision for people. 
They still struggle with guilt over their decision to have a biological child, though they do not regret becoming parents. However, they agreed that two children would feel like too much of a compromise of their priorities.

Jess: It is hard, you don't want other people to feel judged. So many people we know are having second kids. Having one kid seems like a compromise of sorts. If I had a second kid, I would feel like I'd just given up on all of my values.

Quinn always knew that she did not want to have biological children on environmental and humanitarian grounds.

Quinn: I've never had a desire to have a biological child for environmental and humanitarian reasons. It doesn't make sense to bring another child into this world. There are kids who don't have homes or families.

Her husband did want biological children, but he went along with her plan for an international adoption, saving the money by prioritizing the adoption and having a simple wedding and no honeymoon trip.

Quinn: We knew going into adopting that it was going to be expensive, and so we decided to have a pretty minimal wedding. It cost us $\$ 400$ altogether. We didn't have a honeymoon, because we knew we would be traveling as part of the adoption. But we have friends who have told us that adoption is too expensive, but spent money on an expensive Prius or an expensive wedding and honeymoon. But it's just a matter of priorities. If you want the adoption, you can make it happen.

Other informants point out that it is the raising of children in the United States, an advanced industrialized country, which is bad for the environment. Quinn declined to have biological children on environmental grounds, and instead moved a child from a less 
developed country to Portland, Oregon, where he is likely to consume exponentially

more resources over the course of his life.

\subsubsection{Normal People Doing their Best}

My informants frequently agonize over even the smallest decisions, and feel guilty about not making the right sustainability choices. Even the households who were making some of the most extreme interventions into conventional practices expressed the view that they weren't doing enough.

Chris: I almost didn't respond [to the request for participants] because I didn't feel like what we are doing is anywhere close to being sustainable, even though we're relatively... compared to other people, we're probably farther along. I studied environmental science in college. And honestly, a lot of choices and things that we do are not sustainable in terms of the long-term carrying capacity of the planet. Including having two kids, food choices, and garbage creation and the breadth of choices that we make throughout our lives. Like living in a detached, large single family house. Even though it's relatively energy-efficient, we're not net zero and we are generating garbage.

Kyle: When I saw the flyer for this study about sustainable families, the first thing I thought was that I don't think we are sustainable. I don't think that what we are doing is sustainable. Maybe less eco-hostile. I don't think the life I live is eco-friendly. It is just by degrees less eco-hostile. I do want to live, and I do want to live a child. We aren't ready to move to a developing country. So the question is, "How do we live with ourselves?"

At the end of the day, there appears to be no right answer and no perfectly sustainable household with young children-just a lot of people trying to do the best they can to bring their day-to-day lives into alignment with their values despite many factors working against them.

Heather: My husband tells me that I can't do it all, and I understand that, but we can make little steps and those will all be helpful. Anything we can make ourselves helps us get away from consumerism and capitalism. Companies 
aren't ethical. They don't have our health and best interests in mind. They're motivated by their own personal wealth and gain.

My informants are just parents who are trying to make the right choices for their families and the environment in a society that feels out-of-step with their sustainability priorities, but this is a heavy burden.

References:

Fineman, Martha Albertson. 2000. Cracking the Foundational Myths: Independence, Autonomy, and Self-Sufficiency. Journal of Gender, Social Policy \& the Law, 8(15): 13-29.

Mankiw, N. Gregory. 2012. Essentials of Economics, $6^{\text {th }}$ Edition. Mason, OH: Cengage Learning. 
Chapter 7: Conclusion

\subsection{Summary of Contributions}

The primary original scholarly contribution of this dissertation is my thick ethnographic description of a previously unstudied topic: the day-to-day practices of highly ecoconscious households with young children living in a medium-sized metropolitan area in the United States. In these descriptions, I place particular emphasis on social practices in three areas largely neglected in previous research-household waste, cleanliness, and comfort. I make sense of the data I collected over the course of 23 ethnographic interviews using an orienting perspective taken from neoclassical and radical political economic theories of household production. These theories frame my analysis of how households make choices between alternatives using the resources available to them and limited by the factors that constrain them.

Past environmental research on households has focused on "green consumerism" from a marketing or advertising perspective, with aims related to selling products to consumers with environmental interests or critiquing consumers and consumer culture. By modeling "green" households as producers of sustainability rather than consumers of environmental products, the sustainability work that takes place in households is brought into focus. An investigation of household sustainability production makes possible the 
evaluation of the trade-offs inherent in these pro-environmental activities. However, this investigation is not purely economic since, to borrow from McCloskey $(1985,246)$, the thinness of economics comes from the thinness of the questions it asks. Sociological theories of consumption and theories of social practice aid in the analysis of how these choices have evolved over time, how these practices are recursively related to infrastructures and technologies, and how household members view the social meanings of these choices.

I found that there is not one "sustainability" with varying degrees of intensity across a "green" spectrum, but rather different priorities in the sustainability realm-personal health, nature, waste avoidance, technology, and community. My focus on production and practices helps to reveal some of the negative consequences of placing the responsibility for environmental protection on households. Ecologically-conscious households devote substantial time and money to these sustainability efforts, but their efforts frequently stimulate conflicts, and the end results are rarely perfect. Constrained resources and limited information mean household members must make trade-offs between competing priorities, often under duress. Finally, the practices of my informants frequently seek to address and undo problems created at other sites and scales, such as the production, packaging, and distribution of goods. The conclusion I draw from the available evidence is that promoting household-level sustainability efforts may be misguided, as this transfer of institutional responsibility for environmental protection to 
individuals and groups results in even greater burdens on households, whose time, money, and emotional capacities are already stretched to their limits.

\section{$\underline{7.1 \text { Context }}$}

My informants grew up in the era of corporate oil spills, chemical disasters, acid rain, ozone depletion, deforestation, and, somewhat paradoxically, an increasing sense of personal responsibility for the natural environment. They learned about recycling in primary school, they diligently cut up their plastic six-pack rings to save wildlife, and they were bombarded with messages from promotional campaigns like Iron Eyes Cody's famous plea as he paddles his canoe through factory effluent and a discarded fast food meal is hurled at his feet out of a moving vehicle: "People Start Pollution. People Can Stop It."

While the "Crying Indian" ad is one of the most successful American public service announcements of all time (Andersen 2013, 404), less well known is the background story of this ad campaign. It was produced by a front group for the lobbying interests of disposable beverage bottling companies seeking to avoid legislation, motivated by public concerns about waste and littering, that threatened to mandate refillable glass beverage bottles and bottle deposits (Andersen 2013, 407; Strand 2008). By convincing consumers to take on the work of container disposal, beverage bottling companies were able to avoid regulation, secure their profits, and ensure that reusable individual-serving 
beverage packaging all but disappeared as a method for transporting liquids to their end users. This campaign and others like it that promote recycling and "doing your part" for the environment have been so successful at shifting the responsibility for the environment to households and consumers that my informant Orla now describes the experience of not being able to recycle something as painful.

The shift of responsibility for environmental risks from the state and corporations onto households is part of a larger pattern in late $20^{\text {th }}$ and early $21^{\text {st }}$-century America described by Hacker (2006). As Hacker (2006) outlines, the New Deal era saw the role of the government expanded to include providing a minimum standard of living and mitigating the risk of poverty for citizens, with a particular focus on poverty in old age and childhood, due to the death of a working spouse or disability, and due to unemployment or underemployment. To attract workers, the role of employers expanded in the United States to include the provision of pensions and health insurance benefits. Over the course of the last forty years, these policies and benefits provided by the state and employers that reduced the risk to individuals of fluctuations in their wealth and health have eroded. At the same time, public awareness of environmental risks increased, and the responsibility for dealing with these risks have likewise fallen to households and individuals. 


\section{$\underline{7.2 \text { Producing Sustainability in Households }}$}

It is against the backdrop of this social history and more recent public concerns about global warming and the health impacts of chemicals that my highly ecologically-conscious informants are raising young children in one of the most "sustainable" cities in America. My dissertation describes what happens when sustainability-oriented households decide to make interventions into mundane and easy-to-overlook parts of day-to-day life to bring the way they get things done into alignment with their values and priorities. Because their ability to do so is constrained by the culture, society, and economic system in which they live, there are consequences and trade-offs involved in these householdlevel sustainability practices. Before promoting sustainability work at the household level as a solution to environmental and other problems, we must understand the full extent of these trade-offs.

The households I spoke with over the course of this research get day-to-day things done just like everyone else: prioritizing the things that are the most important to them, making use of the resources available to them, and constrained by the factors that limit their options. While I had expected to find households representing varying shades of "green" along a pro-environmental spectrum, what I discovered instead was a set of overlapping priorities in the sustainability realm-personal health, the preservation of nature, the avoidance of waste, technology as a solution to problems, and communitywellbeing. Two or three of these areas tended to be most important to each informant, 
with priorities differing between couples fairly regularly. Households also differed in the extent to which their interest in sustainability was primarily focused on protecting the members of their household or protecting elements outside the household.

To get things done, my informants made use of the various resources available to them. Money can be saved through additional expenditures of unwaged time, and households with little time can achieve their sustainability goals by spending more money. But these resources include more than unwaged work of immediate family members and market goods and services purchased with money from waged work-my informants also receive assistance from extended family and friends and the government and non-profits to help them get things done. Unwaged time is also used to research and gain competence in sustainability practices, and is an important input into provisioning through gleaning, borrowing, and theft. These resources are employed in varying combinations and are both substitutes and compliments in the production of a sustainable life.

I focused the discussion here on three aspects of day-to-day life that have received little scholarly attention: household waste, cleanliness, and comfort. My informants told me that the processing and removing of items that are undesirable or no longer needed from the household represents an important expression of their sustainability priorities, and dealing with product packaging is a major source of frustration. While avoiding 
consumption in the first place is a priority for some households, dealing with unwanted materials through recycling, composting, resale, and giving things away for free is acceptable for others. Many of the households I spoke with decided to devote large amounts of time to cloth diapering their young children believing this to be the most environmentally-friendly choice, though as my informants Jim and Rebecca pointed out, this is likely not the case, even when the diapers are line-dried. Lacking perfect information about the efficacy of their choices, my informants are doing the best they can to do the right thing for their children, communities, and environment.

Cleanliness and comfort represent areas of day-to-day life where meaningful changes in the household demand for resources require accompanying changes in cultural meanings and social norms. While my informants generally believe that cleaning their homes with non-toxic cleansers and line-drying their laundry takes more time, other ways that they have changed day-to-day practices take less time-showering less often and wearing clothes more times between washings. Installing an energy-efficient clothes washing machine saves some electricity, but doesn't change underlying expectations about how often clothes should be washed, what clean towels should feel like, or who should be doing this washing and on what scale. Similarly, energy efficient furnaces and air conditioners can be installed, but they don't change underlying expectations about what sorts of spaces people should be living in and with whom, how people should feel indoors, and the steps they should take to make it feel that way. 
Ultimately it is these underlying expectations that motivate the demand for resources like water, electricity, and natural gas. These hidden and taken-for-granted expectationseven the expectation that related people should live in households-become recursively embedded in our practices, appliances, infrastructures, and homes. The washing machine hook-up in the basement suggests to the inhabitants that there ought to be a clothes washing machine there. The stock of three bedroom houses suggests that households of related people ought to live in them. Each layer reinforces the normalcy of the others, and limits the possibilities for radical changes in demand and ways of getting things done.

My informants are embedded in culture, in society, and an in a particular economic system that constrain their possible actions and choices. In day-to-day life, these constraints appear most visibly in the form of limited time, limited money, cultural objections to certain practices, and limits to available information. These constraints limit the potential efficacy of household-scale changes as each household is repeating the same small-scale tasks without the possibility of benefiting from economies of scale or a larger transformation of the processes my informants' sustainability practices aim to address. Even if we lived in a world in which my informants had limitless time, money, and information, many of their sustainability practices would prove ineffective because of the limitations built into the economic and social structures in which my informants find 
themselves. This isn't to say that one should take no responsibility at all, but rather that there are hard limits to the changes that individuals can make on their own.

\subsection{Suggestions for Future Research}

Social practices research is increasingly gaining recognition by utilities and governments in the UK and Europe as a useful way to investigate the demand by households for resources like electricity, fuel, and water (Lancaster University 2017). However, it is not always clear how to turn the output of this historically-situated descriptive research method into policy prescriptions. The approach I have used here, making sense of research on social practices through the use of a conceptual household production function-is potentially a fruitful first step in large-scale quantitative utility or regulatory research that lays the groundwork for policy. There are three areas that I believe could benefit from future investigations using this approach, and a fourth that would require a more quantitative approach.

\section{Practices in "Conventional" Households}

Throughout this study, I compared the practices of my informants, as they contrasted themselves, to those of "conventional" households, a nebulous and ill-defined concept at best. Because no social practices investigation of more general household-level demand for resources in America has been undertaken, a true comparison of the practices and 
meanings of practices between my highly eco-conscious informants and the "mainstream" was not possible. This is a potentially fruitful area of future research, particularly when combined with cross-cultural comparative approaches.

\section{Practices in Thrift-Minded Households}

The households I spoke with for this study were motivated by ecological considerations to decrease their demand for resources. Other American households may have little to no concern about the environment but may be engaging in practices that allow them to get things done in day-to-day life while consuming few resources. This may be because of poverty or other reasons, such as a religious belief in simplicity and thrift. Given the nature of climate change opinion in America, where only a minority report caring about climate change "a great deal" (Gallup 2016), other reasons that motivate reductions in consumption and their associated practices should be examined. The practices in these households may be instructive, providing new evidence for barriers to change and paths forward.

III. Practices in High-Demand Households

While this is a study of households who are taking deliberate steps to decrease their impacts on the environment, social practices research is needed on high income Americans. Frequent air travel, multiple large homes, and multiple cars are certainly resource-intensive. A better understanding of the social meanings behind these practices 
from research that takes high-income practitioners and their motivations seriously is needed.

\section{Sustainability Work and Gender}

While my informants expressed to me the view that their opposite-sex relationships are egalitarian, the ethnographic methods used here are inadequate for testing the accuracy of these perceptions. There may be unequal divisions of time spent working, whether paid or unpaid, in households. It may be the case that polities and trends that promote sustainability practices create new unpaid work that is primarily assigned to women in households. Quantitative time use research would be needed for this type of analysis.

\subsection{Conclusions: The Futility of Household-Scale Sustainability Practices}

7.5.1 The Household is the Wrong Site for Sustainability Production Changes are needed to mitigate the impacts of climate change, and current large-scale responses such as the Paris Climate Agreement are projected to be inadequate (Schwartz 2016). Among the informants I spoke with for his study, the recent U.S. presidential election has both increased anxiety about the future of the environment and increased their sense of personal responsibility for environmental preservation.

However, this research has revealed the negative consequences that occur when households take on the work of sustainability in addition to the other goods and services 
produced by households for their members. The household production of sustainability generates conflicts, and it frequently demands additional time, money, and effort from people who may have few resources to spare given all of their other responsibilities. Most poignantly, these household sustainability efforts cause people committed to what one informant called a "less eco-hostile existence" to make trade-offs, including of their own sanity and parental desires, to get day-to-day things done in a way that feels consistent with their values. But despite these sacrifices, their efforts frequently fall short of hopes and expectations, such as when they learn after the fact that all of the work they put in to cloth diapering or protecting their children from fluoride was ultimately counter-productive.

Shove et al. $(2015,275)$ argue that because "demand is an outcome of what people do, any radical change depends on reconfiguring the practices that comprise everyday life." However, they also make the point that the extent to which these changes are even possible is limited by existing infrastructures and the complexes of practices that are dependent on them. While Shove and co-authors are referring to physical infrastructures like buildings and roads, perhaps the economy as a whole and social structures can also be thought of as infrastructures that likewise constrain possible actions and choices. The logical extension of these theories of social practice is that infrastructures are also dependent on the practices and practitioners that reproduce infrastructures and make 
them seem necessary and normal. To "reconfigure the practices that comprise everyday life," infrastructures must also be transformed.

\subsubsection{Moving Forward: Pragmatic Pathways}

Many sustainability-oriented practices take more time or more money than conventional ways of getting things done. They require special equipment that saves resources without changing the meaning of practices and the cultural services involved. Or, they require large investments in time and self-provisioning to produce substitutes that avoid purchases from the commercial sector. However, three sustainability practices I discussed with my informants offer the intriguing combination of saving both time and money, as well as resources: selective flushing, decreasing the frequency of showering, and wearing clothes more times between washes. There is a catch: changing these practices on a wider scale would mean redefining what cleanliness means in the United States, a nation obsessed with being clean.

A major limitation to redefining cleanliness is embedded in the infrastructures used to produce it-cultural expectations and technology are recursively related in ways that reinforce the normalcy of these expectations. Why do toilets flush if we aren't meant to flush them? Why shouldn't I wash my clothes after every wearing when it is easy and convenient to do so? Cross-cultural comparisons of practices offer some reassuring counter-evidence, as tumble dryers exist in over half of U.K. households, but 93 percent 
line-dry their laundry (U.K. Office for National Statistics 2011, Project Laundry List 2013,

Fischer \& Kaufmann 2013). There isn't a one-to-one relationship between technology and practices - there are historical and cultural forces that impact what we perceive as acceptable ways to get things done.

Among my informants, a severe drought in California in the late 1980s and early 1990s influenced perceptions of selective flushing, even for informants who had never lived in California (California Department of Water Resources 1993). However, these examples are more the exception than the rule when it comes to the interwoven relationship between institutions, infrastructures, technology, practices, and social meanings. Policies that promote sustainability production within households should, as much as possible, avoid shifting additional work, whether paid or unpaid, onto households, and should instead focus on changing the meanings and infrastructures that motivate practitioners and necessitate practices.

\subsubsection{Moving Forward: Utopian Visions}

Just as choices are constrained by the social and economic institutions we find ourselves in, so is our ability to even conceive of possible paths forward outside those institutions. More efficient appliances get the same things done, just using slightly less energy.

Similarly, progressive reforms and other adjustments to paid and unpaid work are not sufficient to alleviate the problems faced by my informants: they are exhausted, they feel 
like they have no time, and they are having to make upsetting trade-offs between their own sanity and their desire for healthy families, communities, and environment.

The obvious culprit in a radical political economic study is the economic system, pointed to throughout this dissertation as placing limits on the range of possible actions. But simply changing the mode of economic production is not sufficient. While notions of "collective childrearing" in the American mind is conjured as "a nightmare vision of raising children like Perdue chickens" (Benjamin 1988, 204), this needn't be the case. Despite being idealized and frequently used as a political tool in America, families are not always healthy and happy, and can't necessarily be relied upon as sources of care (Barrett \& McIntosh 1982). Recent work by Hopkins (2017) and Harraway (2015) suggests that utopian paths forward must include transformations not only of the economic system but also of our notions of the household and family. The contemporary family-household was formed by capitalism, and at the same time supports its continued existence.

The household sustainability efforts of my informants, while well-intentioned, are most frequently aimed at addressing environmental problems originating outside the household. Each household individually repeats common sustainability tasks that could be achieved more effectively collectively or at a larger scale. At the same time, environmental and social problems are caused by the organization of families into individual households, a modern arrangement that is both socially and environmentally 
taxing. This belief is echoed by my informant, Kyle, when he discusses his reasons for living in intentional community:

Kyle: Everyone doesn't need to have their own washing machine that goes unused $95 \%$ of the time, or your own car, or your own house! People living in their own houses is just absurd. The consumer culture, driven by the need to sell stuff for ever higher profits, creates these absurdities. And you need to be intentional if you want to do something different.

The households I spoke with over the course of this research are trying their best to, as Kyle suggests, do something different. And some pragmatic reforms that involve changing the social meaning of practices in ways that decrease the demand for resources may provide a practical path forward. But without radical transformations in infrastructures and institutions, these efforts will always fall short of what is needed to fully protect people and the environment from harm.

References:

Andersen, Robin. 2013. 'The 'Crying Indian,' Corporations, and Environmentalism: A Halfcentury of Struggle over Environmental Messaging." in Matthew P. McAllister \& Emily West (eds.), Routledge Companion to Advertising and Promotional Culture. New York, NY: Routledge.

Benjamin, Jessica. 1988. The Bonds of Love: Psychoanalysis, Feminism and the Problem of Domination. New York, NY: Pantheon Books.

Gallup News Service. 2016. Gallup Poll Social Series: Environment, March 6, 2016. Accessed 06/18/2016. Available: 
http://www.gallup.com/file/poll/190055/Global_Warming_Trends_160316\%20.p

df

Hacker, Jacob S. 2006. The Great Risk Shift: The Assault on American Jobs, Families, Health Care, and Retirement and How You Can Fight Back. Oxford, UK: Oxford University Press.

Lancaster University. 2017. “Energy demand and social practices." Accessed 06/30/2017. Available: http://www.lancaster.ac.uk/sociology/research/public-sociologyprofiles/energy-demand-and-social-practices/

McCloskey, Donald. 1985. "Thick and Thin Methodologies in the History of Economic Thought." in Neil de Marchi (ed.), The Popperian Legacy in Economics. Cambridge, UK: Cambridge University Press.

Shove, Elizabeth, Matt Watson and Nicola Spurling. 2015. "Conceptualizing connections: Energy demand, infrastructures, and social practices." European Journal of Social Theory 18(3): 274-278.

Schwartz, Jen. 2016. "Why the Paris Climate Agreement Can't Save the Planet." Popular Science, February 10, 2016. Accessed 07/01/2017. Available: http://www.popsci.com/paris-climate-agreement Strand, Ginger. 2008. "The Crying Indian." Orion Magazine, November/December. Accessed 06/25/2017. Available: https://orionmagazine.org/article/the-cryingindian/ 
References

Aleiss, Angela. 1999. "Iron Eyes Cody: Wannabe Indian." Cinéaste 25(1): 31.

Andersen, Robin. 2013. "The 'Crying Indian,' Corporations, and Environmentalism: A Halfcentury of Struggle over Environmental Messaging." in Matthew P. McAllister \& Emily West (eds.), Routledge Companion to Advertising and Promotional Culture. New York, NY: Routledge.

Aune, Margrethe. 2002. "Users versus utilities - the domestication of an energy controlling technology." in Andrew Jamison and Harald Rohracher (eds.), Technology Studies and Sustainable Development. Munich: Profil Verlag, 383-406. - - - 2007. "Energy Comes Home." Energy Policy 35: 5457-5465.

Barrett, Michèle. 1980. Women's Oppression Today: Problems in Marxist Feminist Analysis. London, UK: Verso.

Basole, Amit and Smita Ramnarain. 2016. "Qualitative and ethnographic methods in economics." in Fred Lee and Bruce Cronin (eds.), Handbook of Research Methods and Applications in Heterodox Economics. Cheltenham, UK: Edward Elgar.

Becker, Gary S. 1981. A Treatise on the Family. Cambridge, MA: Harvard University Press.

- - . 1965. "A theory of the allocation of time." The Economic Journal 75(299): 493517.

Beecher, Catherine E. 2007. A Treatise on Domestic Economy for the Use of Young Ladies at Home and at School. Project Gutenberg E-Book \#21829. Available: http://www.gutenberg.org/ebooks/21829

Benjamin, Jessica. 1988. The Bonds of Love: Psychoanalysis, Feminism and the Problem of Domination. New York, NY: Pantheon Books.

Bergmann, Barbara. 1981. "The economic risks of being a housewife." American Economic Review, 71 (2): 81-86

- - - 1995. "Becker's theory of the family: Preposterous conclusions." Feminist Economics 1(1): 141-150.

- - - 2007. "Needed: A new empiricism." The Economists' Voice 4(1): 1-4

Bernardo, Richie. 2016. "2016's Greenest Cities in America." WalletHub October 12, 2016. Available: https://wallethub.com/edu/most-least-green-cities/16246/ accessed 03/26/2017.

Bernstein, Arielle. 2016. "Marie Kondo and the Privilege of Clutter." The Atlantic March 25, 2016. Accessed 08/19/2016. available: http://www.theatlantic.com/entertainment/archive/2016/03/marie-kondo-andthe-privilege-of-clutter/475266/

Bhat, Chandra R. and Frank S. Koppelman. 1999. "A retrospective and prospective survey of time-use research." Transportation 26(2): 119-139. 
Bhatnagar, Amit, Sanjog Misra \& H. Raghav Rao. 2000. "On risk, convenience, and Internet shopping behavior." Communications of the Association for Computing Machinery 43(11): 98-105.

Boltanski, Luc \& Ève Chiapello. 2005. The New Spirit of Capitalism. London: Verso.

Bondar, Paul. 2017. "A New Era of U.S. Climate Action." Rocky Mountain Institute Outlet June 6, 2017. Accessed 06/07/2017. Available: https://www.rmi.org/news/newera-u-s-climate-action

Bott, Elizabeth. 2001. Family and Social Network: Roles, Norms, and External Relationships in Ordinary Urban Families, $2^{\text {nd }}$ Edition. Abingdon, UK: Routledge.

Bourdieu, Pierre. 1984. Distinction: A Social Critique of the Judgement of Taste. Trans. Richard Nice. Cambridge, MA: Harvard University Press.

Bradby, Barbara. "The Remystification of Value." Capital and Class 6(2): 114-133 Bromley-Trujillo, Rebeca. 2017. "Despite Trump, Many Cities and States are Fighting Climate Change. Including Pittsburgh." The Washington Post, June 6, 2017. Accessed 06/07/2017. Available: https://www.washingtonpost.com/news/monkey-cage/wp/2017/06/06/despitetrump-pittsburghs-working-on-slowing-climate-change-so-are-many-other-citiesand-states/

Brown, Doug. 1998. "Be all you can be: Invidious self-development and its social imperative." in Doug Brown (ed.) Thorstein Veblen in the Twenty-first Century: A Commemoration of the Theory of the Leisure Class (1899-1999). Cheltenham, UK: Edward Elgar.

Brown, Lester. 2003. Rescuing a Planet under Stress and a Civilization in Trouble. New York, NY: W.W. Norton \& Company.

California Department of Water Resources. 1993. "California's 1987-92 Drought: A Summary of Six Years of Drought." Accessed 05/29/2017. Available: http://www.water.ca.gov/waterconditions/docs/2_drought-1987-92.pdf

Carfagna, Lindsey B., Emilie A. DuBois, Connor Fitzmaurice, Monique Y. Ouimette, Juliet B. Schor \& Margaret Willis. 2014. "An emerging eco-habitus: the reconfiguration of high cultural capital practices among ethical consumers." Journal of Consumer Culture 14:2, 158-178.

Carlsson-Kanyama, Annika and Anna-Lisa Lindén. 2007. "Energy efficiency in residencesChallenges for women and men in the North." Energy Policy 35: 2161-2172.

Chayka, Kyle. 2016. "The Oppressive Gospel of 'Minimalism." New York Times July 26, 2016. Accessed 08/19/2016. available: http://www.nytimes.com/2016/07/31/magazine/the-oppressive-gospel-ofminimalism.html?_r=0

Chekimaa, Brahim, Syed Azizi Wafa Syed Khalid Wafaa, Oswald Aisat Igaua, Sohaib Chekimab, and Stephen Laison Sondoh Jr. 2016. "Examining green consumerism motivational drivers: does premium price and demographics matter to green purchasing?" Journal of Cleaner Production 112: 3436-3450. 
Child, Lydia Maria. 1999. The American Frugal Housewife. Mineola, NY: Dover Publications.

Chiswick, Carmel U. \& Barry R. Chiswick. 2000. "The cost of living Jewishly and Jewish continuity." Contemporary Jewry 21(1): 78-90.

Chiswick, Carmel U. 1999. "The economics of Jewish continuity." Contemporary Jewry 20(1): 30-56.

Cialdini, Robert B. 2001. "Littering: When Every Litter Bit Hurts." in Public Communication Campaigns, Ronald E. Rice and Charles K. Atkin (eds.). Thousand Oaks, CA: Sage Publications.

Cobb, Carrie L., Mary C. King, and Leopoldo Rodriguez. 2009. "Betwixt and between: The spectrum of formality revealed in the labor market experiences of Mexican migrant workers in the United States." Review of Radical Political Economics 41(3): 365-371.

Collins, Jane L. 1990. "Unwaged labor in comparative perspective: recent theories and unanswered questions." in Jane L. Collins and Martha Gimenez (eds.) Work without Wages: Comparative Studies of Domestic Labor and Self-Employment. Albany, NY: State University of New York Press.

Collins, Patricia Hill. 2000. Black Feminist Thought: Knowledge, Consciousness, and the Politics of Empowerment. New York, NY: Routledge.

Coupland, Jennifer Chang. 2005. "Invisible brands: an ethnography of households and the brands in their kitchen pantries." Journal of Consumer Research 32(1): 106-118.

Cowan, Ruth Schwarz. More Work for Mother: The Ironies of Household Technologies from the Open Hearth to the Microwave. New York, NY: Basic Books.

Dalla Costa, Mariarosa \& Selma James. 1972. The Power of Women and the Subversion of the Community. Bristol, UK: The Falling Wall Press.

Dewey, John. 2011. How We Think. Project Gutenberg EBook \#37423. Available: https://www.gutenberg.org/files/37423/37423-h/37423-h.htm

Diamantopoulosa, Adamantios, Bodo Schlegelmilch, Rudolf Sinkovicsd, and Greg Bohlenc. 2003. "Can socio-demographics still play a role in profiling green consumers? A review of the evidence and an empirical investigation." Journal of Business Research 56: 465-480.

Dietz, Thomas and Eugene A. Rosa. 1997. "The effects of population and affluence on $\mathrm{CO}_{2}$ emissions." Proceedings of the National Academy of Sciences of the United States of America 94(1): 175-179.

Doane, Molly. 2010. "Relationship Coffees: Structure and Agency in the Fair Trade System." In Fair Trade and Social Justice: Global Ethnographies, edited by Mark Moberg. New York: NYU Press.

Douglas, Mary. 2003. The World of Goods: Towards an Anthropology of Consumption. London, UK: Routledge.

Dunlap, Riley E. and Araon M. McCright. 2008. "A widening gap: Republican and Democratic views on climate change." Environment: Science and Policy for Sustainable Development 50(5): 26-35 
Ehrlich, Paul R. and Anne H. Ehrlich. 1974. The End of Affluence: A Blueprint for your Future. New York, NY: Ballantine Books.

Engels, Friedrich. 1902. The Origin of the Family, Private Property and the State. Translated by Ernest Untermann. Chicago, IL: Charles H. Kerr \& Company.

Ewen, Stuart and Elizebeth Ewen. 1992. Channels of Desire: Mass Images and the Shaping of American Consciousness. Minneapolis, MN: University of Minnesota Press.

Ferber, Marianne A. 1995. "The Study of Economics: A Feminist Critique." The American Economic Review 85(2): 357-361.

Ferber, Marianne A. and Birnbaum, Bonnie G. 1977. "The New Home Economics: Retrospects and Prospects." Journal of Consumer Research 4(1):19-28.

Fineman, Martha Albertson. 2000. "Cracking the Foundational Myths: Independence, Autonomy, and Self-Sufficiency." Journal of Gender, Social Policy \& the Law, 8(15): 13-29.

Finkelstein, Eric A. Christopher J. Ruhm \& Katherine M. Kosa. 2005. Economic Causes and Consequences of Obesity. Annual Review of Public Health 26: 239-57.

Fischer, Barry and Nate Kaufman. 2013. "America's most unpopular way to save energy is one of Europe's favorites." Demand Side Management (Opower blog). Accessed 06/22/2013. Available: https://blogs.oracle.com/utilities/americas-mostunpopular-way-of-saving-energy-is-one-of-europes-favorites

Foden-Vencil, Kristian. 2015. "Oregon has Highest Vaccine Exemption Rate in US." Oregon Public Broadcasting News. February 4, 2015. Accessed 05/30/2017. Available: http://www.opb.org/news/article/oregon-has-highest-vaccineexemption-rate-in-us/\#FindSchool

Folbre, Nancy. 1982. "Exploitation comes home: A critique of the Marxian theory of labor power." Cambridge Journal of Economics 6(4): 318-329.

- - - 1986. "Hearts and spades: paradigms of household economics." World Development 14(2): 245-255.

Forlizzi, Jodi. 2007. "How robotic products become social products: an ethnographic study of cleaning in the house." Human-Computer Interaction Institute. Paper 40.

Forsberg, Lucas. 2007. "Negotiating involved fatherhood: Household work, childcare, and spending time with children." Nordic Journal for Masculinity Studies 2(2): 109126.

Foster, Gladys Parker. 1998. "Veblen and the 'Woman Question' in the Twenty-first Century". in Doug Brown (ed.) Thorstein Veblen in the Twenty-first Century: A Commemoration of the Theory of the Leisure Class (1899-1999). Cheltenham, UK: Edward Elgar.

Foster, John Bellamy. 2002. Ecology against Capitalism. New York, NY: Monthly Review Press.

Frankfurt Institute for Social Research. 1972. Aspects of Sociology. Boston, MA: Beacon Press.

Gallup News Service. 2016. "Gallup Poll Social Series: Environment", March 6, 2016. Accessed 06/18/2016. Available: 
http://www.gallup.com/file/poll/190055/Global_Warming_Trends_160316\%20.p $\mathrm{df}$

Gannon, Liz Purchia. 2017. "How to Push Climate Action Forward in the Trump Era." Grist, March 6, 2017. Accessed 06/07/2017. Available:

http://grist.org/opinion/how-to-push-climate-action-forward-in-the-trump-era/

"Gripes and Grievances," Correspondence, 2(2): 4. Cited in Haider, Asad and Salar Mohandesi. 2013. "Workers' Inquiry: A Genealogy." Viewpoint Magazine, September 27, 2013. Available: https://www.viewpointmag.com/2013/09/27/workers-inquiry-a-genealogy/

Glaser, Barney P. and Anselm L. Strauss. 1967. The Discovery of Grounded Theory: Strategies for Qualitative Research. New Brunswick, NJ: Aldine Transaction.

Gliebe, John P. \& Frank S. Koppelman. 2002. A model of joint activity participation between household members. Transportation 29(1): 49-72.

Goldstein, Jonathan P. and Michael G. Hillard. 2008. "Taking the high road only to arrive at the low road: The creation of a reserve army of petty capitalists in the North Maine Woods." Review of Radical Political Economics 40(4): 479-509.

Greenwood, Daphne. 1984. "The Economic Significance of "Woman's Place" in Society: A New-Institutionalist View." Journal of Economic Issues 18(3): 663-680.

Gregory, Chris A. and John C. Altman. 1989. Observing the Economy. New York, NY: Routledge.

Gross-Loh, Christine. 2009. The Diaper-Free Baby: The Natural Toilet Training Alternative. New York, NY: Harper-Collins.

Hacker, Jacob S. 2006. The Great Risk Shift: The Assault on American Jobs, Families, Health Care, and Retirement and How You Can Fight Back. Oxford, UK: Oxford University Press.

Hackett, Bruce and Loren Lutzenhiser. 1991. "Social Structures and Economic Conduct: Interpreting Variations in Household Energy Consumption." Sociological Forum 6(3): 449-470.

Haider, Asad and Salar Mohandesi. 2013. "Workers' Inquiry: A Genealogy." Viewpoint Magazine, September 27, 2013. Available: https://www.viewpointmag.com/2013/09/27/workers-inquiry-a-genealogy/

Harper, Douglas. 1992. "Small N's and community case studies." In Charles C. Ragin and Howard S. Becker, What is a Case? Exploring the Foundations of Social Inquiry. Cambridge, UK: Cambridge University press, 139-158.

Harrison, Jane, Lesley MacGibbon, and Missy Morton. 2001. "Regimes of trustworthiness in qualitative research: the rigors of reciprocity." Qualitative Inquiry 7(3): 323-345.

Heath, Julia A. \& David H. Ciscel. 1988. Patriarchy, Family Structure and the Exploitation of Women's Labor. Journal of Economic Issues 22(3): 781-794.

Hicks, John R. and R. G. D. Allen. 1934. "A reconsideration of the theory of value: Part I." Economica 1(1): 52-76.

Holt, Douglas. 1997. "Distinction in America? Recovering Bourdieu's theory of tastes from its critics." Poetics 25 (2/3): 93-120. 
Jara-Díaz, Sergio R. 2000. "Allocation and valuation of travel-time savings." in David A. Hensher and Kenneth .J. Button (eds.), Handbook of Transportation Modeling. Amsterdam, the Netherlands: Elsevier.

Jennings, Ann L. 1993. 'Public or Private? Institutional Economics and Feminism' in Marianne A. Ferber \& Julie A. Nelson (eds.) Beyond Economic Man: Feminist Theory and Economics. Chicago, IL: University of Chicago Press.

Jorgenson, Andrew K. 2003. "Consumption and Environmental Degradation: A CrossNational Analysis of the Ecological Footprint." Social Problems 50(3): 374-394.

Kaplan, Abraham. 1998. The Conduct of Inquiry: Methodology for Behavioral Science. New Brunswick, NJ: Transaction Publishers.

Kelly, Daniel. 2011. Yuck! The Nature and Moral Significance of Disgust. Cambridge, MA: The MIT Press.

Kerstenetzky, Jaques. 2010. "Alfred Marshall on big business." Cambridge Journal of Economics 34: 569-586.

Klingle, Matthew W. 2003. "Spaces of Consumption in Environmental History." History and Theory 42(4): 94-110.

Knight, Frank H. 1944. "Realism and Relevance in the Theory of Demand." The Journal of Political Economy 54(4): 289-318.

Kolodinsky, Jane M. and Amanda B. Goldstein. 2011. "Time Use and Food Pattern Influences on Obesity." Obesity 19(12): 2327-2335

Lancaster University. 2017. "Energy demand and social practices." Accessed 06/30/2017. Available: http://www.lancaster.ac.uk/sociology/research/public-sociologyprofiles/energy-demand-and-social-practices/

Laslett, Barbara and Johanna Brenner. 1989. "Gender and Social Reproduction: Historical Perspectives." Annual Review of Sociology 15: 381-404.

Lee, Frederic and Bruce Cronin (eds.) 2016. "Introduction." Handbook of Research Methods and Applications in Economics. Cheltenham, UK: Edward Elgar Publishing.

Levin, Sam. 2017. "'Like a Slow Death': Families Fear Pesticide Poisoning after Trump Reverses Ban." The Guardian, April 17, 2017. Accessed 06/07/2017. Available: https://www.theguardian.com/us-news/2017/apr/17/california-pesticidescentral-valley-trump

Livingstone, Sonia. 1992. "The meaning of domestic technologies: a personal construct analysis of familial gender relations." in Eric Hirsch and Roger Silverstone (eds.), Consuming Technologies: Media and Information in Domestic Spaces. London, UK: Routledge.

Logan, Dana W. 2017. "The Lean Closet: Asceticism in Post-industrial Consumer Culture." Journal of the American Academy of Religion 78(1): 1-39.

Lutzenhiser, Loren. 1992. "A cultural model of energy consumption." Energy 17:1, 47-60.

- - . 1993. "Social and behavioral aspects of energy use." Annual Review of Energy and the Environment 18, 247-289. 
- - . 2002. "Greening the Economy from the Bottom Up? Lessons in Consumption from the Energy Case." in Nicole Biggard (ed.) Readings in Economic Sociology. Oxford, UK: Blackwell, 345-356.

Lutzenhiser, Loren \& Marcia Hill Gossard. 2000. "Lifestyle, status, and energy consumption." Proceedings of the 2000 ACEEE Summer Study of Energy Efficiency in Buildings 8, 207-222.

Lutzenhiser, Loren, Laura Cesafsky, Heather Chappells, Marcia Gossard, Dulane Moran, Jane Peters, Mersiha Spahic, Paul Stern, Elizabeth Simmons, and Harold Wilhite. 2009. Behavioral Assumptions Underlying California Residential Sector Energy Efficiency Programs. Report to the California Public Utilities Commission. Berkeley, CA: California Institute for Energy and Environment.

Lynd, Robert S. and Helen Merrell Lynd. 1929. Middletown: A Study in American Culture. San Diego, CA: Harcourt Brace Jovanovich, Publishers.

Malinowski, Bronislaw. 1922. Argonauts of the Western Pacific: An Account of Native Enterprise and Adventure in the Archipelagoes of Melanesian New Guinea. London, UK: Routledge \& Sons, Ltd.

Malm, Andreas. 2015. Fossil Capital: The Rise of Steam Power and the Roots of Global Warming. New York: Verso Books.

Mankiw, N. Gregory. 2012. Essentials of Economics, $6^{\text {th }}$ Edition. Mason, OH: Cengage Learning.

Marshall, Alfred. [1890] 2009. Principles of Economics (Abridged Edition) Cosimo Classics: New York, NY.

- - - 1919. Industry and Trade: A Study of Industrial Technique and Business Organization; and of their Influences on the Conditions of Various Classes and Nations. London, UK: Macmillan.

Marx, Karl. 1938. "A worker's inquiry." New International 4(12): 379-381. Available: https://www.marxists.org/history/etol/newspape/ni/vol04/no12/marx.htm

- - - 1978. "Economic and Philosophic Manuscripts of 1844." in Robert E. Tucker (ed) The Marx-Engels Reader, $2^{\text {nd }}$ Edition. New York, NY: W.W. Norton \& Company.

Matchar, Emily. 2013. Homeward Bound: Why Women are Embracing the New Domesticity. New York, NY: Simon \& Schuster.

McCloskey, Donald [Deirdre]. 1985. "Thick and Thin Methodologies in the History of Economic Thought." in Neil de Marchi (ed.), The Popperian Legacy in Economics. Cambridge, UK: Cambridge University Press.

Micheletti, Michele. 2003. Political Virtue and Shopping: Individuals, Consumerism, and Collective Action. New York, NY: Palgrave Macmillan.

Miller, Edythe. 1972. "Veblen and Women's Lib: A Parallel." Journal of Economic Issues 6(2/3): 75-86.

Morgan, David. 1981. "Men, masculinity, and the process of sociological enquiry" in Helen Roberts (ed.), Doing Feminist Research. London, UK: Routledge \& Kegan Paul Ltd. 30-61. 
Morgan, David L. 2014. Integrating Qualitative and Quantitative Methods: A Pragmatic Approach. Los Angeles, CA: Sage Publications, Inc.

Morgan, Gareth and Linda Smircich. 1980. "The case for qualitative research." The Academy of Management Review 5(4): 491-500.

Moroşanu, Roxana. 2016. An Ethnography of Household Energy Demand in the UK: Everyday Temporailities of Digital Media Usage. New York, NY: Palgrave Macmillan.

Mosak, Jacob L. 1938. "Interrelations of production, price, and derived demand." The Journal of Political Economy 46(6): 761-787.

Murphy, Fiona and Pierre McDonagh. 2016. "Introduction." In Fiona Murphy and Pierre McDonagh (eds.), Envisioning Sustainabilities: Towards an Anthropology of Sustainability. Newcastle upon Tyne, UK: Cambridge Scholars Publishing.

Nath, Vishnu, Rupesh Kumar, Rajat Agrawal, Aditya Gautam, and Vinay Sharma. 2013. "Consumer adoption of green products: Modeling the enablers." Global Business Review 14: 453-470.

National Aeronautics and Space Administration. 2017. "NASA's Climate Kids: What Can We Do to Help?" Accessed 06/07/2017. Available: https://climatekids.nasa.gov/how-to-help/

Netting, Robert McC., Richard R. Wilk, and Eric J. Arnould. 1984. "Introduction." in Robert Netting, Richard R. Wilk, \& Eric J. Arnould (eds). 1984. Households: Comparative and Historical Studies of the Domestic Group. Berkeley, CA: University of California Press.

- - . 1984. Households: Comparative and Historical Studies of the Domestic Group. Berkeley, CA: University of California Press.

Oakley, Ann. 1978. The Sociology of Housework. Bath, UK: The Pittman Press.

- - - 1981. "Interviewing women: a contradiction in terms." in Helen Roberts (ed.), Doing Feminist Research. London, UK: Routledge \& Kegan Paul Ltd., 30-61.

OECD. 2008. Household Behaviour and the Environment: Reviewing the Evidence. Paris, France: Organization for Economic Development and Cooperation.

Parr, Joy. 1997. "What Makes Washday Less Blue? Gender, Nation, and Technology Choice in Postwar Canada." Technology and Culture 38(1): 153-186.

Peterson, Janice. 1998. Veblen and feminist economics: Valuing women's work in the Twenty-first Century. in Doug Brown (ed.) Thorstein Veblen in the Twenty-first Century: A Commemoration of the Theory of the Leisure Class (1899-1999). Cheltenham, UK: Edward Elgar.

Pickbourn, Lynda and Smita Ramnarain. 2016. "Separate or symbiotic? Quantitative and qualitative methods in (heterodox) economics research." in Fred Lee and Bruce Cronin (eds.), Handbook of research methods and applications in heterodox economics. Cheltenham, UK: Edward Elgar.

Pigou, Arthur Cecil. 1956. "In Memoriam: Alfred Marshall" in Memorials of Alfred Marshall, A.C. Pigou (ed.). New York, NY: Kelley \& Millman, Inc. 
Polonsky, Michael J. and Alma T. Mintu-Wimsatt (eds.) 1995. Environmental Marketing: Strategies, Practice, Theory, and Research. New York, NY: The Haworth Press.

Power, Marilyn. 2004. "Social Provisioning as a Starting Point for Feminist Economics." Feminist Economics 10(3): 3-19.

Prasch, Robert. "How is Labor Distinct from Broccoli? Some Unique Characteristics of Labor and their importance for Economic Analysis and Policy." in The Institutionalist Tradition in Labor Economics, Dell P. Champlin and Janet T. Knoedler. Armonk, NY: M.E. Sharpe.

Project Laundry List. 2013. "Laundry Fact Sheet." Accessed 06/22/2017. Available: http://www.laundrylist.org/wp-content/uploads/2013/08/facts.pdf

Rapp, Rayna, Ellen Rosa \& Renate Bridenthal. 1979. "Examining Family History." Feminist Studies 5(1): 174-200.

Ray, Raka and Seemin Qayum. 2009. Cultures of Servitude: Modernity, Domesticity, and Class in India. Stanford, CA: Stanford University Press.

Reckwitz, Andreas. 2002. "Toward a theory of social practices: a development in culturalist theorizing." European Journal of Social Theory 5:2, 243-263.

Reid, Margaret. 1934. The Economics of Household Production. New York, NY: John Wiley \& Sons, Inc.

Rex, Emma and Henrikke Baumann. 2007. "Beyond ecolabels: what green marketing can learn from conventional marketing." Journal of Cleaner Production 15: 567-576.

Rich, Adrienne. 1986. Of woman born: Motherhood as experience and institution. New York, NY: W. W. Norton \& Company.

Rilke, Rainer Maria. 1969. Letters of Rainer Maria Rilke, 1892-1910. Translated by Jane Bannard Greene and M.D. Herter Norton. New York, NY: W.W. Norton.

Robbins, Lionel. 2007. An Essay on the Nature and Significance of Economic Science. Auburn, Alabama: The Mises Institute.

Robinson, Joan. 1964. "Marshall, Marx, and Keynes: Three Views of Capitalism." in Joan Robinson (ed.), Collected Economic Papers, Volume Two. Oxford, UK: Basil Blackwell.

Rode, Jennifer A., Eleanor F. Toye, and Alan F. Blackwell. 2004. "The fuzzy felt ethnography-understanding the programming pattern of domestic appliances." Personal and Ubiquitous Computing 8(3): 161-176.

Rogers, Stephanie. "Hard economic times be damned: 10 U.S. cities make their own green." Ecosalon, October 26, 2011. Available: http://ecosalon.com/americasgreenest-cities-319/ Accessed 03/26/2017.

Rosa, Eugene A. and Thomas Dietz. 2003. "Footprints on the Earth: The environmental consequences of modernity." American Sociological Review 68(2): 279-300.

Rubin, Herbert J. and Irene S. Rubin. 2012. Qualitative Interviewing: The Art of Hearing Data, $2^{\text {nd }}$ Edition. Thousand Oaks, CA: SAGE Publications.

Sarasohn, David. 2011. "Biweekly trash pickup: Get to Know your Garbage." The Oregonian, December 10, 2011. Accessed 05/30/2017. Available: 
http://www.oregonlive.com/news/oregonian/david_sarasohn/index.ssf/2011/12/ biweekly_trash_pickup_get_to_k.html

Sawhill, Isabel B. 1977. Economic perspectives on the family. Daedalus 106(2): 115-125.

Schnaiberg, Allan and Kenneth Alan Gould. 1994. Environment and Society: The Enduring Conflict. Caldwell, NJ: The Blackburn Press.

Schultz, Henry. 1935. "Interrelations of Demand, Price, and Income." The Journal of Political Economy 43(4): 433-481.

Schwartz, Jen. 2016. "Why the Paris Climate Agreement Can't Save the Planet." Popular Science, February 10, 2016. Accessed 07/01/2017. Available:

http://www.popsci.com/paris-climate-agreement

Shabecoff, Philip. 1987. "With No Room at the Dump, U.S. Faces a Garbage Crisis." New York Times, June 29. 1987. Accessed 05/30/2017. Available:

http://www.nytimes.com/1987/06/29/us/with-no-room-at-the-dump-us-faces-agarbage-crisis.html

Shove, Elizabeth \& Alan Warde. 2002. "Inconspicuous Consumption: The Sociology of Consumption, Lifestyles, and the Environment." in Sociological Theory and the Environment: Classical Foundations, Contemporary Insights, edited by Riley E. Dunlap, Frederick H. Buttel, Peter Dickens, \& August Gijswijt, 230-251. Oxford: Rowman \& Littlefield Publishers.

Shove, Elizabeth \& Gordon Walker. 2010. Governing transitions in the sustainability of everyday life. Research Policy 39(4): 471-476.

Shove, Elizabeth \& Mika Pantzar. 2005. "Consumers, Producers and Practices Understanding the invention and reinvention of Nordic walking." Journal of consumer culture 5:1, 43-64.

Shove, Elizabeth, Loren Lutzenhiser, Simon Guy, Bruce Hackett, and Harold Wilhite. 1998. "Energy and Social Systems" in Steve Rayner and Elizabeth Malon (eds.), Human Choice and Climate Change. Columbus, $\mathrm{OH}$ : Battelle Press.

Shove, Elizabeth, Matt Watson \& Nicola Spurling. 2015. Conceptualizing connections: energy demand, infrastructures and social practices. European Journal of Social Theory 18(3): 274-287.

Shove, Elizabeth, Mika Pantzar \& Matt Watson. 2012. The Dynamics of Social Practice: Everyday Life and How it Changes. London, UK: Sage.

Shove, Elizabeth. 2003. Comfort, Cleanliness, and Convenience: The Social Organization of Normality. Oxford, UK: Berg.

- - - 2004. "Sustainability, system innovation and the laundry." in Boelie Elzen, Frank W. Geels, and Kenneth Green (eds.), System Innovation and the Transition to Sustainability: Theory, Evidence and Policy. Cheltenham, UK: Edward Elgar Publishing.

Shrum, L.J., John A. McCarty, and Tina M. Lowrey. 1995. "Buyer characteristics of the green consumer and their implications for advertising strategy." Journal of Advertising 24(2): 71-82. 
Smith, Adam. [1776] 2003. An Inquiry into the Nature and Causes of the Wealth of Nations. New York, NY: Bantam Classic.

Spaargaren, Gert. 2003. "Sustainable consumption: A theoretical and environmental policy perspective." Society and Natural Resources 16, 687-701.

Spradley, James P. 1979. The Ethnographic Interview. Long Grove, IL: Waveland Press, Inc. Stacey, Judith. 1988. "Can there be a feminist ethnography?" Women's Studies International Forum 11(1): 21-27.

- - - 1990. Brave New Families: Stories of Domestic Upheaval in Late Twentieth Century America. New York, NY: Basic Books.

Stanley, Liz and Sue Wise. 1990. "Method, methodology and epistemology in feminist research processes." in Liz Stanley (ed.), Feminist Praxis: Research, Theory and Epistemology in Feminist Sociology. London, UK: Routledge.

Stern, Paul C. 2011. "Contributions of psychology to limiting climate change." American Psychologist 66(4): 303-314.

Stern, Paul C., Thomas Dietz, Vernon W. Ruttan, Robert H. Socolow, and James Sweeney, eds. 1997. Environmentally Significant Consumption: Research Directions. Washington, DC: National Academy Press.

Stigler, George J. 1966. The Theory of Price. New York, NY: MacMillan Publishing Company.

Strand, Ginger. 2008. "The Crying Indian." Orion Magazine, November/December. Accessed 06/25/2017. Available: https://orionmagazine.org/article/the-crying-indian/ Straughan, Robert D. and James A. Roberts. 1999. "Environmental segmentation alternatives: a look at green consumer behavior in the new millennium." Journal of Consumer Marketing 16(6): 558-575.

Streeten, Paul. 2002. "What's wrong with contemporary economics?" Interdisciplinary Science Reviews 27(1): 13-24.

Strengers, Yolande. 2012. "Peak electricity demand and social practice theories: Reframing the role of change agents in the energy sector." Energy Policy 44, 226234.

Svoboda, Elizabeth, Eric Mika and Saba Berhie. 2008. "America's Top 50 Green Cities." Popular Science February 8, 2008. Available: http://www.popsci.com/environment/article/2008-02/americas-50-greenestcities?page=1 Accessed 03/26/2017.

The White House. 2015. "Presidential Proclamation-America Recycles Day, 2015." November 13, 2015. Accessed 06/07/2017. Available: https://obamawhitehouse.archives.gov/the-pressoffice/2015/11/13/presidential-proclamation-america-recycles-day-2015

Trump, Donald (therealdonaldtrump). 2012. "The concept of global warming was created by and for the Chinese in order to make U.S. manufacturing non-competitive." 11:15am, November 6, 2012. Accessed 06/07/2017. Available: https://twitter.com/realdonaldtrump/status/265895292191248385?lang=en 
U.K. Office for National Statistics. 2011. "Living Costs and Food Survey." Accessed 06/22/2017. Available: http://www.ons.gov.uk/ons/rel/family-spending/familyspending/family-spending-2011-edition/consumer-durables-nugget.xls

U.S. Bureau of Labor Statistics. 2016. "American Time Use Survey: Chart 15." Accessed 06/22/2017. Available: https://www.bls.gov/tus/charts/chart15.txt

U.S. Energy Information Administration. 2013. "2009 Residential Energy Consumption Survey: Table HC3.1 Appliances in U.S. Homes, by Housing Unit Type, 2009." Accessed 06/22/2017. Available: https://www.eia.gov/consumption/residential/data/2009/hc/hc3.1.xls

U.S. Environmental Protection Agency. 2016. "What You Can Do about Climate Change." Accessed 06/07/2017. Available: https://19january2017snapshot.epa.gov/climatechange/what-you-can-do-aboutclimate-change_.html

U.S. Global Change Research Program. 2014. "2014 National Climate Assessment." Accessed 06/06/2017. Available: http://nca2014.globalchange.gov/repor

United Nations. 2014. "United Nations and Climate Change: Take Action." Accessed 06/06/2017. Available: http://www.un.org/climatechange/take-action/

Veblen, Thorstein. [1899] 1953. The Theory of the Leisure Class: An Economic Study of Institutions. New York: The New American Library.

- - . 1898. Why is Economics not an Evolutionary Science? The Quarterly Journal of Economics 12(4): 373-397.

Vogel, Lise. 1983. Marxism and the Oppression of Women: Toward a Unitary Theory. New Jersey: Rutgers University Press.

Waddoups, Jeffrey. 1992. Thorstein Veblen and the Feminism of Institutional Economists. Revue Internationale de Sociologie 3(3): 182-204.

Waller, William \& Linda R. Robertson. 1998. The politics of consumption and desire. in Doug Brown (ed.) Thorstein Veblen in the Twenty-first Century: A Commemoration of the Theory of the Leisure Class (1899-1999). Cheltenham, UK: Edward Elgar.

Watson, Sophie. 2015. Mundane objects in the city: Laundry practices and the making and remaking of public/private sociality and space in London and New York. Urban Studies 52(5): 876-890.

Weber, Max. [1905] 2002. The Protestant Ethic and the 'Spirit' of Capitalism and Other Writings. Trans. Peter Baehr \& Gordon C. Wells. New York, NY: Penguin Books.

Weinbaum, Batya and Amy Bridges. 1976. "The Other side of the Paycheck: Monopoly Capital and the Structure of Capitalism." Monthly Review 28(3): 88-103

Wels, Kelly. 2011. Changing Diapers: The Hip Mom's Guide to Modern Cloth Diapering. South Paris, MA: Green Team Enterprises.

Wheelock, Jane \& Elizabeth Oughton. 1996. The household as a focus for research. Journal of Economic Issues 30(1): 143-159.

Wilhite, H., H. Nakagami, T. Masuda, Y. Yamaga, and H. Haneda. 1996. "A cross-cultural analysis of household energy use behavior in Japan and Norway." Energy Policy 24(9): 795-803. 
Wilhite, Harold \& Loren Lutzenhiser. 1999. "Social Loading and Sustainable Consumption." Advances in Consumer Research. 26: 281-287.

Wilhite, Harold L. \& Richard R. Wilk. 1985. "Why don't people weatherize their homes? An ethnographic solution." Energy 10(5), 621-629.

- - . 1987. A method for self-recording household energy use behavior. Energy and Buildings 10: 73-79.

Wilhite, Harold, Elizabeth Shove, Loren Lutzenhiser, and Willett Kempton. 2001. "The Legacy of Twenty Years of Energy Demand Management: We Know More About Individual Behavior But Next to Nothing About Demand" in Ebarhard Jochem, Jayant Sathaye and Daniel Bouille (eds.), Society, Behaviour and Climate Change Mitigation. Dordrecht, Netherlands: Kluwer Academic Publishers.

Wilk, Richard. 2016. "Consuming ourselves to death: The anthropology of consumer culture and climate change." in Susan A. Crate and Mark Nuttall (eds.), Anthropology and Climate Change: From Encounters to Actions. London, UK: Routledge.

Yale Program on Climate Change Communication. 2015. Yale Climate Opinion Maps Data -U.S. 2015. Available: http://climatecommunication.yale.edu/visualizationsdata/ycom-us-2015/. Accessed 11/18/2016.

Young, William, Kumju Hwang, Seonaidh McDonald, and Caroline J. Oates. 2009.

"Sustainable Consumption: Green consumer behavior when purchasing products." Sustainable Development 18(1): 20-31. 
Appendix: Household Profiles

Andrew and Amy

Andrew and Amy are a middle class couple with two children, ages 8 and 5 . They live in a 3,000-square-foot home in inner eastside Portland that was built around 1900 . Their house is heated with a boiler that is as old as the house, and they cool their home with a combination of fans, window AC units, and passive cooling techniques. Andrew and Amy have lived in several regions in the United States, as well as in developing countries. Andrew is white, and Amy is East Asian. Both Andrew and Amy come from conservative and traditional backgrounds, with parents who did not have the same pro-environmental values as they have adopted as adults. They say that their environmentally conscious lifestyle is motivated by a longstanding interest in nature, as well as personal health considerations and to promote the well-being of their larger community and world. They bike or take public transit to their jobs in the downtown area, and reserve the use of their one car for trips involving the children or getting groceries. Because they were having trouble balancing their work schedules and obligations at home, Amy's father lives with them part of the time to help take care of the children and alleviate some of the stresses of chores like packing lunches and grocery shopping.

Brian 
Brian is a middle-class single father with an 8-year-old son who lives with him about half the time. He is white and has a clean-cut but nerdy appearance, with comfortable and practical casual office clothing that could double for hiking gear. He lives in 1,500-squarefoot townhome in inner eastside Portland that has both central heating and cooling that he purchased very deliberately with bike commuting and easy access to grocery stores in mind. His family was traditional but thrift-minded, and his values and ideas about the environment were influenced by his friends and his education. His decisions and practices are meticulously researched and planned according to his value system. He does not own a car and gets to work and most other activities by bicycle but makes frequent use of short term car rental services, mostly for trips related to his son. Riding bicycles with his son is a cherished activity and something he is proud of. He feels that his income is what enables him to live a lifestyle that is consistent with his ethical system but takes a pragmatic approach. The pro-environmental activities he engages in are the ones he enjoys, and he does not appear to feel that he is making any sacrifices in his quality of life for his ethical decisions. His primary concern is avoiding waste and living simply, but he also loves technology, and he views his interest in gadgets as being in direct conflict with his sustainability values.

\section{Chris and Carrie}

Chris and Carrie are a white upper middle class couple with two children, ages 8 and 4. When I spoke with them, they were dressed in comfortable sweaters, jeans, and house 
slippers, and were drinking herbal tea. Their 3,000-square-foot 1950s home on Portland's east side was well-insulated when they bought it, but they have subsequently added additional insulation in the attic, a smart thermostat, and solar panels. The house is heated with an older model gas furnace and has central air conditioning, as well as a natural gas fireplace insert. Chris said that he almost didn't respond to a request for research participants that was forwarded to him because he thought his family wasn't "sustainable" enough to qualify-they opened our conversation by noting that living in a detached home and having two children in a first world country automatically precludes them from being sustainable. The couple were sweet and sincere but simultaneously humorous and somewhat cynical about the ability of any of their lifestyle choices to make a positive impact on the environment. The concept of community is central to Carrie, as this was instilled in her growing up in an intentional community. She was raised to care about the well-being of all people, and sees her efforts in the environmental effort as consistent with these values. Minimizing consumption and rejecting consumer culture is important to Chris, and is a value he has started to talk to the 8 year old about in an ageappropriate and humorous way. Chris commutes to work in downtown Portland by bicycle and car, and Carrie goes to work primarily by car. Both Carrie and Chris would like to travel to work by bicycle more frequently, but bad weather, scheduling, and the transportation needs of their children are barriers.

David and Dayna 
David and Dayna are a white upper-middle-class couple with a one-year-old child. They live in a 1,500-square-foot home in inner eastside Portland that they renovated extensively with the help of Dayna's father, a general contractor. Since moving in, they have installed solar panels, insulation, raised vegetable garden beds, new energy efficient windows, weather stripping, a high-efficiency washer and dryer, and a new highefficiency gas furnace. They have neither central air conditioning nor window AC units. David and Dayna are Pacific Northwest natives, and have the style of typical outdoorsy young professionals in the region-flannel, performance polar fleece, Smart Wool socks, and ethnic jewelry. Both David and Dayna's families of origin are more conventional in their consumption choices, and they both grew up in relatively conservative households in suburban settings. Their backgrounds in science and medicine influence their views on technology and the environment, and friends of theirs have also have impacted their choices, for example their decision to use cloth diapers. They said that knowing other people who have researched and made these lifestyle choices makes it easier for them to adopt new habits themselves. Both David and Dayna are passionate about technology, and believe in the ability of technology to solve environmental problems. They installed their solar panels, with the help of tax credits and other incentives, soon after they completed the major gut renovation of their home. Dayna loves the feeling of being selfsufficient and independent from the electric company, as well as being able to guarantee that the source of her electricity is clean. David says he just loves gadgets and new technology. 
Eric and Emily

Eric and Emily are a white upper-middle-class couple with two children, ages 8 and 5.

They live in a 3,000-square-foot home in inner eastside Portland built around 1930. Since moving in to their current home, they have installed additional insulation and a new highefficiency gas furnace following a home inspection with a local energy efficiency nonprofit, through which they were able to get special financing for home improvements. The home has central heating and cooling, but they avoid using the air conditioning, preferring to use passive cooling techniques instead. Emily works from home, and Eric commutes to work by bicycle-he hates driving and finds it aggravating. The couple owns one car, a minivan, which they use primarily for road trips, taking their children to activities, and grocery shopping. The biggest priority for this family is the health of the individual family members, with environmental considerations coming second. Emily is an avid researcher of health and parenting information, which she gets from books, websites, and blogs. She goes grocery shopping between four and seven days a week, and food purchasing and preparation takes up a considerable amount of her time. The household buys food items from four different stores on a weekly basis to find the best prices. By far, the resource in shortest supply in their household is time. Time was in such short supply that they moved temporarily to be closer to Eric's family, hoping to receive additional assistance with childcare from family members. Both Emily and Eric expressed gratitude for their high incomes, which they believe enables them to make the 
sustainability choices that they do. They also believe that their high levels of education contribute to their knowledge of sustainability practices and their ability to research and understand information related to health and sustainability.

\section{Fiona}

Fiona is a white working class single mother with two children, ages 2 and 15 . She lives in an approximately 1,000-square-foot apartment on Portland's eastside. She was soft spoken, wearing loose-fitting linen clothing in earth tones, and had a gentle demeanor. She was breastfeeding throughout most of our conversation, and seemed skilled at multitasking while nursing. The apartment is heated with baseboard heaters, and she cools the space when it's hot out by opening and closing windows. She participated in a lowincome cloth diaper program and prior to that learned how to make her own diapers out of old shirts and sweatshirts. Fiona uses the bus to get to work, and doesn't own a car. She feels pressed for time since starting to work full-time, and feels the family eats more convenience food items than she'd like as a result. Her household is vegetarian, which she sees as both more environmentally-friendly and more compassionate to other living things. Fiona was not satisfied with recycling as a sustainable activity because of the energy-intensity of recycling. Instead, she prefers to buy few things that aren't food and to limit the amount of packaging that comes into the home in the first place. She believes 
both her lifestyle choices are things that anyone would do if only they were exposed to and educated about them. Her over-all lifestyle choices are motivated by compassion for all living things, including animals and other people. She was particularly concerned about making choices that minimized her negative impact on people living in developing countries, and mentioned an interest in consuming fair trade items. Unlike some of my informants, Fiona did not express a belief that her sustainability practices were expensive or only accessible to more wealthy families.

\section{Gloria and Husband}

Gloria and her husband are a white middle-class couple with four children: six year old twins, a 5 year old and a 3 year old. They live in a 2,500-square-foot home in a suburb of Portland. Gloria's home has both central heating and cooling-she prefers to use neither, but has made compromises with her husband to heat the home to 64 degrees during the winter and to cool the home if it reaches over 84 degrees inside in the summer. Gloria is a stay-at-home mother, and her husband works from home in the IT field. They own two cars but only use one of them, a minivan, with any regularity. I spoke with Gloria at the same time as my conversation with Heather. Both women practice attachment parenting and homeschool their children, and they were having a play-date when I arrived. Gloria and her husband are motivated by concerns related to community and avoiding waste, though each has their own areas of more intense interest and follow-through in their sustainability practices. Her husband is more motivated to avoid waste and buying any 
consumer goods, while Gloria is more interested in attachment parenting and homesteading practices like keeping chickens and growing vegetables. They share a determination to use as little water, electricity, and natural gas as possible. Despite this, she is very critical of families who live "off the grid" in isolation from others. Gloria's interest in sustainability and the environment is motivated by her passion for community and the well-being of others.

\section{Heather and Husband}

Heather and her husband are a white middle-class couple with three children, ages 6, 4, and 2. They live in a 2,000-square-foot home that was built around 1920 in outer westside Portland. The home has gas heat, and they use window AC units in their bedrooms during the summer at night. Heather's husband is from England, and he is not comfortable in warm weather. She homeschools her children and works a full-time schedule of night shifts over the weekend as a nurse. On top of that, she also works as a doula, sells placenta encapsulation services, and sells essential oils through a multi-level marketing business. Heather researches her health choices for her family extensively, and is very skeptical of conventional medicine and cleaning products, both of which she generally avoids. Heather was breastfeeding on and off throughout our conversation, occasionally telling her child that she needed to go eat her lunch rather than continuing to nurse. Heather is a passionate and driven person. Both her home and her personal appearance are extremely tidy, quite a feat for someone working full time, 
homeschooling three young children, and caring for a dog and a flock of chickens. She expresses the idea that the inside of the home is her sustainability domain, while the outside is her husband's. He is interested in vegetable gardening and raises chickens, and would ideally like to have a small farm with pigs and goats. When it comes to her interest in sustainability and natural health and parenting, Heather believes that balance is key. She doesn't want to live what she calls an "Into the Wild" lifestyle, but prefers to integrate natural living into a more moderate, contemporary way of life.

lan and Ivy

Ian and Ivy are a white lower middle class family with one child who is 6 years old. They live in a 1,500-square-foot home that was built around 1920. Both were raised in lowincome households who were motivated by thrift more than environmental concerns, and neither Ivy nor lan are college graduates. The walls were painted lime green, and the house was filled to the brim with brightly colored artworks made by lan and others, as well as clothes, toys, and other reclaimed or gleaned materials. A piece of twine was strung up over the kitchen sink as a place to dry plastic produce and sandwich bread bags for re-use. The couple have a punky artsy style, both wearing large vintage eyeglasses and colorful clothing. The house has baseboard electric heating, but all of the heaters are broken except for the one in the child's room. During cold months, they don't heat the home at all, except for the child's room. Ivy thinks it gets down to the low 50s overnight inside. They have a window AC unit that they have been running on very hot days during 
the summer starting late in Ivy's pregnancy with their daughter. They buy few things new, and when they do they tend to be high-quality tools for cooking or lan's artwork. Most of their clothes are second-hand, and lan says he has a "free box problem" - he frequently sees free items on the street, and takes them home. They like the idea of homesteading and living off-the-grid and "back to the land" because they say this is the most healthy and sustainable way to live. Ivy dreams of homesteading in a more community-oriented than isolated way-she imagines something akin to an artists' colony, and watches YouTube videos of self-sufficient homesteading families for inspiration.

Jim and Jess

Jim and Jess are a white middle class family with a 2 year old child. They live in a less than 1,000-square-foot home on Portland's east side. Jim says that he would prefer to live in a more remote place but sees the decision to live in an urban area as a personal sacrifice he is making for his environmental convictions. The house is heated with a gas furnace, a wood-burning fireplace, and an electric space heater in the baby's room. They cool the home through a passive cooling routine. Since moving in, they have installed additional insulation, weather stripping, rain barrels, a garden, and new windows that open and close. Jim is a careful and deliberate researcher of the environmental impacts of large and small consumption decisions. Jim is frustrated by the difficulty of finding good information about the relative carbon impacts of decisions, and feels guilty when he 
believes he made the wrong choice based on bad information. Jim and Jess do not use a tumble dryer, preferring to hang everything inside on racks and doorframes, a chore they call difficult and time-consuming. It is their strong conviction that one of the worst environmental choices you can make is to have children. They were outspoken about the difficulty of their choice to have a child, a decision they made only when they found the process of adoption too difficult and adoption professionals unsympathetic to the decision of a fertile couple to adopt for environmental reasons. They believe you can't call yourself an "environmentalist" if you have created a biological offspring in a firstworld country. They do not regret their decision to have a child, but do see it as a major compromise of their environmental values for their desire to become parents.

Kyle and Kelly

Kyle and Kelly are a white middle-class couple with one child, a three year old. They live in a 4,000-square-foot house built around 1880 in inner eastside Portland. Their collective household is made up of three families for a total of seven people: Kyle, Kelly, and their three year old daughter, Kelly's mother, and another family with two adults and one child. Living collectively in an intentional community is important for both Kyle and Kelly, who are self-described Socialists and active in a community group focused on human flourishing and liberation. They see intentional community living as a way to reduce consumption, and believe that nuclear families living in individual homes is a wasteful and absurd arrangement. Kelly's mother moved in two years ago to assist with 
their childcare needs, and now also runs a preschool out of the home. Unlike some of the other households with solar panels, Kyle does not seem to valorize the panels or himself for having them. He likes it as a passive way to reduce some of their consumption, but is skeptical of the value of solar panels from a cost-benefit perspective. Kyle believes that living in an urban area is more sustainable than living in a suburban or rural area, including homesteading unless you are a "survivalist." Kyle says he didn't think their household should be participating in this study because he doesn't see their household as "sustainable" but rather as trying to minimize their negative impact on the environment. In his view, it is not actually possible to live sustainably in the United States. Kyle and Kelly decided to have only one child for environmental reasons, and the environmental impact of having a child was something they discussed as a couple prior to conceiving.

\section{Leonda and Husband}

Leonda and their husband are a working class couple with one three-year old child. The family recently relocated together from Appalachia to be near better employment opportunities for themselves and better educational opportunities for the child. They live in an approximately 1,000-square-foot apartment with a roommate who relocated with them. Leonda is black and was wearing their hair in a tinted pink afro, and they had on plastic vintage-style glasses and a second-hand tie-dyed shirt with a cartoon character printed on it. They are a vibrant and passionate person who feels strongly about the 
environment and activism, but feels like their concern for the environment is not fully manifested in their lifestyle choices to the same extent as some of the people they know. Leonda's household received all of the furniture from internet freecycling groups. The apartment has baseboard heat, which they set to around 74 degrees during cold months. They don't have central air but try to open and close the windows to circulate air around the apartment when it's hot out. When they moved to Oregon, Leonda bought themselves a second-hand bike for getting to their Americorp assignment. Their husband uses their car to go to work and bring their daughter to school. Leonda says they have anxiety about taking the bus going back to when they were in their early teens and would be propositioned for sex work at the bus station. Their decision to have only one child was influenced by their environmental values, as they believe that children use a lot of resources. Leonda and their husband receive TANF for their daughter, WIC benefits, and food stamps. Leonda says they doesn't always use their WIC money since it can't be used on organic items, almond milk, or natural juices_staples in the household. Leonda is the driving force behind the household's sustainability efforts, doing all of the initial research into new environmentally friendly practices. They are generally able to convince their husband to follow along once Leonda explains their reasoning.

\section{Mike and Mina}

Mike and Mina are a middle-class couple with two children, ages 5 and 3. Mike is white and Mina is Arab-American. They live in a 1,500-square-foot house built around 1980 in a 
suburb about 30-45 minutes outside of Portland. Mike installed a Nest smart thermostat shortly after they moved into the home. He saw an email from the Energy Trust of Oregon and liked the idea of the rebate and demand-response discounts on their bill. He is generally not involved in Mina's household environmental activities, but he enjoys new technology and the idea of saving money. Mina says that as a stay-at-home mother, her value to the household is in her time. She selected a co-op preschool located around 10 miles away from their home, which she likes because it is affordable and, thanks to parent participation, provides social interactions for her. She cooks everything that she and the children eat (all vegetarian) from scratch. She does a big grocery shopping trip every two weeks, plus supplemental trips and a weekly trip to the farmer's market downtown. The intensity of her driving or any dislike of driving was not something that Mina mentioned, though the location of their home in the suburbs and the locations of the school and businesses she frequents means Mina must spend a lot of time in the car. The family has two cars, and it is their only form of transportation. Mike spent the interview with his arms crossed over his chest, and occasionally rolled his eyes at my questions. Mike does not appear to disagree with Mina's interest in natural living and he is not hostile to environmental concerns. However, he does not do any of the research or work involved in Mina's sustainability practices.

Nathan and Nicole 
Nathan and Nicole are a white upper-class couple. Nicole has two children, ages 5 and 4, who live with them full-time. They live in a 4,000-square-foot home that was built around 2000 in an outer western suburb of Portland. Nathan was wearing a performance-fabric golf shirt and had the style and slightly brash demeanor of a high-tech executive, while Nicole was dressed in an understated cardigan and was geeky and opinionated but decidedly more passive than Nathan. Their home is heated and cooled with a $\$ 90,000$ geothermal system that both Nicole and Nathan were enthusiastic about from a technological perspective. Nathan built an ROI spreadsheet to determine the costeffectiveness of the heating system as he was custom-building the home, which he says is one door away from being LEED-certified. He installed solar hot water heat in his previous home but calculated that it would not be cost-effective in the new home. The couple have a regular housekeeper who uses natural cleaning products that the household provides. Since January, Nicole and Nathan have hired some additional regular household help (they called him both a "butler" and a "handyman") for 20 hours per week. This worker does some grocery shopping, recycling/can return, babysitting, and household work like fixing things that are broken and hanging pictures. Both Nathan and Nicole were educated in science and technology at top universities and are proud of this background. They are skeptical of many mainstream environmental claims, preferring to do the research and understand the science themselves. The driving force between Nathan's lifestyle is an interest in technology and his strong desire to avoid waste. Nicole 
also likes to avoid waste, but sees time as having a monetary value, too, so doesn't always agree with Nathan's desire to fix rather than replace cheap items.

\section{Owen and Orla}

Orla and Owen are a white middle class couple with two children, ages 4 and 2 . They live in a 1,500-square-foot home that was built around 1930 on Portland's east side. Orla and Owen made energy efficiency improvements when they moved in, including replacing a very old oil furnace with a new heat pump and insulating the walls and attic. They decided not to replace their older storm windows because Orla calculated that wouldn't be cost-effective. The house isn't connected to the sewer system, and instead drains to a cesspool in the back yard. For that reason, they are careful about water and the types of soaps and detergents they use. Owen says that when he stands near to someone who uses a conventional scented detergent or soaps, he now finds the smell revolting. He can pick out the scent of Tide in particular, as this is the detergent he grew up with. They believe that living in Portland reduces the cost and the effort involved in obtaining earthfriendly products. The family is solidly middle class, and do not feel financially constrained. Owen expressed his belief that, as busy professionals, that they often buy earth-friendly products rather than finding other non-purchased ways to live a sustainable lifestyle-he says that time and money are substitutes. Orla says that living an environmentally-friendly lifestyle need not be expensive, and that she has many childless friends who live very minimal lifestyles because they have the time to engage in 
"gleaning" and time-intensive practices that allow them to avoid consumption. Before becoming parents, they did more of these kinds of activities. Orla is far more concerned with waste, the environment, and thrift than Owen, but this doesn't appear to be a source of serious conflict or frustration in the relationship.

Penny

Penny is a white, lower-middle-class single mother with two children, ages 9 and 6, who live with her part-time. Her home is under 1,000 square feet, built in the 1980 s in inner eastside Portland. Penny pledged to buy nothing for first half of this year (other than food and personal care products and items the children need for school) because she wanted to disengage from the waste of consumer culture. Penny frequently looks in free boxes on the street when she walks around town and sometimes uses online sources for finding free things. She also does a lot of shopping at second-hand stores, though she says this is getting harder as her son has reached an age where he is very hard on his clothes. Penny is a former vegetarian, and a large motivation for her vegetarianism was the environmental impact of meat production. She contrasts this with other vegetarians she knows, who are more concerned with the impacts on their own individual health and the welfare of individual animals. She believes the same is true for how many people she knows who see themselves as eco-friendly select and purchase personal care products and natural foods - the focus is on themselves and their children rather than the larger impacts on the world. Her goal would be to buy $100 \%$ organic produce, but some items 
at times are cost prohibitive. She is concerned about the impacts of her decisions and the decisions of other people living in advanced industrialized societies on people with "no carbon footprint" who are already dealing with the consequences of environmental problems that they did not themselves cause. When she was talking about her concern for people living “in Africa," Penny's voice waivered.

\section{Quinn and Husband}

Quinn and her husband are a white middle-class couple with one child, age 8, who they adopted from Ethiopia. They live in a 1,500-square-foot home on Portland's east side that was built around the turn of the century. Quinn and her husband are both vegans, motivated primarily by animal welfare concerns. Quinn knew early on that she did not want to have biological children for environmental reasons. She is concerned about overpopulation and the impact of humans on the environment, and also discussed her interests in the humanitarian elements of international adoption. Her husband would have liked to have biological children, but went along with Quinn's international adoption plan. The adoption was expensive, but Quinn believes that it is all just a matter of priorities. For example, her friends who commented about the expense of international adoptions recently bought an expensive hybrid car. A family Quinn knows lives an intensive pro-environmental lifestyle with close to zero waste, but Quinn says she doesn't think that this family has a lower environmental impact than hers because they have biological children. Quinn enjoys being a member of "buy nothing" groups because she 
feels like it cuts down on waste. She gets upset at work when she sees items that can be recycled that were put in a trash can, and often goes to the effort to fish them out and place them in the correct disposal bin. Quinn called herself "lazy" several times during the interview when she was explaining her lack of time and her reasons for not engaging in certain pro-environmental practices. She says she is more "anal" than her husband about her environmental habits, and there appeared to be some tension in the relationship around Quinn's stronger desire to make major environmental and ethical interventions into their day-to-day habits.

\section{Rob and Rebecca}

Rob and Rebecca are a middle-class white couple with two children, ages 3 and 1 . They live in a 2,000-square-foot home on Portland's east side built around 1980. Rebecca sat with me on the carpet, and was breastfeeding on and off during the interview. She was raised working class in the Northwest by parents with connections to the hippy counterculture. She considers herself a socialist and is very concerned about social justice, public health issues, race, and equality. Rob was also mostly raised in the Northwest, and has more of a skeptical, critical approach to the world. This view is influenced in part by his father, whose libertarian views are the product of his personal rags-to-riches story. Today, many of the couple's habits are pragmatic versions of the way Rebecca grew up, sustainability practices like recycling and healthy eating that they say have now become the mainstream and socially-acceptable way of getting things done in their peer group. 
They have a gas furnace, and when it's cold out they heat the home to around 70 degrees, day and night, whether they are home or at work. They have some window AC units, which they try to use sparingly, and Rob has an elaborate passive cooling routine involving a series of fans that he calls his "pseudoscience." Since both Rob and Rebecca work full time, preserving their own sanity has become a priority since having their second child. Rob goes in and out of bike commuting, but the second child makes the time commitment involved in the 8-mile each way bike ride less feasible. They buy mostly organic food, and they use a cloth diaper washing service, but they say that they've stopped making special trips to the recycling center to dispose of items that aren't curbside recyclable.

\section{Scott and Sarah}

Scott and Sarah are an upper middle class multi-racial couple with two children, ages 3 years and 1 year. They live in a 3,000-square-foot new construction home on Portland's inner east side. While they told me that they set the thermostat to 70 degrees during the winter, I was able to observe that the thermostat was set to 72 degrees. Scott, Sarah, and their children were all wearing short-sleeve shirts, and Sarah was breastfeeding during the interview. They are a one car household, and after doing some research about the carbon impacts of buying new cars, they decided to buy their car second-hand. Scott goes to work by bike most days, and Sarah telecommutes. When Scott works from home, which is fairly often, he uses a space heater under his desk to keep his feet warm in 
addition to the central heating system, which is a gas furnace. They also have central air conditioning, which they keep set at 70-72 degrees. There were no blinds on the windows in the house, and they said they might like to get window coverings to keep down their space cooling costs. They buy all organic food, which is something they did prior to the children being born. They heard about a case where male field workers were sterilized by the chemicals they were applying to crops. Sarah said that upset her, and she didn't want to contribute to medical issues for the workers or to those chemicals going into the ground or waterways. Secondarily, she is concerned about long-run exposure to herself and her family members, but that is not her main concern.

\section{Tim and Tara}

Tim and Tara are a lower-middle-class couple who live in a 1,000-squarefoot apartment built around 1960 on Portland's east side. Tim is white, and his 9-year-old child lives with them on weekends. Tara is Latina and takes an active role with her partner's child in teaching him about her sustainability values. Tim and Tara both have a cool vintage style that blends 1960s fashion and youth subculture. The tidy, cozy, and inviting home was decorated similarly, with eclectic second-hand furniture, comic book art, vintage wall hangings, and toys. The home is heated with baseboard units that aren't marked with temperatures, so they don't know what temperature they've set them to, but they just turn them on to "the first click" so it "takes the bite out of the air." They deliberately cluster in a single room during cold months to avoid heating the entire apartment. Until 
two summers ago, they made do with a passive cooling routine when it was hot out. They feel that Portland summers have been getting hotter, so they "gave in" and bought a portable AC unit that they use mostly at night to get their bedroom to a comfortable enough temperature that they can sleep. Moving out of their family homes to different cities on the west coast had a large impact of the sustainability views of both Tim and Tara. In particular, their views and perspectives were changed when they were exposed to highly environmentally-minded people through work and schooling. A word that came up repeatedly in the conversation was "resourceful" - this is a quality that the couple seems to value deeply. Being able to take care of themselves and make use of the materials that are available to them is something they pride themselves on and want to teach to Tim's son.

\section{Victor and Vanessa}

Victor and Vanessa are a white middle-class couple with three children, ages 13, 9, and 6. They live in a 1,000-square-foot condominium unit in a cohousing intentional community on Portland's inner east side that was built around 1960. The home is heated with a gas furnace and has no central cooling. Victor programmed the thermostat to temperatures that are 4-6 degrees colder than Vanessa, who does not work outside the home, would like. Each day when she is home, she has to readjust the thermostat to a more comfortable temperature. The couple moved to Portland in their late 20s, and quickly embraced the region's fun-oriented cycling culture-Vanessa was wearing colorful 
bicycle-print leggings when we spoke. Even in high school growing up in a suburban subdivision, Victor biked as his main form of transportation, though his parents could have afforded to buy him his own car. Both Victor and Vanessa grew up in highly thriftoriented households where thrift was valued for its own sake, and this value has been carried forward into their current lives. The couple values community and traditional face-to-face connection, and Victor is highly critical of technology and social media. He does not have a smart phone, the household does not own a television, and the children are allowed zero screen time on weekdays. Vanessa shops for groceries four or five times a week, and prepares three home-cooked meals each day-Victor does not like to eat in restaurants because he prefers Vanessa's cooking and believes restaurant meals are not healthy. Victor likes the fact that their cohousing community is like a "commune," but that the only chores that are shared are the maintenance tasks on the outside of the homes. Victor remarked that their lifestyle must seem very out of the ordinary compared to typical Americans, but in Portland they are pretty normal.

\section{Wendy and Partner}

Wendy and her partner are a middle-class same-sex couple with one child, age two. They live in a 1,000-square-foot home built around 1950 on Portland's east side. The home is heated with a gas furnace and has no central cooling. While she was pregnant with their child, Wendy bought a window AC unit because she was so uncomfortable in the heat, but she returned it without installing it because she would have felt too guilty using 
electricity that way. Wendy's family is from South America, and they moved to the United States when she was eight. She grew up using passive cooling techniques in a culture that had the siesta to cope with afternoon heat. She still uses these passive cooling routines. Wendy's partner was raised in a highly environmentally-oriented Back-to-the-Land household with strong inclinations towards thrift that continue to influence both of their day-to-day practices around consumption. Eating meat is so important to the culture of Wendy's family that when she came out as gay, her father told her somewhat in jest that he loved her but that if she became a vegetarian that he would disown her. Wendy does most of the cooking in the household, but because Wendy's partner is a vegetarian, Wendy cooks mostly vegetarian food for the family. The household line-dries all of laundry, though this is getting to be more difficult with the amount of laundry generated by a young child. Wendy has tried to compensate for this by wearing her clothes more times between washes and taking a shower about once a week. Wendy is concerned about her carbon footprint as well as her general environmental impacts, particularly around water usage. Wendy says that she has always cared about the environment and was conservation-oriented, but becoming a parent has made her concern about the future more concrete.

Yvonne and Husband

Yvonne and her husband are a white working-class couple with three children, ages 2, 5, and 9. They live in a 900-square-foot home on Portland's inner east side that was built 
around 1910. Yvonne considers her household to be an urban homestead. She stopped working her two jobs in the service industry right before her third child was born. It was too difficult for her to both work outside the home and do all of the time-consuming sustainability-oriented tasks around the house that she believes are important. Now, she manages her family's large garden and does all of the cooking, childcare, and housework. She also works around 15 hours a week for her husband's landscaping business, where he spends around 60 hours a week. Despite these long hours, the family is heavily reliant on the money-saving tasks that Yvonne does around the house to get by, like making their own laundry detergent and all of their food from scratch. She is able to save time by grocery shopping only about once a month at Costco, where she buys 25-pound bags of flour and dried beans. During the winter when their large garden is less productive, she makes a trip to a store for produce around two times a month. She was feeling more pressed for time when her tasks also included the care of several farm animals, but now that the household is down to just two dogs and no livestock, things are more manageable. Yvonne calls herself an amateur herbalist, and is treating her child's asthma and her own chronic health condition with herbs that she forages. She sees companies, conventional medicine, and the government as motivated by the same thing - profit, not the well-being of her family. 